4 norden 



\section{Labour Market Mobility in Nordic Welfare States}

TemaNord 2010:515 


\section{Labour Market Mobility in Nordic Welfare States}

TemaNord 2010:515

(C) Nordic Council of Ministers, Copenhagen 2010

ISBN 978-92-893-1997-3

This publication is available as print-on-demand and can be ordered on www.norden.org/order. Other Nordic publications are available at www.norden.org/publications

Nordic Council of Ministers

Store Strandstræde 18

DK-1255 Copenhagen K

Phone (+45) 33960200

Fax (+45) 33960202

www.norden.org

\section{Nordic Council}

Store Strandstræde 18

DK-1255 Copenhagen K

Phone (+45) 33960400

Fax (+45) 33111870

This publication has been published with financial support by the Nordic Council of Ministers. But the contents of this publication do not necessarily reflect the views, policies or recommendations of the Nordic Council of Ministers.

\section{Nordic co-operation}

Nordic cooperation is one of the world's most extensive forms of regional collaboration, involving Denmark, Finland, Iceland, Norway, Sweden, and three autonomous areas: the Faroe Islands, Greenland, and Åland.

Nordic cooperation has firm traditions in politics, the economy, and culture. It plays an important rol in European and international collaboration, and aims at creating a strong Nordic community in a strong Europe.

Nordic cooperation seeks to safeguard Nordic and regional interests and principles in the global community. Common Nordic values help the region solidify its position as one of the world's most innovative and competitive. 


\section{Content}

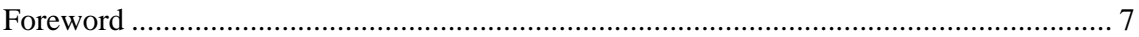

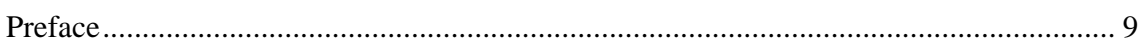

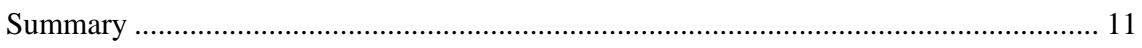

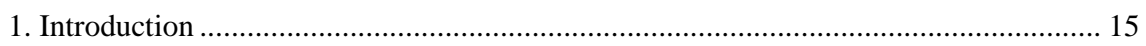

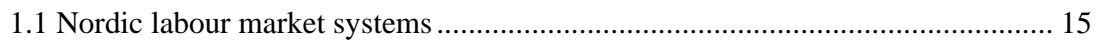

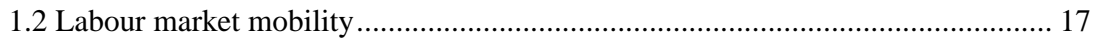

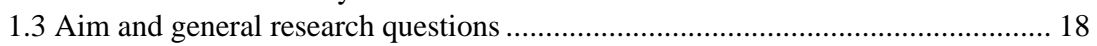

1.4 Research on mobility in the Nordic countries .................................................... 19

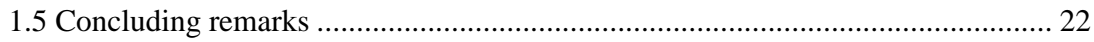

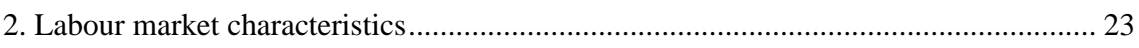

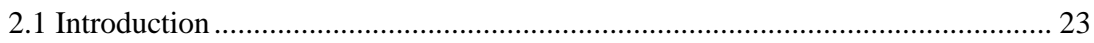

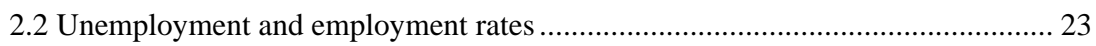

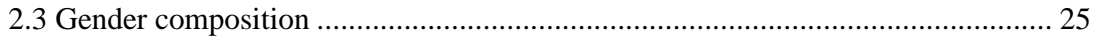

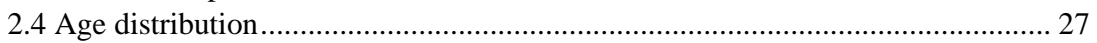

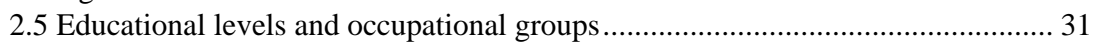

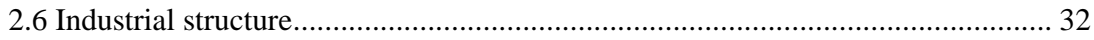

2.7 Temporary contracts and part-time employment................................................ 33

2.8 Concluding remarks .............................................................................................. 34

3. Nordic labour market and welfare systems from a flexicurity perspective ................... 37

3.1 Introduction ....................................................................................................... 37

3.2 Flexicurity as an institutional system - general considerations and the Danish

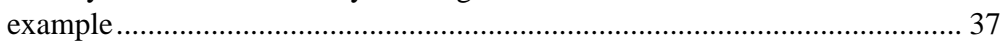

3.3 A comparison of central institutions using international indicators..................... 42

3.4 A comparison of Nordic flexicurity profiles........................................................... 48

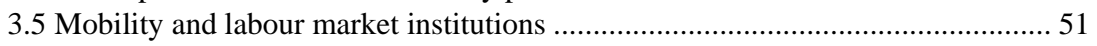

3.6 Summing up: Expected mobility patterns in four Nordic countries....................... 56

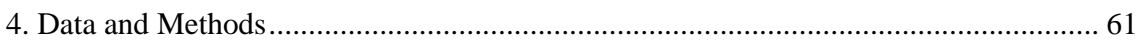

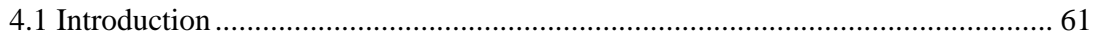

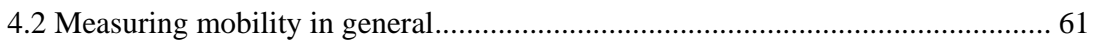

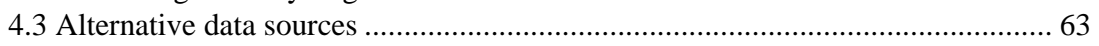

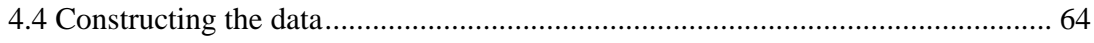

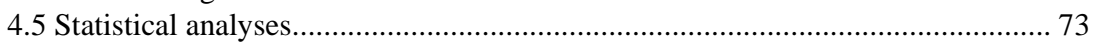

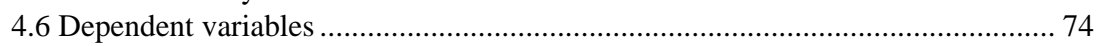

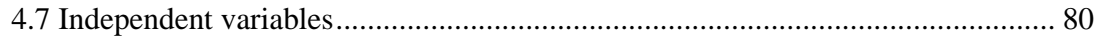

5. Mobility between Employment, Unemployment and Inactivity ................................. 83

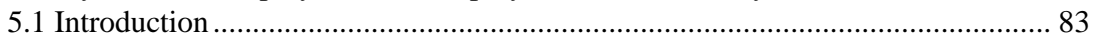

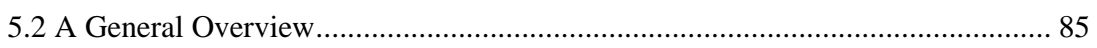

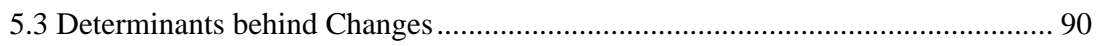

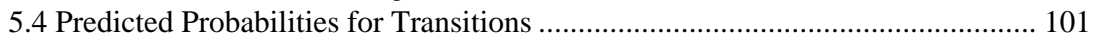

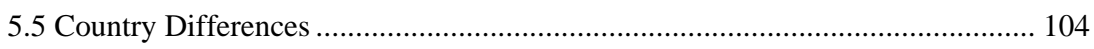

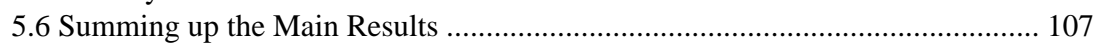




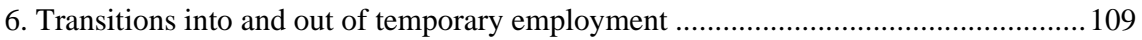

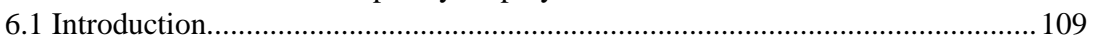

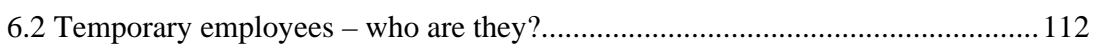

6.3 Mobility to and from temporary employment - a general overview ....................115

6.4. Factors affecting mobility - multivariate analyses...........................................119

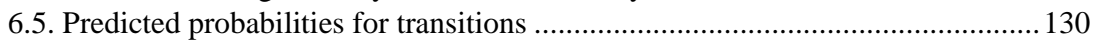

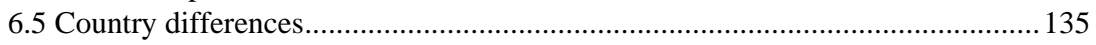

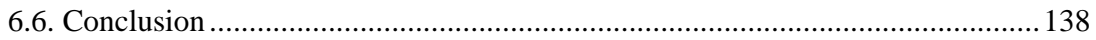

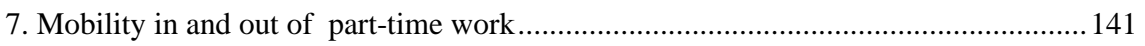

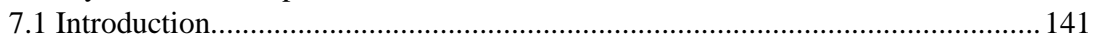

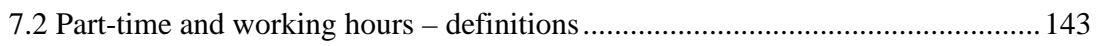

7.3 A general overview: who works part-time? ......................................................... 145

7.4 Labour market mobility into and out of part-time employment ...........................152

7.5 Working time mobility....................................................................................... 161

7.6 Part-time employees who increase their working hours.......................................... 163

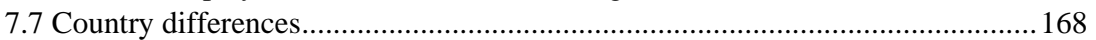

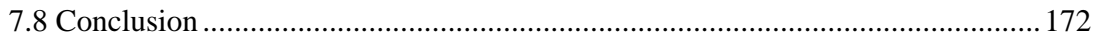

8. Mobility between Workplaces, Occupations and Industries....................................... 175

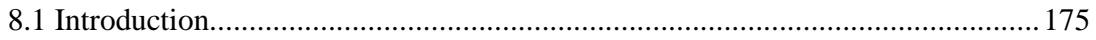

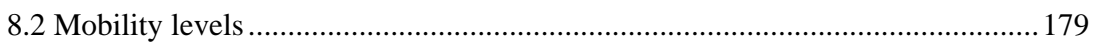

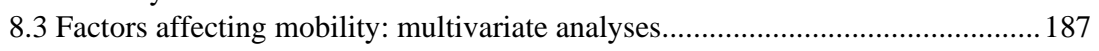

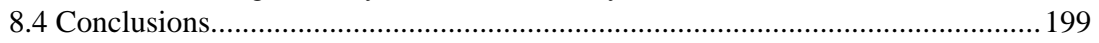

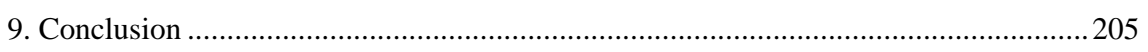

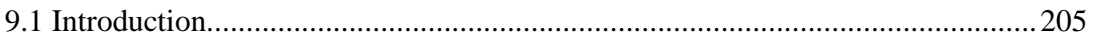

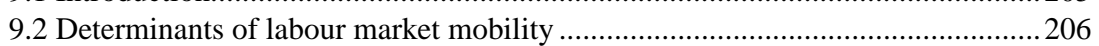

9.3 Mobility rates in the four Nordic countries .......................................................209

9.4 The significance of welfare and labour market institutions..................................211

9.5 Is flexicurity a Danish or a general Nordic phenomenon? ...................................216

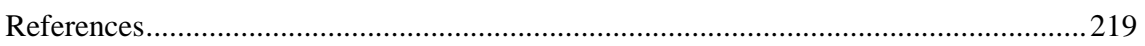

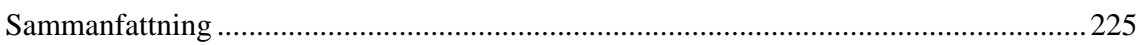

Appendix A National descriptions of institutional frameworks .....................................222

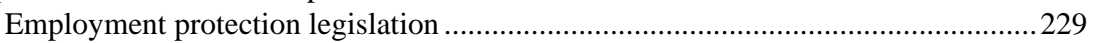

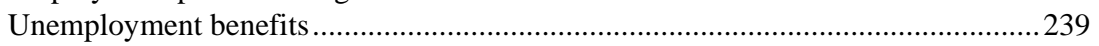

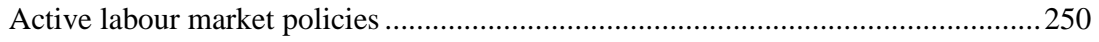

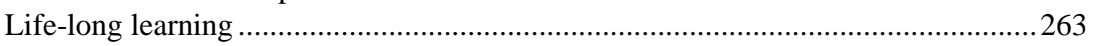

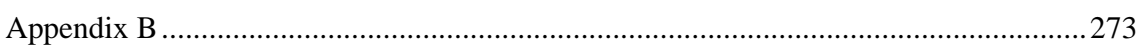

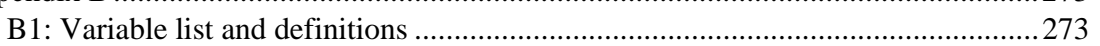

B2: Methods for studying workplace, industrial and occupational mobility.............281 


\section{Foreword}

Globalisation renders certain types of job obsolete, while new ones emerge all the time. This places ever-greater requirements on the ability of labour markets to adapt. Adaptability is crucial for the competitiveness of the Nordic countries as well as the future of welfare in the Region.

Mobility is an important indicator of the adaptability of a workforce. In this study, a number of Nordic researchers looked at labour-market mobility in Denmark, Finland, Norway and Sweden during the period 2000-2006, and analysed the factors that influence mobility. A key element of the study is an assessment of the significance of "flexicurity" with regard to terms and conditions of employment as related to three different types of mobility: a) mobility between employment, unemployment and complete exclusion from the labour market; b) mobility between jobs, trades/professions and industries; and c) mobility between full- and part-time employment.

The Nordic Council of Ministers' Labour Market Committee funded the study in order to illustrate and analyse these important aspects of the labour markets in the Region. I hope that the report will serve as a source of inspiration for national efforts to enhance mobility and adaptability on labour markets and improve our ability to meet the challenges posed by globalisation.

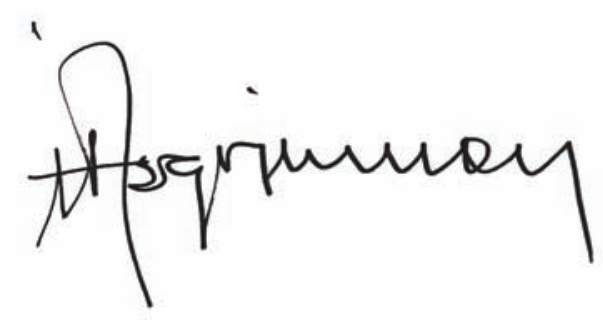

Halldór Ásgrímsson

Secretary General

Nordic Council of Ministers 



\section{Preface}

This report is a result of a 2-year research project on labour market mobility. It is founded on collaboration between four research teams. These are: Professor Per Kongshøj Madsen and PhD student Stine Rasmussen, Centre for Labour Market Research (CARMA), Aalborg University, Denmark; Senior Researcher Simo Aho and PhD student Ilkka Virjo, Work Research Centre (WRC), University of Tampere, Finland; Head of Research Jon Erik Dølvik and researchers Kristine Nergaard and Jørgen Svalund, at Fafo, Norway; Professor Bengt Furåker, Assistant Professor Tomas Berglund (project coordinator) and $\mathrm{PhD}$ student Kristina Lovén, Department of Sociology, University of Gothenburg, Sweden.

The project was funded by the Nordic Council of Ministers and the Research Council of Norway (Arbeidslivsprogrammet).

One of the greatest efforts in the project has been to create a Nordic data set containing the national Labour Force Surveys with their panel structure intact. This could not have been done without help from the Statistics authorities in the respective countries. We especially want to thank Michael Frosch, Jørn Korsbø Petersen, Ivan Thaulow, Statistics Denmark; Veli Rajaniemi, Statistics Finland; Inger Håland, Statistics Norway; and Gunilla Ljungren, Göran Råbäck and Marie-Louise Jädert Rafstedt, Statistics Sweden.

This report is in its entirety a joint product. However, there has been a division of labour resulting in main authors of the different chapters:

Chapter 1: Tomas Berglund

Chapter 2: Simo Aho and Tomas Berglund

Chapter 3: Tomas Berglund and Per Kongshøj Madsen

Chapter 4: Tomas Berglund and Ilkka Virjo

Chapter 5: Tomas Berglund and Bengt Furåker

Chapter 6: Stine Rasmussen

Chapter 7: Kristine Nergaard

Chapter 8: Ilkka Virjo

Chapter 9: Tomas Berglund

Kristina Lovén and Jørgen Svalund have contributed to the national descriptions in Appendix A, and Jon Erik Dølvik as a commentator at our working seminars.

Göteborg, October 30, 2009 



\section{Summary}

This report focuses on labour market mobility during the period 20002006 in four Nordic countries: Denmark, Finland, Norway and Sweden. The purpose is to study rates and determinants of mobility and to understand how differences in the institutional settings in the four countries affect mobility outcomes.

During recent decades, there has been an interest in how labour market and welfare institutions should be organized to facilitate mobility in the labour market. An institutional mix that is contained in the concept "flexicurity" has been promoted, i.e. a combination of institutions that facilitates both flexibility and security. Denmark is regarded as one of the countries that have succeeded in creating flexicurity on the labour market. However, questions have been raised of whether it is only a Danish phenomenon or whether flexicurity is something that also characterises other Nordic countries. In international comparisons evaluating flexicurity profiles, similarities in the institutional frameworks of the Nordic countries have been found. Yet, studying the institutional framework in more detail, there are important differences between the countries that could affect the flexibility and security on the four labour markets. Denmark has the most liberal employment protection legislation among the four countries. Furthermore, the unemployment benefits are more generous in Denmark and the greatest efforts are made there with active labour market polices. Only when it comes to life-long learning policies is the largest number of participants found in Sweden. All in all, the combination of institutions in Denmark, creating the flexicurity framework, is conspicuous also in a Nordic context.

Concentrating on labour market mobility, this report focuses mainly on the flexibility aspect of the flexicurity concept. The general research questions that guide the study are the following:

- How large proportions of various categories of workers in the four countries make different kinds of transitions in the labour market?

- Which are the main determinants behind different forms of labour market mobility? Are there national variations in these respects?

- How can national differences regarding labour market mobility be explained? Are they related to national institutional frameworks?

Three major types of labour market mobility are in focus:

- Transitions between labour market statuses, i.e. employment, unemployment and inactivity. 
- Transitions into and out of atypical employment, i.e. temporary contracts and part-time employment.

- Workplace mobility, occupational mobility and mobility between industries.

The basis for the empirical studies is the Labour Force Surveys (LFS) in the four countries. These surveys have a panel structure that has been utilized to measure changes in labour market situation after one year. The indicators compare the respondent's labour market situation during a reference week at two points in time with 12 months in between. The LFS data have been pooled together in one single data set which has allowed statistical comparisons.

The first transitions studied are mobility between employment, unemployment and inactivity. Two of the most important determinants are age and type of contract. In general, young people have a higher probability than older people of making these transitions. And temporary employees are at higher risk of unemployment or of moving into inactivity than permanent employees. Comparing the countries, the highest probability for transitions into unemployment is found in Denmark. And the highest probability for transitions from unemployment to employment is found in Norway. However, Denmark also has high transition rates from inactivity to employment. For most of the transitions between employment, unemployment and inactivity, the lowest rate is found in Sweden.

Looking at transitions between workplaces, occupations and industries, the differences between the countries are by far largest with occupational mobility and very large also when it comes to workplace mobility. With industrial mobility, the countries are much more alike, but the general pattern can be seen there as well. Overall, Denmark is the most mobile country. Norway ranks second, Finland third and Sweden tends to have the lowest mobility. However, with occupational mobility we find that Finland has the lowest mobility. And as above, the two most powerful predictors were age and type of employment contract.

The countries differ to a great extent concerning the use of temporary contracts on the labour markets. Finland and Sweden have large proportions of temporaries, and in all the countries there is a larger risk for the young, for people born foreign to the country, and in some of the service sectors of having a temporary contract. When making the transition into employment (from unemployment or inactivity), the risk of ending up in a temporary contract is largest in Finland and Sweden. Furthermore, in these two countries the probability is smallest of making a transition from temporary to permanent employment. The chance is greatest in Norway.

The last transitions studied are into and out of part-time jobs. Here too, we find distinct patterns. In Norway such mobility is very common between $25-30 \%$ of the total in employment are in part-time jobs. In Finland the share is between 10 and 15\%. The proportions in Denmark 
and Sweden are in between (20-25\%). As expected, the transition rate from unemployment or inactivity to part-time employment is higher in Norway compared to the average transition rate in the Nordic countries.

The main conclusion of this study is that Denmark has a special combination of institutions related to its labour market. And this flexicurity nexus leads to high mobility rates on the labour market. However, we cannot say exactly which of the institutions affect the mobility rates most. The liberal employment protection legislation in Denmark certainly plays a role, but the generous unemployment benefits and the extensive use of active labour market policies may also be significant in creating employment security and voluntary mobility.

The other three countries differ from the Danish flexicurity system in certain respects. Norway and Sweden differ by their quite strict employment protection legislation. Finland and Norway have less generous unemployment benefits, and Finland makes less effort with active labour market measures.

However, the study has revealed that there are high levels of labour market mobility also in Norway. One explanation for the high mobility figures may be that Norway has had a strong economy for many years. The mobility patterns in Norway may be regarded as the levels we would find on a labour market characterised by full employment. However, there could also be other, non-measured, characteristics of the Norwegian labour market (e.g. industrial relations, regional and decentralization policies or cultural traits) that affect the high transition rates. 



\section{Introduction}

\subsection{Nordic labour market systems}

This report focuses on labour market mobility in four Nordic countries: Denmark, Finland, Norway and Sweden. The purpose is to study rates and determinants of mobility and to understand how differences in the institutional settings in the four countries affect mobility outcomes.

In many comparative studies on welfare and labour market systems, the Nordic countries are pooled together constituting one particular type. One example is Esping-Andersen's famous comparison of welfare state regimes (Esping-Andersen 1996; see also Korpi \& Palme 1999). Others are theories of production and employment regimes (Hall \& Soskice 2001; Gallie 2007). The descriptions are generally of a Nordic regime constituted by quite generous welfare states with universal social security systems. The production systems aim at quality rather than quantity goods and services and the relations between the social partners are welldeveloped, relying on negotiations and collective agreements.

During recent decades the concept of flexibility has come into the forefront in discussions of the functioning of labour markets (see Furåker 2005; Furåker, Håkansson, Karlsson 2007). In times of growing international competition it is said that companies and organisations have a need to be flexible - they must be able to adapt to changing circumstances in their environment, for example regarding demand, to stay profitable. Two central dimensions of adaptation are, firstly, organisations' potential to change their numbers of employees and, secondly, to change the competences needed for production. These two aspects of flexibility are usually called numerical and functional flexibility (Atkinson \& Meager 1986). Other forms are working time and wage flexibility.

Labour market and welfare institutions can affect organisations' potential for flexibility. Employment protection legislation determines how easy it is for employers to fire employees in case of reductions, but could also affect employers' incentives to retrain employees for new work tasks in the organisation. Furthermore, the scope and direction of active labour market measures are of importance for employees' transitions between jobs (qualifying, activating and matching) and the educational system for the supply of competences to the labour market. The social security system and, especially, the levels and construction of unemployment benefits may also affect the potential for flexibility on the labour market, i.e. making employees more or less prone to change and mobility.

However, when we use the concept of flexibility in social sciences we always have to ask "flexibility for whom?" Flexibility is an analytical 
concept that always has to be viewed from some actor's or agent's viewpoint (Jonsson 2007). And much of the discussion of flexibility has had the one-eyed viewpoint of the employers.

In a policy setting, the European Commission has promoted a mix of labour market and welfare institutions that are contained in the concept "flexicurity", a combination of the words flexibility and security (see European Commission 2007). The Commission wants to see a development of institutions that both facilitate flexibility for companies, organisations and individuals, and create security for the labour force and citizens in the member states. However, security is not an unambiguous concept. In a typology by Wilthagen and Tros (2004) four different types of security are distinguished. The first one is job security, i.e. rules for dismissals etc. The second type, employment security, is intuitively not so obvious, but has to do with the relative ease of getting a new job in case of unemployment instead of running the risk of marginalisation and exclusion from the labour market. Income security has to do with insurance against income reductions in case of, for example, unemployment, and combination security refers to the possibilities of combining working and family life, for example via paternal leave.

The proponents of flexicurity are of the opinion that it is possible to create labour market and welfare institutions that facilitate both flexibility and security on the labour market. One of the countries that serve as a model in this regard is Denmark. Here, great flexibility for employers (low employment protection) is combined with a generous welfare state (high unemployment benefits) and extensive use of active labour market measures (Bredgaard, Larsen \& Madsen 2005). The Danish labour market model has been described as a "golden triangle" because of the relationships and effects of these three pillars (see for example OECD 2004).

The other Nordic countries have, from a flexicurity perspective, similarities to Denmark. In international comparisons evaluating flexicurity profiles, they are often grouped together and characterised as countries with high levels of both security and flexibility on their labour markets (European Commission 2006; Muffels 2008).

However, in this report we will go into more detail describing the institutional frameworks in the four countries. These comparisons reveal differences that may affect labour market mobility. For example, Sweden has much stronger employment protection legislation than Denmark, and Finland spends the least on active labour market programmes (OECD 2003; 2004; 2006).

The theories and debate about flexicurity therefore give a new motivation to make internal comparisons between the Nordic countries. The question is whether flexicurity should be regarded as solely a Danish phenomenon or whether it is a more common Nordic labour market feature. Furthermore, the similarities and cultural closeness that obviously exist between the countries can be used as an advantage for comparisons. 
It becomes easier to infer that the differences which may be found have to do with the particular differences in the institutional setting, and not, for example, with great cultural differences.

\subsection{Labour market mobility}

One important rationale behind flexicurity arrangements is that it should facilitate flexibility on the labour market. Numerical flexibility has to do with the potential to hire or fire employees, which affects transitions between jobs or between employment and unemployment. Functional flexibility has to do with changes of competence in organisations, which to some degree coincide with occupational changes. Both types of flexibility imply transitions or mobility between states on the labour market. Consequently, one way to study flexibility is to focus on labour market mobility.

However, labour market mobility is an extensive concept that includes many different types of transitions. In a report by Andersen et al. (2008), they study movements between employers, between occupations and between major statuses on the labour market. Other forms of mobility are, for example, industry mobility and geographical mobility. The economic and social consequences of these different forms of transitions and the mechanisms that hamper or facilitate them are rather different.

This report will focus on three aspects of labour market mobility. Firstly, the main flows between employment, unemployment and inactivity will be studied. These kinds of flows have to do with the economic cycles at large. Moreover, they can give indications of how the dynamics in the economies are affected by the institutional settings. From a flexicurity perspective, the Nordic countries could be said to have made different trade-offs between job security, employment security and income security in their institutional settings (see chapter 3), which may have consequences for the numerical flexibility on the labour market. One way to examine numerical flexibility is to focus on transitions between employment and unemployment. Furthermore, the institutional setting can affect how inclusive or exclusive the labour market is. Studying transitions into and out of the labour force can tell something about how hard or easy it is for certain groups to participate on the labour market, for example immigrants and different age groups.

Secondly, the transitions into and out of employment can be related to the employment status and the conditions of employment that are left or offered on the labour market. Some of the employment situations that are available have been described as atypical employment. Usually fixedterm contracts, part-time employees and, to some degree, selfemployment belong under the concept. Whether atypical forms of employment also should be described as precarious depends on how secure 
they are, compared to more typical forms. On labour markets with low levels of employment protection, such as the Danish, differences in risks of unemployment in open-ended and fixed-term contracts may not be as conspicuous as in countries with more severe legislation such as Sweden and Norway. Furthermore, should part-time employment be regarded at all as atypical in the Nordic countries?

Thirdly, mobility between workplaces, occupations and industries has to some degree to do with structural changes on the labour market. From a macro-perspective, mobility of this kind can be regarded as an indicator of functional flexibility on a labour market level. There must be transitions of competences on the labour market to sectors and industries where they are needed. Transitions between workplaces, occupations or industries may also be hampered or facilitated by the institutional framework. For example, the aim and quality of active labour market policies (ALMP) can affect their participants through upgrading their competences to qualify for a new job. Another factor of importance is to what extent the educational system allows adult retraining, i.e. what has also been called lifelong learning (LLL).

\subsection{Aim and general research questions}

In this report, labour market mobility patterns in Denmark, Finland, Norway and Sweden are compared during the years 2000-2006. The aim is to study how mobility is affected by the different welfare state and labour market institutions that characterise the four Nordic countries. The general research questions that guide the study are the following:

- How large proportions of various categories in the four countries make different kinds of transitions in the labour market?

- Which are the main determinants behind different forms of labour market mobility? Are there national variations in these respects?

- How can national differences regarding labour market mobility be explained? Are they related to national institutional frameworks?

The study focuses on three major types of labour market mobility:

- Transitions between labour market statuses, i.e. employment, unemployment and inactivity.

- Transitions into and out of atypical employment, i.e. temporary contracts and part-time employment.

- Workplace mobility, occupational mobility and mobility between industries.

This report does not focus on geographical mobility, but it is important to remember that all the transitions studied could imply a change in location 
inside the countries (for example between regions) or between countries. The basis for the empirical studies is the Labour Force Surveys (LFS) in the four countries. These surveys have a panel structure that has been utilized to measure changes in labour market situation after one year. The LFS data have been pooled together in one single data set which has allowed statistical comparisons.

The outline of this report is as follows. In the continuation of this introductory chapter, earlier research on mobility that is relevant for the study will be presented. The second chapter presents some data concerning the labour markets in the countries during the studied period, focusing on characteristics of relevance for mobility patterns. In the third chapter, the institutional frameworks of the four labour markets are described and compared from the perspective of flexicurity. The focus is on the employment protection legislations (EPL), the unemployment benefits (UB), active labour market policies (ALMP), and lifelong learning (LLL) institutions in the four countries. Chapter 4 presents data and methods. Chapter 5 analyses patterns and rates of transition between employment, unemployment and inactivity. In chapters 6 and 7, transitions into and out of atypical employment are analysed, the first of the two chapters focusing on temporary contracts and the second on part-time employment. Chapter 8 is a study of workplace mobility, occupational mobility and mobility between industries. Finally, chapter 9 is a summary and some main conclusions of the study are drawn.

\subsection{Research on mobility in the Nordic countries}

This section will present some research on mobility that is of particular interest for the present study. Studies that compare mobility patterns in the Nordic countries and focus on the same types of mobility as in the present study are of main interest. The purpose is to find some indications of the differences in mobility rates to be expected between the countries. Another purpose is to trace which independent variables are of importance to explain mobility outcomes.

There are several studies on so-called job-to-job mobility. This concept includes change of workplace and/or employer. However, it can also refer to internal job mobility, i.e. a change of position or job at the same workplace/employer. One of these studies is a Danish report called Job Mobility in the European Union: Optimising its Social and Economic Benefits, prepared for the European Commission (Andersen et al. 2008). Job-to-job mobility is defined as a change of employer (involuntary or voluntary) and it is estimated by using two different indicators in the study. First, a retrospective question about job change during the last year is used for estimations. The share that has experienced a job change during a year (2005) is found to be $11.5 \%$ in Denmark and 5.7\% in Finland. 
There are no data for Norway and Sweden. Another indicator is average job tenure, i.e. the average amount of time that employees in a country have been working for the current employer. Denmark is here below (approximately 8 years), and Sweden and Finland close to, the EU mean (just above 10 years). There are no data for Norway. Important determinants of job-to-job mobility are found to be age and type of employment contract - young and people with temporary contracts change jobs more often than older and employees with permanent contracts. Gender, education and level of unemployment also have effects, but rather small ones.

In a Nordic study on job-to-job mobility (change of employer), register data are used to estimate and compare mobility rates in the same Nordic countries that are in focus in the present report (Graversen et al. 2003). During the years 1988-1998 the job-to-job mobility rate in Denmark is found to be quite stable - around $19 \%$ of the employed have changed employer after one year. In Finland, there is a sharp decrease in job-to-job mobility from more than $24 \%$ in the late 1980 s down to around $15 \%$ in the middle of the period. For the last 2 years in the series there seems to be an increase in job-to-job mobility. For most years in the period the figures are lowest in Norway. During the two first years the mobility rate is just above $14 \%$. Thereafter, there is a decrease down to year 1995 when the job-to-job mobility rate is close to $11 \%$. However, during the last three years of the period there is a sharp increase which the authors think could be an effect of changes in indicators. The Swedish pattern is close to the Finnish with a sharp decline from a high level (26\%) in the late 1980s down to figures around 19\% during the rest of the period. The main determinants that are found concerning job-to-job mobility are age, education and workplace size. Age works in the same direction as above (negative relationship). Educational level is related to increased mobility rate. Workplace size, on the other hand, decreases the job-to-job mobility rate. There is also found a positive correlation between business cycle and the job-to-job mobility rate in the study, i.e. a procyclic relationship (up-turn, more job changes).

There are also studies made in single Nordic countries. In a Swedish study of mobility between employers during the period 1972-98, a special version of the Swedish LFS is used where the respondent is asked if he/she has changed employer during the last year (Furåker \& Berglund 2009). The mobility rates that are presented are on a much lower level than the figures above where register data are used (see chapter 4 for a more thorough discussion). The Swedish mobility rate fluctuates around $10 \%$ until the late 1980s when it drops down to 6-7\% during the crises in the 1990s. The Swedish study finds that the same independent variables are important for mobility as the studies above. However, they also find some minor effects of changes in the employment protection legislation during the period. 
A Danish study using register data to measure workplace mobility (Bredgaard et al. 2009). Between the measurement points 2003 (Nov) and 2004 (Nov) 15.9\% had changed workplace. Much the same determinants are found as above. However, occupational group seems also to matter, i.e. persons in higher-level jobs are less mobile. Furthermore, family situation affects mobility. Couples with children have less workplace mobility than couples without.

In Finland, workplace mobility has been studied both with register (Virjo et al. 2007) and LFS (Aho et al. 2009) data, with the longest time series stretching from 1989 to 2007. The single most powerful determinant explaining mobility was age - mobility decreased strongly with age. Another important determinant was the type of contract.

In an analysis of workplace changes from 1986 to 2001, a Norwegian study of register data finds a sharp increase in workplace changes around 1995 to a level close to 17\% (Salvanes 2007). However, this increase coincides with the one found in the Nordic study above, which was believed to depend on changing indicators (see Graversen et al. 2003). The latter study shows that the new level of workplace/employer changes continues into the 2000s.

When it comes to the other mobility types that are focused upon in this report, there are few studies that have investigated these forms and compared the Nordic countries. In the research by Andersen et al. (2008) referred to above, both occupational and so-called employment mobility are studied. Occupational mobility is defined as a change in job profile or job content. The rates that are estimated are the share of respondents that have changed occupation one or more times since their entry on the labour market. Furthermore, the direction of the occupational change is presented, i.e. whether it is an upward or downward mobility concerning the skills needed for the job. Denmark, Finland and Sweden are quite close to each other; around $70 \%$ have changed occupation upwardly since their labour market entry (Norway is not included in the analysis). Important determinants to explain occupational mobility are gender (men are more mobile than women), age (the older a person gets, the more likely is occupational mobility, often upward), type of contract (permanent employees tend to make occupational transitions to a lesser degree, but have a higher probability of upward mobility than temporary employees) and unemployment level (higher unemployment, fewer occupational changes).

In the Finnish studies mentioned above, also occupational and industrial mobility was studied (Aho et al. 2009; Virjo et al. 2007). The same determinants as found for workplace mobility (age and type of contracts) also affected these types.

Employment mobility is defined in the study by Andersen et al. (2008) as mobility between general employment statuses, i.e. employment, unemployment and inactivity. Furthermore, they study transitions to different forms of contracts (permanent, temporary) and to full- and part-time. 
The total share of employment mobility of the population of working age is highest in Denmark (around 17\%) during the years 2000-2006. The figures for Finland are approximately 13\% and Sweden 9\% (no figures for Norway are presented). Denmark is also on top when transitions between employment and unemployment and transitions between activity and inactivity are presented. Explanatory variables with strong effects on employment transitions are age, education, type of contract and fulltime/part-time.

\subsection{Concluding remarks}

This brief survey of research shows that the picture concerning labour market mobility in these Nordic countries is not especially clear. Different data sources are used and definitions of some types of mobility, for example occupational, vary considerably. This makes it hard to estimate differences in mobility rates between the countries. Furthermore, there is no particular focus (with some exceptions) on the institutional framework and strategies to try to isolate the effects of the institutions on mobility. However, the presented studies give good indications of which factors have to be under statistical control in the coming analyses in order to sort out business and compositional effects on mobility.

The present study will try to make a contribution to the research on labour market mobility in the Nordic countries through a comprehensive approach to data and indicators. In this respect an important contribution has been to create an integrated data set combining information from the labour force surveys of the four countries. Furthermore, we will statistically try to control for factors that have to do with the composition of the labour force and the business cycle. In that way, we will be in a better position to relate remaining differences between the countries to the specific national institutional frameworks. 


\section{Labour market characteristics}

\subsection{Introduction}

One purpose of this study is to estimate probabilities of mobility in the four countries when economic and compositional factors on the labour market are controlled for in statistical analyses. In the review of earlier research on labour market mobility in a Nordic context, many factors with impact on mobility rates were uncovered. These factors should be included as variables in the statistical analyses to control for structural factors that may not directly be a consequence of institutional differences but of, for example, demographic characteristics.

This chapter will describe some of the main factors during the years under scrutiny that can affect mobility rates in the countries. One important factor is the business cycle and especially the unemployment rate. For example, concerning workplace mobility the effect is shown to be procyclical, i.e. mobility increases when unemployment goes down and decreases when unemployment goes up. However, the direction of the relationship may change if other types of transitions are studied, for example, mobility from employment to unemployment. Furthermore, the research shows that there are effects on mobility due to gender, age, education, industry, type of contract and working-time. If there are variations in the Nordic countries concerning these factors, there could be compositional effects on mobility. One example is that if there are many young and few old people on the labour market in one country, and the opposite in another country, this could affect differences in mobility levels.

\subsection{Unemployment and employment rates}

The first factors of concern are the unemployment and employment rates during the years for the study. These are shown in Figures 2.1 and 2.2. However, the starting and end points are some years before and after the period 2000-06. The first comment to make is that the countries were hit very differently by the economic crises in the 1990s. Finland and Sweden were more affected than Denmark and Norway. There has been a recovery during the second half of the 1990s in both Finland and Sweden, but the unemployment and employment rates have not come back to the levels before the crises. 


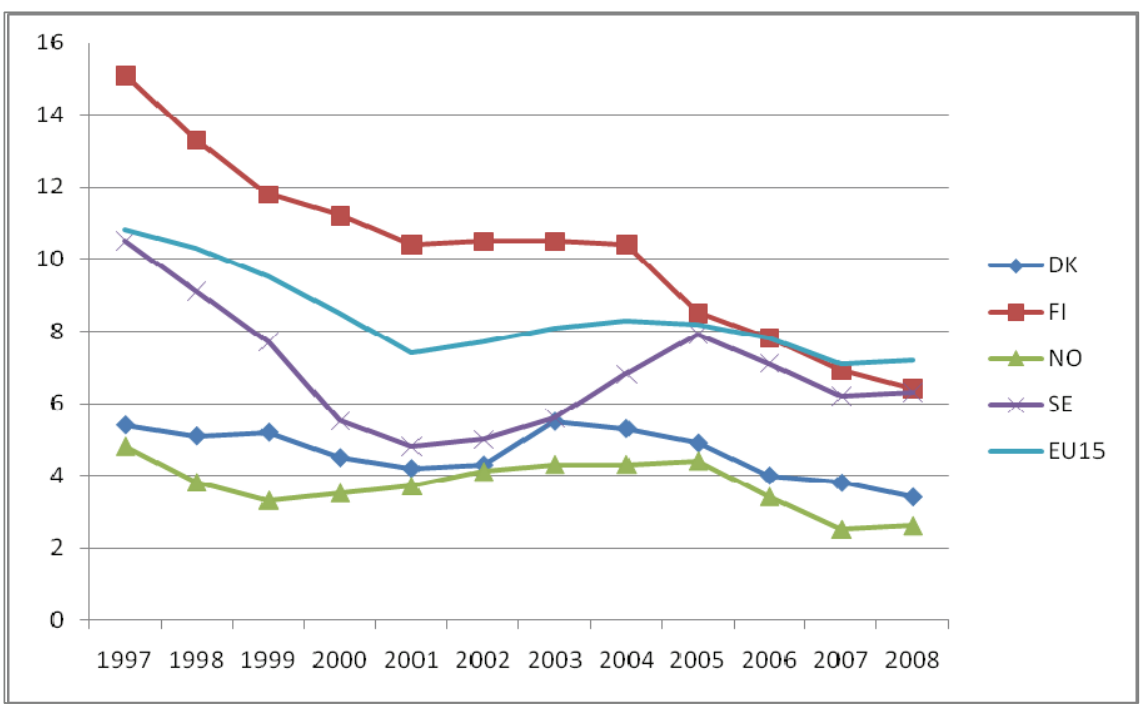

Figure 2.1 Unemployment rate, $15-64$ years Percent. ${ }^{1}$

Source: Eurostat, EU-LFS

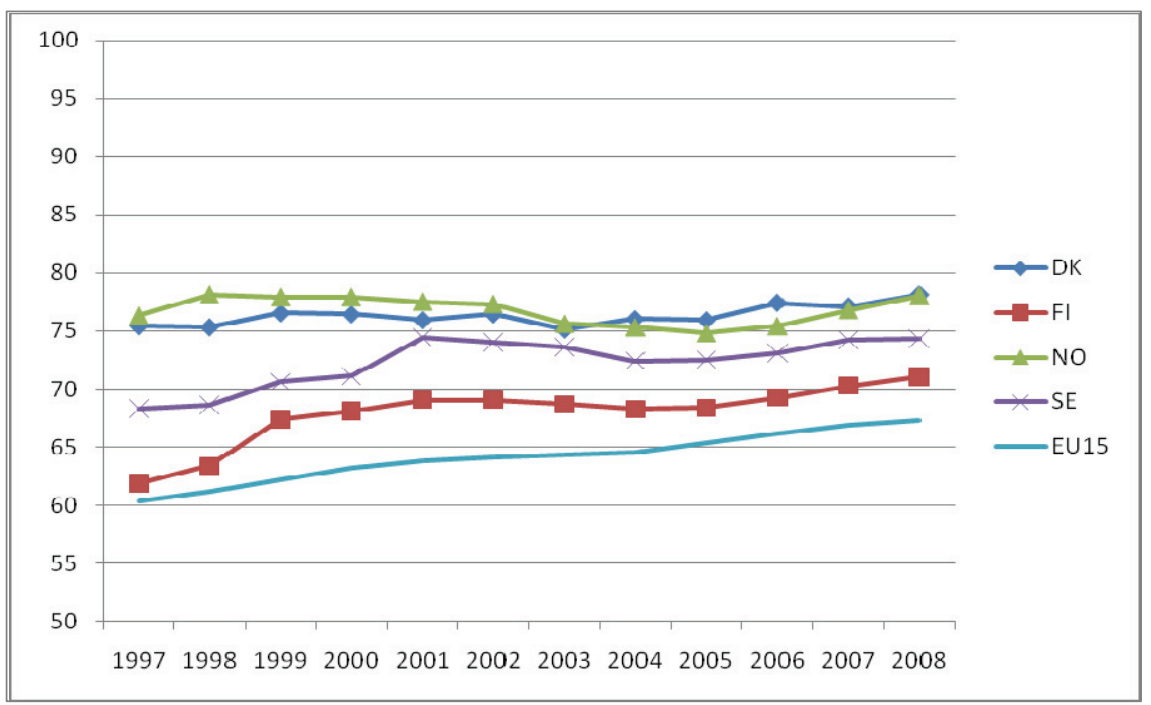

Figure 2.2 Employment rate, 15-64 years.Percent.

Source: Eurostat, EU-LFS

Finland has had a quite constant decline in the unemployment rate and an increase in the employment rate during the time period shown. If we focus on the years 2000-06, we find a significant decrease in the unemployment rate in Finland in the beginning and the end of the period. The same but inverse pattern is found for the employment rate. Generally, the business cycle in Finland has been quite positive during the period, which could affect mobility rates both through more job openings and vacancies, and psychologically, through more risk-taking behaviour on the

${ }^{1}$ From 2005 the Swedish EU-LFS data are adapted to the ILO definition of unemployed, including full-time students searching for a job. Thus, the Swedish data up to 2004 are based on the older definition. 
labour market, i.e. voluntary mobility. However, the unemployment rate during the period is on a higher level in Finland than in the other countries. This indicates that Finland has suffered long-term structural unemployment on the labour market (see Aho 2004). One consequence of this could be lower mobility rates from unemployment to employment compared to the other countries.

The Swedish recovery from the 1990s crises has not been as persistent as the Finnish. Until 2001-02, the unemployment rate falls faster in Sweden than in Finland, but after these years the figures are rising. However, in 2005 the definition of unemployment was changed, which explains the much higher level that year. If we look at the figures for the employment rate, the pattern also reveals a less persistent recovery, with a slight downturn in the employment rate during the middle of the studied period. These patterns affect mobility rates both through the variation in vacancies and through the willingness of the employed to change jobs. The labour force in Sweden may be less certain about the economic development in the country, which could affect voluntary mobility.

In Denmark and Norway the changes in unemployment and employment rates have not been as dramatic as in Finland and Sweden. The unemployment rate has fluctuated around 5\% in Denmark and 4\% in Norway during most of the period in focus (2000-06). In the end of the period there is a quite sharp decrease in both of the countries. The same stable pattern during most of the period is also found for the employment rate (around 75\%), with an increase in the end of the period. During the whole period, the employment rate is at a significantly higher level in both countries than in Finland and Sweden. One possible effect of these patterns is that the mobility rates should to a lesser degree be affected by changes in the unemployment rates. And the better climate in general on the labour markets could affect voluntary mobility rates positively.

\subsection{Gender composition}

The gender composition of the labour markets is also a factor that could have some effects on mobility rates. However, there is no clear-cut evidence for which forms of mobility it can affect and in which direction. There is some evidence that men change occupation (Andersen et al., 2008) and change employer (Furåker \& Berglund 2009) to a higher degree than women. However, the differences are not very conspicuous. 


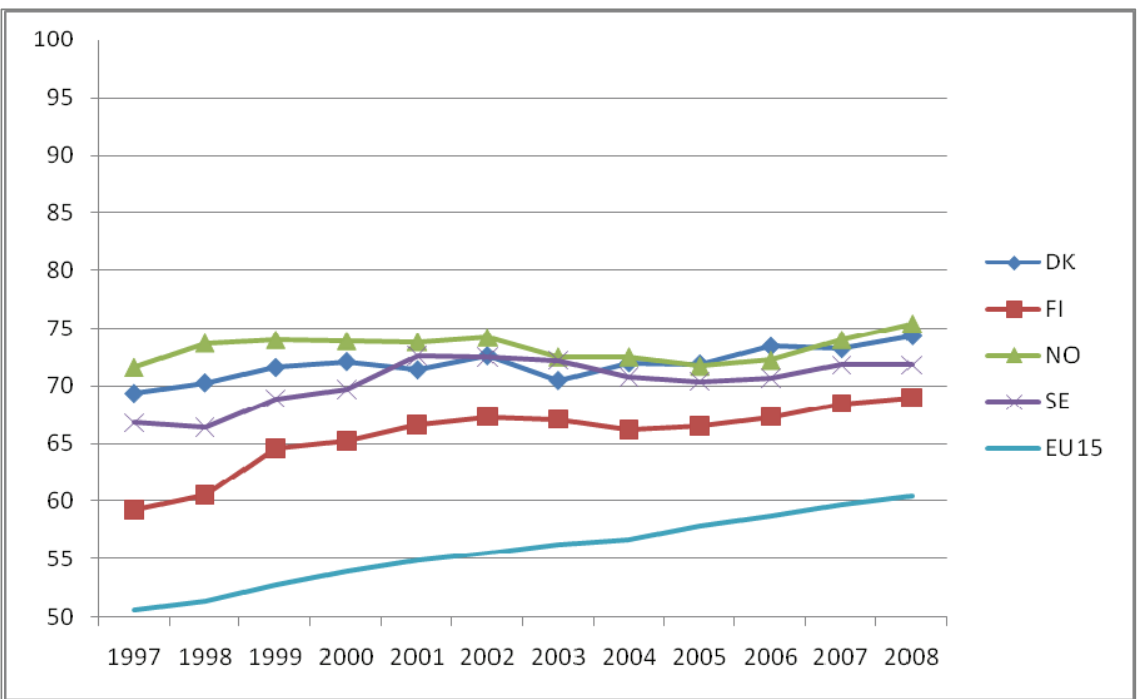

Figure 2.3 Employment rate, women 15-64 years.Percent.

Source: Eurostat, EU-LFS

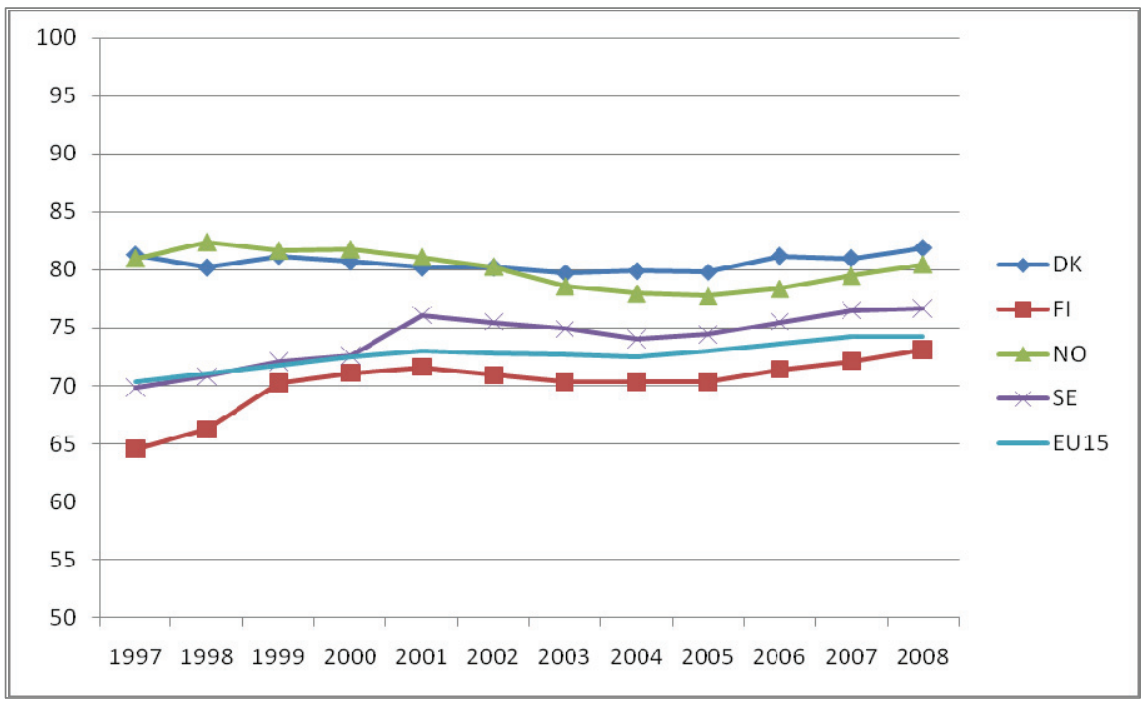

Figure 2.4 Employment rate, men 15-64 years.Percent.

Source: Eurostat, EU-LFS

In Figures 2.3 and 2.4 the employment rates for women and men are presented. The general patterns in the countries follow the ones shown in Figure 2.2 above. In comparison to the EU-15 average, the female participation rate is much higher in the Nordic countries. And in general the employment rate for women is somewhat lower than for men. However, there are some internal Nordic differences of interest. Finland deviates from the other three countries with a clearly lower employment rate for both women and men. The employment rate for men is higher in Denmark and Norway than in Finland and Sweden. Yet the Swedish rate is above the EU-15 average, and the Finnish below. 


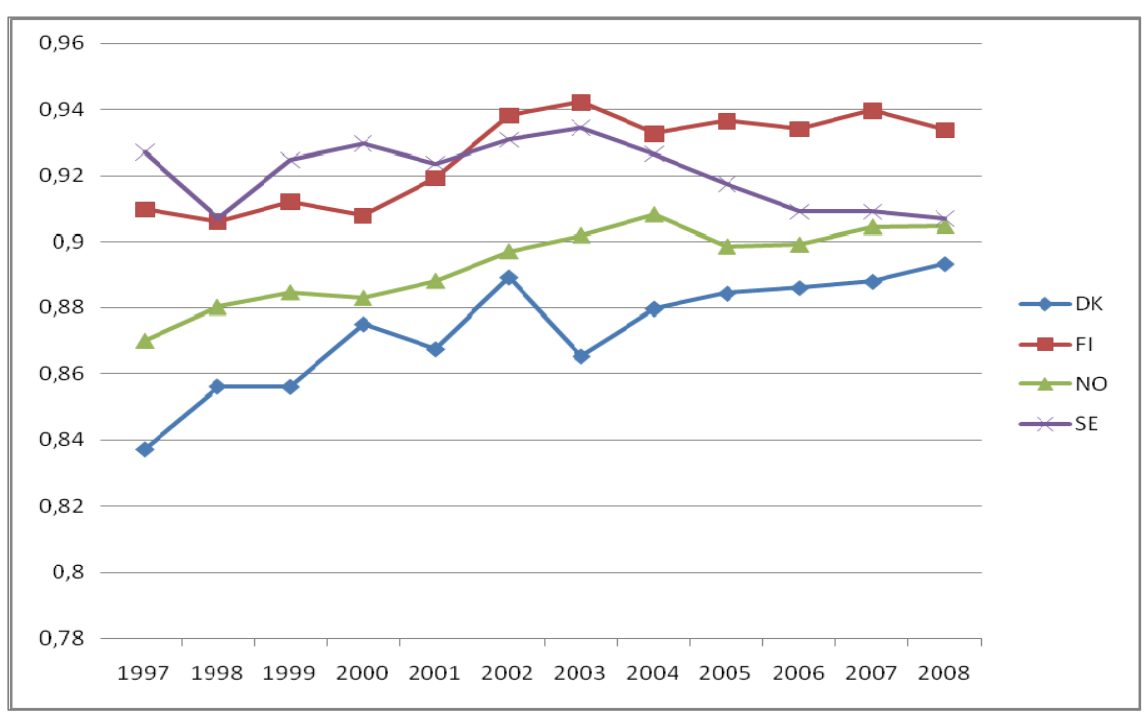

Figure 2.5 Female/male employment ratio (Women / men) 15-64 years. Percent.

Source: Eurostat, EU-LFS

To make the compositional differences more evident, a ratio between the numbers of women and men in employment is presented in Figure 2.5. This gives another picture of the gender distribution in the labour force than the figures above. In the beginning of the period Finland and Sweden stand out with a more even distribution of women and men in employment. Denmark has a less even distribution. However, in the end of the period Denmark, Norway and Sweden are coming closer to each other. Finland still has the most even composition of women and men participating in employment.

\subsection{Age distribution}

Another factor that could have compositional effects on mobility is the age distribution. For many types of transition (e.g. workplace mobility), the research shows that the younger are more mobile than the older. Consequently, a large part of young people on the labour market and a small part of the old could affect some mobility rates. In Figures 2.6 and 2.7 the employment rates for the youngest (15-24 years) and the oldest (55-64 years) age groups are shown. Denmark has the highest employment rate for the young, fluctuating between $60-65 \%$ during the period. In Norway it is around 55\%. However, in Finland and Sweden the employment rate fluctuates between $40-45 \%$. There are many possible explanations for these patterns. One is the more widespread use of apprenticeships in the Danish and Norwegian educational systems. These may have two different effects: firstly, that transitions into employment will be easier for the young because of their closeness to the labour market. Secondly, the use of apprenticeships may in itself increase the employment rate because it 
is usually counted as work in the official statistics (European Commission 2007).

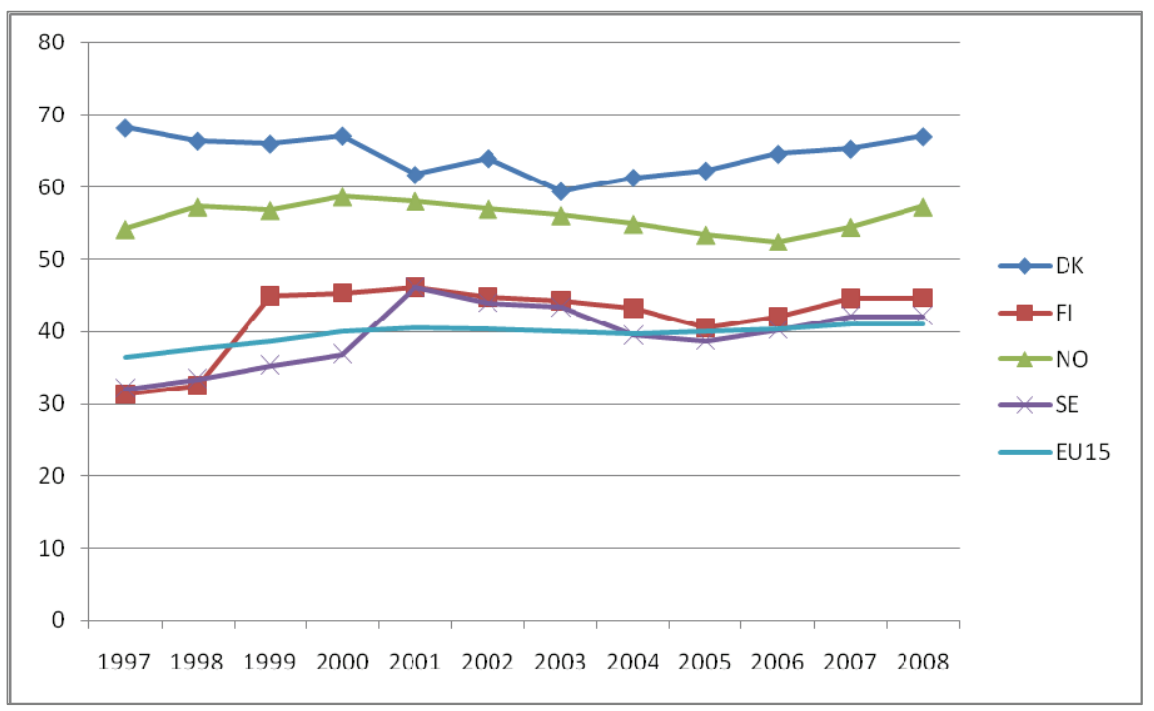

Figure 2.6 Employment rate, 15-24 years. Percent.

Source: Eurostat, EU-LFS

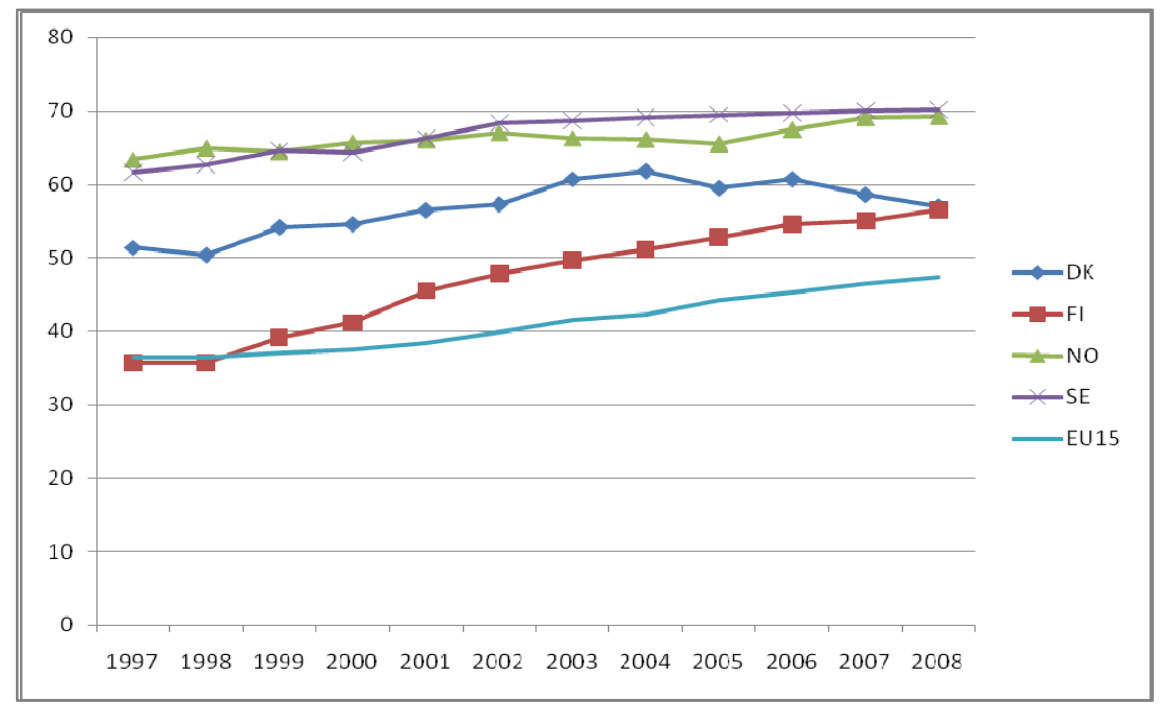

Figure 2.7 Employment rate, 55-64 years. Percent.

Source: Eurostat, EU-LFS

Looking at the oldest age group, other patterns are revealed. In both Norway and Sweden, a quite large proportion of people 55-64 years old is still working. Finland is diverging with a very low employment rate of the oldest in the beginning of the period. The employment rate is then increasing and on the same level as the Danish in the end of the period (57\%). However, it is much lower than the Norwegian and Swedish during the whole period. This pattern is to a great extent due to the Finnish 
system of unemployment benefits and pensions during the period. The system extended the right to unemployment insurance benefits for the aging unemployed until the unemployed person was entitled to a pension. An additional consequence of the system has been that the aging often have been the first to be dismissed if a work force is reduced, leaning on more or less voluntary consent between the employers and the employees (Virjo \& Aho 2002; Hakola \& Määttänen 2009). One of the reasons why the employment rate of the aging has increased during the last ten years beside the improved employment situation in general - is that the extended right to UI benefits has been gradually restricted (for a more detailed description, see Appendix A).

Denmark also has a system that gives incentives to leave the labour market at quite early ages. It is called efterlønsordning (the post-wage retirement). If employees have been paying to the unemployment insurance for more than 25 years and are aged 60 years or older they have the right to leave employment and get unemployment benefits until they get old-age pensions at age 65 . Around $40 \%$ of the Danes aged 60-64 use the system, which is an important explanation for the quite low employment rate for the age group shown in Figure 2.7 (Gjerding 2006).

In Figures 2.8 and 2.9 the proportions of young and old to all in employment are shown. Sweden has the largest proportion of the oldest age group in employment and the lowest proportion, together with Finland, of the youngest. This pattern could have a hampering effect on the mobility rates in the country.

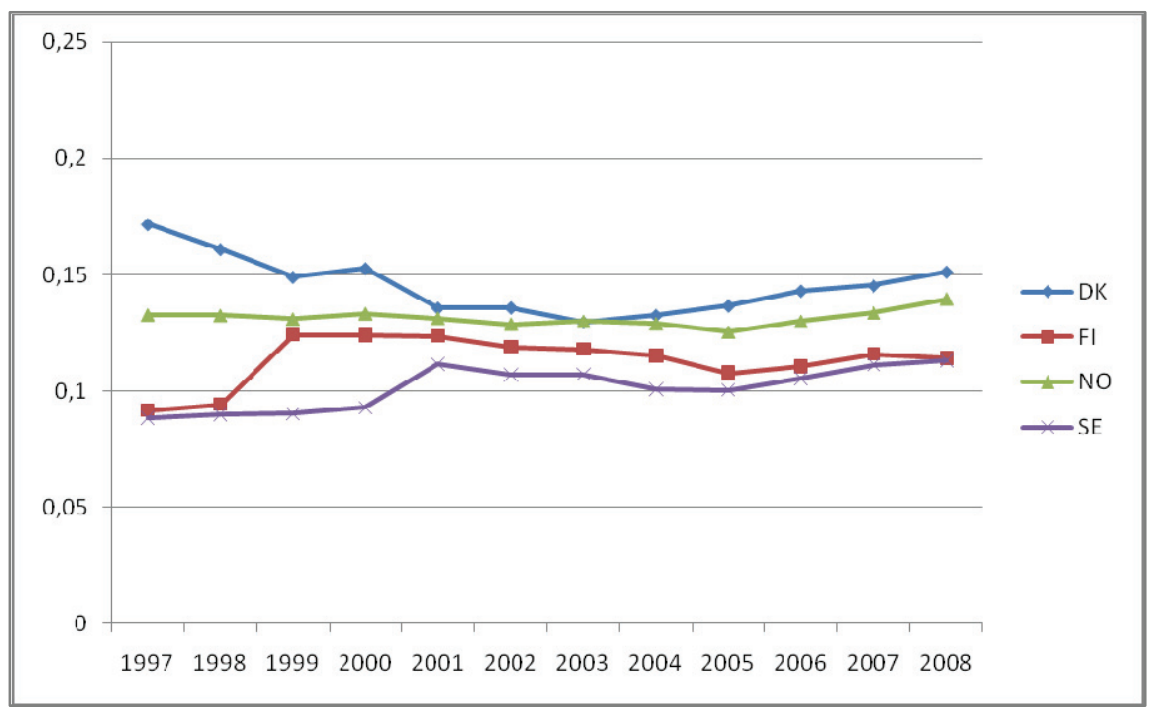

Figure 2.8 Proportion of those aged 15-24 years to all (15-64) in employment. Source: Eurostat, EU-LFS 


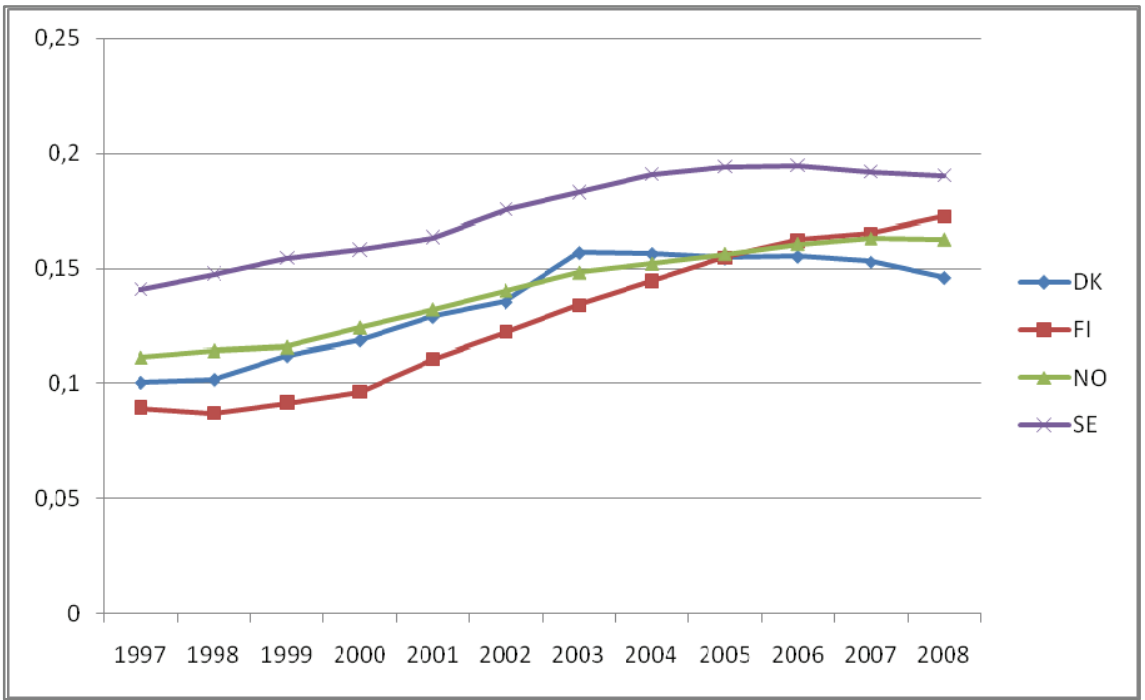

Figure 2.9 Proportion of those aged 55-64 years to all (15-64) in employment. Source: Eurostat, EU-LFS

In addition to the employment rate, another factor much debated is the youth unemployment rate. Figure 2.10 shows the unemployment rate for people aged 15 to 24. In Denmark the youth unemployment has been quite stable on a low level since the beginning of the period shown. Norway is also on a low level, much below the EU average, and closing in to Denmark.

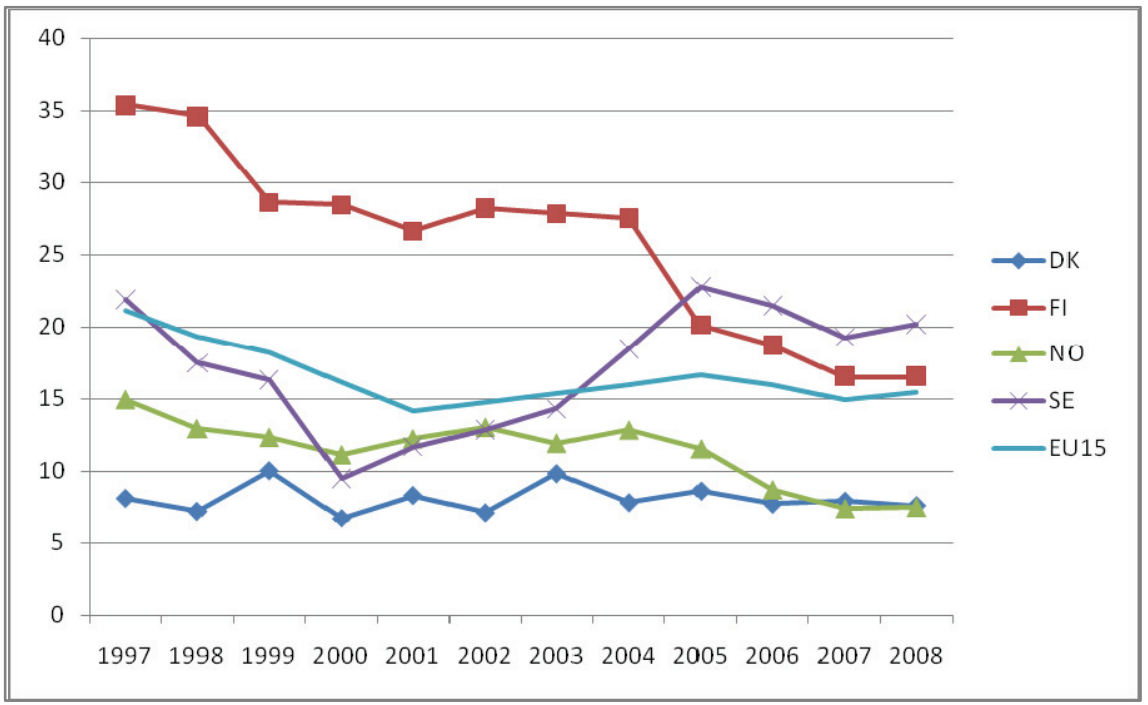

Figure 2.10 Unemployment rate, ages 15-24 years.Percent.

Source: Eurostat, EU-LFS (regarding the Swedish curve, see footnote 1 above).

The picture is very different in Finland and Sweden. Finland started the period studied on a very high level of youth unemployment. In year 2000 it was $28.4 \%$. However, since 2004 there has been a steep decrease and, 
at the end of the period shown, Finland is close to the EU-15 average. In the case of Sweden, the development has not been as positive. Sweden started the studied period with lower youth unemployment than Norway (9.5\% in 2000). In the end of the period it has increased to a higher level than in Finland. In 2006 it was 21.5\%. However, some of the increase is due to the harmonising of indicators. Still, in 2004 youth unemployment was $18.5 \%$, i.e. an increase of $9 \%$ points since 2000 .

\subsection{Educational levels and occupational groups}

In the research on mobility some results indicate that educational level is of significance for mobility rates. However, the effect of education may work in different directions concerning different kinds of mobility. For example, there should be a negative relationship between educational level and the risk of unemployment (lower risk with higher education) and, on the other hand, a positive relationship between educational level and transitions to employment from unemployment (higher chance for employment with higher education). In Figure 2.11 the proportion of persons in employment with tertiary education is presented. Finland has the highest proportion and Sweden, for most of the years, the lowest.

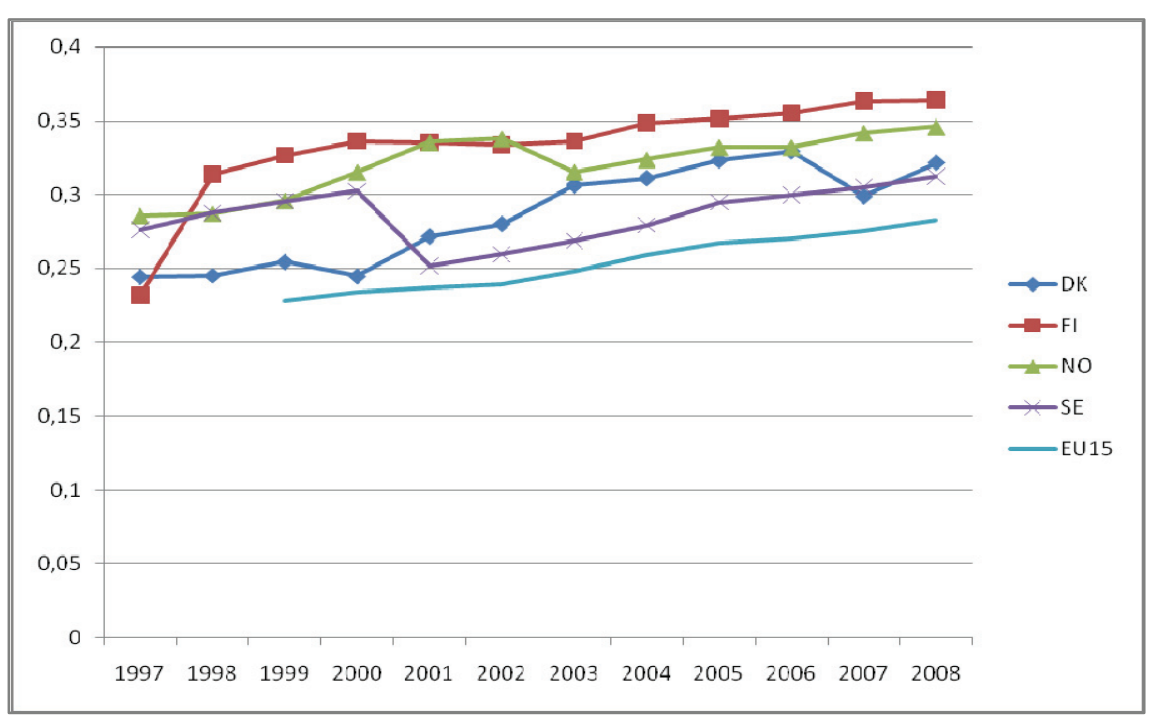

Figure 2.11 Proportion of persons with tertiary education among all in employment aged 15-64 years. Percent.

Source: Eurostat, EU-LFS

The occupational structure in the four countries has many similarities. However, there are a few disparities to notice. Finland and Sweden have higher proportions of professionals in employment than Denmark and, especially, Norway. On the other hand, Norway has a clearly larger proportion of service workers compared to the other countries. In Denmark 
there is a quite high proportion of elementary occupations, which presumably has to do with the large share of young people on the labour market. The consequences of these differences in the occupational structure for mobility patterns and mobility levels are not easy to predict. Generally, however, it is possible to expect higher mobility rates among elementary occupations than professionals.

Table 2.1. Distribution of occupational groups. $15-64$ years. Averagepercent points 2000-2006. Source: Eurostat, EU-LFS.

\begin{tabular}{|c|c|c|c|c|}
\hline ISCO 88 & DK & $\mathrm{FI}$ & NO & SE \\
\hline $\begin{array}{l}\text { Major group 1: } \\
\text { Legislators, Managers etc. }\end{array}$ & 7.2 & 9.1 & 7.2 & 4.8 \\
\hline $\begin{array}{l}\text { Major group 2: } \\
\text { Professionals }\end{array}$ & 14.6 & 17.6 & 11.3 & 18.1 \\
\hline $\begin{array}{l}\text { Major group 3: } \\
\text { Technicians etc. }\end{array}$ & 20.7 & 16.3 & 23.5 & 20.0 \\
\hline $\begin{array}{l}\text { Major group 4: } \\
\text { Clerks }\end{array}$ & 10.1 & 7.7 & 7.9 & 9.7 \\
\hline $\begin{array}{l}\text { Major group 5: } \\
\text { Service workers etc. }\end{array}$ & 15.3 & 14.6 & 22.7 & 18.6 \\
\hline $\begin{array}{l}\text { Major group 6: } \\
\text { Skilled agricultural workers etc. }\end{array}$ & 2.2 & 4.8 & 3.1 & 2.1 \\
\hline $\begin{array}{l}\text { Major group 7: } \\
\text { Craft etc. }\end{array}$ & 11.2 & 12.4 & 10.9 & 10.0 \\
\hline $\begin{array}{l}\text { Major group 8: } \\
\text { Plant and Machine operators etc. }\end{array}$ & 6.6 & 8.7 & 7.6 & 10.3 \\
\hline $\begin{array}{l}\text { Major group 9: } \\
\text { Elementary Occupations }\end{array}$ & 11.4 & 8.2 & 5.3 & 5.8 \\
\hline $\begin{array}{l}\text { Major group 0: } \\
\text { Armed forces }\end{array}$ & 0.4 & 0.4 & 0.5 & 0.2 \\
\hline
\end{tabular}

\subsection{Industrial structure}

In Table 2.2 the industrial structure in the four countries is presented. There are no conspicuous differences between the countries. All four have small primary sectors, shrinking industry sectors and large service sectors. On the margin, Finland has a slightly larger primary and industry sector than the other countries.

Table 2.2. Distribution of Industries. 15-64 years. Averagepercent points 2000-2006.

\begin{tabular}{lcccc}
\hline NACE Rev 1. & DK & FI & NO & SE \\
\hline $\begin{array}{l}\text { A-B: } \\
\text { Agriculture, hunting, fishing }\end{array}$ & 3.1 & 5.1 & 3.6 & 2.2 \\
$\begin{array}{l}\text { C-F: } \\
\text { Industry }\end{array}$ & 24.1 & 26.7 & 21.4 & 23.0 \\
$\begin{array}{l}\text { G-K: } \\
\text { Services }\end{array}$ & 36.4 & 35.7 & 37.2 & 36.8 \\
L: & & & & 5.6 \\
Public administration & 5.8 & 4.8 & 6.0 & 32.3 \\
M-Q: & & & & \\
Other services & 30.4 & 27.4 & 31.6 & \\
\hline
\end{tabular}

Source: Eurostat, EU-LFS. 
A factor that in a more straightforward way can affect labour market mobility is the size of the companies and workplaces. A labour market with a lot of small employers may imply more unstable employment relationships because of greater sensitivity in relation to the business cycle than in larger companies. Moreover, a labour market with a lot of small employers may create more opportunities to change one's employer.

In table 2.3 the shares of employees working in companies of different size are presented. Note that employment in the public sector is not included in these figures. There are some differences to notice. First, Norway has the largest share employed in companies with the smallest number of employees. Finland, on the other hand, has the largest proportion in large companies. In Denmark the private sector is more dominated by small and medium size enterprises than in the other countries.

Table 2.3. Structure of enterprises: shares of the number of employees by the size of enterprise in private sector.

\begin{tabular}{rrrrr}
\hline & DK & FI & NO & SE \\
\hline-9 & 20.2 & 20.3 & 27.6 & 24.9 \\
$10-49$ & 25.4 & 17.6 & 24.5 & 20.4 \\
$50-249$ & 20.6 & 18.4 & 17.6 & 17.9 \\
$250-$ & 33.7 & 43.7 & 30.2 & 36.8 \\
Total & 100 & 100 & 100 & 100 \\
\hline
\end{tabular}

Source: Eurostat SBS data base 2004/2005.

\subsection{Temporary contracts and part-time employment}

Two other factors of importance for mobility rates are the proportions of part-time and temporary workers on the labour market. These categories may have a more loose attachment to the labour market with higher risk of some transitions, especially to unemployment and to inactivity.

Figure 2.12 and 2.13 shows the part-time and temporary workers' proportions of total employment. The first thing to notice is that the four countries have quite different patterns. The use of part-timers is highest in Norway, but high also in both Denmark and Sweden compared to EU-15 average. In Finland the use of part-time workers is on a much lower level than in the other three countries. If we then study the use of temporary workers, we find distinct patterns. Finland and Sweden have much higher proportions of temporary workers than Denmark and Norway.

These patterns will be under scrutiny in chapters 6 and 7. However, they might affect mobility rates. Especially temporary workers have less secure relations to the labour market and therefore higher risks of unemployment or of dropping out from the labour force. The high proportions in both Finland and Sweden may therefore be of significance. 


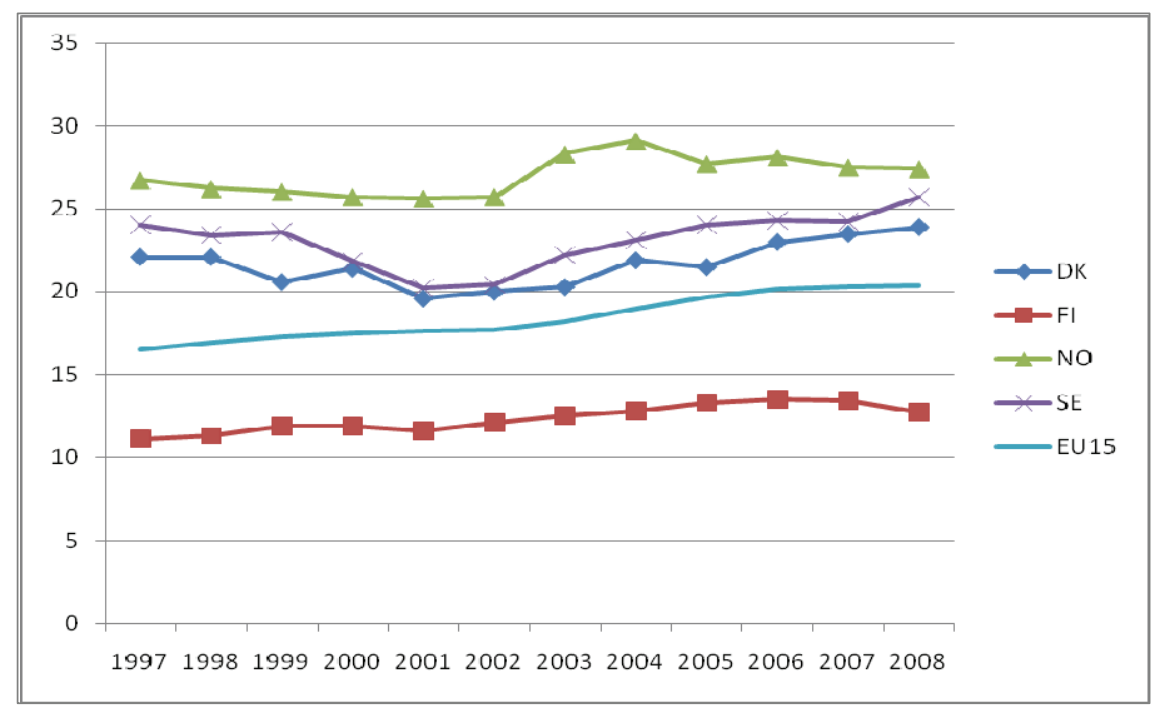

Figure 2.12 Part-time employment as proportion of total employment, 15-64 years. Percent. Source: Eurostat, EU-LFS.

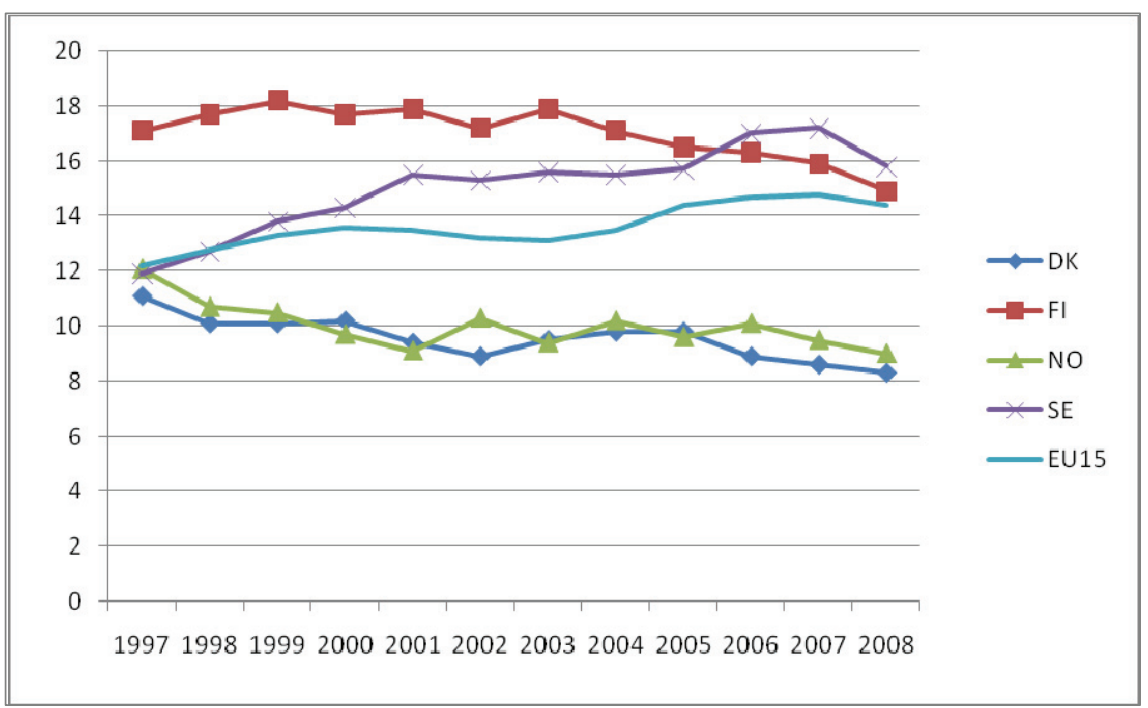

Figure 2.13 Temporary employees as proportion of total numbers of employees, 15-64 years. Percent.

Source: Eurostat, EU-LFS.

\subsection{Concluding remarks}

The purpose of this chapter has been to give a picture of the labour market characteristics of the four countries in focus. As has been shown, they have many features in common and one of these is a high employment rate compared to the EU-15 average. An important explanation for this is the high rate of participation among women.

However, there are also differences between these four Nordic countries, and some of them might have consequences for mobility patterns 
and mobility rates. Two of the most conspicuous are the age structure and the use of temporary contracts. In the first case, the Danish age structure may very well increase some types of mobility. A large number of young people on the labour market may, for example, increase job-to-job mobility. On the other hand, the Swedish age structure with few young and many old on the labour market may hamper mobility. In the second case, there are huge differences in the use of temporary contracts on the labour markets in the four Nordic countries. Finland and Sweden are the most frequent users. However, temporary contracts may be used to create numerical flexibility on the labour market (Håkansson \& Isidorsson 2009). In this way, they might increase some flows on the labour market, for example between employment and unemployment. They might also have consequences for the structure of the flows, i.e. which categories are exposed to some types of mobility. 



\section{Nordic labour market and welfare systems from a flexicurity perspective}

\subsection{Introduction}

This chapter will describe the institutional framework in the four countries from a flexicurity perspective. Especially in the context of the present project, the aim is to establish whether Denmark, as it is often depicted, is really so unique as regards the configuration of its labour market institutions. Is there only a Danish way, or should we consider a more general Nordic model of flexicurity?

For this purpose, the chapter will start with a brief general discussion of the flexicurity concept and then present the manner in which it has been applied in the Danish context, where its elements have been described as a "Golden Triangle". The triangle is constituted by the institutional frameworks of the labour market, social security systems and active labour market policies, and their relations are believed to have a complementary effect on labour market flexibility.

The chapter then compares a number of international indicators, which are assumed to reflect the main flexicurity institutions in both the Nordic countries and other European countries. This is followed by a summary of the four countries' "flexicurity profiles". The chapter concludes with some hypotheses regarding differences in labour market mobility between the countries that can be attributed to the flexicurity profiles.

\subsection{Flexicurity as an institutional system - general considerations and the Danish example}

As is now well known, the fundamental idea behind the concept of flexicurity is the claim that flexibility and security are not necessarily contradictory to one another, but in many situations can be mutually supportive. Furthermore, flexibility is not the monopoly of the employers, just as security is not the monopoly of the employees. In modern labour markets, many employers realise that they have an interest in stable employment relations and in retaining employees who are loyal and well qualified. For their part, many employees have realised that to be able to adjust their work life to more individual preferences, they too have an 
interest in more flexible ways of organising work, e.g. to balance work and family life.

\subsubsection{The Wilthagen matrix}

Both flexibility and security are multi-dimensional concepts, which come in a variety of shapes. Using Atkinson's model of the flexible enterprise as a starting point, it is possible to distinguish between four different forms of flexibility: numerical flexibility, working time flexibility, functional flexibility and wage flexibility (Atkinson, 1984).

A groundbreaking aspect of the flexicurity concept is the linking of these four forms of flexibility with four forms of security (Wilthagen, 1998; Wilthagen \& Tros, 2004). First, job security, which means the security of being able to stay in the same job, and which can be expressed via employment protection and tenure with the same employer. Second, employment security, which means security of staying employed, though not necessarily in the same job; here the general employment situation, active labour market, training and educational policies play a key role. Third, there is income security, which relates to having secure income in case of unemployment, sickness or accidents, and is expressed through the public transfer income systems, such as unemployment and cash benefit systems. And finally, combination security, the possibilities available for combining working and private life, e.g. through retirement schemes, maternity leave, voluntary-sector unpaid work etc.

As illustrated in Figure 3.1, there are sixteen potential combinations of flexibility and security. This matrix is a heuristic tool, applicable for instance in characterising different flexicurity policies or combinations of flexibility and security in certain schemes, or to describe stylized relationships between flexibility and security in different national labour market regimes.

\begin{tabular}{|l|l|l|l|l|}
\hline & Job security & $\begin{array}{l}\text { Employment } \\
\text { security }\end{array}$ & Income security & $\begin{array}{l}\text { Combination } \\
\text { security }\end{array}$ \\
\hline Numerical flexibility & & & & \\
\hline $\begin{array}{l}\text { Working time flexi- } \\
\text { bility }\end{array}$ & & & & \\
\hline Functional flexibility & & & & \\
\hline Wage flexibility & & & & \\
\hline
\end{tabular}

Figure 3.1 Wilthagen matrix: configurations of flexibility and security

Some of the combinations in Figure 3.1 represent trade-offs in the sense that a higher level of, for instance, job security will imply less numerical flexibility and vice versa. In most other cases, the interplay between the various aspects of flexibility and security is more complex. There is therefore some debate concerning the interpretation of the matrix above. 
Sometimes it is seen as an illustration of different trade-offs between forms of security and flexibility, where the term "trade-off" signifies that something must be traded for something else. Thus more numerical flexibility can be balanced by providing some form of security instead, for instance increased income security. However, the flexibility-security nexus can also reflect a mutually supportive or complementary relationship. Among examples of such interrelations could be:

- More combination security (maternity leave and child care) can lead to greater numerical flexibility for women in transitions into and out of the workforce.

- Job security can induce employees to be loyal to the employer and to invest in firm-specific human capital, thereby increasing internal functional flexibility.

- More income security may stimulate numerical flexibility by making it less risky for employees to attempt a job shift.

- More numerical flexibility can facilitate structural change and thereby job growth, which provides more job opportunities and thus more employment security.

In other situations, the nexus may lead to vicious relationships, where for instance more numerical flexibility may induce employers to invest less in employee training and thereby reduce the employment security of the employees. Also more job insecurity leads to overall insecurity, lower investments in human capital and - in the longer run - perhaps lower fertility. The exact character of the interplay between security and flexibility will thus depend on the specific circumstances.

\subsubsection{The Danish case}

In the flexicurity literature, the Danish employment system is often referred to as a prime example of a labour market with a well-functioning flexicurity arrangement - even to such a degree that the "Danish model" and "flexicurity" are sometimes seen as almost identical. The following elements of flexibility and security are conceived as being the main characteristics of the Danish flexicurity model (Madsen, 2006):

- A low level of employment protection, allowing employers to adapt the workforce to changing economic conditions, which makes the high degree of numerical flexibility possible.

- A generous system of economic support for the unemployed.

- Active labour market policies aimed at upgrading the skills of those unemployed who are unable to return directly from unemployment to a new job. 
The outcome of this institutional configuration is a flexible labour market with a high level of external numerical flexibility indicated by high levels of worker flows in and out of employment and unemployment. One can add that there may be other reasons for the high mobility rates, like cultural factors or a dominance of small and medium-sized firms in the Danish economy.

However, the main traits of the Danish labour market model are frequently described as a "golden triangle" involving the three institutional factors listed above; cf. Figure 3.2. The model combines high mobility between jobs with a comprehensive social safety net for the unemployed and an active labour market policy. In fact the mobility (measured by job mobility, job creation, job destruction and average tenure) is remarkably high in an international comparison. The hypothesis, which is to be further explored in the present project, is that the high degree of mobility between employers could be linked to the relatively modest level of job protection in the Danish labour market. Another reason could be higher risk-willingness among workers due to the comprehensive social safety net.

The arrows between the corners of the triangle illustrate flows of people. Even if the unemployment rate is low in an international perspective, around $20 \%$ of the workforce is affected each year by unemployment and receives unemployment benefits or social assistance. The majority of these unemployed persons manage to find their own way back into a new job. Those who become long-term unemployed end up in the target group for the active labour market policy, which - ideally - helps them to find employment again. The model illustrates two of the most important effects in this connection. On the one hand, as a result of the active measures, the participants in various programmes (e.g. job training and education) are upgraded and therefore improve their chances of getting a job. This is the "qualification effect" of ALMP.

On the other hand, the measures can have a motivational (or threat) effect in that unemployed persons, who are approaching the time when they are due for activation, may intensify their search for ordinary jobs, in case they consider activation a negative prospect. Thus one effect of labour market policy will be to influence the flow from unemployment benefits back to work, also for those unemployed who do not actually participate in the active measures. A recent study has in fact argued that this motivational effect accounts for the major part of the overall effect of ALMP (Rosholm \& Svarer, 2008). 


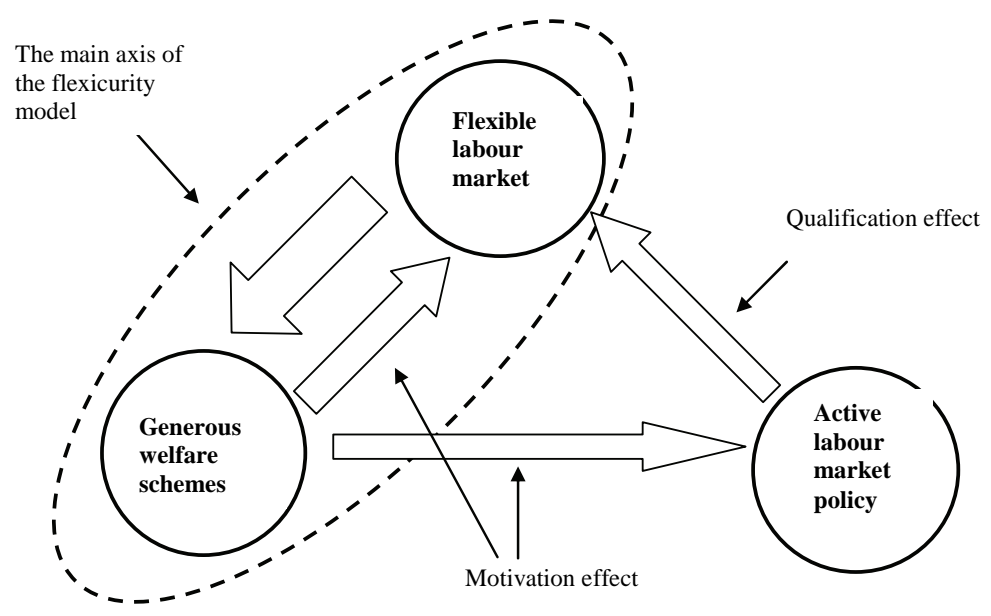

Figure 3.2 The Danish flexicurity model (Madsen, 2006)

The social safety net in the shape of unemployment benefit and social assistance for the unemployed together with the high flexibility form the main axis of the model, in the sense that both elements have been characteristic of the Danish labour market for many years. Recognition of the employers' right to hire and fire at will dates back to the September Compromise of 1899. Danish labour market parties here entered into an agreement that focused on labour market disputes and how to solve them, as well as the appropriate role of organizations in the system. This established centralised negotiations and mechanisms for resolving disputes, and laid the foundation for the practice of self-regulation by labour market parties in most matters of importance to the labour market.

It is therefore important to emphasise that while the term "flexicurity" has only recently been associated with the Danish employment system, its basic characteristics have a long history. Thus while the current attention paid to the Danish model is caused by the significant reduction in unemployment since 1993 and the high employment rate, one should not confuse this recent success with the creation of a fundamentally new version of the Danish employment system during the last decade. On the contrary, one of the fascinating elements of the story about the Danish labour market is the fact that the model has been able to survive since the founding of the modern Danish welfare state in the 1960s in spite of the economic turmoil of the 1970s and 1980s. Furthermore, it has been successful in supporting the ongoing structural changes in the economy, which have kept Denmark in a position among the most affluent countries in the world. If anything happened to the Danish model in recent years, it was a number of labour market reforms that took their beginning in 1993 and thus mainly affected the pillar of active labour market policy in Figure 3.2. 
One should furthermore mention that the three elements highlighted in the "golden triangle" are of course not the only elements that support the interplay between flexibility and security on the Danish labour market. As further described below, lifelong learning supported by public institutions for labour market training etc. plays an important role in supporting both functional flexibility and employment security. So does the provision of combination security in the form of a well-developed public caring system for both children and the elderly. A full understanding of the security-elements in the Danish model therefore requires a more elaborated model than the simple triangle in Figure 3.2 (cf. Bredgaard et al. 2009).

\subsection{A comparison of central institutions using international indicators}

As mentioned in the introduction to the present chapter, a core question of the project is whether Denmark, as it has just been depicted, really is so unique, when it comes to the configuration of its labour market institutions. A few quantitative indicators cannot form a final opinion on this, but a survey of the available data may help us to get a first impression of the similarities and dissimilarities in this respect.

\subsubsection{Employment Protection Legislation}

The level of employment protection legislation (EPL) is one of the central characteristics of the potential numerical flexibility of a flexicurity system.2 In Figure 3.3 the 2003 version of the often-quoted index from the EPL-index from OECD is presented. 3 It is constructed by grading a number of different characteristics of the job protection of an employee with an open-ended contract, the regulation on temporary forms of employment, and the specific requirements for collective dismissals.

\footnotetext{
${ }^{2}$ For a survey of the available evidence, see for instance Employment in Europe 2006, chapter 2.

${ }^{3}$ A version for 2008 is now available from OECD. One interesting finding in the new index is that the overall EPL for Sweden has been liberalised compared to the 2003 evaluation and is now ranked second among the Nordic countries (after Denmark). This is due to the liberal regulations of temporary employees. However, concerning regular employees the rank order is Denmark (1.5), Norway (2.2), Finland (2.4) and Sweden (2.7).
} 


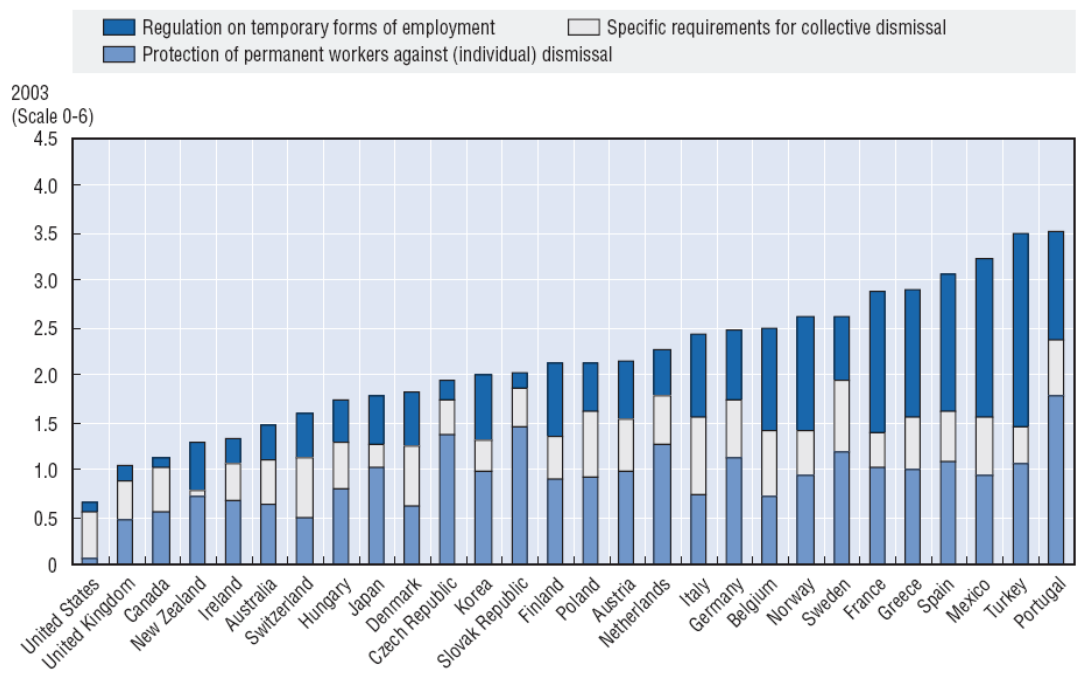

Figure 3.3 Indicator of employment protection.

Source: OECD (2004), chapter 2, chart 2.1

The indicator ranks the Nordic countries rather differently. Norway and Sweden stand out with a rather high level of overall EPL. Finland is close to average, while Denmark is found in the lower end of the spectrum. Furthermore, the balance between the three different aspects of EPL differs somewhat. If one focuses on the protection of workers with an openended contract, Denmark falls to a low position close to the liberal models found for instance in the UK and Ireland. The actual value of the EPL indicator for Denmark is 1.5. For Finland it is 2.2, Norway 2.3 and Sweden 2.9.

Several methodological criticisms can be raised against the OECD indicator. The grading and weighting procedure can be considered rather arbitrary. Further, in each country there may be fairly different levels of protection for different groups of employees, which makes the concept of an average protection level somewhat dubious. Finally, there may of course be a difference between the stipulations found in labour law and general agreements, on the one hand, and the actual enforcement of those rules on the other hand.

In the appendix there is a more detailed presentation and discussion of the actual protection regime found in each of the Nordic countries.

\subsubsection{Unemployment benefits}

A crucial institution influencing the functioning of flexicurity systems characterised by low EPL and a high level of job-to-job-mobility is the unemployment benefit system. In the description of the Danish model, the basic axis was thus between the flexible labour market and the benefit system. In this section we therefore discuss the available information that can be applied, when comparing benefit systems across countries. 


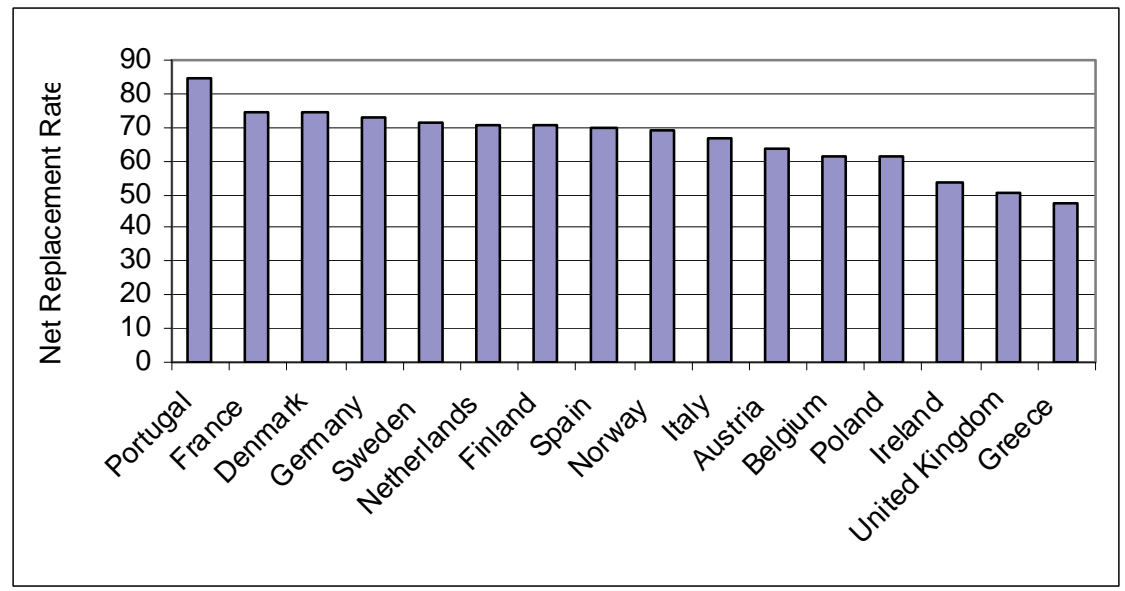

Figure 3.4 Net replacement rates 2005 for the average of six family types and three income levels in the initial phase of unemployment.

Source: OECD (2007), table 3.1.

The standard source of information, when it comes to comparing benefit systems, is the regular publication on Benefits and Wages from OECD (OECD, 2007). It contains detailed information about gross and net replacement rates for different income levels, duration of unemployment and family types. The net replacement rates take into account the taxation of benefits and also other social cash benefits than regular unemployment benefits. Comparing benefit levels across countries is complicated due to, among other things, the different duration of regular unemployment benefits and the different ways in which benefits are dependent on previous income. The data can therefore only give a rough indication of the relative income of unemployed compared to employed persons. Also they do not give an impression of the share of the workforce that is eligible for the different kind of benefits.

With these caveats, Figure 3.4 presents an overview of the average net placement rates for a number of European countries including the Nordic ones. The figure shows net replacement rates only for a short spell of unemployment (one month).

The picture of the net replacement rates for the initial phase of unemployment is rather mixed. The Nordic countries are in the high end of the range, but several countries, including countries of Southern Europe, rank at the same level or even higher. Among the Nordic countries, Denmark has the highest level of income security, but the difference between Denmark and the other Nordic countries is not exceptional.

The figures presented above are in many ways "averages of averages" and only vaguely represent the true situation of the unemployed. Because of differences in the systems, comparing their generosity is difficult. In the following, we present the systems of the four countries in some detail, and furthermore refer to the annex for more information.

All four countries have a primary, earnings-related unemployment benefit, also called Unemployment Insurance (UI). Its replacement rate 
is obviously an important factor in the generosity of the system. However, the benefit cannot be received indefinitely, nor is it available to everybody. For those not entitled to UI, its replacement rate is of course irrelevant.

As a rule, the secondary systems available to those not receiving UI are always less generous than the primary earnings-related benefit, and the difference is larger for high-income earners. Thus, looking at the share of unemployed entitled to the primary benefit is at least as important as its replacement rate.

In Table 3.1, we take a look at three important aspects of the generosity of primary unemployment benefits, namely replacement rate, duration, and coverage. All figures presented relate to the primary earnings-related benefit (UI). First, we present net replacement figures for different income levels, as calculated by the OECD. Second, we give the maximum duration of the primary benefit. The duration given is what applies for most unemployed - there may be exceptions for e.g. those who are near pension age. Other rules may also apply, such as obligatory participation in activation.

Finally, we show a coveragepercent for UI. To be noted is that the coverage is calculated from administrative figures, i.e. registered unemployed job seekers. The definition of an unemployed person is thus different than the one used in LFS, and there can be some methodological differences between the countries.

Table 3.1 Key figures of primary unemployment insurance benefit in four Nordic countries (for period 2000-2006). Net replacements rates in 2005 for short-term and long-term unemployed at different income levels, average of six family types. Coverage is calculated as a share of registered unemployed job-seekers.

\begin{tabular}{|c|c|c|c|c|c|}
\hline \multirow[b]{2}{*}{$\begin{array}{l}\text { Income level (percent of } \\
\text { average worker (AW) }\end{array}$} & \multicolumn{3}{|c|}{$\begin{array}{l}\text { Net replacement rate, initial phase (one } \\
\text { month of unemployment) }\end{array}$} & \multirow{2}{*}{$\begin{array}{r}\text { Maximum } \\
\text { duration }\end{array}$} & \multirow{2}{*}{$\begin{array}{r}\text { Coverage (of } \\
\text { registered } \\
\text { unemployed) }\end{array}$} \\
\hline & $67 \%$ & $100 \%$ & $150 \%$ & & \\
\hline Denmark & 91 & 72 & 59 & 48 months & $79 \%$ \\
\hline Finland & 81 & 71 & 59 & 24 months & $42 \%$ \\
\hline Norway & 79 & 73 & 56 & $\begin{array}{r}36 / 24 \\
\text { months }\end{array}$ & $60 \%$ \\
\hline Sweden & 88 & 71 & 56 & $\begin{array}{r}28(14+14) \\
\text { months }\end{array}$ & $64 \%$ \\
\hline
\end{tabular}

Source: Replacement rates OECD (2007), tables 3.1 and 3.2.

Duration and coverage: DK: Databanks of Statistics Denmark, coverage calculated for 2007. FI: Ministry of Employment and the Economy, coverage calculated for 2003. NO: Coverage is an estimated average for the period 2000-2006. NAV Arbeid og velferd Nr. 2-2007. SE: IAF / Arbetsförmedlingen, coverage calculated for 2004.

${ }^{4}$ In 2004 the maximum period a person can get employment benefits was reduced from 152 weeks to 104 weeks. 
Concerning the replacement rates, the only major difference between the countries is found for the lowest income level, where Denmark stands out as more generous than Finland and Norway, but not much different from Sweden.

The generosity of the Danish system is further stressed with duration and coverage. It covers the largest share of unemployed (nearly 80\%) and can be received for a duration of four years.

The duration of UI is shorter in the other three countries. Concerning the coverage, we observe large differences. In Finland only a minority of the unemployed receive the primary UI benefit. Also in Norway and Sweden the coverage is lower than in Denmark.

Our conclusion is that the most generous UB can be found in Denmark, followed by Sweden and Norway. Finland is considerably less generous, when the coverage of UI is taken into account.

\subsubsection{Active labour market policies}

Along with the benefit system, active labour market policy plays a crucial role in balancing high numerical flexibility with employment security. Two main sources can be applied for the international comparison of active labour market policies. For several years, the OECD has compiled statistics on national expenditure on active and passive labour market policy and on the number of participants. More recently, Eurostat has developed its own more detailed statistics on the same subject. Below, the latter are applied for the international comparison. ${ }^{5}$

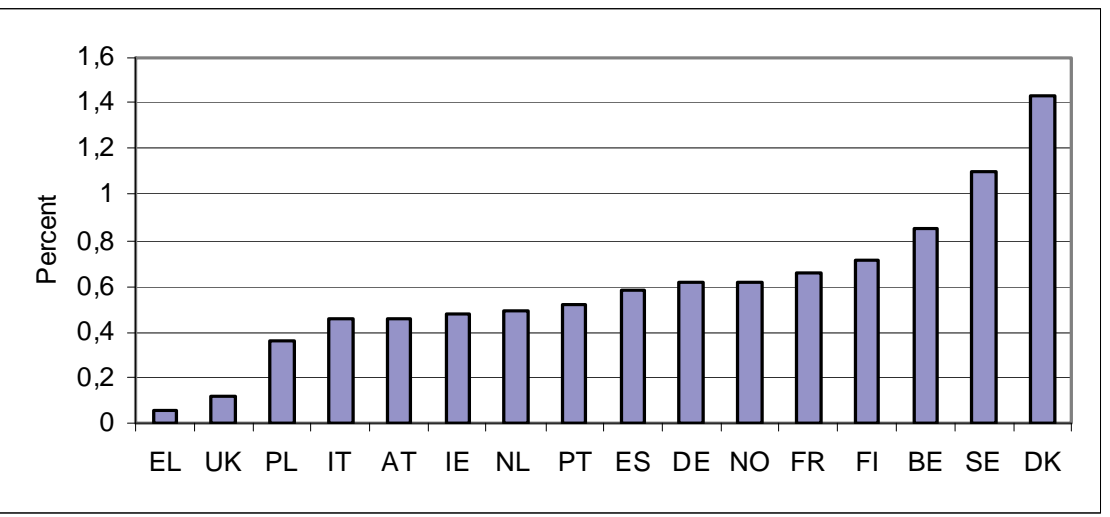

Figure 3.5 Expenditure for active labour market policy in 2005 as a share of GDP in selected European countries. For Denmark data refer to 2004.

Source: Eurostat Statistics in Focus 45/2008.

In Figure 3.5 the information on the expenditure on active labour market policy is summarized. The countries are ranked by the expenditure's share of GDP. Denmark and Sweden stand out as the countries with the

\footnotetext{
${ }^{5}$ A rough comparison suggests that for the countries in question, the difference between the two sources is minor.
} 
highest expenditure share for active measures. The remaining Nordic countries are mixed in with other European countries.

The data in Figure 3.5 do not take the different levels of unemployment into account. However, available information on the spending levels on active measures per unemployed person calculated in PPS also places Denmark as the Nordic country with the highest level of spending (Figure 3.6). In this comparison Sweden and Norway spend almost the same amount per person wanting to work and Finland the least.

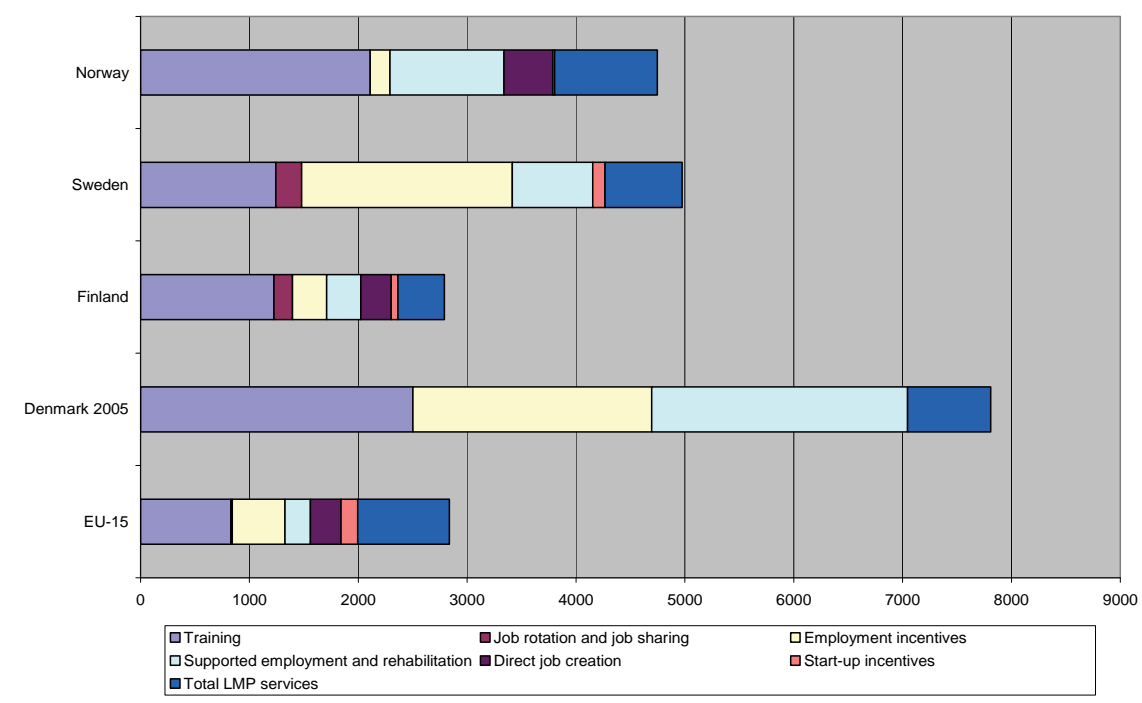

Figure 3.6 ALMP expenditure by category per person wanting to work (in PPS) in EU-15 and Nordic countries in 2006 (Denmark 2005)

Source Eurostat table B.1.4

\subsubsection{Lifelong learning}

Within the EU the main source of information concerning lifelong learning is the Labour Force Surveys, where participants are asked whether they have taken part in education or training during the last four weeks before the interview. This statistic thus includes both formal labour market education and training provided by private providers. The outcome is shown in Figure 3.7, which indicates that the Nordic countries (together with the UK) top the ranking when it comes to lifelong learning in the EU. 


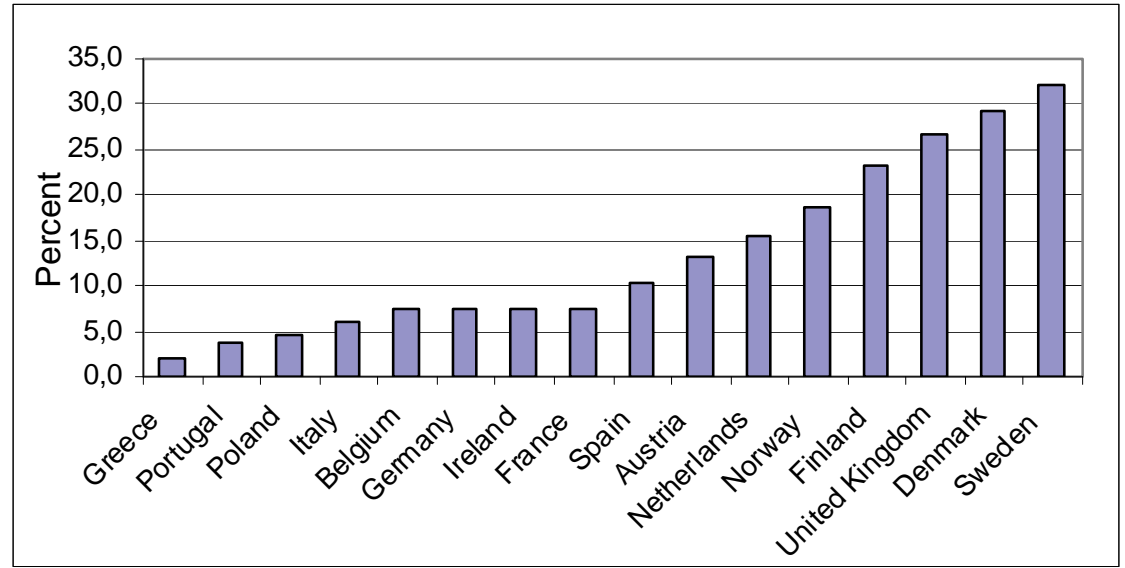

Figure 3.7 Participants in life-long learning in 2006, percent of people 25-64 years old.'

Source: Eurostat Yearbook 2008

\subsection{A comparison of Nordic flexicurity profiles}

In the appendix (A) more precise descriptions are presented of the countries' institutional framework, regarding EPL, UB, ALMP and LLL. The focus in this section is to compare the countries' flexicurity profiles. For this comparison, Denmark has been looked upon as a reference country, i.e. as an example of a labour market organized in line with the principles of flexicurity. In this regard, the three other Nordic countries' flexicurity profile will be compared to Denmark. ${ }^{6}$

To illustrate the profiles, four indexes of EPL, UB, ALMP and LLL have been used (see Table 3.2). The four indexes are calculated as follows:

- EPL: OECD’s EPL-index (2003) divided by 6 (maximum value of index).

- UB: The share of UB in GDP divided by the rate of unemployment (see Furåker 2009).

- ALMP: ALMP expenditure as share of GDP divided by the rate of unemployment (see Furåker 2009).

- LLL: share of persons aged 25-64 taking part in LLL (based on EULFS).

\footnotetext{
${ }^{6}$ This attempt to summarize various aspects of flexicurity as national indicators is in line with the approach of, for instance, the European Union's Employment Committee (EMCO), which in June 2009 published a report on indicators to be applied for Monitoring and Analysis of Flexicurity Policies.
} 
Table 3.2: Standardized values of main institutional indicators

\begin{tabular}{lcccc}
\hline & EPL & UB & ALMP & LLL \\
& $\mathbf{2 0 0 3}$ & $\mathbf{2 0 0 3}$ & $\mathbf{2 0 0 3}$ & $\mathbf{2 0 0 6}$ \\
\hline Denmark & 0.30 & 0.34 & 0.31 & 0.29 \\
Finland & 0.35 & 0.18 & 0.10 & 0.23 \\
Norway & 0.43 & 0.19 & 0.18 & 0.19 \\
Sweden & 0.43 & 0.22 & 0.23 & 0.32 \\
\hline
\end{tabular}

The EPL score indicates stronger employment protection legislation. Maximum (full protection due to OECD definition) is 1 and zero protection is 0 . To get standardized indications of how ambitious and prioritized the support and measures are against unemployment, the expenditures on passive and active measures have been divided by the rate of unemployment (see Furåker 2009). However, this index construction is only reasonable if the size of the GNP per capita is fairly comparable, which is the case comparing these affluent countries. The LLL ratio is the share of the population aged 25 to 64 that has taken part in training or education during a reference week. A flexicurity profile should imply low values of EPL and high values of the other three indicators.

Figure 3.8 illustrates the profiles of the four countries. Denmark is here used as a reference case, i.e as a country that has institutions creating a flexicurity framework. Denmark appears somewhat as an outlier in a Nordic context in the sense that it has the highest values for ALMP, UB and the lowest for EPL. Only when it comes to LLL does Denmark have

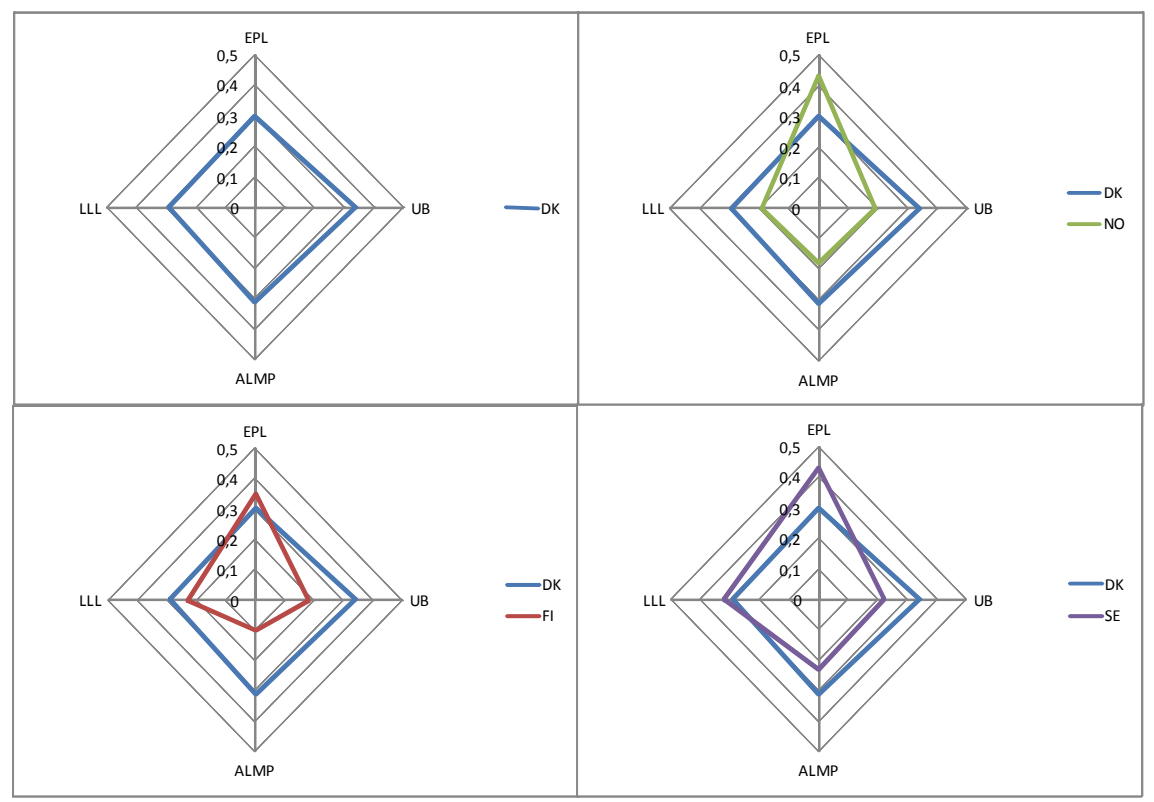

Figure 3.8 Flexicurity profiles of four Nordic countries. Based on Table 3.2. 
a lower value than Sweden. The portrayal of Denmark as a clear example of a "flexicurity" configuration fits well with the view of flexicurity found also with the European Commission (Employment in Europe 2006, chapter 2). Also, not surprisingly, it also fits well with the standard picture of the "Danish model" as traditionally illustrated by the Golden Triangle in section 3.1 above.

The figures can be said to illustrate different trade-offs between flexibility and security on the Nordic labour markets. The low EPL in Denmark is compensated for by substantial efforts on ALMP and UB that must largely be paid by the public through taxes. In Norway and Sweden there has been less willingness during the period to support flexibility through more costly labour market policies. In Finland the employment protection legislation is not particularly strong compared to Norway and Sweden. However, there seem not to have been strong demands to compensate for this through more efforts on labour market policies. The result is an institutional environment that to a lesser degree compensates for labour market risks.

Looking at the institutional framework in more detail (see Appendix A), the following characteristics of the labour market institutions during the period 2000-2006 are the most conspicuous:

- EPL: The low job protection in Denmark. However, the entire Danish labour market is not equally liberalized - some sectors are more protected than others due to collective agreements. Sweden has the strongest protection of regular employees, but quite liberal rules concerning temporary employees. Norway has more strict rules concerning temporaries. For regular employees, the rules are more liberal than the Swedish but more severe than the Danish. The Finnish rules for regular employees are on the same level as the Norwegian. However, they are more liberal than the Norwegian concerning temporary employees.

- UB: The long potential duration time in Denmark (48 months) compared to the other three countries (24-28 months) and the high coverage. However, in Finland the so-called Labour Market Support has, in principle, no time limit.

- ALMP: The low overall expenditures per unemployed person in Finland. The high overall expenditures on ALMPs in Denmark, and especially on supported employment and rehabilitation per unemployed in Denmark (see Table 3.6).

If the illustrations in Figure 3.8 are taken as valid representations of the institutional characteristics of the four Nordic countries with respect to the core dimensions of flexicurity, the observed variations across countries should thus allow a test of a number of hypotheses concerning the 
association between such institutional characteristics and various aspects of labour market mobility.

In the following section a preliminary overview is given of the possible correlations to be studied.

\subsection{Mobility and labour market institutions}

In this section, the focus is on possible relationships between labour market institutions and labour market mobility. The purpose is to briefly summarize the main mechanisms through which the institutions can influence different kinds of mobility on the labour market. Focus is on the expected isolated effects of the different institutions. Later some of the potential interactions between the individual institutions are discussed, as they play themselves out in the different versions of the Nordic model (cf. Magnusson et al. 2008).

\subsubsection{Employment protection legislation}

There is an extensive literature on the effects of employment protection legislation on unemployment and labour market mobility (see for example Nickell 1997; OECD 2004; European Commission, 2006; Skedinger 2008). The general view is that the strictness of EPL affects mobility rates downward in two main ways: through employers hiring and firing decisions, or through voluntary mobility decisions by the employees. This will have an effect on the composition of unemployment with respect to short- and long-term unemployment. However, there is no agreement on whether EPL also affects the total level of employment or unemployment.

Furthermore, the relationship between EPL and the uses of temporary contracts has been studied, which indirectly could have an influence on mobility (Boeri 1999; OECD 2004).

Employers' hiring and firing decisions are thought to be affected by the strictness of EPL (Skedinger 2008). The argument here is that the strictness of EPL influences the costs of firing an employee: it is harder to lay off an employee if the EPL is strict, and therefore it will cost more for the employer. Because of the large costs of dismissals, employees will be more careful about whom they employ and this will slow down the hiring process. Consequently, the mechanism points in the direction of a negative relation between EPL and the mobility from employment to unemployment or vice versa.

However, all mobility by the employees is not involuntary as a consequence of employers' hiring and firing decisions. Mobility could also be a voluntary decision by the employee. In this regard, EPL is believed to influence employees' voluntary decision of changing employer (Furåker \& Berglund 2009). In many constructions of the employment protection 
legislation, the employee "earns" protection on the basis of how long he/she has been employed in the organisation. This implies that the employee has made an investment in protection. And if the employee changes employer, the investment will be lost. This may make employees more reluctant about mobility between employers. Consequently, the strictness of EPL probably has a negative relation to job-to-job mobility.

There is also an indirect effect of EPL with consequences for mobility. In countries with strict EPL there is a tendency to use temporary contracts as a way to create numerical flexibility in organisations (Boeri 1999; OECD 2004). Through the use of temporary contracts, the organisation can employ without the rising costs of firing. However, using temporary employees to create flexibility on a labour market with strict EPL is only the case if the legislation is liberal enough to allow for these kinds of contracts. The general effect of temporary contracts as a functional alternative to liberal EPL may imply a positive impact on both mobility from employment to unemployment and mobility from unemployment to employment. This can reduce the general negative effects of EPL on mobility.

However, in countries with strict EPL there should be a higher risk than in countries with low EPL that transitions from employment to unemployment and from unemployment to employment are made by temporary employees. Furthermore, temporaries may be overrepresented in jobto-job mobility because their limited type of contract makes them more involved in on-the-job search for future employment (Boeri 1999).

\subsubsection{Unemployment benefits}

There are several different mechanisms affecting labour market mobility that are related to unemployment benefits. Some of them are rooted in mainstream economic theory, while others take the literature on Transitional Labour Markets and social risk management as their starting point.

Within mainstream economic theory, one finds arguments about reservation wages, search intensity and moral hazard. The first two mechanisms are related to each other and are believed to influence mobility from unemployment to employment. The third affects job-to-job mobility and mobility between employment and unemployment.

Reservation wage is defined as the minimum wage that an unemployed person is prepared to accept in a job offer (Layder et al. 1991; Mortensen 1977; Nordlund \& Strand 2008; Åberg 2001). The level of the reservation wage is calculated by the individual through relating the present income as an unemployed to the prospective wage and security of a future job. Obviously, individual preferences such as the value of free time or the importance of a work community also influence this "calculation". If the wage of a job offer exceeds the reservation wage, the individual will leave unemployment. If not, it will be more rational to stay unemployed and search for a better-paid job. Furthermore, if the reserva- 
tion wage falls during the unemployment spell, the theory says that the probability of finding an acceptable job will increase. It is also probable that the actual reservation wage changes from one job offer to another, depending on other qualities of the job.

If the first mechanism has to do with criteria for making a choice (accepting a job), the second mechanism, search intensity, has to do with the creation of opportunities to make choices, i.e. to collect information about job vacancies (Layder et al. 1991). Search intensity is related to the unemployed person's motivation to find a job. This motivation is affected by the difference between the reservation wage and the income as an unemployed (often through UB). The more the reservation wage exceeds the income, the higher search intensity is expected. Furthermore, the search intensity is affected by the individual's perceptions of the chances to find a new job. Discouraged workers may reduce their search if they consider the chances of getting a job to be very low.

According to mainstream economic theory, both these mechanisms have a relation to the design of the UB. The replacement rate of the benefit system is expected to affect both the reservation wage and the search intensity of the unemployed. Furthermore, the maximum duration of the UB is significant. The reservation wage tends to fall and search intensity to rise when the end of the benefit period is approaching. However, the effects of these mechanisms on employment probabilities may not be very significant if the benefit period is very long (Virjo et al. 2006). A selection process may be going on, implying that the unemployed who are least demanded on the labour market have the highest probability of reaching the end of the benefit period.

All in all, the general conclusion is that mobility from unemployment to employment could be affected by the design of the unemployment benefit (Nickell 1997). Both the replacement rate and the maximum duration of the UB are expected to have a negative relation to mobility from unemployment to employment - i.e. the greater the replacement rate and the longer the maximum duration, less mobility from unemployment to employment is expected.

However, there could also be another mechanism operating here that economists usually call moral hazard. This concept refers to an economic behaviour that can appear in relation to public social security systems (Lindbeck 2003). Because of the public funding of the systems, the expenses involved in risk-taking behaviour are collective rather than individual. This makes it possible for the individual to take more and greater risks than would otherwise have been done. In relation to the UB, the allin-all generosity of the system could create incentives for moral-hazard behaviour of the individuals. One such risk-taking behaviour is to change employer (Boone 2004). A change of employer might involve a greater risk of dismissals for newcomers on a job, for example because of the 
rules of EPL (rules like "last in first out") or because the employer has not invested much in the training of new employees.

Thus, the generosity of UB could influence the willingness to take the risk of job-to-job mobility. This implies a positive relation between the generosity of the UB and mobility between employment and unemployment (failed risk-taking) or job-to-job mobility (succeeded risk-taking). However, it is important to notice that the concept of moral hazard is here used as a theoretical description of an economic behaviour, and not as a normative concept. It is important to notice that there are moral hazards also in relation to employers' behaviour, i.e. it becomes easier to dismiss workers if the public pays the costs involved without direct contributions from the employers.

While most of mainstream economic theory takes a sceptical or even critical view of the role of UB with respect to labour mobility, the growing literature on Transitional Labour Markets (TLM) and flexicurity has a much more positive assessment of the interplay between UB and labour mobility (see for instance Schmid 2008). The main argument is that the security provided by UB increases the willingness of workers to take the risk of leaving a job and move to a new position.

The income security given by the UB will thus encourage risk-taking and therefore labour mobility. It will also make a lower level of EPL more acceptable by the workers and underpin a more rapid structural change of the economy and thereby also the creation of new jobs. A benefit system with high compensation rates and broad coverage is therefore a prime example of the support for transitions from the perspective of TLM, or a way to reach a win-win situation from the point of view of flexicurity.

\subsubsection{Active labour market policies}

In the literature, one can find indications of both positive and negative effects of ALMPs on labour market mobility. Furthermore, different kinds of active labour market policies seem to have different effects. As has been described above, there are at least four main types of ALMPs. The first one is public employment services (PES), which has as a main purpose to facilitate the matching process between employers and job seekers and make it more efficient (Calmfors et al. 2001). Consequently, it is reasonable to expect a positive relationship between investments in PES and mobility from unemployment to employment and job-to-job mobility.

In the literature on the Danish flexicurity model, ALMPs (beside PES) are believed to have a positive motivational effect on the unemployed person's search intensity (Bredgaard, Larsen \& Madsen, 2005). The argument here is that the programs in the ALMPs may not be very attractive for the unemployed, and that if activation programs, decided by the 
employment office, are coming closer during the unemployment spell, the search activity will be higher to avoid coming into programs. This "threat" may have a positive effect on mobility from unemployment to employment and thus balance the potential negative incentives of a more generous unemployment benefit system.

ALMPs that aim at labour market training are furthermore believed to have a qualification effect on the unemployed (Bredgaard, Larsen \& Madsen, 2005; Calmfors et al. 2001). When there are structural changes in the labour market, employees may need training to upgrade their skills and competences, or if their skills become obsolete they may need training and education for a new job in another occupation or industry. Labour market training has the function of facilitating these kinds of transitions, i.e. occupational or industrial mobility. From the perspective of flexicurity, this form of ALMP thus provides employment security for the workers by giving them better competences to get another job, if they lose the one they have.

Job creation is also believed to have a qualifying effect on the job training. Furthermore, these policies aim, through the use of subsidised employment, at matching between employers and people who usually are farther away from regular employment, for example long-time unemployed or young and inexperienced workers (Layder et al. 1991).

However, there are also indications that ALMPs could have negative effects on labour market mobility (Calmfors et al. 2001; Fredriksson \& Johansson 2003). Firstly, some ALMPs can create "lock-in" effects. The mechanism here is that unemployed persons' search behaviour is less intensive when they participate or soon are going to participate in programmes (i.e. opposite to the motivational effect above) and they are also less willing to move regionally during participation. Particularly problematic are ALMPs that re-qualify for unemployment benefits (Carling et al. 1996; Sianesi 2004) or if the income is higher during participation in programmes.

Secondly, ALMPs can have so-called "crowding-out effects". This implies that some job creation programs have the side effect of crowding out regular employment through the supply of subsidized labour. Both of these possible negative effects of ALMPs on labour market mobility may slow down mobility from unemployment to employment. However, these negative conclusions on the effects of ALMPs were based on studies conducted during the 1990s' mass unemployment crisis in Sweden. In later studies, positive effects of ALMPs (labour market training) on the mobility out of unemployment have been found (de Luna et al. 2008).

All in all, the research indicates that ALMPs are related to three types of mobility: mobility from unemployment to employment, job-to-job mobility, and occupational/industrial mobility. Public employment services seem to facilitate the matching process, i.e. the mobility from unemployment to employment or job-to-job mobility. However, the re- 
search comes to different conclusions on the effects of labour market training and job creation. This is also exemplified by the results from the recent Danish study (Bredgaard et al. 2009), which concludes that ALMP on the one hand seems to support mobility from unemployment into employment, but on the other hand that a rather high number of participants in ALPM return to a new programme later.

\subsubsection{Lifelong learning systems}

The significance of adult education for labour market mobility is not so well documented. From a flexicurity perspective, one would expect LLL to have a positive effect on mobility between jobs and from unemployment to employment through its effects on the competences of the participants (employment security). A recent study based on Danish data indicates that persons in employment who participated in labour market training have greater chances of moving to another job than nonparticipants. But they also had a greater chance of going into unemployment or leaving the workforce. The latter is probably caused by labour market training being used more intensively for persons who are in employment, but facing a risk of unemployment, e.g. due to plant closures. ${ }^{7}$

\subsection{Summing up: Expected mobility patterns in four Nordic countries}

Labour market mobility is an ambiguous concept. There are many different kinds of mobility, and the labour market institutions that have been described above may affect the different kinds of mobility in different ways. Furthermore, there is disagreement with respect to the size and the positive or negative nature of the various effects.

It is also important to note that the institutional arrangements cannot be seen in isolation. They may interact and thus support mobility patterns that are different from those expected if one only looks at the anticipated effects from each of the institutions separately.

The main purpose of this section is to sum up some of the expectations that one may have concerning the observations to be found in the empirical material. In the conclusion we shall return to these expected outcomes and discuss the degree to which they are reflected in the empirical results from our analysis.

\subsubsection{Expected effects from institutional factors}

With these caveats we can, based on available research, sum up the expected effects from the various institutions as follows.

\footnotetext{
${ }^{7}$ For a detailed exposition of the Danish results, see Bredgaard et al. (2008).
} 
First of all, we will expect a stricter EPL to have negative effects on mobility between employment and unemployment in both directions. We will also expect negative effects on workplace mobility, occupational mobility and mobility between industries.

On the other hand, we will expect a stricter EPL to increase mobility from unemployment or inactivity to temporary employment, due to the employer's incentive to avoid permanent contracts under such a regime. Also internal mobility could be positively affected, since both employers and employees would prefer a more stable employment relationship due to the costs of dismissal and finding employment as newly hired.

When it comes to the generosity measured by the duration and replacement rate of UB, we may expect negative effects on the mobility from unemployment to employment caused by the economic disincentives from high benefit levels. On the other hand, the generosity of UB could increase the mobility from employment to unemployment, again due to the economic incentives for the workers. We would also expect a positive effect of more generous unemployment benefits on workplace mobility, occupational mobility and mobility between industries, because a higher benefit level could encourage the willingness of employees to make more risky transitions.

When it comes to ALMP, we will in general expect positive effects of more resourceful ALMP on the mobility from unemployment to employment, due to both qualification and motivation effects. A more ambitious ALMP could also increase the functional flexibility of the workforce and thus lead to higher mobility between workplaces, occupations and industries.

Finally, we will expect the scope of LLL to have positive effects on mobility between unemployment and inactivity on one hand and employment on the other, based on the assumption that LLL increases the employability of the participants. Also mobility between workplaces and occupational and industrial mobility could be stimulated by LLL, again due to the potential positive effects on the external functional flexibility of the participants.

\subsubsection{Expected similarities and differences between the Nordic countries}

With these considerations in mind and the judgments about the countries' flexicurity profiles, the following overall patterns of mobility can be expected, when comparing the four Nordic countries of the present study:

Denmark will have a higher mobility rate from employment to unemployment than the other three countries. The explanation is a combined effect of less strict EPL and rather generous UB.

When it comes to mobility from unemployment to employment, complex mechanisms may be operating. Firstly, the replacement rate of the UB could have a negative relation to mobility out of unemployment. 
Denmark has the most generous replacement rate, which points in the direction of less mobility from unemployment to employment compared to the other countries. However, the differences in replacement rate between the countries are quite small, which may undermine this type of effect. Also it may be counteracted by a generally higher level of mobility on the Danish labour market.

Secondly, the duration of the UB may also be significant, in that a longer duration may lead to less mobility out of unemployment. In Finland there is a potential of infinite duration of UB (the LMS), which should lead to less mobility from unemployment to employment compared to the other countries.

Thirdly, the capacity of active measures (ALMP) should have a positive effect on mobility out of unemployment in a situation without mass unemployment. The mechanisms here are the motivation and qualification effects of active measures. Both Denmark and Sweden come out well in the use of active measures, which points in the direction of higher mobility rates out of unemployment.

Fourthly, less strict EPL makes employers less reluctant to employ, which points toward higher mobility rates out of employment in Denmark.

The overall outcome of these different considerations is hard to determine a priori. However, previous empirical analysis would point to an expectation of finding the highest mobility rates from unemployment to employment in Denmark, as a combined effect of less strict EPL and the scope of ALMP.

Furthermore, one might expect Denmark and Sweden to have higher rates of occupational mobility compared to Finland and Norway due to the combined effect of more extensive use of ALMPs and LLL.

Also, one could expect Sweden to have higher rates of mobility from unemployment or inactivity to temporary employment than in the other countries, as an effect of a strict EPL in combination with liberal legislation for the use of temporaries. This will especially be in contrast to Norway, which also has a severe EPL, but less liberal legislation regarding temporaries.

Workplace mobility is facilitated by less strict EPL, generous UB (replacement rate), and the effectiveness of the matching process by the public employment services (PES). The differences between the countries are not so conspicuous when it comes to the generosity of the UB or the role of the PES. The great differences have to do with EPL, which is less strict in Denmark. This could lead to a higher rate of workplace mobility in comparison to the other three countries.

Finally, due to a more numerically flexible labour market with less strict EPL and extensive use of active labour market programmes, Denmark could be expected to have a higher rate of industrial mobility than Finland, Norway and Sweden. 
Having thus outlined a number of our ex ante considerations concerning the interrelations between the institutional factors and mobility patterns, we can now turn to the empirical analysis of the different aspects of mobility and their determinants. 



\section{Data and Methods}

\subsection{Introduction}

The aim of this study is to compare mobility patterns and mobility levels in the four countries. A central idea is to study what happens when several factors that have to do with business cycles and labour force composition are ruled out as explanations for possible differences. For this purpose data from the individual countries have been merged together into a single data set.

The Labour Force Surveys (LFS) are conducted by statistical authorities to collect statistics about the labour force participation and activities of the population. The statistics can be presented on a monthly basis and are among other things used to estimate official employment and unemployment rates. In most countries, the LFS includes a panel construction. This means that the same person is interviewed several times, which makes it possible to study changes between interviews. In this study, the panel structure has been used in order to study labour market mobility.

The panel structure of the LFS is not the same in our four countries. However, in all of them it is possible to construct a setting where two measurements with 12 months in between are compared in order to study mobility. For each country, we have created such a data set. Then, we have checked what time periods and variables are comparable enough between all four countries. Finally we have combined the data into a single data set.

This chapter begins with some general reflections about studying mobility on the labour market. We then move on to describe how the 12-month follow-up setting has been constructed in each country. Simultaneously, the vast possibilities but also the limitations associated with the data are described. We also present the dependent and independent variables used in the analyses in this report, and reflect upon the possible differences in study methodology and/or definitions. These issues especially come up when studying job-to-job, occupational and industrial mobility.

\subsection{Measuring mobility in general}

Generally speaking, there are two principal methods for studying mobility. One possibility is a retrospective survey. In the most common and simple form, this means asking individuals whether they have been mobile, e.g. changed jobs during a timeframe, typically during the last year. Another variant is to ask what their status is now and what it was e.g. 12 months ago, and compare these results. 
The other possibility is a panel, which means that the situation of the individual is measured at several (at least two) time points. These are then compared in order to see whether the status one is interested in has remained the same. The panel method can further be divided into two possibilities, which are register (the situation is registered continually or at regular intervals) and a panel consisting of multiple surveys.

An essential feature of most mobility studies is that two points of time are compared with a "black box" in between. Obviously, labour market transitions in real life can be complicated and take a lot of time. Such a setting does not capture this complexity. For instance, in order to observe an occupational change that occurs with unemployment in between, one must have at least three measurement points.

Both methods have their advantages and problems. Retrospective surveys have been found to underestimate mobility (Solga 2001). People tend to forget to report about changes, especially minor ones; the researchers have to rely on the respondent's own definition of a transition. Further, the time frame of mobility is not accurate. When people are asked whether they changed job during the last 12 months, they often do not remember precisely when a change occurred. One possible explanation for the underestimation of mobility is that they tend to think about a shorter time.

Panels consisting of several surveys and registers, on the other hand, have been found to overestimate mobility, at least in its more complicated forms, such as occupational transitions. This is due to classification problems, which have received a lot of attention in international mobility research. Typically, the respondent is asked to describe his/her occupation, which is then classified according to the description given. This procedure is repeated for each survey time point. Minor changes in the choice of words and/or the change of the person choosing the category may easily lead to a situation where the occupation is classified into a different category, even though it in fact had remained the same (so-called "artificial mobility"). The same problem has been found in virtually all studies, where occupation has been recoded at every measurement time regardless of change of employment status. This is called "independent coding" as opposed to "dependent coding", where information from the first measurement is used when conducting the survey. For instance, the person is asked "is your occupation still XX", and only if the answer is "no" will recoding occur.

In some cases, the problem of independent coding has been dealt with by retrospective recoding of the individuals' occupation from year to year (Kambourov and Manovskii 2004, Sabirianova 2000). In others, artificial mobility has been reduced by taking into account only such changes of occupation/industry where another change (change of employer or employer's characteristics) has taken place at the same time or during the same year (Isaoglu 2006, to some extent also Virjo et al. 2007). 
As a rule, the LFSs in our four countries use the dependent coding technique. There are some exceptions to the rule, though; later in this chapter, we describe this matter in more detail.

Another problem with panels is "panel mortality", which means that some of the initial participants do not answer to the later surveys. The longer the panel, the more mortality there is. Further, we can assume that the most mobile people are more likely to fall outside of the panel, as they may be more likely to move - even abroad. In Labour Force Surveys, the panel is constantly renewed in order to keep the panel mortality problem to a minimum - which is why we do not see any signs of significant panel mortality in our samples.

\subsection{Alternative data sources}

The data set we have created by combining LFS panels from several countries is to our knowledge unique; such a setting has not been used before. Constructing the data has been laborious, which raises the obvious question whether it has been worth the effort. Why have we not used some of the existing possibilities?

An available micro-dataset using LFS is the European Union Labour Force Survey (EU-LFS), which also includes Norway. The EU-LFS has a time series covering the years 1983-2007 with quarterly data. The data include detailed information about people's labour market situations, but have the major drawback of not including the panel structure. Thus, the possibilities for studying mobility with the EU-LFS are very limited.

Andersen et al. (2008) use it to study mobility between main labour market statuses. Mobility is measured by a retrospective question about the main status (employed, unemployed etc.) of the respondent one year before the survey. As mentioned, there can be reliability problems with retrospective questions. Further, the EU-LFS does not contain detailed information about the respondent's situation the year before, which makes it hard to analyse causal factors explaining the respondent's present situation.

Another possible way to go is register data. One example is the study by Graversen et al. (2003) focusing on job-to-job mobility in the same countries as in the present study. The advantages with such data are clear: the data include the whole population or at least a very large sample of it, with no non-response problems. Thus, very small subsets of the population can be analysed. Often, matches between employees and employers, unemployment spells, and a lot of other facts can be made and followed over a long time.

However, there are also major drawbacks with registers, especially when they are used for international comparisons. These drawbacks are caused by the fact that registers seldom, if ever, are constructed for the 
purpose of scientific study. Registering practices are formed for administrative purposes - meaning that they will also be different over time and in place in order to suit the needs of administration in the present state of legislation. This brings at least two large problems. First, registers often include "artificial" mobility caused by technical details. Even in national studies, they have to be thoroughly "cleaned" in order to produce reliable results (see Virjo et al. 2007 - the results acquired with "uncleaned" data are similar to those reported by Gravesen et al. 2003).

Second, the problems are even larger when using registers for international comparisons. The national practices in managing the registers can differ in ways that are very hard for the researcher to discover and pay attention to in the analyses. If the LFS data have systematic error in estimating the level of mobility, the error is very likely to be similar in all countries because the data are gathered in a standardized way - even though context and the exact wordings of questions in different languages can never be completely standardized.

For register data, there are no such standards and it is possible that the kind of overestimation found in Finnish registers does not occur elsewhere. Thus, the data are not only somewhat different in each country to begin with; they also must be "cleaned" in a specific way in each country. Combining such data reliably in the way we have done with LFS data is an extremely difficult task. Using register data is therefore associated with great risks in comparing levels and rates of mobility between countries. A further drawback with registers is that "occupation" is seldom registered, which makes occupational changes impossible to measure.

The LFS data have also drawbacks and one is that labour market mobility tends to be underestimated due to problems in counting both main and secondary jobs in the mobility estimates (Harđarsson 2003). Furthermore, people have a tendency to underreport changes in status because their memory falls short. However, these problems should be equal in all the countries (we have no reason to believe that, for example, Finns' memories are better than those of Danes) and minimized through the use of the panel structure in LFS. The methods and indicators used in LFS are highly standardised and well documented. This makes it possible to evaluate the reliability of the measures used. All in all, LFS is a reliable data source for international comparisons.

\subsection{Constructing the data}

The present study takes its departure in the Labour Force Surveys in the four countries. Below and in Appendix B there are detailed descriptions of the indicators. The samples are random and of enough size for statistical inferences with relatively small confidence intervals (Table 4.1). The 
age span of 16-63 years has been decided for reasons of data - for these ages, we have complete data from all four countries.

Table 4.1 Sample size, population aged 16-63 years.

\begin{tabular}{rrrrr}
\hline & Denmark & Finland & Norway & Sweden \\
\hline 2000 & 11,969 & 21,867 & 9,609 & 19,920 \\
2001 & 11,910 & 21,306 & 9,385 & 19,659 \\
2002 & 11,841 & 21,134 & 9,681 & 24,835 \\
2003 & 11,206 & 20,851 & 9,563 & 22,924 \\
2004 & 10,894 & 20,499 & 9,571 & 19,911 \\
2005 & 10,645 & 20,116 & 9,486 & 11,203 \\
2006 & 0 & 19,225 & 9,023 & 22,332 \\
Total & 68,465 & 144,998 & 66,320 & 140,784 \\
\hline
\end{tabular}

When using the EU-LFS, one drawback is that only retrospective questions can be used to measure mobility. This problem can be overcome with the exception of workplace mobility, where we have to rely on a retrospective question - by using the panel structure, which is a feature of the LFS in all four countries studied. People in the panel take part in the survey several times. Each time, they are asked e.g. if they are in employment during the interview week, which occupation they have, how many hours they have worked and so on. Consequently, the questions refer to the respondent's present situation, which should make the indicators more reliable than using retrospective questions.

The structures of the national samples used in the study are not exactly the same. The reason for this is two-fold. Firstly, the panel structure is not standardized, meaning that the countries differ in how a one-year followup can be constructed. Secondly, the Swedish data set existed before the Nordic project was launched. Initially the thought was to use it as a model for how the samples should be organized in all countries. However, the Swedish model would have resulted in very small sample sizes, especially in Denmark. Therefore, a decision was made to use a different structure of the samples in Denmark and Finland than in Norway and Sweden. In the following, we describe in detail the process of constructing the one-year follow-up in each country.

In all analyses of this report, mobility is studied during a period of one year. The points of measurement are referred to as $t$ and $t+1$. What $t$ and $t+1$ exactly are in the countries is described below. When reporting a time series, e.g. mobility between occupations in 2000-06, the year given refers to the year of measurement point $t$, in other words the start year of possible mobility. For instance, an occupational mobility of $10.0 \%$ in Sweden for the year 2002 means that $10 \%$ changed occupation between 2002 and 2003. Also, in most cases the background information refers to time $t$. Thus, when we mention the respondent's age or education, it means his or her education at time $t$, not $t+1$. 


\subsubsection{Sweden}

Each respondent in the survey stays in the panel for two years (see Figure 4.1). During this time, the respondent is interviewed eight times with an interval of three months - thus, they are interviewed quarterly. The Swedish LFS is organised in three monthly samples (A-C). The samples are divided into 8 rotation groups which are successively changed. After the eighth interview, the respondents in the eighth rotation group are dropped from the panel and replaced. The starting point (and consequently the endpoint for the eighth rotation group) can occur at any month of the year.

The sample size for each monthly sample has fluctuated from 17,000 to 22,000 during the studied period (2000-2006). The target population is people residing in Sweden and - until 2005 - between 16 and 64 years. From 2005, the age span was widened to $15-74$ years as an adaptation to EU standards.

$\left.\begin{array}{|l|l|l|l|l|l|l|l|l|l|}\hline & & \text { R 1 } & \text { R 2 } & \text { R 3 } & \text { R 4 } & \text { R 5 } & \text { R 6 } & \text { R 7 } & \text { R 8 } \\ \hline \text { Y1 } & \text { Jan } & \text { A } & \text { A } & \text { A } & \text { A } & \text { A } & \text { A } & \text { A } & \text { A } \\ \hline & \text { Feb } & \text { B } & \text { B } & \text { B } & \text { B } & \text { B } & \text { B } & \text { B } & \text { B } \\ \hline & \text { Mar } & \text { C } & \text { C } & \text { C } & \text { C } & \text { C } & \text { C } & \text { C } & \text { C }\end{array}\right\}$ 1st Quarter (t)

Figure 4.1. The Swedish data set

The Swedish data set for our study has been constructed in the following way. The first quarter of the year $t$ is our starting point. Respondents from the rotation groups that will stay in LFS at least to the first quarter the next year $(t+1)$ are chosen for the sample (i.e. rotation groups 1-4). These rotation groups in the three monthly samples are then pooled to- 
gether. The data set also contains information about the respondents' labour market situation in the 3 quarters between $t$ and $t+1$. In this study, such information is only used when it is necessary in order to construct the respondent's status at $t+1$.

The total dropouts from the surveys are around 20\%. In Table 4.1 the yearly sample sizes after dropouts are shown. For most of the years the $\mathrm{N}$ is around 20,000. However, in 2005 there was a major reconstruction of the Swedish LFS, which is why the sample for that year has only half of the size for the other years.

In this report, we will study population aged 16-63 years. The reason is that until 2005, respondents turning 64 left the LFS. The same age span is of course used for the other countries.

\subsubsection{Norway}

The Norwegian LFS and the data set used in our study are very similar to their Swedish counterparts (see Figure 4.2). There are some differences, though. Firstly, there is only one sample for each quarter. Secondly, the sampling unit is not individuals but families (a special family register, together with the population register, is used as the sampling frame). All members in the family between 16 and 74 years old (15-74 since 2006) are interviewed.

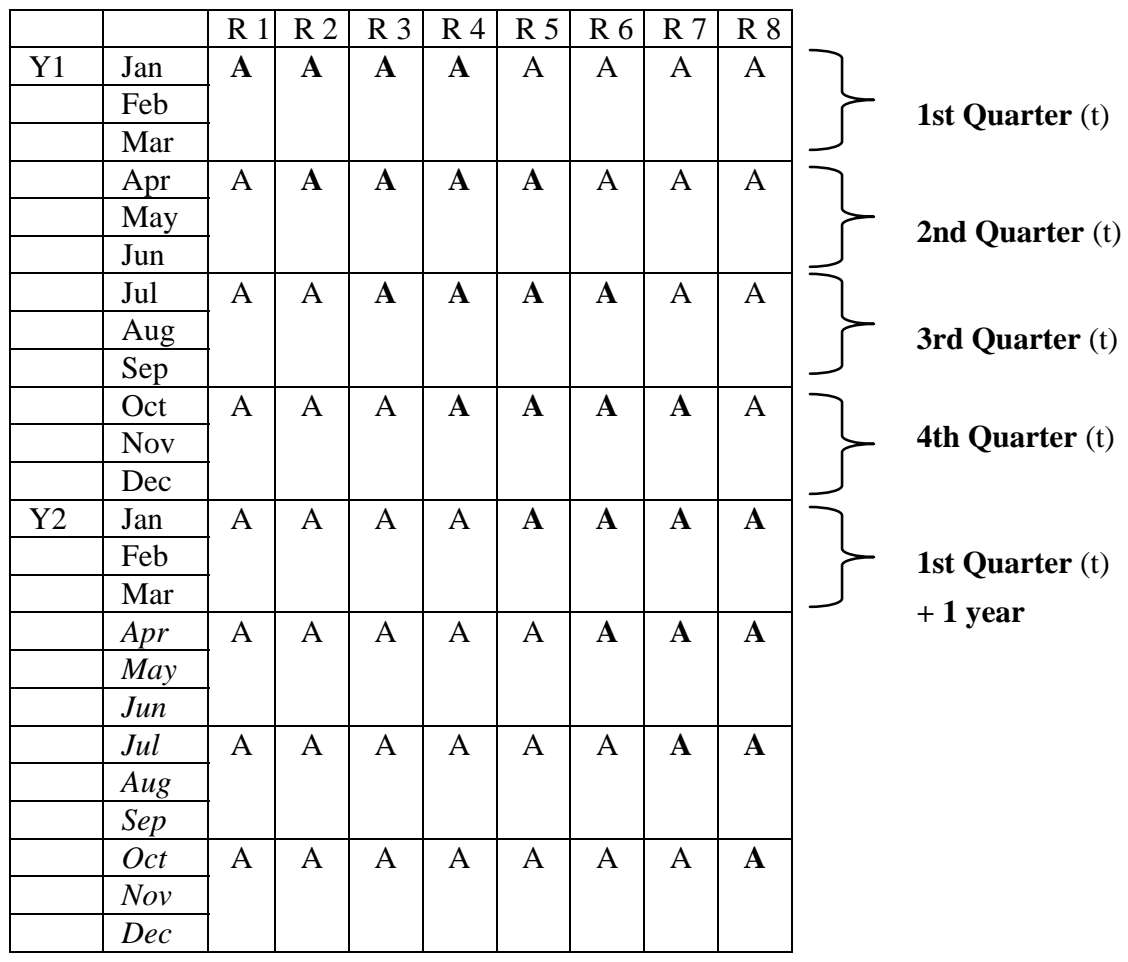

Figure 4.2. The Norwegian data set 
The sample size in each quarter is approximately 24,000 respondents. As in Sweden, the sample is constituted by a panel in which each family participates 8 times during 2 years. Thus, they are interviewed one time every quarter. The panel is successively replaced through a system of eight rotation groups - one exchanged each quarter.

The Norwegian data set is organized like the Swedish. The starting point is the first quarter each year and rotation groups 1-4 are followed to the first quarter of the next year. However, one main difference is the size of the group of respondents that are included in the data set. After missing cases (around 10\%), the yearly sample of 16-63-year-olds is around 10,000.

\subsubsection{Denmark}

The Danish LFS is a rotating panel survey. In every quarter of the year a sample of approximately 16,000 persons aged 15-74 years is selected (15-66 years in 2000). This sample is then divided into 13 subgroups and each subgroup is interviewed with reference to a specific week in the quarter. Hereafter the respondents are interviewed two more times. The second interview takes place one quarter after the first interview and the third one year after the second interview. The response rate is lower in Denmark than in the other three countries (63-68\%).

Because of the rotation structure in the Danish panel, only one third of the sample also takes part in the survey 12 months later. In combination with the lower response rate, this means that the data set would have become very small if it had been constructed in the same way as in Norway and Sweden. In order to get a larger sample, the data set has been constructed using all the quarters during a year as a starting point (Figure 4.3). Another thing to notice is that the starting point $t$ is the second interview which is compared to the third interview 12 months later (at $t+1$ ).

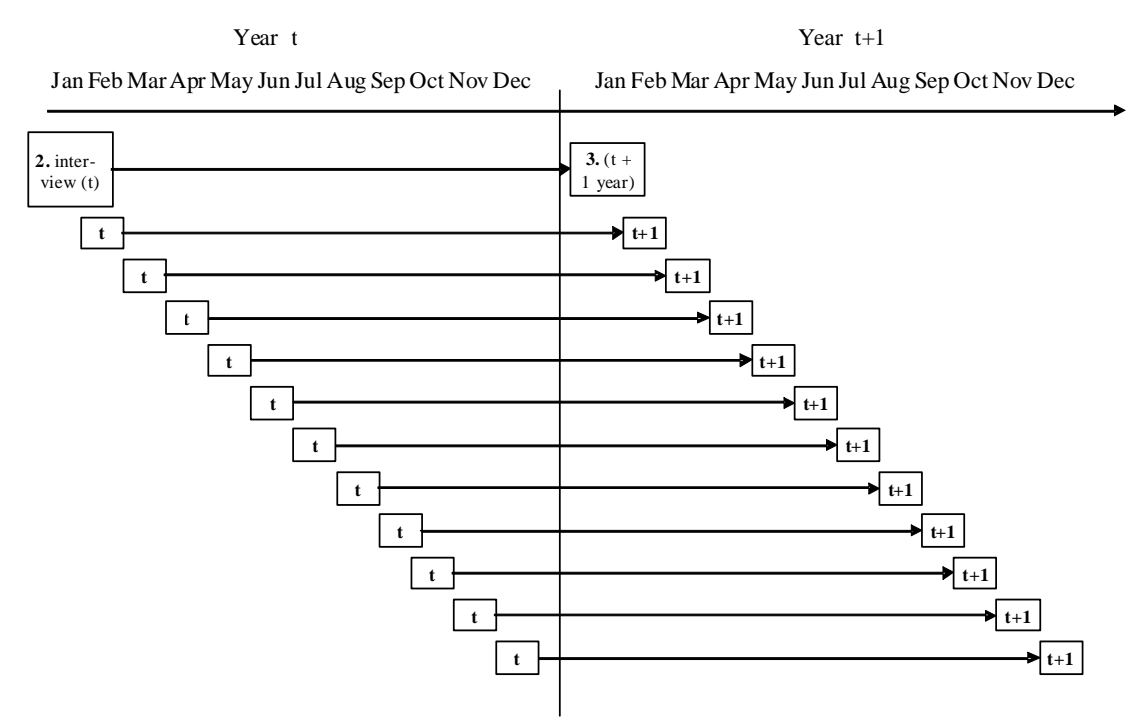

Figure 4.3 The Danish data set 


\subsubsection{Finland}

In Finland, the LFS consists of monthly samples including respondents from five rotation groups. The sample size each month is approximately 12,000 , i.e. 36,000 each quarter. The sample unit is individuals aged 15 to 74 permanently residing in Finland. The response rate during our study period has fluctuated between 78 and $85 \%$.

The panel structure is different from the other countries (Figure 4.4). There are five interviews, which take place with an interval of three months except for the fourth interview, which is done six months after the third.

From the Finnish panel structure, it is possible to construct a data set in both ways, i.e. as it has been done in Sweden and Norway, and as it has been done in Denmark. The Swedish model would have resulted in a smaller sample size, which is why the Danish model was chosen. That way, our data set comes to include all participants aged 16-63 in the Finnish LFS. Time $t$ is evenly distributed throughout the year, which means that the mobility rates produced are annual averages.

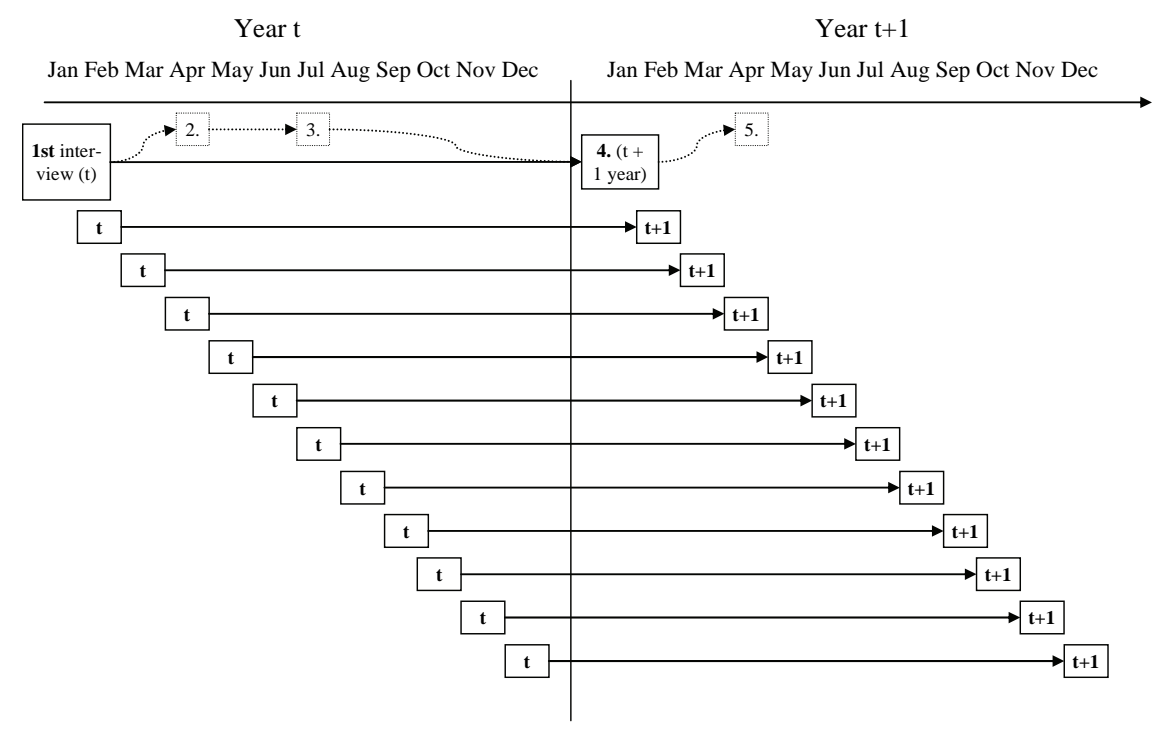

Figure 4.4 The Finnish data set

\subsubsection{Some remarks about the effects of data construction}

In each country we have formed a data set making it possible to study mobility over a period of 12 months. The four data sets have then been pooled together, which makes it possible to have multivariate analyses with the country as one of the independent variables. The combined database is located on a server of Statistic Denmark. All researchers in our group have had remote access to the database.

Apart from the obvious things such as sample size, there are two major differences between the individual data sets, which may have some 
bearing on our results. The less important one has to do with the number of interviews between $t$ and $t+1$. In Sweden and Norway, there are three interviews in between. In Finland there are two and in Denmark none. The number of in-between interviews only has relevance to variables which are constructed by accumulation. An example is occupation: in each interview, the respondents will be asked whether they still hold the same occupation as in the last interview. A series of "no" answers will result in no occupational mobility. It is possible that the fact that there is a different number of interviews has some effect on the outcome of such variables - this issue is dealt with in more detail later.

More importantly, there is a difference in when our measuring points occur. In Sweden and Norway, mobility is measured between the $1^{\text {st }}$ quarter of year $t$ and the $1^{\text {st }}$ quarter of year $t+1$. In Denmark and Finland, the measuring points are evenly distributed throughout the year, meaning that the mobility rates produced are annual averages.

The question is how this might affect our results. If and when there are seasonal differences in mobility, this may cause differences between Sweden and Norway on one hand and Finland and Denmark on the other. Put in seasonal terms, we only measure mobility from one spring to another in Sweden and Norway, whereas we also have "summer-summer", "autumn-autumn" and "winter-winter" mobility in Denmark and Finland.

To get some clue to the consequences of this difference in data structures, we have made a comparison with the Finnish data. As we have the whole LFS population from Finland, we can easily select only mobility between $1^{\text {st }}$ quarter in year $t$ and $1^{\text {st }}$ quarter in $t+1$. That way, we see what the Finnish results would have been if the data were constructed in the Swedish way. In Table 4.2, such mobility rates for the different indicators used in this study (defined later in this chapter) are compared with the results obtained through the Finnish construction. Similar comparisons cannot be done with our Norwegian ${ }^{8}$ and Swedish datasets, and with the Danish data set the comparison would be less reliable, as the sample size for the "Swedish model" would be very small.

When it comes to mobility between labour market statuses (employment, unemployment, inactivity), the differences seen in Table 4.2 are remarkably small. We can thus assume that these kinds of results are very comparable between the countries even though the data sets have a slightly different construction.

\footnotetext{
${ }^{8}$ With Norwegian data, we were able to replicate some of the comparisons in Table 4.2 - with the difference that we compared results between $1^{\text {st }}$ quarter $t$ and $1^{\text {st }}$ quarter $t+1$ with the mobility between $2^{\text {nd }}$ quarter $t$ and $2^{\text {nd }}$ quarter $t+1$. The results obtained confirmed the overall picture from Table 4.2.
} 
Table 4.2 Mobility rates for different indicators in Finland; a comparison of the data structure in FI and DK vs. the structure in NO and SE. Population aged 16-63 years.percent.

\begin{tabular}{lrr}
\hline & First Quarter & All quarters \\
\hline Employment to unemployment & 2.7 & 2.6 \\
Employment to inactivity & 6.7 & 6.7 \\
Unemployment to employment & 38.1 & 38.9 \\
Unemployment to Inactivity & 27.4 & 27.3 \\
Inactivity to employment & 11.6 & 11.8 \\
Inactivity to unemployment & 5.4 & 5.2 \\
& & 11.1 \\
Workplace mobility & 9.7 & 9.2 \\
Occupational mobility & 8.3 & 7.7 \\
Industrial mobility & 7.2 & 2.7 \\
& & 32.8 \\
Into temporary contracts & 2.5 & 3.3 \\
Out of temporary contracts & 35.2 & 3.9 \\
Into part-time (up to 34 hrs/week) from full-time & 3.6 & 3.8 \\
Into full-time from part-time & & \\
\hline
\end{tabular}

In some other indicators, we see larger differences. Firstly, the SwedishNorwegian way produces somewhat lower workplace, occupational and industrial mobility rates. This is an expected finding, as people working seasonally only during the summer will of course have changed workplace, and are more likely to have also changed occupation and/or industry than others. A conclusion is that with these three forms of mobility, the Swedish and Norwegian rates will be somewhat underestimated when compared to Finland and Denmark.

A further difference can be seen regarding atypical work. With the Finnish-Danish data construction, we get somewhat higher rates of transitions into temporary contracts, and lower rates of transitions out of temporary contracts and into part-time work. The difference regarding transitions out of temporary contracts is especially large.

For future research, we think that the way used in Finland and Denmark is better. It generates much larger yearly samples and smooths out seasonal differences. Such a design is entirely possible with the Swedish and Norwegian LFSs. As mentioned before, the reason why this is not done in the present study is that the Swedish data existed in the present form before the comparative project. After finding out that we could not use it as a model, we did not have the possibility to rearrange it in a way similar to Denmark and Finland.

\subsubsection{Consequences of weights and response rates}

A last remark concerning data is that no weights have been used in the analyses. In the normal use of LFS, weights are utilized to produce absolute numbers and compensate for biases due to non-responses. In general, however, the bias in the LFS due to non-responses is not that severe compared to other samples. The reason is a high response rate. However, when the sample is broken down into smaller categories, for example 
unemployed or temporary employees, there may be larger problems with non-responses.

In this study, we have chosen not to use weights in the analyses. The main reason is that it is simply not possible to weigh transitions between $t$ and $t+1$ when transition rates in the population are unknown. ${ }^{9}$

Because the main subject of interest in our study - the transitions cannot be corrected by weight variables, we have chosen not to use them in the few descriptive sections, either. This may cause slight deviation from official figures.

There is, however, a mechanism that can cause problems in our analyses. This occurs if a person's probability of taking part in LFS changes along with his/her status on the labour market.

This is obviously a possible source of error in all of our mobility analyses. If the group making the studied transition has a higher or lower combined response rate than the stable group, the transition rate will be over- or underestimated. ${ }^{10}$ It is a well-known fact, confirmed by weight variables in our data sets, that the employed have a higher response probability than the unemployed. This leads us to believe that we tend to overestimate transitions from non-employment into employment while underestimating transitions from employment to non-employment. It is very difficult to speculate about how this mechanism might affect the other transitions studied in this report.

However, there is a strong argument for assuming that the errors in our estimations actually are smaller than they appear in the example. This is because the probability of taking part in the survey at $t+1$ is not independent of the probability of having taken part at $t$. In other words, the likelihood of answering to an LFS survey can be thought of as a personal trait, which is not likely to change just because the person has been mobile on the labour market. ${ }^{11}$ The probability of answering at $t+1$ is most likely more dependent on whether the person has answered at $t$ than it is on the person's labour market status. This argument is confirmed by calculations with the Finnish data: the probability of answering at $t+1$ is

\footnotetext{
${ }^{9}$ The weights used in LFS are only available for cross-sections - that is, either $t$ or $t+1$. Our sample consists of individuals who have answered both at $t$ and at $t+1$. Weights can be applied to crosssections, because the actual frequencies of the weighed population groups are known. A central starting point of this study is that transition rates are unknown. We cannot know, for instance, if people who have changed workplace are more or less likely to take part in a survey than people who have not done so.

${ }^{10}$ To illustrate, let us consider a fictive, simplified example: Let us assume that we have a sample of 1000 people who are all unemployed at $t$. In real life, 500 of them have become employed at $t+1$ while 500 remain unemployed. The correct transition rate is obviously $50 \%$. Let us further assume that an employed person has a response probability of $90 \%$ for one interview in the survey, while an unemployed person's probability is $80 \%$, and that the response probabilities are not interdependent. With these assumptions, our data capture $64 \%$ (80\% x 80\%) of those who remain unemployed, while $72 \%$ ( $80 \%$ x 90\%) of those making the transition are included. Of the original 1000, we will then have in our data 360 people making the transition ( $72 \%$ x 500), and 320 people (64\% x 500) remaining unemployed. Thus, we overestimate the transition rate to $360 /(320+360)=52.9 \%$.

${ }^{11}$ In terms of the example above: even if the general response rate is $90 \%$ among employed and $80 \%$ among unemployed, it is not likely that the probability of any given person to take part in the survey would change by ten percentage points if the person were to make a transition between the two states.
} 
much more dependent on if one has answered at $t$ than it is on the person's labour market status. ${ }^{12}$

Further, it should be noted that the above mechanism has nothing to do with differences in response rates between countries or years in general. If non-response is randomly distributed, the estimate of a certain type of mobility should be nearly as reliable with a $60 \%$ response rate as it is with an $80 \%$ one. What matters is if there are relative differences between the response rates of the mobile and the non-mobile.

In conclusion, we believe that having different response rates between countries and years, and not correcting with weights, has relatively little effect on our results. ${ }^{13}$ It should be kept in mind that most analyses have built-in controls in the sense that they only operate with subpopulations or include control variables. However, there is a possibility that the mobility rates reported deviate from the ones in reality - due to pure chance (as always in statistics) or through the mechanism reported above of different response rates for different kinds of transitions. The deviations are likely to be small and we have no reason to think they would be different from one country to another.

\subsection{Statistical analyses}

There are several different strategies used to analyse mobility throughout this report. One of the main ways is to present gross mobility rates for the mobility indicators. This is more complicated than it sounds, as differences in definitions and data set construction must be taken into account when interpreting the results.

Gross mobility figures do not take into consideration differences in the composition of the national labour markets or differences in business cycles. To control for these factors multivariate analyses have to be conducted.

All the multivariate analyses used in this report are either binomial or multinomial logistic regressions. These statistical techniques are appropriate to use - instead of ordinary least-square regressions - when the dependent variables are on a nominal level and we try to estimate the probability for a certain outcome (Long 1997). Some of the dependent variables presented below are dichotomies, e.g. workplace mobility. In

\footnotetext{
${ }^{12}$ During 2000-06, the response rate of a single interview in the Finnish LFS varied between 77 and 84 per cent for those aged 15-63. However, for those who had not answered at $t$, the probability of taking part at $t+1$ was only 32\%. By labour market status at $t$, the average response rates at $t+1$ where as follows: $93 \%$ for the employed, $89 \%$ for the unemployed, and $91 \%$ for the inactive.

${ }^{13}$ This assumption was tested with one of the models - only for Finland, though, as weight variables are not included in the combined data. The results of the logistic regression on factors affecting workplace mobility (chapter 8) were compared with and without cross-sectional weights from time $t$. (The weight variable was adjusted so that it did not inflate the number of cases in the analysis). In short, the models produced almost identical results. Of course, we saw small differences in the coefficients, but nothing that would change the interpretation of the model. This supports our position that using or not using weights has little effect on our results.
} 
these cases, binomial logistic regression is used. However, in other cases the dependent variables have more than two values, and multinomial regression is the appropriate statistical technique.

In the analyses in this report the regression coefficients presented are in the form of odds ratios. An odds is a probability that a certain event will occur divided by the probability that it will not happen (e.g. probability of changing jobs divided by the probability of staying in the same job). An odds ratio is two odds divided by each other. In most analyses, we use reference categories to which an odds for a certain category is compared. For example, if men are the reference category, the odds for women is divided by the odds for men (Odds(w)/Odds(m)). A ratio of 1 indicates that the odds for women and men are equal. A ratio below 1 indicates a lower odds for women than for men that the event will occur (e.g. a workplace change) and a ratio above 1 indicates a higher odds for women than for men for the event to occur. For instance, an odds ratio of 1.10 tells us that women have a 10 per cent higher probability of workplace change than men do, when all other variables in the model are controlled for.

In some of the analyses, the concept "predicted probability" is used. This refers to the probability of an outcome (e.g. change of workplace) for an individual with certain characteristics on the variables in the statistical model used in the analysis (e.g. female, aged 35-44, married, with children etc.). Predicted probabilities are used to give illustrations of the probability of mobility for certain categories, whereas odds ratios always are only relative measures that do not give concrete indications of probable mobility rates. However, it is important to remember that the predicted probabilities presented are not absolute values, but statistical predictions according to a model, with the normal statistical uncertainties.

\subsection{Dependent variables}

In this section, we briefly address the main differences between the countries regarding data and definitions. We also state our main conclusions about how they may affect the results - these conclusions are then kept in mind when interpreting the results. For readability, we have tried to keep this section as short as possible. A more detailed account of the differences is presented in Appendix B.

In all analyses, mobility is studied for a one-year period. In other words, transitions between $t$ and $t+1$ are studied. It is important to notice that this way of measuring mobility somewhat underestimates the amount of total transitions. For instance, if a person is employed at both $t$ and $t+1$, we record no transition even if s/he has been unemployed and/or inactive sometime in between. 
4.6.1 Mobility between main labour market statuses: Employment, unemployment and inactivity

Main labour market statuses refer to whether the respondent is employed, unemployed or inactive during the studied reference week. In general, one is counted as employed if one has worked at least 1 hour during the reference week as employed, self-employed or as a contributing family worker. Furthermore, individuals temporarily absent from work because of sickness, parental leave or vacation are usually included in the category.

Unemployed are individuals that are not employed during the reference week, but are available for work, want to have work and have actively searched for work during the preceding four weeks. Also, people waiting for a job to start soon may be counted in this category. Students looking for work in the way described are included in the category.

The LFS in Sweden was adapted to the international definition as late as 2007. However, for purposes of international comparison, sufficient data were gathered already during our study period. We have therefore been able to add full-time students searching for a job to the Swedish official category of unemployed in LFS. The unemployment indicators are thus to a great extent similar between the four countries.

Inactive are individuals not classified as either employed or unemployed. Main groups in this category are students and retired people. Latent job seekers - people who want to have a job and are available for work, but have not actively searched for one - are also included.

Participants in active labour market policy programmes may end up in any of the three categories depending on the nature of the programme and whether they have actively searched for work lately. Subsidized jobs with regular pay are counted as employment. Many trainee positions are counted as unemployment if the person fulfils the active search criterion. Some educational programmes have the nature of studying, and participants are most likely to be categorized as inactive.

In the analyses to come, there are three different possible outcomes at $t+1$ for each labour market status at $t$. For example, if you are employed at $t$ you can remain employed at $t+1$ or you can have made a transition into unemployment or inactivity. In chapter 5 , all six possible transitions are listed.

\subsubsection{Mobility into and out of temporary jobs and part-time jobs}

The information used on temporary employment in chapter 6 is the type of contract the person has in his/her main job. In the LFS it is first of all determined whether the respondent works as a wage-earner or as selfemployed or helping family member. If the respondent is a wage-earner, then he or she is asked whether the job is permanent/a work contract of 
unlimited duration or whether the job is temporary/a contract of limited duration.

Combining the information of type of contract with the information of main labour market status, it has been possible to create indicators on the flows into temporary employment and out of temporary employment. As above, the transitions have been measured on a one-year basis.

In the LFS, there are many different indicators of working time, and they are not all found in the exact same form in our four countries. In the analyses made in this report, ordinary working time in main job has been used as a point of departure to distinguish between full-time and part-time jobs. It must be pointed out, though, that the original question resulting in this variable varies between the countries. In Finland and Denmark, the question refers to normal working time, including paid and unpaid overtime if it has become customary. In Norway, the question is about contracted working time and in Sweden about agreed working time. In practice, we may expect some difference especially between Finland and Denmark on one hand, Sweden and Norway on the other.

A full-time job is defined as a job with an ordinary working time of 35 hours or more during a week. Part-time jobs are further divided in long part-time (20-34 hours) and short part-time (1-19 hours) jobs. In the same way as for type of contract, the information of working time has been combined with main labour market status, which makes it possible to measure many different kinds of transitions into and out of part-time employment. Furthermore, upward change in working time has been studied (see chapter 7 for a more elaborate presentation of the indicators).

\subsubsection{Workplace, occupational and industrial mobility}

In this section, we provide an insight into the issues specific to the analysis of workplace, occupational, and industrial mobility. Even though the Labour Force Surveys (LFS) are highly standardized and thus similar across our four countries, there are some important differences. In addition, we lack comparable data for some countries and years - an overview of what is missing can also easily be obtained from Tables 8.1-8.3 in chapter 8.

On a general level, we must note that occupational and industrial mobility cannot be studied between non-employment and employment. It would of course be highly relevant to know e.g. if a person who has moved from unemployment to employment has changed occupation. This cannot be studied, as an occupation is generally not registered for an unemployed person in LFS, and especially not in a similar manner in all of our countries.

Further, we must keep in mind that there is a slight difference in the construction of the data sets. In Sweden and Norway, mobility is studied between the first quarter of year $t$ and first quarter of year $t+1$ - whereas 
in Finland and Denmark, start and end points are evenly distributed over the years. In all cases, the period when mobility occurs / does not occur is 12 months.

The indicators of industrial and occupational mobility have a different character than those of workplace mobility. Firstly, workplace mobility is the form of mobility where definitions vary the most between countries. Secondly, workplace mobility measures whether a person has switched workplaces at least once between $t$ and $t+1$. Thus, a possible workplacechange will be observed even if the person has returned to his original workplace by $t+1$. With occupation and industry, we only compare $t$ and $t+1$ and do not observe what has happened in between.

All forms of mobility described below are measured only when the person is employed at both $t$ and $t+1$.

\section{Dependent / independent coding in our data}

Coding of the variables is, as a rule, dependent. In follow-up interviews, the person is e.g. asked whether his/her occupation is still the same - and only if it has changed will recoding take place. This rule has exceptions in some of the countries. For instance, if a person cannot be reached for one of the interviews, the next interview will in some countries be a new independent interview - while in some countries, it will be a follow-up of the last completed interview. For more details about independent / dependent coding in LFS in our countries, see Appendix B.

Independent coding of job-related variables is used in all countries if the person has been non-employed in the previous interview. This means that e.g. if a person has been briefly unemployed during an in-between interview, independent coding will be used. Mobility between employment and non-employment varies over time, so this may have some bearing on the results.

There is more independent coding in Norway above all, but also in Sweden, than in Denmark and Finland. Our conclusion is that the Norwegian mobility rates most likely contain a somewhat higher share of artificial mobility than the others do.

\section{Occupational mobility}

In principle, the construction of the occupational mobility variable is very simple. Occupation at $t$ is compared with occupation at $t+1$, and if they are not the same, then there is mobility.

The reliability of the variable has to do with the issue of dependent / independent coding. In the typical case where dependent coding is used, the occupational code is defined in the first interview. In follow-up interviews, the person is asked if s/he still has the same occupation. If the 
answer is "yes" in all interviews leading up to $t+1$, the code remains the same and there is no mobility.

If not stated otherwise, the comparison is done on a 3-digit level of the occupational classification. As an example, this level of detail separates "travel staff (guides, etc.)" from "restaurant staff (cooks, etc.)" - but does not distinguish between waiters, bartenders and cooks. International Standard Classification of Occupations (ISCO) is used in all countries as a rule, although there may be some national variations.

For Finland, data comparable with ISCO exist from 2002, which is why mobility between 2000 and 2002 is not used in the comparisons.

For Denmark, we have learned from DST that the way industry and occupation are coded was changed somewhat in 2001. This leads to abnormally high mobility levels between 2000 and 2001. Therefore, comparable occupational and industrial mobility is available for Denmark between 2001 and 2006.

\section{Industrial mobility}

Industrial mobility is measured on 2-digit level of the NACE classification (with slight national variations). The variable is constructed in the same way as the occupational mobility variable.

In most cases, information about industry is acquired from register based on the name of the interviewee's employer. The exception is Norway, where the industry code is decided based on what the interviewee says.

Industrial mobility may occur even in cases where the actual change in the individual's work environment is very small. This can be the case when a firm changes its official line of business or merges with another firm.

For Sweden, we do not have information about industrial mobility between 2002 and 2003.

\section{Workplace mobility}

In a number of studies, this phenomenon has been called job-to-job mobility. However, to be precise, the LFS does not measure change of job. Also, previous studies have had very different and partly contradictory definitions of what is meant by a job or job-to-job mobility. This is why we have decided to use a more exact term.

To complicate things even more, the definition is not the same in all of our countries.

- In Denmark, Finland, and Norway, the variable refers to a change of physical workplace.

- In Sweden, it refers to a change of employer. 
Thus, the most precise term possible would be workplace / employer mobility. For convenience, and because Sweden is the exception, we have consequently decided to use the term workplace mobility in this study. When looking at the results, we will remind you of the deviating Swedish definition.

Workplace change is thus not to be equated with a change in employment contract. For instance, several consecutive temporary contracts within the same physical workplace / employer will be considered as one. A shift from a temporary to a permanent contract will not in itself constitute workplace mobility, either.

However, if there is any unemployment or time outside of the labour force at all between contracts, this will be recorded as a workplace change. Thus, workplace mobility is not a straightforward comparison of jobs at $t$ and $t+1$. If there has been any change or disruption between $t$ and $t+1$, a workplace change will be indicated even if the person had then returned to the exact same workplace / employer.

Further, a person may have changed task within the same workplace / employer (for instance, from being a doorman to a chef in a restaurant), but this does not register as a workplace change in the LFS. Also, the name of the workplace or company may have changed - through a merger or otherwise - but if the person is still working at the same physical place (or same employer in case of Sweden), no workplace mobility has taken place.

In Denmark, Finland, and Norway, the concept of workplace change is not to be equated with employer change, either. You can change workplace while your employer and possibly also your terms of employment stay the same. This is the case e.g. when a teacher moves from one school to another within the same municipality. Thus the definition of workplace mobility in these three countries always comes down to physical workplace.

In Sweden, however, changes of workplace with the same employer do not constitute mobility according to our variable. This means that Swedish workplace mobility will be somewhat underestimated in comparison to the other three countries. This may be especially true for Sweden with its large public sector. ${ }^{14}$ The larger the employers, the more probable it is to change physical workplace without changing employer. Thus, when interpreting the results, we should keep in mind that Swedish workplace mobility will probably seem lower than it actually is (or would be with the exact same definition).

A further complication is that workplace mobility cannot be measured in a standardized way across countries. A detailed description of the variable in each country is provided in Appendix B. Briefly, it can be said

\footnotetext{
${ }^{14}$ Still, it must be kept in mind that the employer in Swedish LFS is the entity paying your salary. These entities are not infinitely huge in the public sector, either - this depends on the organization. Thus, it is likely that a change of physical workplace will most often result in a change of employer in Sweden.
} 
that Finland and Denmark base their measure purely on one retrospective question asked at $t+1$ : "when did you start working at your current workplace?” If the person started less than 12 months ago, a workplace change is observed - provided, of course, that the person was employed at $t$.

In Sweden, interviewees are asked whether they have changed employer since the last interview. The 12-month variable is accumulated from four interviews: if the answer is "yes" at least once, a workplace change is indicated. If there has been a change, it is always controlled that an actual change of employer has taken place, not merely a change of name.

In Norway, we have the possibility of using either the retrospective question or a cumulative one, but not for the exact same period. Unfortunately, the retrospective question used in Finland and Denmark is in Norway asked only in the second quarter of the year - while the other mobility variables from Norway normally describe mobility from first quarter in $t$ to first quarter in $t+1$. This has led us to construct two alternative workplace mobility measures for Norway.

In our primary variable, we have used a hybrid construction, where information from the retrospective question is used when possible and adapted to the $1^{\text {st }}-1^{\text {st }}$ quarter period. What makes the variable a hybrid is that such information is not always available. Whenever this is the case, cumulative information from follow-up interviews is used. A small proportion does not have this information either - for them workplacechange is equated with industrial mobility.

The alternative variable is similar to the Finnish and Danish variables and describes workplace change between $2^{\text {nd }}$ quarter $t$ and $2^{\text {nd }}$ quarter $t+1$ according to a retrospective question. No other information has been used. This makes for a larger share of missing cases, which are as random as the overall non-response in LFS. Mobility rates given by the alternative variable are more comparable with the other countries, especially with Denmark and Finland. As the period of measurement is different, this variable cannot be used when studying combinations of different forms of mobility.

Because of changes in LFS, workplace mobility from Norway and Sweden are not available from 2005 onwards.

\subsection{Independent variables}

Earlier research has found many different factors that may affect labour market mobility (see chapter 1). Our strategy has been to incorporate most of these possible determinants in a standard model that, with minor differences, has been used in a similar way in all multivariate analyses conducted in the report. The independent variables and their categories have been driven by data (what is available in all countries), theory (what 
can be expected to have an effect on mobility), and testing (e.g. what categorization works best).

The first group of variables has to do with individual characteristics, including gender, age, marital status, children, national origin and education. The first three variables are operationalised very similarly in the four countries. (For a more detailed account of our variables, see Appendix B.)

The variable "children", referring to whether the respondent has children living at home, is a bit more complicated. In the Norwegian LFS, parenthood is only registered for women. In the analyses to come, this has been handled in different ways. One strategy has been to exclude the variable "children" from the analysis, another to create a combination variable of gender and children that differentiates between three categories: men, women without children, women with children.

National origin is operationalised in very broad categories. We separate between native-born, born in another Nordic country, born elsewhere in Europe or North America, and born elsewhere. Educational level differentiates between primary, secondary and tertiary level in accordance with the international classification of education (ISCED).

The second group of variables has to do with the individual's labour market and work situation. These include industrial and occupational categories, and type of employment contract, which is used not only as a dependent variable but also as an independent variable in some of the analyses. The same applies to working time. We also use the size of the workplace, where we have had to cut down categories to four in order to make the variable comparable. Where appropriate, we also have a variable about the individual's situation outside the labour force.

The last group of variables tries to capture contextual and structural factors by measuring unemployment level, unemployment change, and regional population density.

Unemployment level is measured regionally. What poses problems is that the level and within-country variation of unemployment are very different in the four countries. Especially the general level is higher and within-country variations are larger in Finland. We have tried to solve this problem in the following way:

- In parallel analyses, we have used a relative unemployment measure: with low-, medium- or high-unemployment regions within each country. Thus, the categories are defined differently in each country for cut-points, see Appendix B.

- In combined analyses, we have used an absolute measure, where the three categories low/medium/high are constructed relative to the four countries as a group.

A third indicator of unemployment is annual change in national (not regional) unemployment rate. With these measures, we try to capture struc- 
tural unemployment (with the unemployment level variable) as well as business cycle (with the unemployment change variable) in all models.

Finally, in some of the analyses we use regional population density, i.e. persons per square kilometre in the region. 


\section{Mobility between Employment, Unemployment and Inactivity}

\subsection{Introduction}

This chapter deals with transitions between three employment statusesemployment, unemployment and inactivity—in Denmark, Finland, Norway and Sweden. The crucial question is whether patterns differ across the four countries and - if so-whether differences can be explained by reference to the institutional arrangements described previously in this report.

Mobility is measured in the following way. Each individual in the data set has been surveyed at two points in time with one year in between. Thus, for example, for individuals who were surveyed during the first quarter of $2000\left(\mathrm{~T}_{1}\right)$ we also have information referring to the first quarter $2001\left(T_{2}\right)$. If there is a change of employment status from $T_{1}$ to $T_{2}$, mobility has occurred. This design includes a black box as we have two observations with one year in between but do not know what has happened in the meantime. An individual who was employed at both $T_{1}$ and $T_{2}$ may very well have had a break-due to unemployment, education, etc.-in between. Similarly, an individual who has gone from employment at $\mathrm{T}_{1}$ to inactivity at $T_{2}$ may have been unemployed during some period before becoming inactive. With this design we obviously do not have all relevant information, but we believe the drawback is rather limited.

In this chapter the six possible transitions to be dealt with are:

a) from employment to unemployment

b) from unemployment to employment

c) from employment to inactivity

d) from inactivity to employment

e) from unemployment to inactivity; and

f) from inactivity to unemployment.

However, all these transitions are not equally interesting. As we are particularly interested in transitions involving employment, our main focus will be on (a), (b), (c) and (d) above, but in one way or another all six will be touched upon.

The principal purpose with the following analysis is to compare the four countries in terms of various mobility rates. From the previous presentation in this volume we expect that transitions from employment to unemployment are more frequent when employment protection legislation is weak. This speaks for a pattern with the highest rates in Denmark 
and the lowest in Norway and Sweden. On the other hand, to some extent, the proportion of fixed-term contracts may be a compensatory mechanism. In other words, the Swedish figures might not be as low as would be the case if the legislation were the only factor in operation.

With respect to transitions from employment to inactivity, we must expect something similar to switches from employment to unemployment. It is likely that the strictness of employment protection legislation is the important determinant, possibly in combination with the patterns regarding fixed-term contracts.

Also transitions to employment may be affected by employment protection legislation. If it is costly for employers to dismiss workers, they may be more hesitant to hire people. Such a mechanism can thus slow down the flows from unemployment or inactivity. Actually, this is the conclusion that the OECD (2004) has drawn by examining data from a large number of countries. We should consequently expect transition rates to employment to be particularly high in Denmark. However, this assumption perhaps needs to be modified when taking the impact of unemployment benefits and active labour market policy into account. On the one hand, generous unemployment benefits-in terms of replacement levels and duration-may have a negative impact on flows out of unemployment; the assumption is then that people on benefits are less in a hurry to find a job. There is a great deal of empirical research pointing in that direction (see, e.g., Nickell 1997). On the other hand, active labour market policies may increase chances for job seekers to find work, but it still remains a rather controversial issue what impact such policies in fact have (Martin and Grubb 2001).

In these respects, Denmark is perhaps the most interesting country among the four under scrutiny here. It has rather generous unemployment insurance and it spends more on active labour market policies than most other OECD member states. At the same time, the other Nordic countries also score rather high on these measures. The main difference may be the strictness of employment protection legislation. If the flexicurity model functions as has been suggested, Denmark's mixture of measures (the "golden triangle") might lead to high levels of transitions from unemployment and inactivity to employment. Nevertheless, it is possible that some of the measures contradict each other. Our data will hopefully throw more light on these issues.

The chapter is divided into five main sections. First, we provide a broad description of the flows in the labour markets. This gives an indication of how mobility levels vary across the countries and over time. Second, we examine the main determinants behind the transitions. We then include various variables such as sex, age, industry, type of employment contract, size of workplace, and regional and national unemployment levels. The question is then whether the main determinants behind mobility patterns are generally the same in all four countries. Third, we show 
the predicted probabilities of transitions for a number of categoriesmale manual workers, female manual workers, male professionals, female professionals, etc. The categories are selected to represent fairly large occupational groupings. We can thus see, for example, if the predicted probabilities for transition from employment into unemployment are higher for male manual workers of a certain age than for female manual workers of the same age and if there are cross-national differences in this respect. Finally, we use country as an independent variable in multivariate regression analyses. This means an attempt to rule out the impact of other factors, such as individual and workplace characteristics and business cycles. If, after controlling for other factors, the country variable still shows significant effects, we have an indication that the national institutional arrangements matter.

\subsection{A General Overview}

We start this presentation by providing some general data on what has happened to people in Denmark, Finland, Norway and Sweden from one year to the next in the period 2000-07. In Table 5.1 we can see whether individuals in different employment statuses have remained in the same category or switched to another at the second point of observation.

To begin with, we find that - in all four countries - more than $90 \%$ of those who were employed at $T_{1}$ are also employed at $T_{2}$. There are no great differences in this respect between the four countries, but Sweden and Norway score somewhat higher than Finland and Denmark (as mentioned in the note in the table, the Danish data set only covers the period 2000-06). The next row shows the proportion that was unemployed and it is generally low; it varies from $3.1 \%$ in Denmark to $1.5 \%$ in Norway. The third option is that people have switched to inactivity, which means that they have left the labour force. These proportions are also low but higher than the proportions having become unemployed; the top score is found for Finland (6.2\%) and the bottom score for Sweden (4\%).

Turning next to those who were unemployed at the time of the first observation, we should notice that this category is much smaller, but also that it the most mobile. The proportion remaining in the same status at $T_{2}$ is thus the lowest in the table. Moreover, in this case, the cross-national variation is greater. The proportion of the unemployed who have got a job is clearly highest in Norway (54.6\%) and clearly lowest in Finland (39.5\%). In these two countries, the relationship between the proportions of unemployed at $T_{2}$ is basically reversed (although on a lower level), whereas thepercentages that have left the labour force are almost exactly the same. Again, it should be recalled that people need not have had the same employment status all the time; in this case, it is thus possible that they have had jobs or been inactive in between. Denmark and above all 
Sweden have lower figures on these transitions to inactivity and, in Sweden, this adds up to the highest proportion unemployed one year later.

Table 5.1 Stability and change of employment status from one year to the next, among individuals aged 16-63 years. Average proportions 2000-07 in four Nordic countries.percentages

\begin{tabular}{|c|c|c|c|c|}
\hline & Denmark* & Finland & Norway & Sweden \\
\hline \multicolumn{5}{|c|}{ Employed at $T_{1}$, status at $T_{2}$} \\
\hline Employed & 91.4 & 91.2 & 93.0 & 93.9 \\
\hline Unemployed & 3.1 & 2.6 & 1.5 & 2.1 \\
\hline Inactive & 5.6 & 6.2 & 5.5 & 4.0 \\
\hline $\mathrm{N}$ & 52,106 & 93,177 & 47,735 & 106,349 \\
\hline \multicolumn{5}{|c|}{ Unemployed $T_{1}$, status at $T_{2}$} \\
\hline Employed & 49.3 & 39.5 & 54.6 & 43.9 \\
\hline Unemployed & 27.5 & 33.7 & 18.6 & 34.2 \\
\hline Inactive & 24.3 & 26.8 & 26.7 & 21.9 \\
\hline $\mathrm{N}$ & 4,717 & 8,359 & 1,803 & 6,701 \\
\hline \multicolumn{5}{|c|}{ Inactive $T_{1}$, status at $T_{2}$} \\
\hline Employed & 21.7 & 18.3 & 23.6 & 18.2 \\
\hline Unemployed & 7.4 & 7.9 & 5.0 & 8.0 \\
\hline Inactive & 70.9 & 73.9 & 71.4 & 73.9 \\
\hline $\mathrm{N}$ & 11,642 & 31,960 & 12,107 & 27,734 \\
\hline
\end{tabular}

* The period for Denmark is 2000-06.

Finally, Table 5.1 shows the degree of stability and mobility regarding those who were inactive at the first observation. In all four countries, more than $70 \%$ of the inactive population had the same employment status also when surveyed the second time. Figures are somewhat higher in Sweden and Finland. The most striking cross-national differences are found for transitions to employment; this proportion is highest in Norway and lowest in Sweden, and this difference amounts to more than 5percentage points. In terms of transitions to unemployment Denmark, Finland and Sweden have about the same proportions, whereas Norway scores lower.

As Table 5.1 presents averages for 2000-07 and, in the Danish case, 2000-06, it does not tell us whether or not there is variation in the national figures across the period. Actually, there is some such variation worth taking a closer look at. We therefore provide year-by-year information in the form of diagrams for each one of the transitions under study. In Diagram 5.1 we show data on switches from employment to unemployment. 


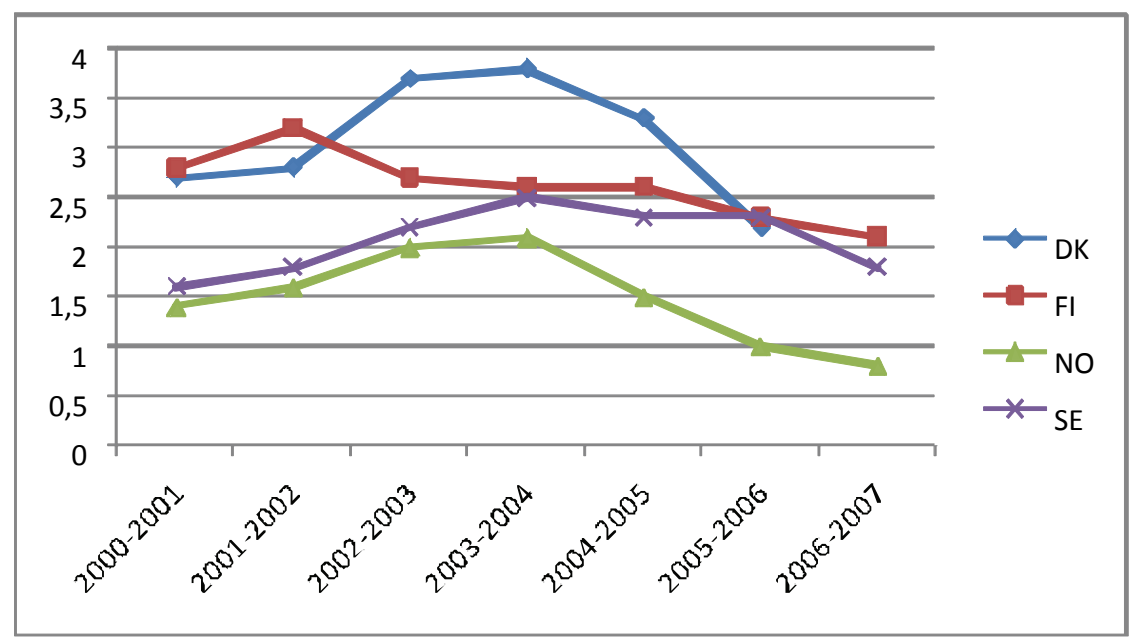

Diagram 5.1 Employment to unemployment transition rates from one year to the next, in four Nordic countries, 2000-07.percentages

Denmark, Norway and Sweden all had increasing figures up to 2003-04, whereas the Finnish curve started to bend down already from 2001-02. After the peak, the decline was particularly strong in Denmark, with the transition rate reaching approximately the same level as in Finland and Sweden by 2005-06 (actually even lower). Norway also shows successively lower figures from 2003-04. The Finnish and Swedish curves are quite close to one another from that same point in time. Another thing to mention is that the Norwegian curve is located below the other three throughout the whole period.

Diagram 5.2 presents the patterns regarding transitions from unemployment to employment. As we can see, there is relatively little intranational variation across time. With some exceptions, the cross-national differences are more or less the same during the entire period. The Finnish and Swedish figures are lower than those for both Norway and Denmark throughout. Sweden has a somewhat higher rate than Finland most of the years. Moreover, the Danish rate surpasses the Norwegian in 2005-06, in spite of the fact that Norway has a higher average for the period as a whole. As we do not yet have Danish data for 2006-07, we cannot tell whether the 2005-06 result is a one-off affair or not. 


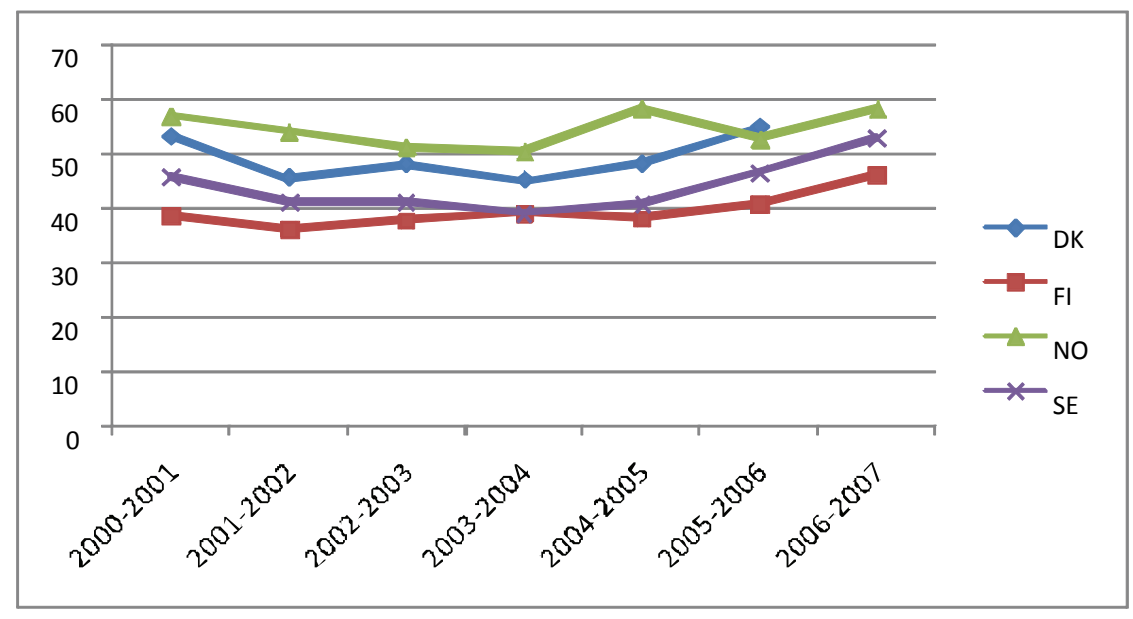

Diagram 5.2 Unemployment to employment transition rates from one year to the next, in four Nordic countries, 2000-07.percentages

There is also some mobility from employment to inactivity. We should recall that individuals older than 63 years at $T_{1}$ are not included in the data set. Accordingly, retirement at age 65, which often is considered to be the normal retirement age, is not included. However, those who stop working earlier appear in our data. It must also be pointed out that many transitions from employment to inactivity are due to the fact that people enter education.

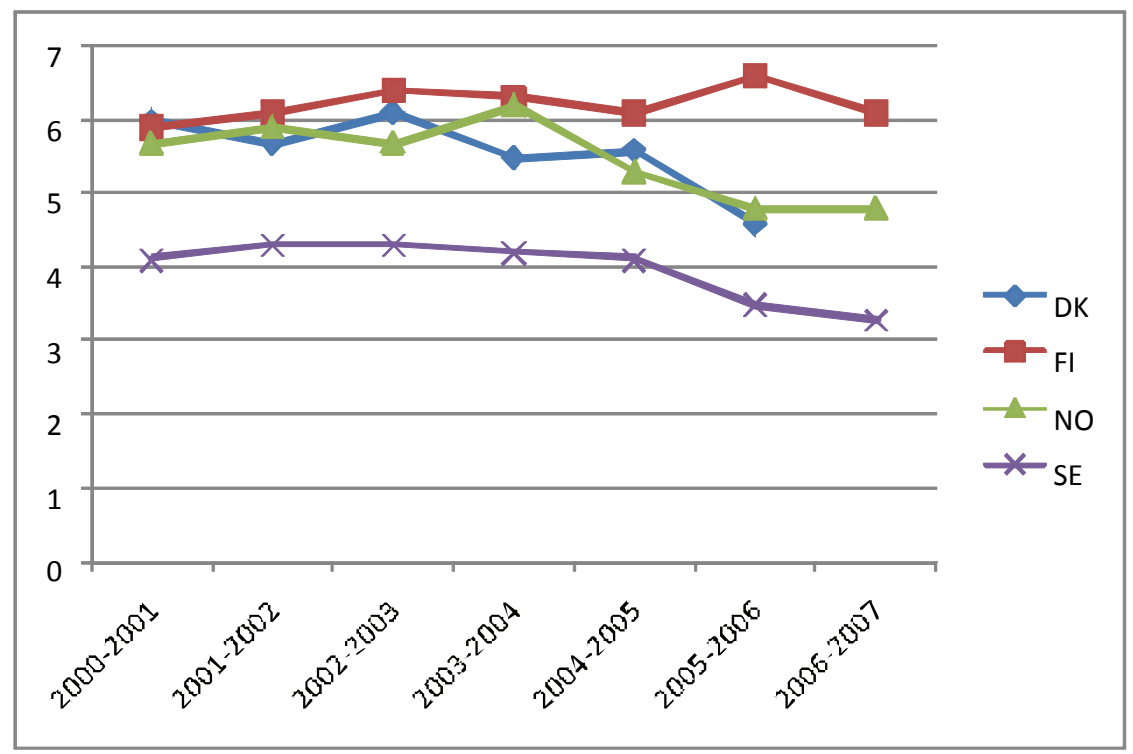

Diagram 5.3 Employment to inactivity transition rates from one year to the next, in four Nordic countries, 2000-07.percentages

Diagram 5.3 shows the rates regarding transitions from employment to inactivity. In general, the Finnish rates are highest and the gap in relation to those of the other three countries is particularly large towards the end 
of the period. Although partly rather close to the Finnish curve, the Danish and Norwegian levels interchangeably rank second and third. Sweden, on the other hand, shows considerably lower rates the whole way.

Finally, Diagram 5.4 deals with changes from inactivity to employment. In this case, Norway has the highest average and the Norwegian curve is located above those for the other three all the time. Denmark has the second highest mean and the transition rate is close to the Norwegian on five of the six occasions under comparison. In contrast, Finland and Sweden have lower transition rates than Norway and Denmark throughout. The curves cross one another at two points in time and the end result is that the two countries have the same averages.

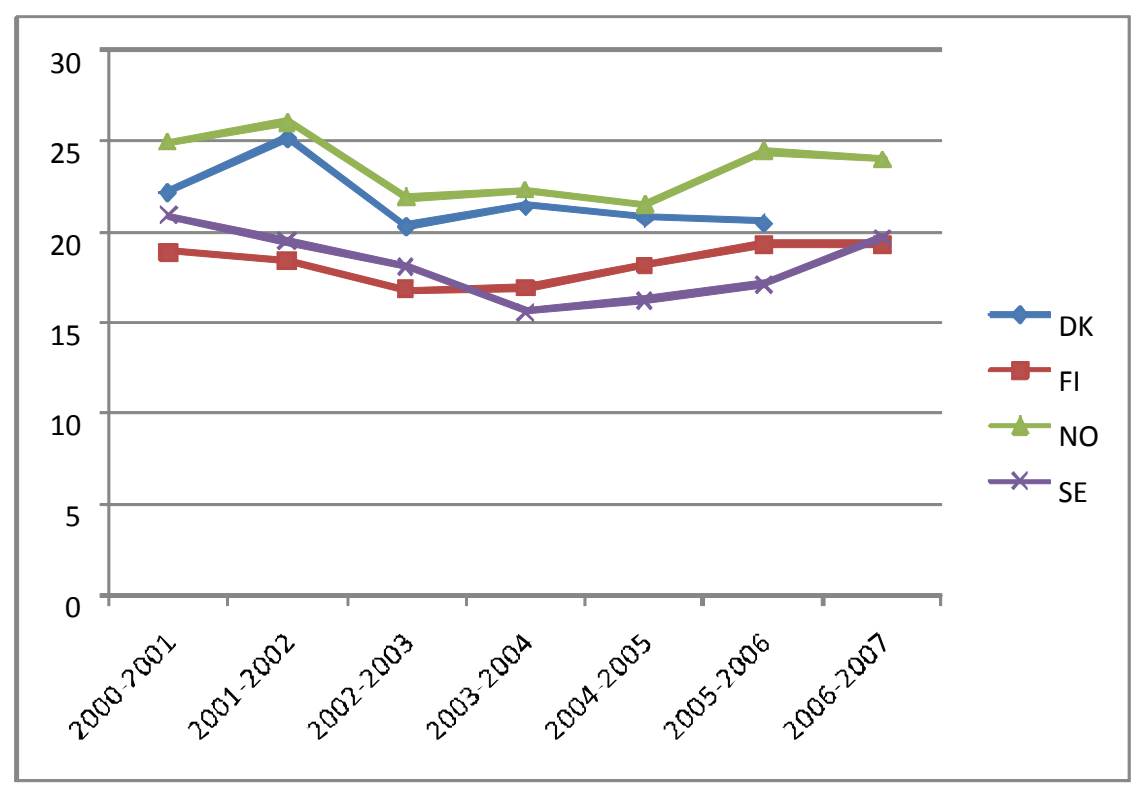

Diagram 5.4 Inactivity to employment transition rates from one year to the next, in four Nordic countries, 2000-07.percentages

From the general descriptive statistics presented in this section it is obvious that there are clear differences in mobility levels between the four Nordic countries. By comparison with the other two countries, Denmark and Finland both have high rates concerning transitions from employment to non-employment, that is, unemployment and inactivity (Diagrams 5.1 and 5.3). With respect to transitions into employment, we most often find Norway together with Denmark at the top (Diagrams 5.2 and 5.4). Norway also stands out with high levels of "positive" mobility flows out of unemployment and inactivity to employment. For most of the years studied it has the highest proportions in these respects. In contrast, Sweden often has the lowest mobility rates, for example regarding transitions into and out of employment. Finland is close to Sweden on mobility from unemployment and inactivity to employment. However, quite a large part of the Finnish population, especially compared to that in Sweden, enters employment. 
The next step in the analysis is to look at the determinants behind the three types of transition rates. We ask whether these rates are related to factors such as age, sex, industry (in case of transitions from employment), etc. The perhaps most interesting question is whether the patterns are similar in the four countries or whether there are some differences associated with the specific national context.

\subsection{Determinants behind Changes}

In this section, we present a number of multinomial logistic regressions aimed at identifying crucial determinants behind some of the changes at the centre of our attention. Multinomial regressions are used, as in each case there are three options. The range of outcomes includes the following: (a) individuals can remain in the same employment status (as employed, unemployed or inactive) as one year before, and this is the reference category; (b) if employed they may become unemployed or inactive; (c) if unemployed they may become employed or inactive; and (d) if inactive they may become employed or unemployed.

There are several independent variables to be used in the regressions. Throughout, we include sex, age, marital status, children at home (except for Norway where this information is not available), national origin, education, county unemployment rates and annual changes in national employment rates. In the regressions on transitions from employment, we add industry, occupational category, type of employment, working hours and number of employees at the workplace. All these variables can be expected to have some impact at least on some of the transitions in question. In connection with each table we will discuss to what extent the results fit in with what could be expected.

Table 5.2 shows the outcome on transitions from employment to unemployment and inactivity respectively. Starting with sex, there are two main conclusions to be drawn. The patterns regarding transitions from employment to unemployment are rather inconsistent across countries. In Denmark men are less likely than women to become unemployed, in Norway it is the other way around, and Finland and Sweden show no sexsignificant differences. The second conclusion is that women tend to exit employment for inactivity more often than men do in three of the countries: Denmark, Finland and Sweden. Only Norway has no clear sex difference in this respect. 
Table 5.2 Effects of various factors on transitions from employment. Multinomial logistic regression. Odds ratios

\begin{tabular}{|c|c|c|c|c|}
\hline & \multicolumn{4}{|c|}{ To unemployment } \\
\hline & Denmark & Finland & Norway & Sweden \\
\hline \multicolumn{5}{|l|}{ Gender } \\
\hline Male & 0.85 & 0.96 n.s. & 1.21 & 1.04 n.s. \\
\hline Female (ref.) & 1 & 1 & 1 & 1 \\
\hline \multicolumn{5}{|l|}{ Age } \\
\hline $16-24$ & 0.78 & 0.70 & 1.96 & 1.12 n.s. \\
\hline $25-34$ & 1.03 n.s. & 0.79 & 1.92 & 1.00 n.s. \\
\hline $35-44$ & 1.03 n.s. & 0.93 n.s. & 1.60 & 1.07 n.s. \\
\hline $45-54$ (ref.) & 1 & 1 & 1 & 1 \\
\hline $55-63$ & 1.31 & 1.01 n.s. & 0.90 n.s. & 1.14 n.s. \\
\hline \multicolumn{5}{|l|}{ Marital status } \\
\hline Married/cohabitant (ref.) & 1 & 1 & 1 & 1 \\
\hline Single & 1.30 & 1.45 & 1.79 & 1.47 \\
\hline \multicolumn{5}{|l|}{ Children at home } \\
\hline Yes & 0.96 n.s. & 0.95 n.s. & - & 0.79 \\
\hline No (ref.) & 1 & 1 & - & 1 \\
\hline \multicolumn{5}{|l|}{ National origin } \\
\hline Natives (ref.) & 1 & 1 & 1 & 1 \\
\hline Other Nordic & 1.17 n.s. & 1.04 n.s. & 1.50 n.s. & 1.38 \\
\hline Other European/N. American & 1.35 n.s. & 0.94 n.s. & 1.38 n.s. & 2.02 \\
\hline Other & 1.58 & 1.54 & 2.84 & 2.59 \\
\hline \multicolumn{5}{|l|}{ Education } \\
\hline Primary & 1.22 & 1.62 & 2.04 & 1.37 \\
\hline Secondary & 1.01 n.s. & 1.30 & 1.35 & 1.36 \\
\hline Tertiary (ref.) & 1 & 1 & 1 & 1 \\
\hline \multicolumn{5}{|l|}{ Industry } \\
\hline Agriculture & 0.88 n.s. & 0.50 & 0.79 n.s. & 0.86 n.s. \\
\hline Manufacturing (ref.) & 1 & 1 & 1 & 1 \\
\hline Construction & 0.81 n.s. & 1.20 n.s. & 0.68 & 1.41 \\
\hline Trade, etc. & 0.81 & 0.83 & 1.00 n.s. & 1.21 \\
\hline Transport, etc. & 0.67 & 0.70 & 0.76 n.s. & 0.77 \\
\hline Finance, etc. & 0.37 & 0.36 & 0.98 n.s. & 0.83 n.s. \\
\hline Real estate, etc. & 0.86 n.s. & 1.27 & 1.30 n.s. & 1.50 \\
\hline Public administration & 0.46 & 0.65 & 0.49 & 0.63 \\
\hline Education & 0.64 & 0.61 & 0.60 & 0.61 \\
\hline Health care & 0.48 & 0.70 & 0.52 & 0.47 \\
\hline Social \& personal services & 0.88 n.s. & 0.98 n.s. & 0.91 & 0.99 n.s. \\
\hline \multicolumn{5}{|l|}{ Occupational category } \\
\hline Managers & 0.52 & 0.79 n.s. & 0.94 n.s. & 0.75 \\
\hline Professionals & 0.58 & 0.53 & 0.76 n.s. & 0.75 \\
\hline Semi-professionals & 0.78 & 0.70 & 0.73 n.s. & 0.68 \\
\hline Service workers & 1.11 n.s. & 0.82 & 1.02 n.s. & 0.85 \\
\hline Manual workers (ref.) & 1 & 1 & 1 & 1 \\
\hline \multicolumn{5}{|l|}{ Employment contract } \\
\hline Permanent (ref.) & 1 & 1 & 1 & 1 \\
\hline Temporary & 4.74 & 8.70 & 3.73 & 6.21 \\
\hline Self-employed & 0.31 & 0.53 & 0.77 n.s. & 0.61 \\
\hline \multicolumn{5}{|l|}{ Working time } \\
\hline $1-19$ & 1.42 & 1.77 & 1.14 n.s. & 1.03 n.s. \\
\hline 20-34 & 1.21 & 1.97 & 1.39 & 0.89 n.s. \\
\hline 35- (ref.) & 1 & 1 & 1 & 1 \\
\hline \multicolumn{5}{|l|}{ Size of workplace } \\
\hline 1-10 (ref.) & 1 & 1 & 1 & 1 \\
\hline $11-19$ & 0.79 & 0.81 & 0.83 n.s. & 0.79 \\
\hline 20-49 & 0.73 & 0.73 & 0.88 n.s. & 0.68 \\
\hline $50+$ & 0.52 & 0.59 & 0.72 & 0.64 \\
\hline \multicolumn{5}{|l|}{ County unemployment } \\
\hline Low (ref.) & 1 & 1 & 1 & 1 \\
\hline Medium & 1.19 & 1.03 n.s. & 0.90 n.s. & 1.33 \\
\hline High & 1.43 & 1.38 & 0.91 n.s. & 1.70 \\
\hline $\begin{array}{l}\text { Annual change in national } \\
\text { unemployment level }\end{array}$ & 1.27 & 1.35 & 1.55 & 1.42 \\
\hline
\end{tabular}


Table 5.2 Continued

\begin{tabular}{|c|c|c|c|c|}
\hline & \multicolumn{4}{|c|}{ To inactivity } \\
\hline & Denmark & Finland & Norway & Sweden \\
\hline \multicolumn{5}{|l|}{ Gender } \\
\hline Male & 0.80 & 0.71 & 0.91 n.s. & 0.80 \\
\hline Female (ref.) & 1 & 1 & 1 & 1 \\
\hline \multicolumn{5}{|l|}{ Age } \\
\hline $16-24$ & 3.05 & 3.76 & 3.49 & 4.43 \\
\hline $25-34$ & 2.21 & 1.74 & 1.68 & 1.93 \\
\hline $35-44$ & 1.17 n.s. & 0.92 n.s. & 1.01 n.s. & 1.14 n.s. \\
\hline 45-54 (ref.) & 1 & 1 & 1 & 1 \\
\hline $55-63$ & 5.69 & 4.25 & 2.91 & 3.57 \\
\hline \multicolumn{5}{|l|}{ Marital status } \\
\hline Married/cohabitant (ref.) & 1 & 1 & 1 & 1 \\
\hline Single & 1.09 n.s. & 1.15 & 1.42 & 1.17 \\
\hline \multicolumn{5}{|l|}{ Children at home } \\
\hline Yes & 0.83 & 1.47 & - & 0.75 \\
\hline No (ref.) & 1 & 1 & - & 1 \\
\hline \multicolumn{5}{|l|}{ National origin } \\
\hline Natives (ref.) & 1 & 1 & 1 & 1 \\
\hline Other Nordic & 1.02 n.s. & 0.80 n.s. & 1.15 n.s. & 1.27 \\
\hline Other European/N. American & 1.50 & 1.05 n.s. & 1.33 & 1.29 \\
\hline Other & 2.42 & 1.47 & 1.63 & 1.86 \\
\hline \multicolumn{5}{|l|}{ Education } \\
\hline Primary & 1.71 & 1.40 & 1.46 & 1.38 \\
\hline Secondary & 1.34 & 1.02 n.s. & 1.14 n.s. & 1.18 \\
\hline Tertiary (ref.) & 1 & 1 & 1 & 1 \\
\hline \multicolumn{5}{|l|}{ Industry } \\
\hline Agriculture & 1.02 & 0.94 n.s. & 1.23 n.s. & 0.89 n.s. \\
\hline Manufacturing (ref.) & 1 & 1 & 1 & 1 \\
\hline Construction & 0.69 & 1.12 n.s. & 0.91 n.s. & 0.99 n.s. \\
\hline Trade, etc. & 0.83 & 0.94 n.s. & 1.22 & 0.98 n.s. \\
\hline Transport, etc. & 0.80 & 1.00 n.s. & 1.14 n.s. & 1.00 n.s. \\
\hline Finance, etc. & 0.48 & 1.02 n.s. & 0.94 n.s. & 1.30 n.s. \\
\hline Real estate, etc. & 0.85 n.s. & 1.06 n.s. & 1.32 & 1.09 n.s. \\
\hline Public administration & 0.85 n.s. & 1.17 n.s. & 1.30 & 1.06 n.s. \\
\hline Education & 0.91 n.s. & 1.08 n.s. & 1.15 n.s. & 0.96 n.s. \\
\hline Health care & 0.97 n.s. & 1.23 & 1.14 n.s. & 0.81 \\
\hline Social \& personal services & 0.86 n.s. & 1.15 n.s. & 1.36 & 1.03 n.s. \\
\hline \multicolumn{5}{|l|}{ Occupational category } \\
\hline Managers & 0.65 & 0.58 & 0.53 & 0.87 n.s. \\
\hline Professionals & 0.57 & 0.54 & 0.47 & 0.84 \\
\hline Semi-professionals & 0.63 & 0.71 & 0.65 & 0.93 n.s. \\
\hline Service workers & 0.97 n.s. & 0.73 & 0.84 & 1.10 n.s. \\
\hline Manual workers (ref.) & 1 & 1 & 1 & 1 \\
\hline \multicolumn{5}{|l|}{ Employment contract } \\
\hline Permanent (ref.) & 1 & 1 & 1 & 1 \\
\hline Temporary & 2.66 & 2.65 & 2.11 & 3.35 \\
\hline Self-employed & 0.81 & 0.70 & 1.17 n.s. & 0.98 n.s. \\
\hline \multicolumn{5}{|l|}{ Working time } \\
\hline $1-19$ & 3.06 & 2.37 & 2.69 & 2.53 \\
\hline $20-34$ & 1.52 & 1.73 & 1.54 & 1.68 \\
\hline $35-$ (ref.) & 1 & 1 & 1 & 1 \\
\hline \multicolumn{5}{|l|}{ Size of workplace } \\
\hline $1-10$ (ref.) & 1 & 1 & 1 & 1 \\
\hline $11-19$ & 0.97 n.s. & 0.80 & 0.87 & 0.79 \\
\hline $20-49$ & 0.92 n.s. & 0.84 & 1.07 n.s. & 0.80 \\
\hline $50+$ & 0.77 & 0.79 & 0.96 n.s. & 0.79 \\
\hline \multicolumn{5}{|l|}{ County unemployment } \\
\hline Low (ref.) & 1 & 1 & 1 & 1 \\
\hline Medium & 1.07 n.s. & 1.04 n.s. & 1.01 n.s. & 1.02 n.s. \\
\hline High & 1.13 & 1.11 & 1.07 n.s. & 1.07 n.s. \\
\hline $\begin{array}{l}\text { Annual change in national } \\
\text { unemployment level }\end{array}$ & 1.19 & 1.04 n.s. & 1.17 & 1.18 \\
\hline Nagelkerke $\mathrm{R}^{2}$ & 0.16 & 0.18 & 0.16 & 0.19 \\
\hline $\mathrm{N}$ & 51,506 & 78,939 & 47,383 & 106,012 \\
\hline
\end{tabular}

No sign $=p<0.05 ;$ n.s. $=$ not significant. 
When analysing mobility, age is a very important factor. This also holds true for the present data set. In all four countries, transitions to inactivity are particularly common both among the two youngest categories (aged 16-24 and 25-34 years) and among the oldest workers (aged 55-63 years). Generally, the younger are inclined to go into education and the older to retire. However, concerning flows from employment to unemployment some notable cross-national differences appear. Denmark and Finland resemble each other in terms of low risks among the youngest to become unemployed. For Norway we find enhanced odds for all those who are younger than the reference category, whereas in Sweden there are no significant age differences at all.

These age patterns do not correspond to the general belief that young age is associated with a greater risk of unemployment. This belief is based on the fact that employment protection legislation is aimed at protecting employees with longer tenure. However, age is strongly related to type of employment. Temporary jobs are much more common among youths than among others. Thus, not controlling for type of employment makes some of the cross-national differences disappear. The most noteworthy effect is that the two youngest age categories then get higher odds than the reference category in all the regressions. Still, the coefficients for the youngest are particularly low in Denmark, which probably has to do with its weak employment protection legislation and, accordingly, the rather limited need among employers to hire people on temporary contracts.

We also have two family-related variables; they refer to marital status and to whether or not people have children under the age of 18 years at home. The latter variable is not, however, available in the Norwegian data set. Singles generally have a higher risk of being unemployed one year after the first observation, which is in line with what we might have expected. Except for Denmark, they also tend to become inactive more frequently than married or cohabitant individuals. Furthermore, we might suppose that employed individuals with children at home have a lower risk of switching from jobs to unemployment or inactivity. This hypothesis is confirmed empirically only in Sweden; Denmark and Finland both fall short of such expectations and Norway is not included in the analysis. However, we must note that there can be interaction effects between the variables gender and children at home. For example, it is possible that the risk of inactivity is higher for women than for men when they both have children at home. Such aspects have not been analyzed in the present chapter.

With respect to country of origin, there are some things to note. In all four countries, the category "other" has a clearly elevated risk of showing up in unemployment and inactivity one year later. However, the odds ratio for this category differs somewhat across the countries, with lower rates of transition to unemployment in Denmark and Finland compared to 
Norway and Sweden. Similarly, the odds ratio for transitions to inactivity is higher for "others" in Denmark than in the other three countries. In Sweden there is greater risk of transition to unemployment or inactivity for all non-natives, although the size of the coefficients is dependent on where people come from. We could also register the lack of significant differences between Nordic immigrants and natives in Denmark, Norway and Finland.

In all the regressions, we find higher odds of being unemployed or inactive at $T_{2}$ among people with primary education compared to the reference category (individuals with tertiary education). Such a pattern is basically in line with the idea that education is a crucial factor behind people's human capital on the labour market, affecting their chances for secure jobs. However, the differences across educational categories regarding odds for transitions to unemployment are smallest in the Danish context. This indicates that the unemployment risk is to a lesser degree structured by education in Denmark than in the other countries, that is, the risk is more evenly distributed. On the other hand, the transitions into inactivity are more strongly related to education in Denmark than in the three other cases.

The next five variables are all related to people's jobs. Industry is the first and Manufacturing is here taken as the reference category. As we can see, most coefficients are lower than 1 , although often statistically non-significant. In Denmark, no other industry has higher odds than Manufacturing or even the same, whereas a few such cases appear in all the other countries. In Sweden, the relative risk of being unemployed at $\mathrm{T}_{2}$ is particularly high for individuals who have had jobs in Real estate, etc. and Construction. At the same time, patterns regarding industry are affected by type of employment, especially in Finland and Norway. When this variable is left out of the analysis, the risk of transitions to inactivity increases in industries in which the public sector dominates. This suggests that temporary contracts have a significant role for creating flexibility in the public sector.

As regards occupation, manual workers have been selected as the reference category. All other categories have either lower odds for unemployment and inactivity or higher but statistically non-significant odds (three cases). There are some inconsistencies, but on the whole these results fit in with the patterns found in connection with education.

Type of employment is indeed an important factor. A distinction is made between employees on permanent (open-ended) contracts, employees on temporary (fixed-term) contracts, and self-employed. The first category is the reference category. As expected, the odds of being unemployed or inactive are much higher for temporary workers and this holds everywhere. The self-employed generally have lower odds, but there are some exceptions in Norway and Sweden. As has been described above (see Chapter 2), temporary contracts are more common in Finland and 
Sweden. The analysis also shows that in these two countries the relative risk among people in temporary jobs of becoming unemployed is much greater than in Denmark and Norway.

Working time is a related variable, insofar as shorter hours can be said to entail being in a more peripheral position at the workplace. To some extent, the results resemble those on type of employment. It is most frequently those with shorter hours who run the greatest risk of being unemployed or inactive after one year. Yet, concerning transitions to unemployment, the Norwegian and Swedish patterns do not correspond to such a picture. In these countries, shorter part-time work may not be regarded as "atypical employment" involving more risky employment conditions (see Chapter 7).

Size of workplace is an important variable, but the classification does not embrace as many categories as we would have liked to have. The reason is the lack of detail in this respect in the Danish data set, in which no further divisions can be made for workplaces having 50 or more employees. We have thus simply adjusted the whole data set to the Danish classification. Still, the main pattern is that larger workplaces are associated with lower risks of being unemployed or inactive after one year from the first observation. This is hardly surprising, as larger units can be expected to provide more stable employment. For Norway, we find one exception from this pattern; there is no significant relationship between size of workplace and transitions to inactivity.

Finally, we have two variables on unemployment. The first measures unemployment rates at the county level. For each country these rates are divided into three categories - low, medium and high - and this is done in relative terms. In other words, the classification is done within each country relative to the unemployment level in the country (see Chapter 4 and Appendix B for more details). The second variable is a measure of changes in national unemployment rates (inpercentage points) from one year to the next, and this variable is treated as continuous. An odds ratio above 1 indicates an increased risk of the transition in question and an odds ratio below 1 indicates a decreased risk. As we expected, the relative county unemployment level is generally associated with an elevated risk of becoming unemployed. However, Norway does not fit in with expectations; we do not find any significant effect of that kind there. Regarding mobility to inactivity, the impact of county unemployment level is not very clear-cut. The outcome on the second variable is more unambiguous. An increase in the national unemployment rate by onepercentage point means an increased risk of being unemployed or inactive at $T_{2}$. Finland represents an exception in this respect by showing no significant association for transitions to inactivity.

The next task is to examine the transitions from unemployment from one year to another. In this case, the possible destinations are employment and inactivity. As the unemployed have no job, the work-related 
variables in Table 5.2 are excluded, but the other independent variables are the same. Table 5.3 presents the outcome.

Concerning sex, the results are similar in all four countries. Males tend less often to be employed or inactive at $T_{2}$, that is, they are less likely than women to leave unemployment for a job and to move out of the labour force, for example to enrol in education. Also the age pattern is rather distinct. The two youngest categories have higher odds in all but one regression (mobility into inactivity among Norwegians aged 25-34) to make transitions either to employment or to inactivity. The oldest category (aged 55-63 years) has lower odds of being employed one year later (although the coefficient is not significant in Norway). With respect to mobility to inactivity, the oldest category has higher odds than the reference category in Denmark and Finland but not in Norway and Sweden. This pattern is probably associated with differences in the pension systems and with the higher employment rates for the oldest age group in the latter two countries.

Table 5.3 Effects of various factors on transitions from unemployment. Multinomial logistic regression. Odds ratios

\begin{tabular}{|c|c|c|c|c|}
\hline & \multicolumn{4}{|c|}{ To employment } \\
\hline & Denmark & Finland & Norway & Sweden \\
\hline \multicolumn{5}{|l|}{ Gender } \\
\hline Male & 0.83 & 0.79 & 0.72 & 0.87 \\
\hline Female (ref.) & 1 & 1 & 1 & 1 \\
\hline \multicolumn{5}{|l|}{ Age } \\
\hline $16-24$ & 2.95 & 2.51 & 1.98 & 2.43 \\
\hline $25-34$ & 2.05 & 1.82 & 1.78 & 1.91 \\
\hline $35-44$ & 1.38 & 1.27 & 0.99 n.s. & 1.48 \\
\hline 45-54 (ref.) & 1 & 1 & 1 & 1 \\
\hline $55-63$ & 0.52 & 0.42 & 0.72 n.s. & 0.60 \\
\hline \multicolumn{5}{|l|}{ Marital status } \\
\hline Married/cohabitant (ref.) & 1 & 1 & 1 & 1 \\
\hline Single & 0.83 & 0.73 & 0.68 & 0.79 \\
\hline \multicolumn{5}{|l|}{ Children at home } \\
\hline Yes & 1.35 & 1.16 & - & 1.24 \\
\hline No (ref.) & 1 & 1 & - & 1 \\
\hline \multicolumn{5}{|l|}{ National origin } \\
\hline Natives (ref.) & 1 & 1 & 1 & 1 \\
\hline Other Nordic & 2.47 n.s. & 0.69 n.s. & 0.70 n.s. & 1.39 n.s. \\
\hline Other European/N. Amer. & 0.91 n.s. & 0.77 n.s. & 0.50 & 0.60 \\
\hline Other & 0.77 n.s. & 0.67 & 0.73 n.s. & 0.58 \\
\hline \multicolumn{5}{|l|}{ Education } \\
\hline Primary & 1.00 n.s. & 0.67 & 0.61 & 0.60 \\
\hline Secondary & 1.04 n.s. & 0.84 & 0.90 & 0.77 \\
\hline Tertiary (ref.) & 1 & 1 & 1 & 1 \\
\hline \multicolumn{5}{|l|}{ County unemployment } \\
\hline Low (ref.) & 1 & 1 & 1 & 1 \\
\hline Medium & 0.90 n.s. & 0.94 n.s. & 0.71 n.s. & 0.86 n.s. \\
\hline High & 0.72 & 0.74 & 0.51 & 0.72 \\
\hline \multicolumn{5}{|l|}{ Annual change in national } \\
\hline unemployment level & 0.83 & 0.76 & 0.82 n.s. & 0.73 \\
\hline
\end{tabular}


Table 5.3 continued

\begin{tabular}{|c|c|c|c|c|}
\hline & \multicolumn{4}{|c|}{ To inactivity } \\
\hline & Denmark & Finland & Norway & Sweden \\
\hline \multicolumn{5}{|l|}{ Gender } \\
\hline Male & 0.60 & 0.76 & 0.67 & 0.54 \\
\hline Female (ref.) & 1 & 1 & 1 & 1 \\
\hline \multicolumn{5}{|l|}{ Age } \\
\hline $16-24$ & 2.66 & 2.53 & 1.98 & 3.62 \\
\hline $25-34$ & 1.46 & 1.34 & 1.11 n.s. & 1.90 \\
\hline $35-44$ & 0.97 n.s. & 1.01 n.s. & 0.65 n.s. & 1.33 \\
\hline 45-54 (ref.) & 1 & 1 & 1 & 1 \\
\hline $55-63$ & 2.35 & 2.36 & 1.15 n.s. & 1.01 n.s. \\
\hline \multicolumn{5}{|l|}{ Marital status } \\
\hline Married/cohabitant (ref.) & 1 & 1 & 1 & 1 \\
\hline Single & 1.05 n.s. & 1.22 & 1.04 n.s. & 0.92 n.s. \\
\hline \multicolumn{5}{|l|}{ Children at home } \\
\hline Yes & 1.41 & 1.24 & - & 1.03 n.s. \\
\hline No (ref.) & 1 & 1 & - & 1 \\
\hline \multicolumn{5}{|l|}{ National origin } \\
\hline Natives (ref.) & 1 & 1 & 1 & 1 \\
\hline Other Nordic & 2.79 n.s. & 0.70 n.s. & 0.80 n.s. & 1.28 n.s. \\
\hline Other European/N. Amer. & 0.74 n.s. & 1.32 n.s. & 0.79 n.s. & 0.61 \\
\hline Other & 1.16 n.s. & 0.94 n.s. & 1.32 n.s. & 1.02 n.s. \\
\hline \multicolumn{5}{|l|}{ Education } \\
\hline Primary & 1.50 & 1.40 & 1.39 n.s. & 1.09 n.s. \\
\hline Secondary & 1.20 n.s. & 1.32 & 1.18 n.s. & 0.85 n.s. \\
\hline Tertiary (ref.) & 1 & 1 & 1 & 1 \\
\hline \multicolumn{5}{|l|}{ County unemployment } \\
\hline Low (ref.) & 1 & 1 & 1 & 1 \\
\hline Medium & 0.88 n.s. & 0.97 n.s. & 0.85 n.s. & 0.84 n.s. \\
\hline High & 0.83 n.s. & 0.84 & 0.68 n.s. & 0.75 \\
\hline \multicolumn{5}{|l|}{ Annual change in national } \\
\hline unemployment level & 1.02 n.s. & 1.11 n.s. & 0.83 n.s. & 1.00 n.s. \\
\hline Nagelkerke $\mathrm{R}^{2}$ & 0.13 & 0.11 & 0.10 & 0.11 \\
\hline $\mathrm{N}$ & 4,717 & 8,359 & 1,803 & 6,697 \\
\hline
\end{tabular}

No sign $=p<0.05 ;$ n.s. $=$ not significant.

On marital status, the results are rather inconclusive, whereas obviously children at home is a factor making people change their status in one way or the other, that is, they either find a job or leave the labour market. Unemployed Swedes with children at home, however, are not very often inactive one year later. The results regarding national origin are frequently not statistically significant, which is associated with the fact that most of the categories are small. Thus we find no significant effects for Denmark and only one for Finland and Norway. In Sweden, individuals born outside the Nordic countries are less likely to be employed at $T_{2}$.

Education appears to generate similar results as were found in table 5.2 concerning transitions from unemployment to employment. In contrast to the other three countries, no differences are found between educational levels in Denmark. In Finland, Norway and Sweden, mobility from unemployment to employment is evidently structured by education and unemployed individuals with primary or secondary schooling have lower odds to get a job. Focusing on transitions to inactivity, we discover that the unemployed with merely primary schooling are relatively more often inactive at $\mathrm{T}_{2}$ in Denmark and Finland. In Norway and Sweden there are no statistically significant effects in this regard. 
The impact of the unemployment variables turns out to be in line with expectations. In some respects the patterns are similar in all the countries. High county unemployment lowers the chances of having employment at the second observation. The same holds for increasing national unemployment, although in that case we find no statistically reliable outcome for Norway. Generally, the pattern of the variable is similar with respect to transitions to inactivity, but it is not equally straightforward in all the four countries.

Table 5.4 shows the results from the multinomial regressions on what has happened to people who were from the beginning, at $T_{1}$, outside the labour force. If they have not kept their status, they have become either employed or unemployed. The independent variables are the same as in Table 5.3 but with one addition, which is a classification of inactive people as to why they are inactive. Among other things, these individuals may be students, home-working or military conscripts. Somewhat more surprising is the category "searching for job", as people who actually look for work are usually classified as unemployed. This seems to be an inconsistency in the labour force surveys. It should also be mentioned that the category "other" includes individuals who are early retirees or who have got a sickness pension. Moreover, the category contains inmates in mental hospitals, prisons and other institutions.

The differences between men and women are small and we cannot see any clear sex patterns. In contrast, some of the age patterns are very distinct. It is the younger categories (all three with lower age than the reference category) that have most often become employed, which is of course precisely what we would expect. The second youngest also frequently become unemployed, but this does not hold for the 16-24-year-olds, who probably remain in the educational system if they do not get a job. In all four countries, the oldest category (aged 55-63 years) has lower odds both to become employed and to become unemployed; these individuals thus tend to be relatively stable in their position outside the labour force.

Inactive singles are less likely than married or cohabitant people to be employed at $\mathrm{T}_{2}$. In Denmark and Finland they tend to be unemployed, but in Norway and Sweden there are no statistically significant differences in this respect. The variable on children at home is not included in the Norwegian data set, but it is available in the other three. This factor does not seem to matter in the Danish case, whereas the results in Finland and Sweden point in opposite directions. Having children at home means lower odds to be employed or unemployed in Finland and higher in Sweden. However, it is possible that interaction effects between gender and children at home are at work. 
Table 5.4 Effects of various factors on transitions from inactivity. Multinomial logistic regression. Odds ratios

\begin{tabular}{|c|c|c|c|c|}
\hline & \multicolumn{4}{|c|}{ To employment } \\
\hline & Denmark & Finland & Norway & Sweden \\
\hline \multicolumn{5}{|l|}{ Gender } \\
\hline Male & 1.05 n.s. & 0.84 & 0.96 n.s. & 1.01 n.s. \\
\hline Female (ref.) & 1 & 1 & 1 & 1 \\
\hline \multicolumn{5}{|l|}{ Age } \\
\hline $16-24$ & 2.17 & 1.78 & 2.29 & 2.32 \\
\hline $25-34$ & 2.22 & 2.65 & 2.96 & 2.82 \\
\hline $35-44$ & 1.36 & 2.09 & 1.86 & 2.04 \\
\hline 45-54 (ref.) & 1 & 1 & 1 & 1 \\
\hline $55-63$ & 0.18 & 0.20 & 0.56 & 0.37 \\
\hline \multicolumn{5}{|l|}{ Marital status } \\
\hline Married/cohabitant (ref.) & 1 & 1 & 1 & 1 \\
\hline Single & 0.88 & 0.64 & 0.70 & 0.76 \\
\hline \multicolumn{5}{|l|}{ Children at home } \\
\hline Yes & 1.10 n.s. & 0.83 & - & 1.13 \\
\hline No (ref.) & 1 & 1 & - & 1 \\
\hline \multicolumn{5}{|l|}{ National origin } \\
\hline Natives (ref.) & 1 & 1 & 1 & 1 \\
\hline Other Nordic & 0.44 & 1.40 & 1.04 n.s. & 0.84 n.s. \\
\hline Other European/N.American & 0.61 & 0.72 n.s. & 0.94 n.s. & 0.76 \\
\hline Other & 0.56 & 0.70 & 0.81 & 0.60 \\
\hline \multicolumn{5}{|l|}{ Education } \\
\hline Primary & 0.64 & 0.43 & 0.46 & 0.53 \\
\hline Secondary & 0.77 & 0.72 & 0.62 & 0.91 n.s. \\
\hline Tertiary (ref.) & 1 & 1 & 1 & 1 \\
\hline \multicolumn{5}{|l|}{ Inactivity categories } \\
\hline Student (ref.) & 1 & 1 & 1 & 1 \\
\hline Home-working & 0.52 & 0.56 & 0.59 & 0.73 \\
\hline Searching for job & 1.63 & 1.42 & 1.64 & 1.58 \\
\hline Military service & 5.23 & 4.50 & 3.18 & 2.66 \\
\hline Other & 0.36 & 0.36 & 0.31 & 0.22 \\
\hline \multicolumn{5}{|l|}{ County unemployment } \\
\hline Low (ref.) & 1 & 1 & 1 & 1 \\
\hline Medium & 1.05 n.s. & 0.88 & 0.99 n.s. & 0.85 \\
\hline High & 1.00 n.s. & 0.77 & 1.05 n.s. & 0.77 \\
\hline $\begin{array}{l}\text { Annual change in national } \\
\text { unemployment level }\end{array}$ & 0.93 n.s. & 0.79 & 0.96 n.s. & 0.82 \\
\hline
\end{tabular}


Table 5.4 continued

\begin{tabular}{|c|c|c|c|c|}
\hline & \multicolumn{4}{|c|}{ To unemployment } \\
\hline & Denmark & Finland & Norway & Sweden \\
\hline \multicolumn{5}{|l|}{ Gender } \\
\hline Male & 1.05 n.s. & 0.92 n.s. & 1.09 n.s. & 1.20 \\
\hline Female (ref.) & 1 & 1 & 1 & 1 \\
\hline \multicolumn{5}{|l|}{ Age } \\
\hline $16-24$ & 1.29 n.s. & 0.99 n.s. & 1.20 n.s. & 0.97 n.s. \\
\hline $25-34$ & 1.69 & 1.88 & 1.59 & 1.37 \\
\hline $35-44$ & 1.29 n.s. & 1.42 & 1.30 n.s. & 1.44 \\
\hline 45-54 (ref.) & 1 & 1 & 1 & 1 \\
\hline $55-63$ & 0.27 & 0.31 & 0.26 & 0.54 \\
\hline \multicolumn{5}{|l|}{ Marital status } \\
\hline Married/cohabitant (ref.) & 1 & 1 & 1 & 1 \\
\hline Single & 0.82 & 0.79 & 1.27 n.s. & 0.98 n.s. \\
\hline \multicolumn{5}{|l|}{ Children at home } \\
\hline Yes & 1.02 n.s. & 0.75 & - & 1.34 \\
\hline No (ref.) & 1 & 1 & - & 1 \\
\hline \multicolumn{5}{|l|}{ National origin } \\
\hline Natives (ref.) & 1 & 1 & 1 & 1 \\
\hline Other Nordic & 1.13 n.s. & 1.39 n.s. & 0.51 n.s. & 0.78 n.s. \\
\hline Other European/N.American & 1.10 n.s. & 1.49 n.s. & 1.69 & 1.26 \\
\hline Other & 0.78 n.s. & 1.55 & 1.32 n.s. & 1.35 \\
\hline \multicolumn{5}{|l|}{ Education } \\
\hline Primary & 0.59 & 0.79 & 0.73 & 0.88 n.s. \\
\hline Secondary & 0.74 & 0.91 n.s. & 0.66 & 1.13 n.s. \\
\hline Tertiary (ref.) & 1 & 1 & 1 & 1 \\
\hline \multicolumn{5}{|l|}{ Inactivity categories } \\
\hline Student (ref.) & 1 & 1 & 1 & 1 \\
\hline Home-working & 0.25 & 0.61 & 0.86 n.s. & 0.92 n.s. \\
\hline Searching for job & 2.99 & 2.31 & 4.69 & 2.57 \\
\hline Military service & 1.86 n.s. & 3.13 & 2.73 & 1.83 \\
\hline Other & 0.43 & 0.26 & 0.39 & 0.14 \\
\hline \multicolumn{5}{|l|}{ County unemployment } \\
\hline Low (ref.) & 1 & 1 & 1 & 1 \\
\hline Medium & 1.07 n.s. & 1.14 & 1.08 n.s. & 1.15 \\
\hline High & 1.14 n.s. & 1.17 & 1.19 n.s. & 1.24 \\
\hline \multicolumn{5}{|l|}{ Annual change in national } \\
\hline unemployment level & 1.08 n.s. & 0.95 n.s. & 1.20 & 0.89 \\
\hline Nagelkerke $\mathrm{R}^{2}$ & 0.33 & 0.27 & 0.21 & 0.24 \\
\hline $\mathrm{N}$ & 11,642 & 31,959 & 12,036 & 26,673 \\
\hline
\end{tabular}

No sign $=p<0.05 ;$ n.s. $=$ not significant.

Generally, being born outside Europe and North America is associated with smaller chances of being employed at the second observation. The same holds for people originating from other non-Nordic countries (other European/North American) in Denmark and Sweden, and in Denmark also for people from other Nordic countries.

Education is again a significant factor. By and large, its relationship to the two kinds of mobility implies that primary and quite often also secondary education decreases the likelihood of becoming employed or unemployed. However, it might be observed that Sweden is an exception with respect to mobility into joblessness.

Turning then to the variable "inactivity categories", we find two categories with significantly higher odds than the reference category (students) of being both employed and unemployed: those searching for jobs and those involved in military services. The Danish figure on conscripts' transitions to unemployment is not, though, statistically significant. For 
the home-working and the category "other", odds are most often below that of the reference category and frequently very much below it.

The unemployment variables seem to have no impact at all in Denmark, and in Norway it is only increases in national unemployment that step up the risk of becoming unemployed. In contrast, we discover clear effects in Finland and Sweden and these effects are rather similar. Higher county levels of unemployment lower the chances of being employed, but increase the risk of being unemployed. A rise in the national figures tends to decrease the odds of becoming employed and - in the Swedish case also of becoming unemployed.

\subsection{Predicted Probabilities for Transitions}

In this section, we present the probabilities for transitions for a few selected categories, to make the analysis somewhat more tangible. The first type of transition is that between employment and unemployment, and in two diagrams (5.5 and 5.6) we concentrate on manual workers and professionals respectively. In each case, four subcategories appear covering males, females, youth and people born outside Europe and North America.

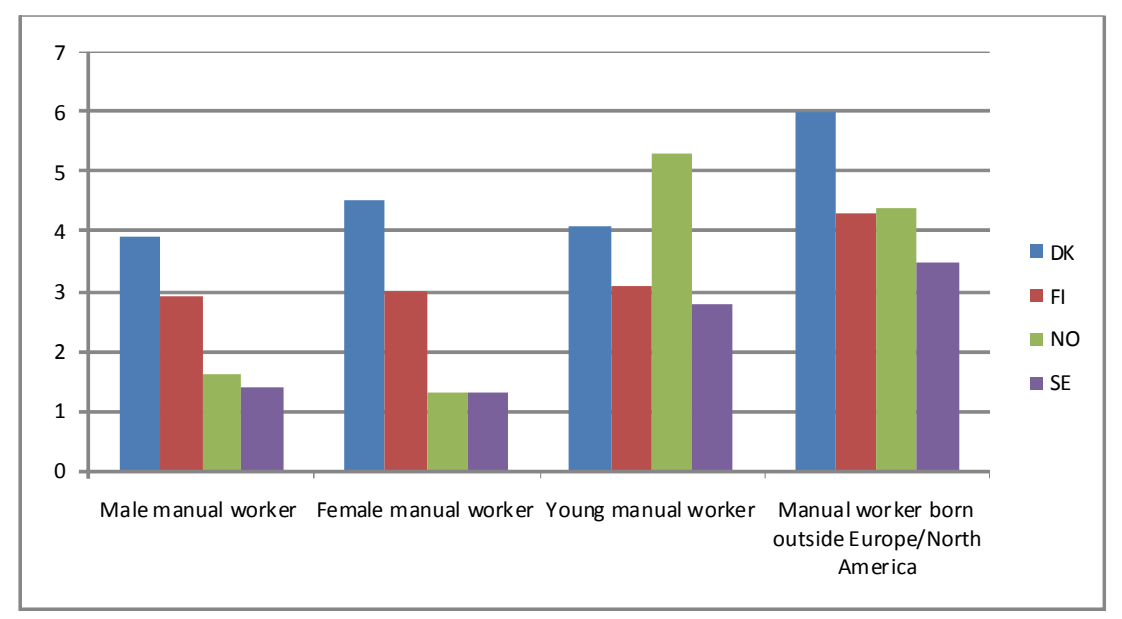

Diagram 5.5 Predicted probabilities for various categories of manual workers employed at $T_{1}$ to be unemployed at $T_{2}$.

Note: Male manual workers: 45-54 years, married, children (except for Norway), native born, primary education, employed in manufacturing, open-ended contract, weekly working hours $35+$, size of workplace $50+$, no change in national unem-

ployment rate, low county unemployment. Female manual workers: except sex, all variables equal to those for the previous category. Young manual workers: male, age 16-24 years, single, no children at home, all other variables equal to those for male manual workers. Manual workers born outside Europe/North America: except country of origin, all variables equal to those for male manual workers.

In Diagram 5.5 the four bars to the left refer to male manual workers, aged 45-54 years, employed in manufacturing and with a number of other characteristics specified under the diagram. It turns out that the probability for this category to become unemployed is much higher in Denmark 
than in any of the other three countries. The Finnish bar is the second highest, the Norwegian is third and the Swedish is the lowest. Next, we see that the pattern for women with the same characteristics is very similar. There are, however, some differences to note. The score for Danish women is higher than for Danish men. We find a similar outcome for Finland, but in this case the difference between the two sexes is small. In Norway and Sweden women have lower scores than men. The female probabilities in the latter two countries are basically the same.

As expected, the probabilities for switching from employment to unemployment are relatively high among young male workers in manufacturing (third set of bars). This is most striking for Norway but also for Sweden, whereas the female figures are in fact higher in Denmark and basically the same in Finland. Nonetheless, the score for young male manual workers in Sweden is lower than in the three other countries.

Turning to the bars furthest to the right, we find that immigrant manual workers from outside Europe and North America score the highest of all categories except in Norway, where youths are still ahead. Regarding this immigrant category, Denmark shows the highest probability rate, Norway is second, Finland third and Sweden fourth.

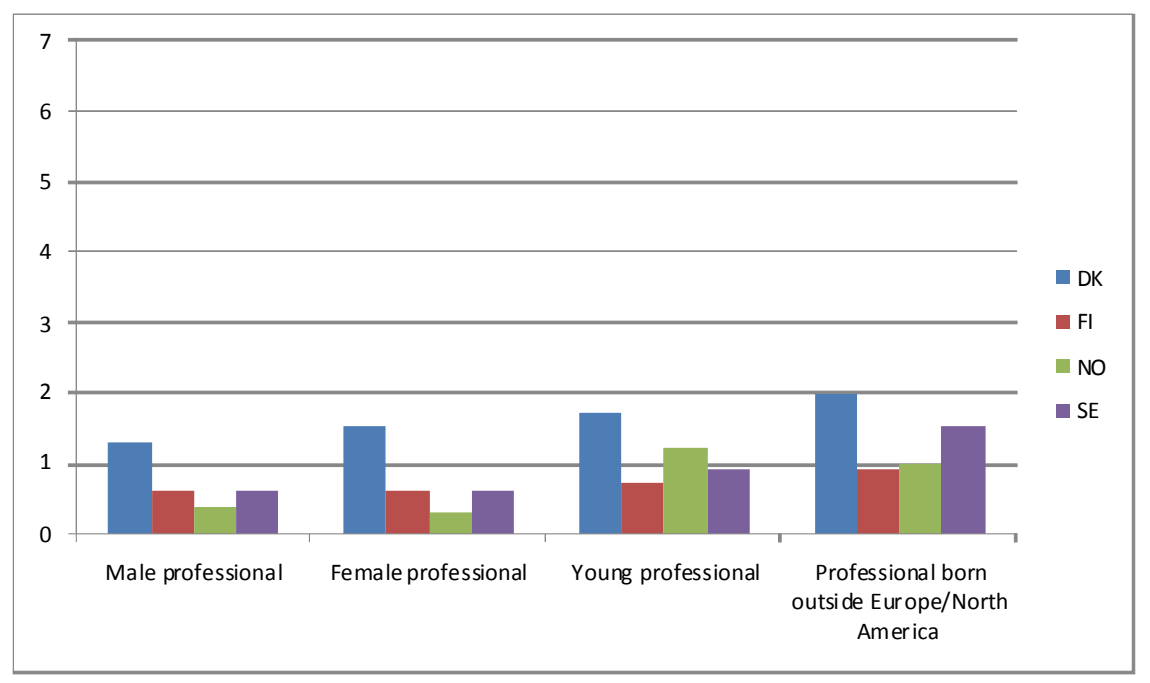

Diagram 5.6 Predicted probabilities for various categories of professionals employed at $T_{1}$ to be unemployed at $T_{2}$.

Note: Male professionals: 45-54 years, married, children (except for Norway), native born, tertiary education, employed in education, open-ended contract, weekly working hours $35+$, size of workplace $50+$, no change in national unemployment rate, low county unemployment. Female professionals: except sex, all variables equal to those for the previous category. Young professionals: male, age 25-34 years, single, no children at home, all other variables equal to those for male manual workers. Professionals born outside Europe/North America: except country of origin, all variables equal to those for male manual workers.

The most striking thing with Diagram 5.6 is that all bars are clearly lower than those in the previous diagram, and the main reason is of course that Diagram 5.6 deals with professionals in education. In this case, the youth category refers to individuals aged 24-34 years (the rationale for this should be obvious). There is no doubt that the probability of becoming 
unemployed is much lower for professionals in the educational sector than for manual workers in manufacturing. The differences between the categories in Diagram 5.6 and those in Diagram 5.5 are thus very much related to occupational category, educational level and sector of employment.

The two last sets of bars show that both young professionals and immigrant professionals from outside Europe/North America score relatively high. With respect to cross-national differences we see that the Danish bars are throughout the tallest, whereas the patterns for the other three countries are rather mixed.

Diagram 5.7 shows probabilities for various categories of unemployed to be employed one year later. In this case, as expected, bars are generally much taller than we have seen previously. As the basic category consists of unemployed individuals, there are no work-related data included, but controls for unemployment levels and changes have been carried out. In all countries, probabilities are highest for youth and lowest for the immigrant category.

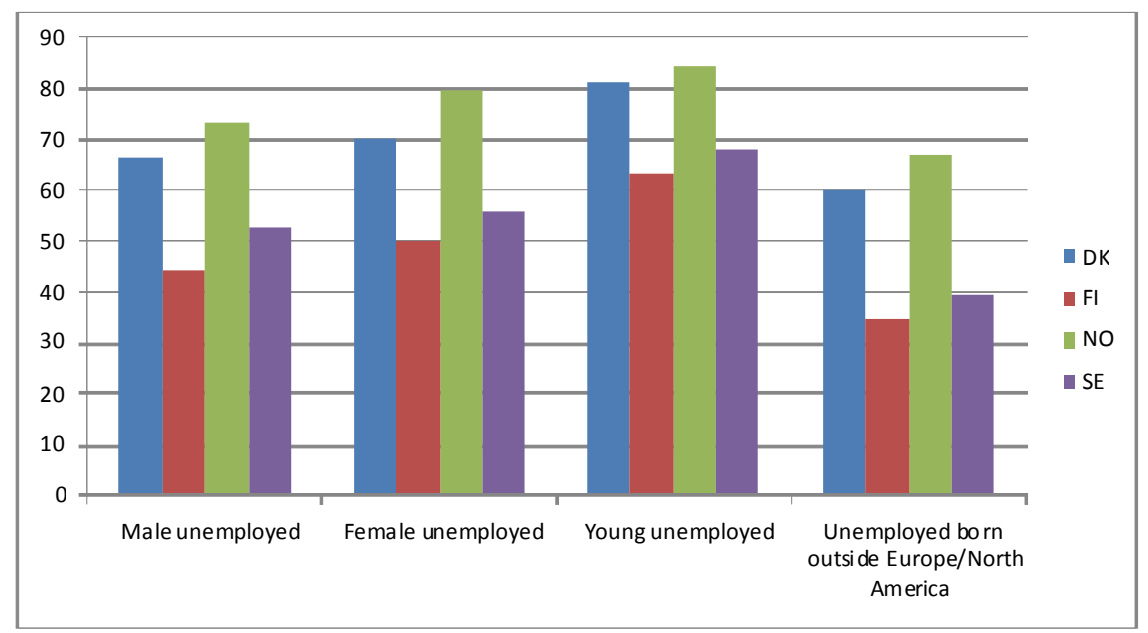

Diagram 5.7 Predicted probabilities for various categories of unemployed at $T_{1}$ to be employed at $T_{2}$.

Note: Unemployed males: 45-54 years, married, children (except for Norway), native born, primary education, no change in national unemployment rate, low county unemployment. Unemployed females: except sex, all variables equal to those for the previous category. Young unemployed: male, 16-24 years, single, no children at home, all other variables equal to those for the male unemployed. Unemployed born outside Europe/ North America: except for national origin, all variables equal to those for unemployed males.

This time, the country patterns differ from those shown in the two preceding diagrams. Norway has the tallest bars right through and Denmark is consistently second. All the way, the lowest probabilities appear for Finland and Sweden is thus third in the rank order.

The last diagram (5.8) focuses on another category, namely individuals who were students at $T_{1}$ and the probability that they have entered employment one year later. Compared to the preceding, therefore, the categories are defined differently and there are only three of them. We 
show no separate youth category, as the individuals included here are 2534 years of age. Moreover, they are single and they have no children at home.

Starting with the male category, we see that the probability of becoming employed is highest in Denmark, but Norway is not so far behind, whereas the scores for Finland and in particular Sweden are lower. Regarding females, the pattern is rather similar, but the differences between Denmark, Finland and Norway are very small. In contrast, the Swedish bar is clearly lower. Finally, for the immigrant category, Norway is at the top and Sweden clearly at the bottom. Generally, the probabilities for students born outside Europe/North America to get a job after a year are lower than for the other two categories; this holds for all four countries.

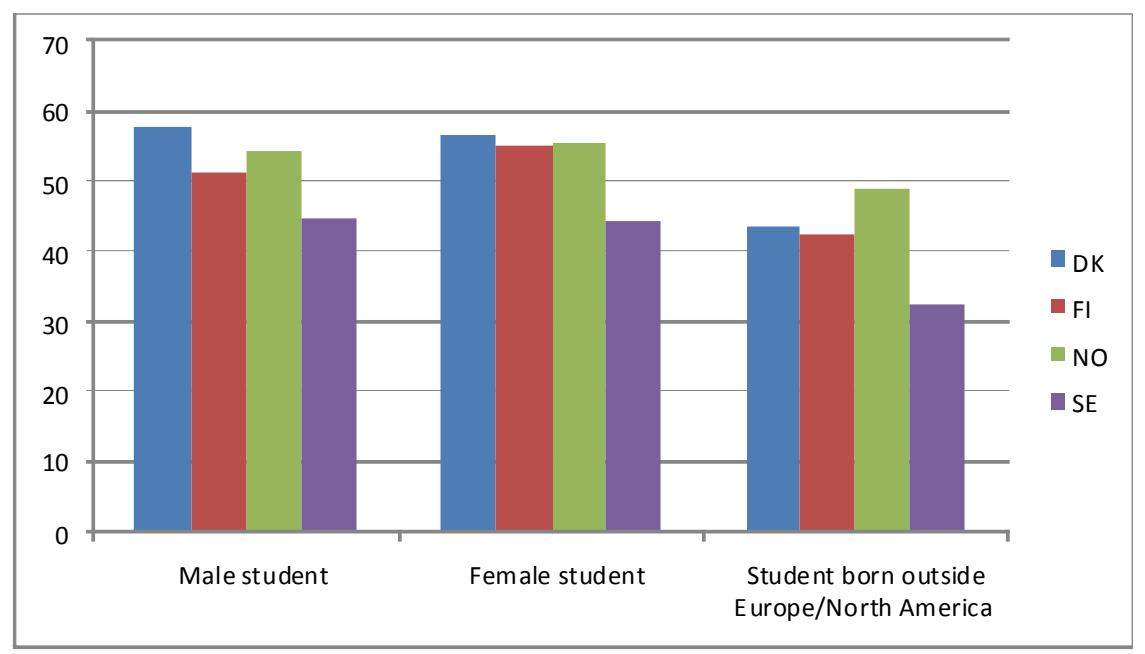

Diagram 5.8 Predicted probabilities for various categories of students at $T_{1}$ to be unemployed at $T_{2}$.

Note: Male students: 25-34 years, single, no children (except for Norway), native born, tertiary education, no change in national unemployment rate, low county unemployment. Female students: except sex, all variables equal to those for the previous category. Students born outside Europe/North America: except for national origin, all variables equal to those for male students.

As the final step in our analysis, we examine the impact of country as an independent variable while at the same time controlling for all other variables available. This will hopefully allow us to draw some more wellfounded conclusions in regard to cross-national differences.

\subsection{Country Differences}

So far we have found a great deal of cross-national differences, but the question is what happens when the data from all the countries are run in the same regressions. The idea is then to control for as much as possible of the variation caused by differences in labour force composition, industrial structure, work and employment conditions, unemployment situation, 
etc. If there is still - after controls for all other available variables - significant cross-national variation, we must ask whether it can be explained with reference to institutional arrangements in the four countries.

The following analyses all include three different models. In the first of these, country is the only dependent variable; this is the point of departure. The reference category is the mean of odds for the four countries. In the subsequent two models, a large number of control variables are stepwise taken in for the purpose of checking whether national differences - given that such differences appear-can be explained that way. In Model 3 the classification of county unemployment levels is different from that used in the regressions shown in Tables 5.2-5.4. In these regressions we have a distinction between high, medium and low county unemployment relative to the distribution in each country. Now there are still three categories, but they are defined relative to the distribution in the Nordic countries taken as a whole (for a detailed description, see Chapter 4 and Appendix B). Furthermore, it should be noted that the time span in the following tables is $2000-06$, as we have no data for Denmark regarding transitions between 2006 and 2007.

Table 5.5 focuses on transitions from employment to unemployment. Certain cross-national differences are immediately revealed. Looking first at Model 1, we see that both Denmark and Finland have higher odds than the mean for employed individuals to be unemployed at the second observation, whereas the scores are lower above all for Norway but also for Sweden. When control variables are introduced in Models 2 and 3, certain changes take place. The most striking differences in relation to Model 1 are the higher odds for Denmark and the lower odds for Finland and Sweden. Finland thus comes down to approximately the Nordic mean. Both Norway and Sweden score clearly below the mean, but with Models 2 and 3 the two countries approach each other so that in the end there is hardly any difference at all between them.

Table 5.5 Odds ratios for four Nordic countries regarding transitions from employment to unemployment, 2000-06. Binomial logistic regression

\begin{tabular}{llll}
\hline Country (ref. = mean of odds) & Model 1 & Model 2 & Model 3 \\
\hline Denmark & 1.39 & 1.52 & 1.53 \\
Finland & 1.18 & 1.11 & 0.99 n.s. \\
Norway & 0.67 & 0.69 & 0.82 \\
Sweden & 0.91 & 0.86 & 0.81 \\
\hline
\end{tabular}

No sign $=p<0.05 ;$ n.s. $=$ not significant .

Note: Model 1 includes only country as independent variable. Model 2 includes country and all the variables in Table 5.2, except children at home, county unemployment level and change in national unemployment. Model 3 includes country and all the variables in Table 5.2, except children at home and with another classification of county unemployment rates.

In Table 5.6 we examine the impact of the country variable on transitions from employment to inactivity. The three models are the same as in Table 5.5 and the patterns appearing are rather similar as well. There is, however, one obvious exception. Finland scores the highest, also after the 
controls done in Models 2 and 3, and Denmark is therefore second. Norway comes third with a coefficient close to the average, while Sweden is fourth with a significantly lower figure. In other words, employed individuals run the greatest risk of having switched into inactivity one year later in Finland and the lowest risk in Sweden.

Table 5.6 Odds ratios for four Nordic countries regarding transitions from employment to inactivity, 2000-06. Binomial logistic regression

\begin{tabular}{llll}
\hline Country (ref. = mean of odds) & Model 1 & Model 2 & Model 3 \\
\hline Denmark & 1.06 & 1.15 & 1.14 \\
Finland & 1.22 & 1.32 & 1.32 \\
Norway & 1.03 n.s. & 0.94 & 0.96 n.s. \\
Sweden & 0.75 & 0.70 & 0.69 \\
\hline
\end{tabular}

No sign $=p<0.05 ;$ n.s. $=$ not significant.

Note: See note in Table 5.5 .

Next, we will turn to cross-national differences regarding transitions from unemployment to employment. As we now deal with the unemployed, we have no information on people's jobs. The dependent variables in Table 5.7, Model 2, are thus the same as in Table 5.3, except that country is included and "children at home" and the two measures on unemployment are excluded. Model 3 is similar but we then add the reclassified variable on county unemployment and the variable on changes in national unemployment rates.

Table 5.7 Odds ratios for four Nordic countries regarding transitions from unemployment to employment, 2000-06. Binomial logistic regression

\begin{tabular}{llll}
\hline Country (ref. = mean of odds) & Model 1 & Model 2 & Model 3 \\
\hline Denmark & 1.06 n.s. & 1.16 & 1.17 \\
Finland & 0.70 & 0.64 & 0.71 \\
Norway & 1.74 & 1.66 & 1.39 \\
Sweden & 0.78 & 0.82 & 0.87 \\
\hline
\end{tabular}

No sign $=p<0.05 ;$ n.s. $=$ not significant.

Note: Model 1 includes only country as independent variable. Model 2 includes country and all the variables in Table 5.3, except children at home, unemployment level and unemployment change. Model 3 includes country and all the variables in Table 5.3, except children at home and with another classification of county unemployment rates.

Table 5.7 shows that the chances for an unemployed individual to have a job one year later are greatest in Norway, although the odds ratio decreases for each of the two models in which control variables are introduced. Denmark comes second and we can observe that with controls the Danish coefficient goes in the opposite direction as in Norway. At the same time, for Finland and Sweden the odds ratios are significantly lower than the Nordic average.

We also want to look at transitions from inactivity to employment in the same ways as for the other transitions. This is done in Table 5.8. As we now deal with the inactive population, the classification of inactivity 
categories is included. Thus Model 2 comprises the variables in Table 5.4 , with the addition of country and with the exception of "children at home" and the unemployment variables. Model 3 includes country and all the variables in Table 5.4 but with another classification of county unemployment rates and except "children at home".

Table 5.8 Odds ratios for four Nordic countries regarding transitions from inactivity to employment, 2000-06. Binomial logistic regression

\begin{tabular}{lllc}
\hline Country (ref. = mean of odds) & Model 1 & Model 2 & Model 3 \\
\hline Denmark & 1.10 & 1.37 & 1.36 \\
Finland & 0.88 & 0.87 & 0.94 \\
Norway & 1.19 & 1.13 & 1.02 n.s. \\
Sweden & 0.87 & 0.74 & 0.76 \\
\hline
\end{tabular}

No sign $=p<0.05 ;$ n.s. $=$ not significant.

Note: Model 1 includes only country as independent variable. Model 2 includes country and all the variables in Table 5.4, except children at home, county unemployment rate and change in national unemployment. Model 3 includes country and all the variables in Table 5.4, except children at home and with another classification of county unemployment rates.

In Model 1, Norway has the highest odds, with Denmark second and Finland and Sweden clearly behind. However, with the controls the outcome becomes partly different. In Models 2 and 3, Denmark has the highest odds and Norway is second. In Model 3, the Norwegian coefficient is no longer significantly different from the mean for the four countries. In contrast, the Finnish coefficient increases with the controls in Model 3, but even so it is clearly lower than that of the reference category. Simultaneously, controlling for other variables does not save Sweden from showing the lowest odds ratio of all.

It should be added that we have also done some other controls. Because age is an important variable in connection with mobility and because particularly younger and older individuals are mobility-prone - for very different reasons - we have run some regressions with only primeage individuals (aged 25-54 years). Although the results of these are very much the same, one minor thing could be mentioned. Regarding transitions from inactivity to employment as shown in Table 5.8, Finland scores significantly lower than the Nordic mean, but for the 25-54-yearolds there is no such difference. Thus, by excluding the youngest and the oldest individuals, Finland turns out to be just an average Nordic country in this respect. As for the rest of these alternative regressions, there are some increases and decreases in coefficients, but the general patterns remain intact.

\subsection{Summing up the Main Results}

We can now summarize the results in this chapter. This is done in Table 5.9 which gives the four countries a rank number with respect to the outcome in Tables 5.5-5.8. In one case, regarding transitions from employ- 
ment to unemployment, we have given Norway and Sweden the same rank, as the odds ratios presented in Table 5.5 are almost the same for the two countries.

Table 5.9 Summary of rankings in Tables 5.5-5.8

\begin{tabular}{lcccc}
\hline Transitions & Denmark & Finland & Norway & Sweden \\
\hline $\begin{array}{l}\text { From employment to } \\
\text { unemployment }\end{array}$ & 1 & 2 & 3 & 3 \\
$\begin{array}{l}\text { From employment to } \\
\text { inactivity }\end{array}$ & 2 & 1 & 3 & 4 \\
$\begin{array}{l}\text { From unemployment to } \\
\text { employment }\end{array}$ & 2 & 4 & 1 & 3 \\
$\begin{array}{l}\text { From inactivity to employ- } \\
\text { ment }\end{array}$ & 1 & 3 & 2 & 4 \\
\hline
\end{tabular}

Generally, Denmark gets the highest ranks - never below second - and Sweden the lowest - never higher than third. Finland and Norway appear somewhere in between. Undoubtedly, by and large mobility rates are higher in Denmark than in the other three countries. However, we need to make some further comments regarding the Danish pattern in relation to that for Norway. It is evidently more likely that an employed individual becomes unemployed one year later in Denmark. Such a transition is "negative" in the sense that it adds to unemployment, but it can be compensated for if transition rates in the opposite direction are high. Now, the unemployed in Denmark are rather likely to become employed, but the unemployed in Norway are even more likely to do so. In other words, the "negative" flows from employment into unemployment are lower in Norway and the "positive" flows in the opposite direction are higher. On the other hand, it seems easier for a person outside the labour force to find a job in Denmark and this is another "positive" aspect. 


\section{Transitions into and out of temporary employment}

\subsection{Introduction}

The objective of this chapter is to study transitions into and out of temporary employment in Denmark, Finland, Norway and Sweden. As in the previous chapter, the most important question in this chapter is also whether patterns of transitions differ across the four countries and whether differences can be explained with reference to the different institutional arrangements.

Temporary employment is one among several types of employment that are often referred to as "non-standard employment", "alternative work arrangements", "flexible forms of employment" or "atypical employment". These somewhat different terms refer to the fact that the employment relations differ from what is perceived to be standard work. Standard work is most often defined as full-time work of indefinite duration which is performed at the employer's place of business under the employer's direction (Kalleberg 2000:341). Temporary work differs from standard work in the sense that it is of limited duration and will terminate at a certain point of time.

In a flexicurity perspective, temporary employment is often associated with numerical flexibility, i.e. organisations' ability to change the number of employees. In some countries with strict EPL for permanent workers, temporary contracts have been used to create numerical flexibility in organisations because they can employ without the rising cost of firing. In this way organisations can more easily adapt to the changing circumstances in their environment, for example regarding demand. This use of temporary contracts as an instrument to create numerical flexibility has, however, generated great attention to the security aspect of temporary contracts. Today it is widely debated and investigated to what degree temporary contracts lead to integration or marginalisation on the labour market. The research seems to point in both directions. Supporters of the marginalisation perspective associate temporary employment with insecurity and precariousness. They see temporary employment as a "trap" or "dead-end". This means that someone working in a temporary contract is either repeatedly having temporary contracts or else finding him- or herself moving continuously between unemployment and temporary employment. Some argue that this can lead to a dual or segmented labour market with a core of permanent workers and a peripheral group of temporary employees (OECD 2002, Gash 2008). This perspective also often 
emphasizes the more unfavourable sides of temporary employment, like the lesser degree of job satisfaction, the greater risk of poverty and the inferior quality of the jobs (Booth et al. 2000a, Booth et al. 2000b, Gash 2005). On the contrary, the integrative perspective emphasizes the more positive features of temporary employment. This perspective sees temporary employment as a way of gaining access to the labour market or as an "entry port", "stepping stone" or "bridge" to more stable employment. One view of this is to regard temporary employment as a form of probationary contract where the temporary employee can prove him- or herself on the job. The employers can therefore screen the skills of the temporary workers before offering them a permanent job (Gash 2008).

In a Nordic context some research has also focused on this matter. Jouko Nätti has investigated the "bridge and trap" metaphor in Finland in the 1980s by using data from the LFS. His investigation was based on a number of retrospective questions on previous unemployment, previous job change and whether the temporary job was voluntary or not. He concluded that temporary employment in Finland has elements of both traps and bridges, and that these elements accumulate in different groups of temporary workers. According to Nätti, temporary employment most often forms a trap for those who were previously unemployed, older and less educated. On the other hand, temporary employment serves as a bridge for several groups. This is the case for young people using temporary employment as a transitory phase between studies and permanent work. It can also be the case for women in the public sector who are formally temporary employees but seem to be in rather stable positions anyhow (Nätti 1993).

Nätti's point about temporary work in Finland having elements of both traps and bridges is also found in a Swedish study from 2001 by Kristina Håkanson. In Håkanson's study a cohort of temporary workers was followed over a 4-year period, using both register-based data and LFS-data. She concluded that some forms of temporary employment (especially probational contracts) serve as stepping stones to permanent work while others (for instance seasonal work) lead to labour market segmentation. Other types of temporary contracts can serve as both stepping stones and dead ends. The report also concluded that men, older people and more educated persons are more likely than women, young people and the less educated to use temporary employment as a stepping stone to permanent work (Håkanson 2001).

In Denmark there is very limited knowledge about temporary employment and few studies have been made. One study by Tor Eriksson and Peter Jensen used data from the European Community Household Panel (ECHP) and a Nordic survey. The study was, however, mainly focused on characteristics of the temporary employees and not concerned with mobility patterns. Still, they do find a larger probability of temporary employment among those who previously were temporarily em- 
ployed (Eriksson and Jensen 2003). A recent study by Vanessa Gash also used ECHP data to investigate the "bridge and trap" metaphor. She compared Denmark to West Germany, France and the UK. However, with minor exceptions, she did not find differences between the countries for temporary workers' transition into either permanent employment or unemployment, despite differences in the institutional arrangements in the countries (Gash 2008).

A study from Norway by Kristine Neergaard used the Norwegian LFS for the years 1996-2002 to investigate whether temporary contracts in Norway lead to stable employment or marginalisation. The respondents were followed over a period of two years. One of the main conclusions in the study is that most temporary contracts actually lead to stable employment (Neergaard 2004). For Norway there is therefore evidence that temporary contracts have an integrative character.

All in all, the existing studies show that the Nordic labour markets seem to offer different conditions for temporary employees. In some countries as well as for some groups, temporary employment seems more precarious and insecure compared to others. However, none of these studies have had a comparative Nordic focus. It is therefore difficult on the basis of these studies to determine whether some Nordic countries offer better conditions for temporary employees than others. This chapter will hopefully shed some light on the matter.

When it comes to transitions to and from temporary employment, our general expectation is that liberal employment protection legislation, both for permanent and for temporary employees, lessens the differences between the categories. In a country with liberal EPL, the costs of firing permanent employees are lower, and the employers therefore need not resort to temporary labour in order to stay flexible. Since Denmark is the country with the lowest level of EPL, we therefore expect fewer transitions from a position outside employment to temporary employment here. We also expect a higher transition rate from temporary employment to permanent work in Denmark. Norway has a more strict EPL for regular workers compared to Denmark, but also a more restrictive use of temporary contracts compared to the other countries. We would therefore also for Norway expect a lesser flow into temporary employment from a position outside employment, since there are restrictions on the use of temporary contracts. When it comes to transitions to permanent employment, it is more difficult to know what to expect in the Norwegian case. However, since temporary contracts are only allowed under certain circumstances (for instance for trainees), it could point in the direction of a larger flow from temporary employment to permanent employment. Previous research supports this view (Neergaard 2004). Sweden has the most restrictive EPL for regular workers and the most liberal regulation on temporary employment. For Sweden we would therefore expect a higher flow into temporary employment from a position of not being employed, compared 
to the other countries. We would also expect fewer temporary employees to move into permanent employment in Sweden, due to the differences in EPL for permanent and temporary employees. In Finland the EPL for the regular workers are about the same as in Norway, but they have a more liberal use of temporary contracts compared to Norway. Finland could therefore resemble Sweden rather than Norway in terms of the flows into and out of temporary employment. Whether these expectations prove correct will be the object of investigation in this chapter.

We will begin the chapter by providing some information on the characteristics of the temporary employees and the temporary jobs in Denmark, Finland, Norway and Sweden (section 6.2). The aim is to determine whether there is a similar pattern in the four countries as to who are more likely to be working in temporary jobs. In section 6.3 we will examine the main flows into and out of temporary work in the four countries with descriptive statistics. In section 6.4 we present a number of multivariate analyses of factors affecting the transitions presented in section 6.3. The question to be answered is what determines the different transitions and whether the main determinants behind the transitions generally are the same in the four countries. In order to grasp the multivariate analyses better, we will in section 6.5 show some predicted probabilities for some of the transitions. Finally, we use country as an independent variable in the multivariate analyses (section 6.6). Just as in chapter 5, we attempt to rule out the impact of other factors. If country shows significant effects after controlling for other factors, we have an indication that national institutional arrangements may matter.

\subsection{Temporary employees - who are they?}

In this section we take a closer look at the characteristics of the temporary employees and the temporary jobs in Denmark, Finland, Norway and Sweden. In order to do this we have conducted four logistic regression analyses (one for each country) testing the odds of being in a temporary job compared to working in a permanent job or as self-employed at time $t$. Time $t$ is the first point of observation in our data. Logistic regression analysis has been chosen because it enables us to determine who are more likely to be temporarily employed when all other factors are held constant. In order to make the four regression models comparable we have included the same independent variables in all models. The independent variables are by large the same as those which were applied in chapter 5 - that is, age, marital status, education, national origin, gender-children ${ }^{15}$, occupational category, industry, working hours and number of employees at the workplace. Two variables on unemployment have also been in-

\footnotetext{
${ }^{15}$ Because we only have information about children for women in Norway, a combination variable of gender and children has been used in the models.
} 
cluded in the models: county unemployment and annual change in national unemployment. They are included in order to control for business trends. The outcome is shown in Table 6.1.

The main conclusion to draw from the four regression models in Table 6.1 is that the temporary employees in the four Nordic countries to a large extent share the same characteristics. With a few minor exceptions, women, persons with a non-Nordic background and persons who are not married are more likely to work in a temporary contract in all four countries. We also find a higher probability of working in a temporary contract in the lower occupational groups. A similar pattern in all four countries is also found for the industries. Working within industries like education, health care, public administration and social and personal services gives higher probabilities of temporary employment in all four countries. We also see a higher probability of temporary employment in several of the other industries than in the reference group of manufacturing, but the odds ratios are not as high here as in the aforementioned industries.

When it comes to age, we see some interesting similarities as well as differences between the countries. In all countries young people are more likely than the older age groups to be employed in temporary jobs. There seems to be a somewhat linear effect of age where the older you are, the less likely you are to work in a temporary job. This indicates that temporary employment in all four countries to some degree is a youth-specific phenomenon. If we then investigate the odds ratios for the younger age groups a bit more closely, we see that they are smaller in Denmark (especially for the age group 16-24 but also for 25-34) compared to the other three countries. This indicates that temporary employment is associated with the younger generations to a lesser degree in Denmark than in Finland, Norway and Sweden.

The effect of education is not clear-cut. In Denmark and Norway those with a secondary level of education are least likely to work in a temporary job. In Finland those with a primary or secondary level of education are most likely to be temporarily employed. In Sweden we see the opposite tendency. Here, those with a tertiary level of education are most likely to be temporarily employed.

In all four countries, working less than full-time (defined as minimum 35 hours per week) gives a higher risk of being in a temporary contract. In Denmark and Finland we do, however, see a smaller probability for those working under 20 hours a week. The opposite tendency is noticed in Sweden where those working less than 20 hours per week are 6 times more likely to be in temporary employment compared to full-time workers. Temporary employment therefore seems to be more associated with shorter working hours in Sweden compared to especially Denmark and Finland. This could point in the direction of temporary employment being more precarious in Sweden, if short working time is taken as an indication of a more marginalised position at the labour market. 
Table 6.1 Effects of various factors on temporary employment (separate models for each country). Binomial logistic regression. Odds ratios for temporary employment vs. permanent employment or self-employment at time t.

\begin{tabular}{|c|c|c|c|c|}
\hline & Denmark & Finland & Norway & Sweden \\
\hline \multicolumn{5}{|l|}{ Gender (ref. man) } \\
\hline Woman with children & $1.23^{\star *}$ & $1.35^{\star \star}$ & $1.17^{\star \star}$ & $0.88^{\star *}$ \\
\hline Woman without children & $1.23^{\star \star}$ & $1.32^{\star \star}$ & 1.06 & $1.13^{\star *}$ \\
\hline \multicolumn{5}{|l|}{ Age (ref. 45-54) } \\
\hline $16-24$ & $4.45^{\star \star}$ & $10.25^{\star \star}$ & $8.16^{\star \star}$ & $7.81^{\star \star}$ \\
\hline $25-34$ & $1.90^{* *}$ & $3.77^{\star \star}$ & $3.57^{\star \star}$ & $3.09 * *$ \\
\hline $35-44$ & $1.22^{\star *}$ & $1.50^{\star *}$ & $1.78^{\star *}$ & $1.70^{* *}$ \\
\hline $55-63$ & 1.08 & $0.61^{* *}$ & $0.71^{* *}$ & $0.80 * *$ \\
\hline \multicolumn{5}{|l|}{ Marital status (ref. married) } \\
\hline Cohabitant & $1.43^{\star *}$ & $1.29 * *$ & $1.44^{\star *}$ & $1.31^{\star *}$ \\
\hline Single & $1.76^{\star \star}$ & $1.66^{\star \star}$ & $1.91^{\star \star}$ & $1.68^{\star *}$ \\
\hline \multicolumn{5}{|l|}{ National origin (ref. native) } \\
\hline Other Nordic & 1.30 & 1.11 & 1.10 & $1.25^{\star \star}$ \\
\hline Other European/N. American & $1.98^{\star *}$ & $1.55^{\star \star}$ & $1.33^{* *}$ & $1.85^{\star \star}$ \\
\hline Other & $1.81^{\star *}$ & $2.23^{\star \star}$ & $1.46^{\star \star}$ & $2.13^{\star *}$ \\
\hline \multicolumn{5}{|l|}{ Education (ref. tertiary) } \\
\hline Primary & 1.43 & $1.32^{\star *}$ & 0.94 & $0.81^{\star *}$ \\
\hline Secondary & $0.93^{\star *}$ & $1.16^{\star \star}$ & $0.85^{\star \star}$ & $0.83^{\star *}$ \\
\hline \multicolumn{5}{|l|}{ Industry (ref. manufacturing) } \\
\hline Agriculture & $1.32^{*}$ & $0.72^{\star \star}$ & $0.49 * \star$ & 0.82 \\
\hline Construction & $1.67^{\star \star}$ & $1.38^{\star \star}$ & 1.02 & $1.23^{\star \star}$ \\
\hline Trade etc. & $1.19^{\star}$ & $0.87^{\star *}$ & $0.80^{* *}$ & $1.53^{\star *}$ \\
\hline Transport etc. & 0.93 & 0.91 & 1.09 & $1.69^{\star *}$ \\
\hline Finance etc. & 0.96 & $1.37^{\star *}$ & $1.45^{\star}$ & $1.65^{\star \star}$ \\
\hline Real estate etc. & 1.19 & $1.21^{\star \star}$ & $1.54^{\star *}$ & $1.55^{\star \star}$ \\
\hline Public administration & $2.54^{\star *}$ & $3.27^{\star *}$ & $3.35^{\star *}$ & $3.25^{\star *}$ \\
\hline Education & $3.91^{* *}$ & $6.83^{\star *}$ & $5.05^{\star \star}$ & $4.85^{\star *}$ \\
\hline Health care & $3.30^{* *}$ & $4.82^{\star \star}$ & $3.08^{\star *}$ & $2.92^{\star *}$ \\
\hline Social and personal services & $3.68^{* *}$ & $3.30 * \star$ & $1.82^{\star \star}$ & $3.18^{\star *}$ \\
\hline \multicolumn{5}{|l|}{ Occupational category (ref. manual worker) } \\
\hline Managers & $0.19 * *$ & $0.25^{\star *}$ & $0.27^{\star *}$ & $0.26^{\star *}$ \\
\hline Professionals & $0.77^{\star *}$ & $0.78^{\star *}$ & $0.74^{* *}$ & $0.76^{\star *}$ \\
\hline Semi-professionals & $0.62^{\star *}$ & $0.69^{\star \star}$ & $0.71^{\star *}$ & $0.50^{\star *}$ \\
\hline Service workers & $0.89^{*}$ & $0.81^{\star \star}$ & $0.83^{\star \star}$ & $0.92^{\star}$ \\
\hline \multicolumn{5}{|l|}{ Working time (ref. 35+) } \\
\hline $1-19$ & $0.78^{\star *}$ & $0.83^{\star *}$ & $2.13^{\star \star}$ & $6.21^{\star *}$ \\
\hline $20-29$ & $1.39 * *$ & $1.75^{\star \star}$ & $2.04^{\star \star}$ & $2.81^{\star \star}$ \\
\hline $30-34$ & $1.27^{\star *}$ & $2.12^{\star \star}$ & $1.43^{\star *}$ & $1.55^{\star \star}$ \\
\hline \multicolumn{5}{|l|}{ Size of workplace (ref. 1-10) } \\
\hline $11-19$ & $1.20^{\star *}$ & $1.18^{\star *}$ & $0.88^{\star}$ & 1.06 \\
\hline $20-49$ & 1.09 & $1.07^{\star}$ & 1.01 & 1.02 \\
\hline $50+$ & 0.93 & $1.11^{\star *}$ & 1.04 & $0.92^{\star *}$ \\
\hline \multicolumn{5}{|l|}{ Unemployment (by county) (ref. low) } \\
\hline Medium & $1.13^{\star *}$ & $1.14^{\star *}$ & 0.97 & $1.16^{\star \star}$ \\
\hline High & $1.27^{\star *}$ & $1.51^{\star \star}$ & $1.09^{*}$ & $1.33^{\star *}$ \\
\hline Annual change in national unemployment & 1.03 & $0.92^{\star}$ & 1.00 & 1.01 \\
\hline Nagelkerke $\mathrm{R}^{2}$ & 0.153 & 0.285 & 0.299 & 0.297 \\
\hline $\mathrm{N}$ & 51506 & 84824 & 50537 & 106109 \\
\hline
\end{tabular}

Finally, two variables on unemployment have been included. The measure on annual change in national unemployment does not seem to have an effect, but the measure on unemployment rate on the county level does. As explained in chapter 5 , this variable is divided into three categories and measures whether the unemployment level at county level in each country is low, medium or high. In all countries we see that the higher the unemployment level is, the higher is the probability of being in a temporary job. 
All in all, the analyses presented in this section show that the temporary employees and temporary jobs in the four Nordic countries to a large degree are very much alike. We do, however, see some differences between the countries - for instance when it comes to age and working time. The next question is now whether we see similar or different patterns in the flows into and out of temporary employment in the four countries.

\subsection{Mobility to and from temporary employment - a general overview}

In this section we provide an overview of the main transitions into and out of temporary employment in the four Nordic countries based on descriptive statistics. Table 6.2 presents different transitions into temporary employment. Our starting point is people who are not in temporary employment at the first point of observation ( $t$ ). Those in employment may either be in a permanent contract or work as self-employed. The persons who are not employed may be either unemployed, students or inactive. ${ }^{16}$ For these groups, we give the share of people who have made the transition into temporary employment one year later $(t+1)$. They are highlighted with bold in the table. For comparison, we also show the share of each group that has made the transition into self-employment and permanent employment.

We would not, in general, expect many transitions from a permanent to a temporary contract, since the permanent contract is by far the most secure contract to work in. Looking at the numbers we see that this transition is very rare indeed. In all countries less than $4 \%$ of those permanently employed who are still employed one year later have changed to a temporary contract. Even fewer self-employed make this transition. If we were to find differences between the countries, we would expect to see a larger share of permanent workers make the transition to temporary work in Denmark, where there is in general more mobility and where there is a smaller difference in EPL between a temporary and a permanent position. This seems to be the case, as Denmark has a slightly higher share that moved from permanent to temporary employment than the other countries. Overall, the country differences are small. Thus, it seems that temporary employment is not something that employed persons are pursuing to a large extent. Once a more permanent job has been obtained, individuals are more likely to stay in this position.

\footnotetext{
${ }^{16}$ In chapter 5 we had two groups of not employed - "unemployed" and "inactive". In this section we have however chosen to divide the group of "inactive" into "students" and "other inactives". The group "unemployed" is therefore the same as in chapter 5, and they are defined as persons who do not have a job but are available for work. "Students" are persons who reported undergoing education at the first point of observation. "Other inactives" are a very heterogeneous group consisting of both homeworking persons, pensioners, people in military service, and unemployed who have not actively searched for a job recently. For more information on this, see Appendix B.
} 
Table 6.2 Transitions into temporary employment, self-employment and permanent employment for employed and not employed individuals aged 16-63 from t to t+1.percentages

\begin{tabular}{|c|c|c|c|c|}
\hline & Denmark & Finland & Norway & Sweden \\
\hline \multicolumn{5}{|c|}{ From permanent employment to: } \\
\hline - temporary employment & 3.6 & 2.7 & 2.6 & 2.3 \\
\hline - self-employment & 1.3 & 1.0 & 1.0 & 0.7 \\
\hline - permanent employment & 95.1 & 96.3 & 96.5 & 96.9 \\
\hline Total & 100.0 & 100.0 & 100.0 & 100.0 \\
\hline $\mathrm{N}$ & 39835 & 64050 & 37743 & 80604 \\
\hline \multicolumn{5}{|l|}{ From self employment to: } \\
\hline - temporary employment & 2.0 & 1.6 & 2.1 & 1.8 \\
\hline - self-employment & 87.6 & 95.0 & 87.1 & 94.6 \\
\hline - permanent employment & 10.4 & 3.4 & 10.8 & 3.6 \\
\hline Total & 100.0 & 100.0 & 100.0 & 100.0 \\
\hline $\mathrm{N}$ & 3613 & 11060 & 3165 & 9476 \\
\hline \multicolumn{5}{|l|}{ From unemployment to: } \\
\hline - temporary employment & 32.7 & 59.3 & 27.5 & 56.3 \\
\hline - self-employment & 4.0 & 3.5 & 5.2 & 5.5 \\
\hline - permanent employment & 63.4 & 37.1 & 67.2 & 30.8 \\
\hline Total & 100.0 & 100 & 100.0 & 100.0 \\
\hline $\mathrm{N}$ & 2303 & 3279 & 977 & 2954 \\
\hline \multicolumn{5}{|l|}{ From student to: } \\
\hline - temporary employment & 36.8 & 57.2 & 35.2 & 67.6 \\
\hline - self-employment & 3.2 & 4.0 & 2.7 & 3.5 \\
\hline - permanent employment & 60.0 & 38.8 & 62.1 & 28.8 \\
\hline Total & 100.0 & 100.0 & 100.0 & 100.0 \\
\hline $\mathrm{N}$ & 1276 & 2625 & 1744 & 3567 \\
\hline \multicolumn{5}{|l|}{ From other inactive to: } \\
\hline - temporary employment & 36.4 & 42.4 & 25.8 & 56.7 \\
\hline - self-employment & 9.2 & 9.2 & 12.0 & 7.8 \\
\hline - permanent employment & 54.4 & 48.4 & 62.2 & 35.5 \\
\hline Total & 100.0 & 100.0 & 100.0 & 100.0 \\
\hline $\mathrm{N}$ & 1256 & 3201 & 1085 & 1475 \\
\hline
\end{tabular}

For those not working, our expectation is that in countries with strict EPL for regular workers (especially Sweden) it is more difficult for persons outside employment to obtain employment in a permanent contract. We therefore expect the transition rates from non-employment to temporary employment to be higher in these countries. Since Norway also has a somewhat restrictive use of temporary contracts, the transition rates for Norway from non-employment to temporary employment will probably be smaller.

In Table 6.2 we see that the majority of the unemployed in Finland and Sweden who have moved to employment one year later are working in a temporary contract. Around 5\% have moved to self-employment in both countries and the rest to permanent employment. In Denmark and Norway the tendency is very much the opposite. In Denmark every third of those unemployed who have gained employment are working in a temporary contract, while almost two out of three have moved directly into permanent work. A very small share has made the transition to selfemployment. In Norway the share of people who have got a permanent contract is even higher. 
For those who were students at the first point of observation, we see the same pattern as with the unemployed. ${ }^{17}$ In all countries very few have made the transition into self-employment, while more students have become temporary workers in Finland and Sweden than in Denmark and Norway. Thus, it seems more normal for a former student to move directly into permanent employment in Denmark and Norway. If we assume that a student is a person who is entering the labour market for the first time, then we see that in especially Sweden the first job is most often a temporary one, since 3 out of 4 of those students who obtained a job are in temporary employment.

Lastly, we look at the group of people who were inactive at time $t$. Again, we see a pattern similar to the unemployed and the students. In Finland and Sweden a larger share are temporarily employed one year later compared to Denmark and Norway. The numbers for Finland are, though, closer to the level in Denmark and Norway this time.

Looking at the non-employed persons together, the overall pattern is that in Finland and Sweden, which are also the countries with the highest share of temporary workers, persons outside employment are more likely to enter employment in a temporary contract than in a permanent contract. The opposite tendency seems to be the case in Denmark and Norway. These preliminary results are in line with our expectations.

In the next table we move on to investigate transitions out of temporary employment. Our starting point is persons in temporary employment at the first point of observation $(t)$. We then look at their situation one year later $(t+1)$. As in Table 6.2 we have grouped the non-employed into unemployed, students and other inactives.

Table 6.3: Transitions from temporary employment at $t$ to other statuses at $t+1$ for individuals aged 16-63. percentages

\begin{tabular}{lrrrr}
\hline & Danmark & Finland & Norway & Sweden \\
\hline To temporary employment & 32.5 & 48.9 & 28.3 & 46.6 \\
To permanent employment & 42.5 & 24.5 & 49.8 & 30.0 \\
To self-employment & 1.4 & 1.2 & 1.7 & 1.3 \\
To unemployment & 10.1 & 10.4 & 5.2 & 7.6 \\
To other inactivity & 8.7 & 9.3 & 7.4 & 6.4 \\
To student & 4.8 & 5.7 & 7.6 & 8.1 \\
Total & 100.0 & 100.0 & 100.0 & 100.0 \\
Total in employment & 76.4 & 74.6 & 79.8 & 77.9 \\
$\mathrm{~N}$ & 5303 & 13182 & 4189 & 12601 \\
\hline
\end{tabular}

When it comes to transitions out of temporary employment, our expectation is that in countries with a strict level of EPL for the regular workers, it may be more difficult for a temporary employee to move to permanent work - especially if temporary contracts are used to create numerical

\footnotetext{
${ }^{17}$ For this group we should be aware that they can in principle be students rather than employed at $t+1$. Those students who one year later are registered in the LFS as employed are those who in the interview at $t+1$ stated that they had worked in the reference week, but this does not necessarily preclude them from also being students.
} 
flexibility. At the same time a temporary employee will therefore probably be more likely to either stay in temporary employment or move to a position as not employed in a country with strict EPL. This could be the case in Sweden and probably also in Finland. Norway also has a strict EPL for the regular workers, but since they also have strict regulations on the use of temporary contracts, a different pattern may be seen here. From previous research we also know that many temporary jobs lead to stable employment (Neergaard 2004). We therefore expect a higher transition rate in Norway from temporary work to permanent work. For Denmark we expect more transitions to permanent work since there is a smaller difference in EPL between a temporary and a permanent position. But since Denmark also is the most mobile country, there may be a large flow to unemployment and inactivity here. We did in fact see in chapter 5 that Denmark had a high transition rate to unemployment in general. This may also be the case when the focus is solely on those working in temporary contracts.

The first thing to notice about Table 6.3 is the share of the temporary employed that are still employed at $t+1$. These numbers are shown in the column "total in employment". They give a picture of a very high degree of employment stability in all countries, since $75-80 \%$ of all temporary employed are still in employment one year later. However, we also see minor differences between the countries. In Finland, fewest of the temporary workers are employed one year later, and in Norway the largest share are employed. If we compare these numbers with the share of permanent workers and self-employed that are in employment one year later, then we see significant differences in all countries. In all four countries between 92 and 96\% of all permanent workers and all self-employed are in employment one year later (results for permanent employees and selfemployed are not shown in the table). This is, however, not at all a surprising result since it is evident from the very nature of the temporary contract that it will eventually terminate. It therefore automatically gives a higher risk of becoming unemployed compared to persons working in contracts of indefinite duration.

If we then study the movements out of employment for the temporary workers in more detail, we see that a larger share of the temporary workers in Denmark and Finland move to unemployment and inactivity than in Norway and Sweden. However, a larger share become students in Norway and Sweden.

For the transitions to the same or another type of employment, very few temporary employees move to a position of being self-employed the next year. This is the case for fewer than $2 \%$ of all temporary workers in all countries. Conversely, very few self-employed move to temporary employment (Table 6.2). Mobility between temporary employment and self-employment does not seem to be a very widespread type of mobility in any of the countries. What does in fact seem to be a more interesting 
type of transition is the transition to permanent work versus staying in temporary employment. In Finland and Sweden almost half of the temporary workers are still in temporary employment one year later. In Denmark the number is $32.5 \%$ and in Norway $28.3 \%$. On the one hand this may mean that the temporary contracts are of longer duration in Finland and Sweden than in Denmark and Norway. It may also indicate that more people stay in repeated temporary employment over time in Finland and Sweden.

For the transition to permanent work, almost half of the temporary workers in Norway have moved into permanent employment, while around $42 \%$ in Denmark have. In Sweden and Finland this transition is much rarer. Of all temporary workers who are employed one year later, one third have moved to a permanent position in Finland, 38.5\% have done the same in Sweden, $62.4 \%$ in Norway and 55.6\% in Denmark (results not shown).

To conclude our preliminary investigation of both entry patterns and exit patterns, more non-employed persons are recruited to temporary work compared to permanent work in Finland and Sweden; they stay in temporary employment longer, and make the transition into permanent employment to a lesser degree, than Danish and Norwegian temporaries. Whether these preliminary findings still hold when other factors are controlled for will be subject to investigation in the end of this chapter. In the next section we will, however, take a closer look at the determinants behind some of the transitions in order to learn what can explain the different transitions.

\subsection{Factors affecting mobility - multivariate analyses}

In this section we study determinants behind a number of the transitions presented in the previous section in a multivariate setting. The aim is to find out what determines the different transitions and whether the main determinants behind the transitions generally are the same in the four countries. This is done by applying logistic regression models. In cases where the dependent variable has two values, binomial logistic regression has been applied, and in cases when the dependent variable has more than two values, multinomial logistic regression is used.

A number of independent variables are used in the regression models. Throughout we include the combined gender-children variable, age, national origin and education. When the transition is from employment, we furthermore include industry, occupational category, working hours and number of employees at the workplace. In all analyses, county unemployment rates and annual changes in national unemployment rates are also included in order to control for business trends. 
Three transitions to and from temporary employment are of interest to study in a multivariate setting:

a) From a position as not employed to temporary employment

b) From temporary employment to permanent employment

c) From temporary employment to a position as not employed

Each of these transitions will be analysed separately in the three following sections.

\subsubsection{From non-employment to temporary employment}

We will start with transitions from a position as not employed to temporary employment. We saw in the previous section that this transition could be made by different categories of non-employed persons - unemployed, students and other inactives. However, in this analysis we deal with all persons who are not in employment as one group. We have, however, included an independent variable giving the respondents' status before the transition. We are therefore able to determine whether some groups of non-employed are more likely to end up in temporary employment compared to others without having to estimate separate models for each group of non-employed.

We have estimated a binomial logistic regression model for each country testing the odds of a non-employed person making the transition into temporary employment. Notice that we are testing the probability of making the transition into temporary employment compared to making the transition into permanent employment/self-employment. Another variant could be to test the probability of obtaining a temporary job compared to staying in a position as not employed. However, in this report we find it more relevant to make the first comparison rather than the second. The outcome is presented in Table 6.4.

The first point to notice about Table 6.4 is the low numbers for Nagelkerke in most countries. This means that the independent variables included in the regression models predict very little of the transition to temporary employment. Least is explained in Denmark and Norway, and most in Finland and Sweden. Therefore, we see very few significant results especially in Norway. 
Table 6.4. Effects of various factors on transitions from not employed to temporary employment. Separate models for each country. Binomial logistic regression. Odds ratios for transition from non-employment to temporary employment vs. permanent employment/self-employment

\begin{tabular}{|c|c|c|c|c|}
\hline & Denmark & Finland & Norway & Sweden \\
\hline \multicolumn{5}{|l|}{ Gender (ref. man) } \\
\hline Woman with children & $1.88^{\star \star}$ & $1.53^{\star \star}$ & $1.42^{\star \star}$ & $2.09 * *$ \\
\hline Woman without children & $1.74^{\star \star}$ & $1.77^{\star \star}$ & $1.38^{\star \star}$ & $1.77^{\star \star}$ \\
\hline \multicolumn{5}{|l|}{ Age (ref. 45-54) } \\
\hline $16-24$ & $0.62^{\star \star}$ & 1.05 & 0.83 & 1.06 \\
\hline $25-34$ & $0.74^{\star *}$ & 0.91 & 0.80 & $0.76^{\star *}$ \\
\hline $35-44$ & $0.76^{\star \star}$ & $0.81^{*}$ & 0,79 & 0.82 \\
\hline $55-63$ & 1.23 & 1.06 & $0.53^{\star \star}$ & $1.45^{\star \star}$ \\
\hline \multicolumn{5}{|l|}{ Marital status (ref. married) } \\
\hline Cohabitant & 1.11 & 1.08 & 1.13 & $1.20^{*}$ \\
\hline Single & $1.33^{\star *}$ & $1.44^{\star *}$ & 1.07 & $1.42^{\star \star}$ \\
\hline \multicolumn{5}{|l|}{ National origin (ref. native) } \\
\hline Other Nordic & $0.35^{\star}$ & 0.95 & 0.71 & 0.98 \\
\hline Other European/N. American & 1.27 & 0.81 & 1.28 & $1.35^{\star \star}$ \\
\hline Other & 1.13 & $2.27^{\star \star}$ & 1.27 & 1.15 \\
\hline \multicolumn{5}{|l|}{ Education (ref. tertiary) } \\
\hline Primary & 0.97 & 1.08 & 0.83 & 1.06 \\
\hline Secondary & $0.75^{\star \star}$ & 1.07 & 0.86 & 0.98 \\
\hline \multicolumn{5}{|l|}{ Status at time $\mathrm{t}$ (ref. unemployed) } \\
\hline Inactive & 1.12 & $0.53^{\star \star}$ & 0.91 & 0.97 \\
\hline Student & $1.38^{\star \star}$ & $0.78^{\star \star}$ & $1.39 \star \star$ & $1.45^{\star \star}$ \\
\hline \multicolumn{5}{|l|}{ Unemployment (by county) (ref. low) } \\
\hline Medium & 1.11 & $1.32^{\star \star}$ & 1.01 & $1.26^{\star \star}$ \\
\hline High & 1.16 & $1.81^{\star \star}$ & 1.11 & $1.83^{\star \star}$ \\
\hline Annual change in national unemployment & 1.03 & 1.11 & $0.88^{\star}$ & 1.06 \\
\hline Nagelkerke $\mathrm{R}^{2}$ & 0.041 & 0.075 & 0.031 & 0.062 \\
\hline $\mathrm{N}$ & 4835 & 9105 & 3802 & 7990 \\
\hline
\end{tabular}

The first similarity to observe from Table 6.4 is that women are more likely to make the transition into temporary employment rather than permanent employment compared to men, when other factors are controlled for. It should be noted here that we made another model where industry at time $t+1$ was added to the model. This was done since we know that many temporaries are found in certain female-dominated sectors (see section 6.2). Perhaps the effect of gender would disappear or diminish if we control for industry. When industry is in the model, the effect of gender is still there, but with slightly smaller odds ratios than in a model without industry. This means that even though we control for the industries which the temporaries are working in, women are still more likely to move to temporary employment once they get employed.

Another similarity is that singles are most likely to move to temporary employment. This association is however not present in Norway.

Education does not seem to be a strong explanatory factor in the countries. Neither does national origin, with minor exceptions. In Finland a national origin outside Europe or North America doubles the odds of making the transition to temporary employment compared with someone born in Finland. In Sweden having a European or North American origin elevates the odds. 
Age seems in general not very important in Finland, Norway and Sweden, but we do see some effects for some of the age groups. In Sweden it is clear that the oldest age group is most likely to move to temporary employment and the 25-34-year-olds are least likely. In Norway the oldest age group is least likely, and in Finland there is a low odds ratio for the 35-44-year-olds. However, in Denmark we see a stronger and clearer effect. Here, the younger a non-employed person is, the less likely is the transition to temporary employment rather than permanent employment. Thus, the oldest age groups in Denmark are more likely to become temporary employees. The explanation could be that those older people who are not in employment form a certain group with a lesser degree of human capital. When they return to employment it most often will be in a temporary job - for instance in a so-called flex job. A flex job is held by targeted individuals with permanently reduced working ability and is intended as an alternative to disability pension. A person working in a flex job is employed in an organisation with reduced working hours, and the organisation receives a wage subsidy (Bredgaard et al. 2009). The flex jobs are of limited duration, but most often individuals stay in these jobs until they become pensioners.

In order to find out whether some groups of non-employed persons are more likely to move to temporary employment rather than permanent work, we have included a variable on the respondents' status before the transition. The person may be either unemployed, a student or inactive. We see two tendencies in the analysis of the effect from previous status. In Denmark, Norway and Sweden, former students are more likely to move to temporary employment compared to the reference group of unemployed. In Finland it is, however, the reference group of unemployed that are most likely to make the transition compared to both students and other inactives.

Finally, two variables on unemployment have been included. The first one measures unemployment rates at the county level and is divided into low, medium and high. This measure plays a significant role only in Finland and Sweden. Here, the higher the level of unemployment, the higher is the probability of moving to temporary employment rather than permanent. This could mean that Finnish and Swedish employers are more reluctant to hire people on a permanent basis when the unemployment levels are high. Instead they hire on a temporary basis, wherefore the odds increase as unemployment levels go up. The second measure on annual change in national unemployment rate seems only to play a minor role in Norway.

\subsubsection{From temporary employment to permanent employment}

The second transition to be examined is mobility from temporary employment to permanent employment. For this transition we have also 
estimated a binary logistic regression model for each of the countries, predicting the odds of moving from a temporary contract to permanent employment compared to staying in a temporary contract. Since the transition is from employment, we have also included a number of workplace-related variables like industry, occupational category, working time and size of workplace. Table 6.5 presents the outcome.

Again, the first point to notice is that Nagelkerke is rather small in most countries, especially in Denmark and Norway. This means that the variables included in the model do not explain a great deal of the transition from temporary employment to permanent employment in either of the countries. Least is explained in Denmark and Norway, where we have many insignificant results.

Starting with sex, this factor seems to play a significant role only in Finland, where Finnish women are less likely than Finnish men to move to permanent employment. There is no such difference found in the other countries, with a minor exception for Denmark. We did see in the previous analysis that women in all four countries are more likely to obtain a job in a temporary contract compared to a permanent contract, but men and women are equally likely to move to permanent work. However, the exception here is Finland, where women do not move to permanent employment to the same degree as men.

We saw in the first section of this chapter that temporary work is associated with the younger generations. It is however not the youngest that move to permanent employment in any of the countries. In Denmark, 1624 year olds are least likely to move to permanent work, while no difference is found for the rest of the age groups. In Finland and Sweden, the 25-34-year-olds have the highest odds of moving to permanent work (also 35-44-year-olds in Finland). In Norway age does not matter for the transition.

In all countries but Denmark, singles are less likely to move to permanent work. The other two variables relating to the individual level - education and national origin - do not seem to play a role. The same was to a large degree the case in the previous analysis.

We then move on to the workplace-related variables. Starting with working time, this seems to be a strong significant factor in Sweden but not in the other countries. For Sweden it is very clear that low working hours are associated with less probability of moving to permanent employment. The effect seems to be linear; i.e. the lower the number of working hours, the less likely is the transition to permanent employment. 
Table 6.5. Effects of various factors on transitions from temporary employment to permanent employment. Separate models for each country. Binomial logistic regression. Odds ratios for transition from temporary employment to permanent employment vs. still in temporary employment

\begin{tabular}{|c|c|c|c|c|}
\hline & Denmark & Finland & Norway & Sweden \\
\hline \multicolumn{5}{|l|}{ Gender (ref. man) } \\
\hline Woman with children & 0.99 & $0.71^{\star *}$ & 0.99 & 1.05 \\
\hline Woman without children & $0.74^{\star}$ & $0.76^{\star *}$ & 0.89 & 0.90 \\
\hline \multicolumn{5}{|l|}{ Age (ref. 45-54) } \\
\hline $16-24$ & $0.65^{\star \star}$ & 1.50 & 0.82 & 1.02 \\
\hline $25-34$ & 0.91 & $1.25^{\star}$ & 0.87 & $1.26^{*}$ \\
\hline $35-44$ & 1.00 & $1.23^{\star}$ & 0.83 & 1.12 \\
\hline $55-63$ & 0.81 & $0.72^{\star}$ & 0.96 & $0.58^{\star \star}$ \\
\hline \multicolumn{5}{|l|}{ Marital status (ref. married) } \\
\hline Cohabitant & 1.15 & 1.00 & $0.69^{*}$ & 1.00 \\
\hline Single & 0.93 & $0.87^{*}$ & $0.66^{* *}$ & $0.88^{*}$ \\
\hline \multicolumn{5}{|l|}{ National origin (ref. native) } \\
\hline Other Nordic & 0.88 & 0.98 & 1.07 & 1.09 \\
\hline Other European/N. American & $0.66^{*}$ & 0.95 & 0.92 & 1.10 \\
\hline Other & 1.08 & 0.93 & 1.10 & 0.92 \\
\hline \multicolumn{5}{|l|}{ Education (ref. tertiary) } \\
\hline Primary & $0.78^{*}$ & 0.92 & 1.09 & 0.91 \\
\hline Secondary & 1.00 & 0.94 & 1.10 & 1.08 \\
\hline \multicolumn{5}{|l|}{ Industry (ref. manufacturing) } \\
\hline Agriculture & 1.09 & 0.72 & 0.87 & $0.52^{*}$ \\
\hline Construction & 0.86 & $0.76^{\star}$ & 0.98 & 0.61 \\
\hline Trade etc. & 1.25 & 1.05 & $1.54^{\star}$ & $0.73^{\star}$ \\
\hline Transport etc. & 1.03 & 1.14 & 1.42 & $0.72^{\star}$ \\
\hline Finance etc. & 1.93 & 0.86 & 1.28 & 0.71 \\
\hline Real estate etc. & 1.09 & 0.89 & 1.25 & 0.84 \\
\hline Public administration & $0.61^{*}$ & $0.48^{\star *}$ & 0.79 & $0.42^{\star *}$ \\
\hline Education & 0.79 & $0.36^{\star *}$ & $0.56^{*}$ & $0.32^{\star *}$ \\
\hline Health care & 0.92 & $0.50^{* *}$ & 0.76 & $0.44^{\star *}$ \\
\hline Social and personal services & $0.72^{*}$ & $0.39 * *$ & 1.31 & $0.39 * *$ \\
\hline \multicolumn{5}{|l|}{ Occupational category (ref. manual worker) } \\
\hline Managers & 0.99 & 1.15 & 1.26 & 0.83 \\
\hline Professionals & $0.70^{*}$ & 0.92 & 0.86 & 0.87 \\
\hline Semi-professionals & 1.12 & 1.12 & 0.83 & $1.28^{\star}$ \\
\hline Service workers & 1.11 & 0.99 & 0.85 & 1.01 \\
\hline \multicolumn{5}{|l|}{ Working time (ref. 35+) } \\
\hline $1-19$ & 1.06 & 1.01 & 0.87 & $0.40^{\star \star}$ \\
\hline $20-29$ & 1.23 & 0.91 & 0.91 & $0.60^{\star *}$ \\
\hline $30-34$ & 0.90 & $0.82^{\star}$ & 0.85 & $0.75^{\star \star}$ \\
\hline \multicolumn{5}{|l|}{ Size of workplace (ref. 1-10) } \\
\hline $11-19$ & 0.93 & 0.96 & 1.07 & 0.96 \\
\hline $20-49$ & 1.06 & $0.85^{\star}$ & 0.69 & 0.99 \\
\hline $50+$ & 0.99 & $0.80^{*}$ & 0.89 & 1.07 \\
\hline \multicolumn{5}{|l|}{ Unemployment (by county) (ref. low) } \\
\hline Medium & 0.90 & $0.76^{\star *}$ & $1.20^{*}$ & $0.74^{\star *}$ \\
\hline High & 0.91 & $0.67^{* *}$ & 1.05 & $0.69 * *$ \\
\hline Annual change in national unemployment & 0.91 & 1.12 & 0.95 & $0.88^{*}$ \\
\hline Nagelkerke $\mathrm{R}^{2}$ & 0.042 & 0.076 & 0.052 & 0.113 \\
\hline $\mathrm{N}$ & 3932 & 8198 & 3304 & 9767 \\
\hline
\end{tabular}

Industry is an important factor in Finland and Sweden but not in Denmark and Norway. In Finland and Sweden, working in the service sector (public administration, education and research, health care and social and personal services) gives lower odds of moving to permanent work. The pattern seems to be a bit stronger in Sweden than Finland, since the odds are lower in Sweden. We did in fact see in the beginning of the chapter that it is very common in these industries to have temporary employment, but temporaries do not seem to shift to permanent work. 
With minor exceptions, the rest of the workplace-related variables (occupational category and size or firm) do not seem to play a significant role in any of the countries.

The measure on regional unemployment is important only in Finland and Sweden and partly in Norway. In Finland and Sweden, the transition to permanent employment becomes rarer when the level of unemployment becomes higher. This is in line with the previous analysis, where the transitions to temporary employment became more frequent when unemployment levels got higher. As regards the second measure of unemployment, it is only significant in Sweden. When the unemployment rate increases by onepercentage point in Sweden, then the odds of becoming permanently employed decrease.

\subsubsection{From temporary employment to non-employment}

The third and last transition of interest is from temporary employment to a position as not employed. We saw in section 6.3 that the transition could be either to unemployment, to the educational system (a position as student) or to another position as inactive. Even though moving to the educational system and to inactivity are two different things, one could argue that moving to these two positions means being in a more peripheral position compared to those moving to unemployment. Moving to unemployment means that the respondent is actively seeking work and is available for work. This brings the group closer to employment than those moving to the educational system and to inactivity. In this analysis we therefore consider two transitions - the first one being the transition to unemployment, and the second one being the transition to inactivity and the educational system all together. Since the dependent variable has more than two values, multinomial logistic regression has been applied. The same independent variables as in the previous regression analysis are included in the analysis. ${ }^{18}$ Table 6.6 shows the outcome.

\footnotetext{
${ }^{18}$ Due to the lower number of respondents making the transition to unemployment, we have had to collapse one of the independent variables into fewer categories in order to make the analysis meaningful. The group of "managers" is therefore collapsed with the group of "professionals" in the variable on occupational groups.
} 
Table 6.6 Effects of various factors on transitions from temporary employment to non-employment. Separate models for each country. Multinomial logistic regression. Odds ratios for transition to unemployment or inactivity vs. staying in employment.

\begin{tabular}{|c|c|c|c|c|}
\hline & \multicolumn{4}{|c|}{ To unemployment } \\
\hline & Denmark & Finland & Norway & Sweden \\
\hline \multicolumn{5}{|l|}{ Gender (ref. man) } \\
\hline Woman with children & 1.09 & 0.91 & 0.87 & $0.74^{\star \star}$ \\
\hline Woman without children & 1.00 & 0.87 & 0.71 & 0.94 \\
\hline \multicolumn{5}{|l|}{ Age (ref. 45-54) } \\
\hline $16-24$ & $0.30^{* *}$ & $0.40^{\star \star}$ & 0.90 & $0.51^{\star \star}$ \\
\hline $25-34$ & $0.67^{\star \star}$ & $0.44^{\star \star}$ & 0.92 & $0.53^{\star \star}$ \\
\hline $35-44$ & $0.74^{*}$ & $0.65^{\star *}$ & 1.03 & $0.77^{*}$ \\
\hline $55-63$ & 1.37 & 1.30 & 0.89 & 1.06 \\
\hline \multicolumn{5}{|l|}{ Marital status (ref. married) } \\
\hline Cohabitant & 0.79 & 1.17 & 0.74 & $1.36^{\star *}$ \\
\hline Single & 1.00 & $1.38^{\star *}$ & 1.46 & $1.78^{\star \star}$ \\
\hline \multicolumn{5}{|l|}{ National origin (ref. native) } \\
\hline Other Nordic & 1.43 & 0.98 & 1.59 & 1.27 \\
\hline Other European/N. American & 0.90 & 0.84 & 0.98 & $1.63^{\star *}$ \\
\hline Other & $1.56^{\star}$ & $1.65^{\star}$ & $1.87^{*}$ & $1.56^{\star \star}$ \\
\hline \multicolumn{5}{|l|}{ Education (ref. tertiary) } \\
\hline Primary & 1.22 & $1.87^{\star \star}$ & $3.04^{* *}$ & $1.36^{\star}$ \\
\hline Secondary & 1.15 & $1.47^{\star *}$ & $2.50 * *$ & $1.32^{\star *}$ \\
\hline \multicolumn{5}{|l|}{ Industry (ref. manufacturing) } \\
\hline Agriculture & 0.58 & $.55^{\star}$ & 1.51 & 0.98 \\
\hline Construction & $0.55^{\star}$ & 0.96 & 0.76 & $1.55^{\star}$ \\
\hline Trade etc. & $0.63^{\star}$ & $0.73^{\star}$ & 1.20 & 1.08 \\
\hline Transport etc. & 0.71 & $0.66^{*}$ & 1.46 & $0.61^{\star *}$ \\
\hline Finance etc. & $0.21^{*}$ & 0.42 & $4.10^{*}$ & 1.00 \\
\hline Real estate etc. & 0.80 & 1.22 & 1.85 & 1.19 \\
\hline Public administration & 0.73 & 1.14 & 0.71 & 1.09 \\
\hline Education & 0.70 & 0.80 & 1.42 & 0.78 \\
\hline Health care & $0.53^{\star \star}$ & 0.87 & 0.95 & $0.63^{\star \star}$ \\
\hline Social and personal services & 1.07 & 1.03 & 1.17 & 1.07 \\
\hline \multicolumn{5}{|l|}{ Occupational category (ref. manual worker) } \\
\hline Managers+professionals & 0.74 & $0.47^{\star \star}$ & 0.67 & $0.52^{\star *}$ \\
\hline Semi-professionals & $1.49^{*}$ & $0.76^{\star}$ & 0.76 & $0.63^{\star \star}$ \\
\hline Service workers & $1.53^{\star}$ & 0.89 & 1.00 & $0.73^{\star \star}$ \\
\hline \multicolumn{5}{|l|}{ Working time (ref. $35+$ ) } \\
\hline $1-19$ & 0.71 & 1.11 & 0.86 & 0.96 \\
\hline $20-29$ & 0.82 & $1.80^{* *}$ & 1.20 & 0.93 \\
\hline $30-34$ & 1.19 & $2.27^{\star \star}$ & 1.31 & $0.62^{\star \star}$ \\
\hline \multicolumn{5}{|l|}{ Size of workplace (ref. 1-10) } \\
\hline $11-19$ & 0.97 & $0.78^{\star}$ & $.61^{\star}$ & 0.83 \\
\hline $20-49$ & 0.89 & $0.75^{\star \star}$ & $.46^{\star \star}$ & $.81^{*}$ \\
\hline $50+$ & $0.65^{\star \star}$ & $0.64^{\star \star}$ & 0.80 & 0.83 \\
\hline \multicolumn{5}{|l|}{ Unemployment (by county) (ref. low) } \\
\hline Medium & 1.14 & 1.17 & 0.86 & $1.36^{\star *}$ \\
\hline High & $1.45^{\star \star}$ & $1.44^{\star \star}$ & 0.97 & 1.59 ** \\
\hline Annual change in national unemployment & 1.12 & $1.47^{\star *}$ & $1.40^{*}$ & $1.29 * \star$ \\
\hline
\end{tabular}


Table 6.6 continued

\begin{tabular}{|c|c|c|c|c|}
\hline & \multicolumn{4}{|c|}{ To inactivity (students included) } \\
\hline & Denmark & Finland & Norway & Sweden \\
\hline \multicolumn{5}{|l|}{ Gender (ref. man) } \\
\hline Woman with children & $1.36^{*}$ & $1.28^{\star *}$ & 1.16 & $1.55^{\star \star}$ \\
\hline Woman without children & 1.08 & 0.87 & 0.86 & $1.15^{\star}$ \\
\hline \multicolumn{5}{|l|}{ Age (ref. 45-54) } \\
\hline $16-24$ & $1.68^{\star *}$ & $2.52^{\star \star}$ & $2.14^{\star *}$ & $5.17^{\star \star}$ \\
\hline $25-34$ & $1.85^{\star \star}$ & $1.26^{*}$ & 0.99 & $2.54^{\star *}$ \\
\hline $35-44$ & .98 & $0.69^{\star *}$ & 0.73 & 1.31 \\
\hline $55-63$ & $4.06^{\star *}$ & $2.97^{\star *}$ & $2.32^{\star \star}$ & $2.25^{\star \star}$ \\
\hline \multicolumn{5}{|l|}{ Marital status (ref. married) } \\
\hline Cohabitant & $1.32^{\star}$ & $0.80 *$ & 0.79 & 0.93 \\
\hline Single & $1.33^{\star}$ & 0.95 & 1.22 & $1.23^{*}$ \\
\hline \multicolumn{5}{|l|}{ National origin (ref. native) } \\
\hline Other Nordic & 1.03 & 0.59 & 1.05 & 1.05 \\
\hline Other European/N. American & 1.35 & 0.81 & 1.10 & 1.10 \\
\hline Other & $2.51^{\star *}$ & 1.26 & 1.25 & $1.35^{\star \star}$ \\
\hline \multicolumn{5}{|l|}{ Education (ref. tertiary) } \\
\hline Primary & $1.51^{\star *}$ & $1.99^{\star *}$ & 1.14 & 1.14 \\
\hline Secondary & $1.40^{*}$ & $1.32^{\star *}$ & 1.11 & 1.12 \\
\hline \multicolumn{5}{|l|}{ Industry (ref. manufacturing) } \\
\hline Agriculture & 0.88 & 0.97 & $1.98^{*}$ & 0.71 \\
\hline Construction & $0.44^{\star \star}$ & 0.92 & 0.78 & 0.69 \\
\hline Trade etc. & $0.63^{\star}$ & $0.75^{\star}$ & 0.97 & 0.81 \\
\hline Transport etc. & 0.62 & 0.92 & 0.99 & 0.88 \\
\hline Finance etc. & 0.35 & 0.51 & 1.06 & 0.99 \\
\hline Real estate etc. & 0.86 & 0.96 & 1.19 & 1.13 \\
\hline Public administration & 0.93 & 1.06 & 0.91 & 1.01 \\
\hline Education & 1.22 & 0.98 & 1.04 & 1.02 \\
\hline Health care & 0.99 & 1.24 & 1.06 & 0.95 \\
\hline Social and personal services & 0.73 & 1.08 & 1.03 & 0.96 \\
\hline \multicolumn{5}{|l|}{ Occupational category (ref. manual worker) } \\
\hline Managers+professionals & $0.62^{*}$ & $0.57^{\star *}$ & 0.68 & $.69^{\star *}$ \\
\hline Semi-professionals & 0.74 & $0.72^{\star \star}$ & 0.84 & 0.88 \\
\hline Service workers & 1.16 & 0.89 & 0.96 & 1.00 \\
\hline \multicolumn{5}{|l|}{ Working time (ref. 35+) } \\
\hline $1-19$ & $1.87^{\star *}$ & $1.71^{\star *}$ & $2.36^{\star \star}$ & $1.93^{\star *}$ \\
\hline 20-29 & $1.42^{*}$ & $1.64^{\star *}$ & $1.60^{\star *}$ & $1.56^{\star *}$ \\
\hline $30-34$ & $1.53^{\star *}$ & $1.93^{\star *}$ & 1.43 & 1.10 \\
\hline \multicolumn{5}{|l|}{ Size of workplace (ref. 1-10) } \\
\hline $11-19$ & 0.79 & $0.80^{*}$ & 0.87 & $.77^{\star \star}$ \\
\hline $20-49$ & $0.68^{\star *}$ & $0.81^{*}$ & 1.11 & 0.85 \\
\hline $50+$ & $0.63^{\star *}$ & $0.73^{\star *}$ & 0.87 & $.77^{\star *}$ \\
\hline \multicolumn{5}{|l|}{ Unemployment (by county) (ref. low) } \\
\hline Medium & 0.96 & 1.03 & 0.88 & 1.02 \\
\hline High & 1.11 & 1.13 & 0.98 & 1.08 \\
\hline Annual change in national unemployment & 1.17 & $1.22^{\star}$ & $1.20^{\star}$ & $1.28^{* \star}$ \\
\hline Nagelkerke $\mathrm{R}^{2}$ & 0.114 & 0.155 & 0.128 & 0.134 \\
\hline $\mathrm{N}$ & 5128 & 10980 & 4119 & 12538 \\
\hline
\end{tabular}

In this analysis Nagelkerke is somewhat stronger than in the previous two analyses. The independent variables therefore seem to be better predictors in the transition to non-employment than the other two transitions investigated earlier.

The first variable included in the analysis is the combined gender-andchildren variable. In general, the variable seems to have no effect for the transition to unemployment, but a significant effect for the transition to inactivity. In all countries but Norway, women with children have elevated odds of moving to inactivity. An explanation for this could be that 
when women go on maternity leave they are grouped in the category "inactive". Another reason is of course that women to a larger degree than men move to inactivity.

Age is, however, an important factor in the countries. In all countries the youngest and the oldest age group are most likely to move to inactivity. This pattern is expected since young people most likely move to the educational system and older people become pensioners. For the transition to unemployed, it is to a lesser degree made by young people in all countries but Norway. Here, age is not important.

The next variable we will turn to is marital status. It does not play a role in Norway, but gives in general higher probability of unemployment and inactivity in the other countries when the respondents are not married.

In all four countries, being born outside Europe or North America gives higher odds of becoming unemployed. This is also the case in Denmark and Sweden for the transition to inactivity. One important point should be mentioned here. We saw in the previous analysis that natives and non-natives have equal probability of moving to a permanent job. In this analysis we actually see that persons who are born outside Europe or North America are more at risk of becoming unemployed compared to natives even though they are just as likely as natives to move to a permanent job. And in Denmark and Sweden it is the case not only for the transition to unemployment, but also for the transition to inactivity. This could suggest that temporary employment is more precarious for nonnatives than for natives.

In general a lower level of education elevates the risk of moving to a position as not employed. In Finland those with primary and secondary education are more at risk of becoming both unemployed and inactive. In Norway and Sweden this effect is only found for the transition to unemployment, and in Denmark only for the transition to inactivity.

We now move on to the workplace-related factors. The first variable is industry, and in general this variable seems not very significant. It has practically no effect in any of the countries for the transition to inactivity, but some effect for the transition to unemployment. One interesting result is, however, that working in a temporary contract in the finance sector in Norway gives elevated odds for unemployment. Another interesting result is that working in health care in Denmark and Sweden gives lower probability of becoming unemployed. In the previous section we saw that working in health care also gave lower odds of moving to permanent work. One explanation for this could be that in the health sector it is rather normal to have staff in temporary contracts who really are permanently employed.

Occupational category seems to have different impact in the four countries. In Finland and to some extent Sweden, the level of occupation seems to have an impact on the probability of becoming unemployed. 
The higher an occupational group one belongs to, the less likely is the transition to unemployment in inactivity. In Norway we see no effect on occupation, and in Denmark only for the transition to unemployment. Here, service workers and semi-professionals have higher odds.

Working time seems to be a strong factor for the transition to inactivity. In all countries working less than full-time gives higher risk of inactivity. In Finland this is also the case for the transition to unemployment.

The last variable related to the workplace is the size of the workplace. The general picture is that larger workplaces give smaller odds of moving to unemployment as well as inactivity. The reason is probably that in larger companies it is easier to find another position for an employee compared to a smaller-sized firm.

The last two variables included in the analysis have to do with the level of unemployment. The first variable, which is the relative level of county unemployment, is an important factor only for the transition to unemployment. A high level of unemployment at the county level gives higher risk of making the transition to unemployment in Denmark, Finland and Sweden. No effect is found in Norway. As regards the other factor on unemployment - the annual change in national unemployment it is not important in Denmark. In the three other countries we see the same pattern as with the first unemployment measure.

\subsubsection{Summary}

In this section we have examined the determinants behind transitions into temporary employment, transitions to permanent employment and transitions to a position as not employed. There are some interesting results to sum up.

First of all, the determinants behind the different transitions have surprisingly little effect - especially for the transition into temporary employment and for the transition to permanent employment. Besides this, the determinants seem to matter most in Finland and Sweden compared to Denmark and Norway.

For the transition from outside employment to temporary employment, a similar pattern was found in all countries - women make the transition into temporary employment to a larger degree than men. Singles are also more likely to make the transition in most countries. In Finland and Sweden, national origin also played a role for the transition. So did a former position as student in Denmark, Norway and Sweden.

For the transition to permanent work, we did in fact see more crossnational differences. In Finland women are less likely to move to permanent work, while no effect was found in the other countries. In Finland and Sweden, working in certain sectors also gave a lower risk of moving to permanent work. Industries did not play a significant role in Denmark and Norway. From this analysis we also learned that persons with a for- 
eign background are just as likely as natives to move to permanent employment. The same goes for level of education and occupational categories. We have therefore not found evidence that those moving into permanent employment are more educated or more skilled than those who stay in temporary employment.

However, for the transition to a position outside employment we did find more significant results than in the previous analyses. We have found evidence in most countries that persons with a foreign background, less educated people, and persons in the lower occupational groups have elevated odds of moving to unemployment or inactivity. This could indicate the presence of some sort of selection mechanism where the less skilled and less educated temporaries tend to move away from employment. They still have the same probability of moving to permanent work, but they tend to a larger degree to move to positions outside employment.

\subsection{Predicted probabilities for transitions}

In order to illustrate better some of the cross-national similarities and differences from the previous multivariate analyses, we have calculated the predicted probabilities for the transitions for a number of selected categories. The point is to create different models or ideal types of persons and then calculate the groups' probability of making a certain transition. This is done for different groups in each country.

We will start with the transition from non-employment to temporary employment. In Diagram 6.1 we have created four ideal types - an unemployed male model, an unemployed and single female model, an unemployed non-native model and a female student model. What the different models more precisely consist of can be read below the diagram. The four bars to the left in the diagram refer to the unemployed male model. In Finland and Sweden the probability for this group to become temporary employees is higher than in Denmark and Norway. The Finnish bar is highest and the Swedish bar is second but very close to Finland. Denmark is third and Norway fourth, and they are also placed very close to each other. In the next model we have unemployed single women. In all countries we see a rather sharp increase in the probabilities compared to the male model. In the third model we have an unemployed male with an origin outside Europe or North America. In Denmark, Norway and Sweden the probabilities resemble the ones in the male model. This is, however, not the case in Finland, where this model has around the same probability as the female model of moving to temporary employment. The last model refers to a female student. We find that this model has the highest probability in Sweden and next Finland. Denmark comes third and Norway fourth. Thus, the general picture from Diagram 6.1 is that regardless of the characteristics of the models, the probabilities of making the transi- 
tion to temporary work are always higher in Finland and Sweden compared to Denmark and Norway. Norway is in general the country with the lowest probabilities. In Norway there also seem to be the smallest differences between the probabilities in the different models. On the other hand, Finland and Sweden are the two countries with the highest probabilities of becoming temporary employees.

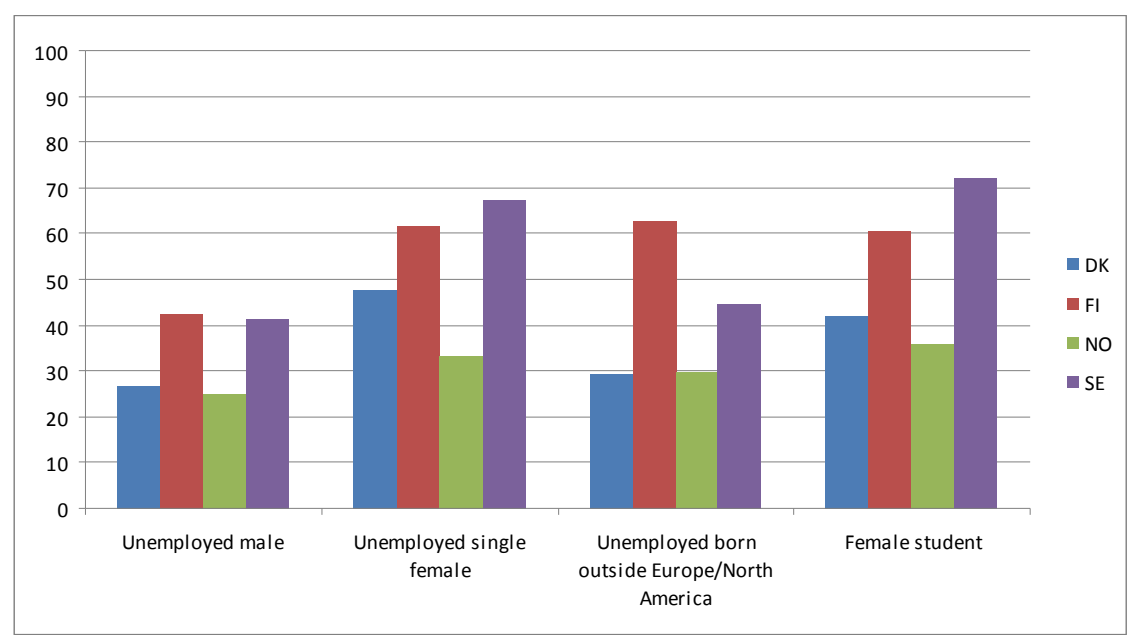

Diagram 6.1 Predicted probabilities for various categories of not employed at $t$ to be in temporary employment at $t+1$.percent.

Note: Unemployed male: man, 45-54 years old, married, primary education, native born, unemployed at $t$, low county unemployment, no change in national unemployment rate. Unemployed and single female: male model but male is replaced by a woman with children and married is replaced with single. Unemployed born outside Europe/North America: male model but native born replaced with born outside Europe or North America. Female student: woman, 16-24 years old, living alone, primary education, native born, student at $t$, low county unemployment, no change in national unemployment rate.

The next type of transition of interest is from temporary employment to permanent employment. The probabilities of making this transition for different groups are shown in Diagrams 6.2 and 6.3. In the first diagram are different models of professional ideal types, and in the second are different models of service workers. Starting with the professional models in Diagram 6.2, the first thing to notice is that professionals have the highest probability of becoming permanent employees in Norway and Denmark, compared to Finland and Sweden. Norway is in general placed highest and Denmark second. Sweden is third and Finland fourth. The general picture in Diagram 6.2 is that nothing major happens with the probabilities in the different models when certain characteristics are changed. This means that certain groups of professionals in each country do not differ very much from each other when it comes to the probability of moving to permanent work. However, there is one change worth mentioning. In Finland when the man (male professional model) is replaced with a woman who is working slightly fewer hours than the man but still has all the same characteristics (female professional model), the probabilities decrease somewhat in Finland. 


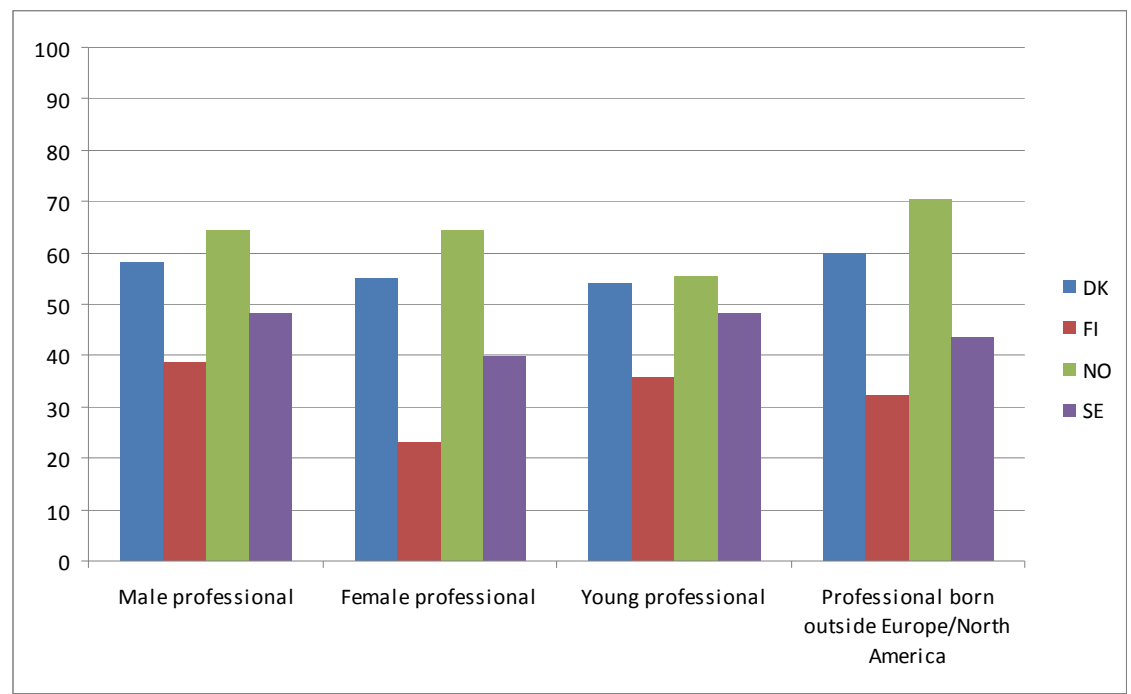

Diagram 6.2 Predicted probabilities for professionals' transitions from temporary employment at $t$ to permanent employment at $t+1$.percent

Note: Male professional model: man, 45-54 years old, married, tertiary education, full time work (35+ weekly hours), health care, professional, size of workplace $50+$, low county unemployment, no change in national unemployment rate. Female professional model: male model but male is replaced by a woman with children and full-time work is replaced with 30-34 hours per week. Young professional model: male model but 45-54 years replaced with 25-34 years. Professional born outside Europe/North America model: male model but native born replaced with born outside Europe or North America.

In Diagram 6.3 we have calculated the predicted probabilities for groups of lower educational levels and lower occupational groups compared to the professional models - that is, people with a primary level of education working as service workers in the industry "social and personal services". Looking at the model in general, we again find the highest probabilities in Norway and Denmark and the lowest in Finland and Sweden. Norway actually has very high probabilities of becoming permanent employees in all the service worker models. Denmark is second, Sweden third and Finland fourth. Thus, the pattern is the same as with the professional models.

As with Diagram 6.2, nothing major happens with the probabilities in the different models when certain characteristics are changed. However, in Denmark and Norway we see lower probabilities in the young professional models compared to the other three models. In Finland and Sweden the probabilities seems a bit lower in the female professional model. 


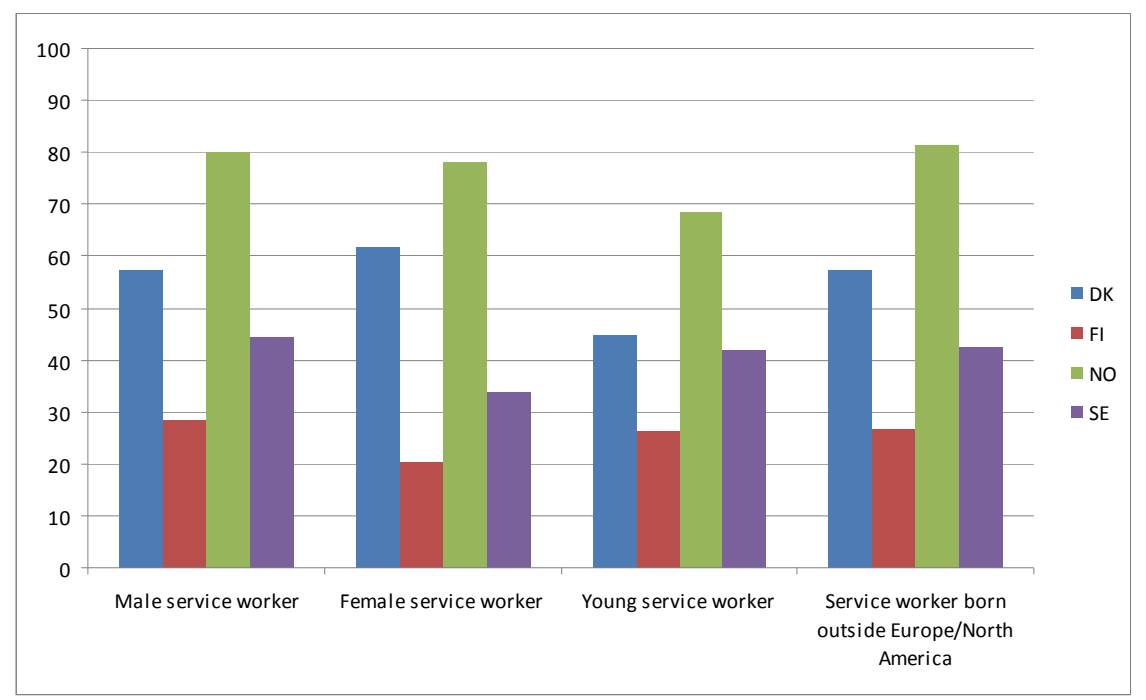

Diagram 6.3 Predicted probabilities for service workers transitions from temporary employment at $t$ to permanent employment at $t+1$.percent

Note: Male service worker model: man, 45-54 years old, married, primary education, full time work (35+ weekly hours), social and personal services, service worker, size of workplace 50+, low county unemployment, no change in national unemployment rate. Female service worker model: male model but male replaced with woman with children and working time replaced with 20-29 hours per week. Young service worker model: male model but $45-54$ years replaced by $16-24$ years and married replaced with single. Service worker born outside Europe/North America model: male model but native born replaced by born outside Europe or North America.

In the next two diagrams we have the predicted probabilities for the transitions to unemployment. In these diagrams we have used the same ideal types as in Diagrams 6.2 and 6.3. In Diagram 6.4 we have different models of professionals. The first thing to notice is that the professional models in general have low probabilities of becoming unemployed in all countries. The probabilities are higher in Denmark and Finland compared to Norway and Sweden. In some models the highest probability is found in Denmark, while in other models it is the Finnish bars that are highest.

When it comes to the different models, certain things are worth mentioning. First of all, the highest probability in all models is found in the Finnish female professional model. Secondly, the young professional models seem to have the lowest probabilities of moving to unemployment in all countries. A reason could be that if young temporaries lose their job, they do not move to unemployment but go into the educational system instead. Thirdly, we also see that in all countries having a nonEuropean background elevates the probability of becoming unemployed. For this model, the probability is highest in Denmark and Finland. 


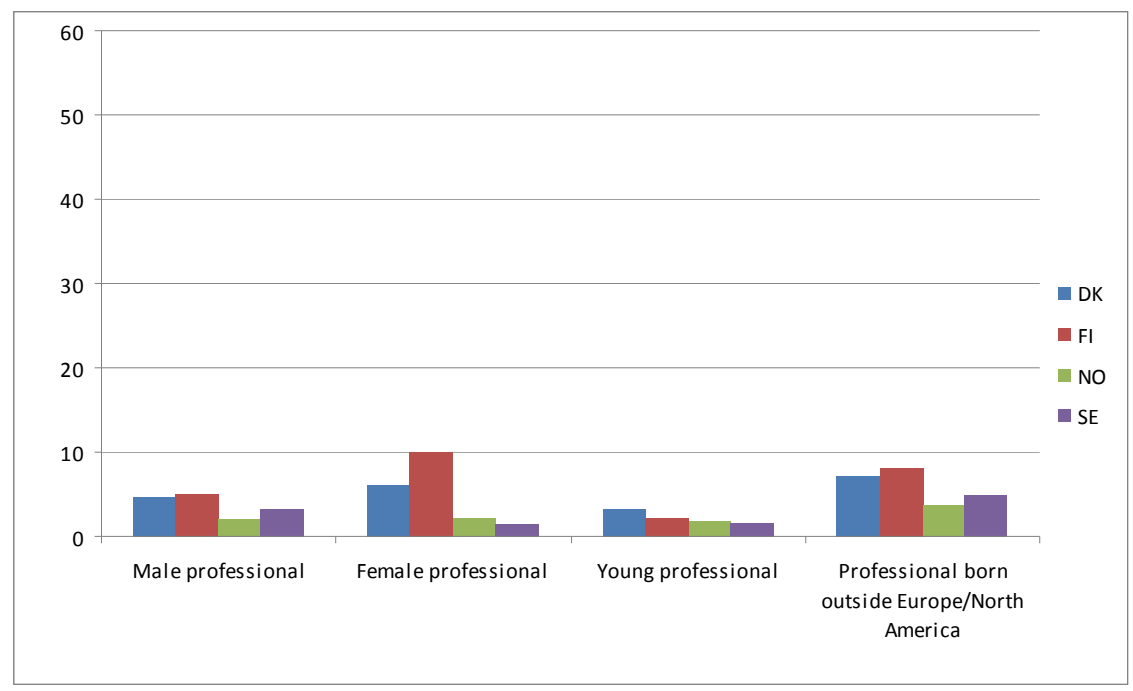

Diagram 6.4 Predicted probabilities for professionals' transitions from temporary employment at $t$ to unemployment at $t+1$.percent.

Note: Male professional model: man, 45-54 years old, married, tertiary education, full time work (35+ weekly hours), health care, manager or professional, size of workplace 50+, low county unemployment, no change in national unemployment rate. Female professional model: male model but male is replaced with a woman with children and full-time work is

replaced with 30-34 hours per week. Young professional model: male model but 45-54 years replaced with 25-34 years. Professional model born outside Europe or North America: male model but native born replaced with born outside Europe or North America.

In the next and last model we have the predicted probabilities for the service worker models. Again, the probabilities are higher in Denmark and Finland than in Norway and Sweden. When comparing with the previous diagram we see that the service worker models in general have higher probabilities than the professional models. This means that the service worker models in general have higher risk of unemployment than the professional models of temporary employees. Those who are most at risk in all countries are service workers with an origin outside Europe or North America. Women are also more at risk in especially Finland. Young people are least at risk in all countries. The explanation is probably the same as before - that young people to a larger degree move to the educational system rather than to unemployment. 


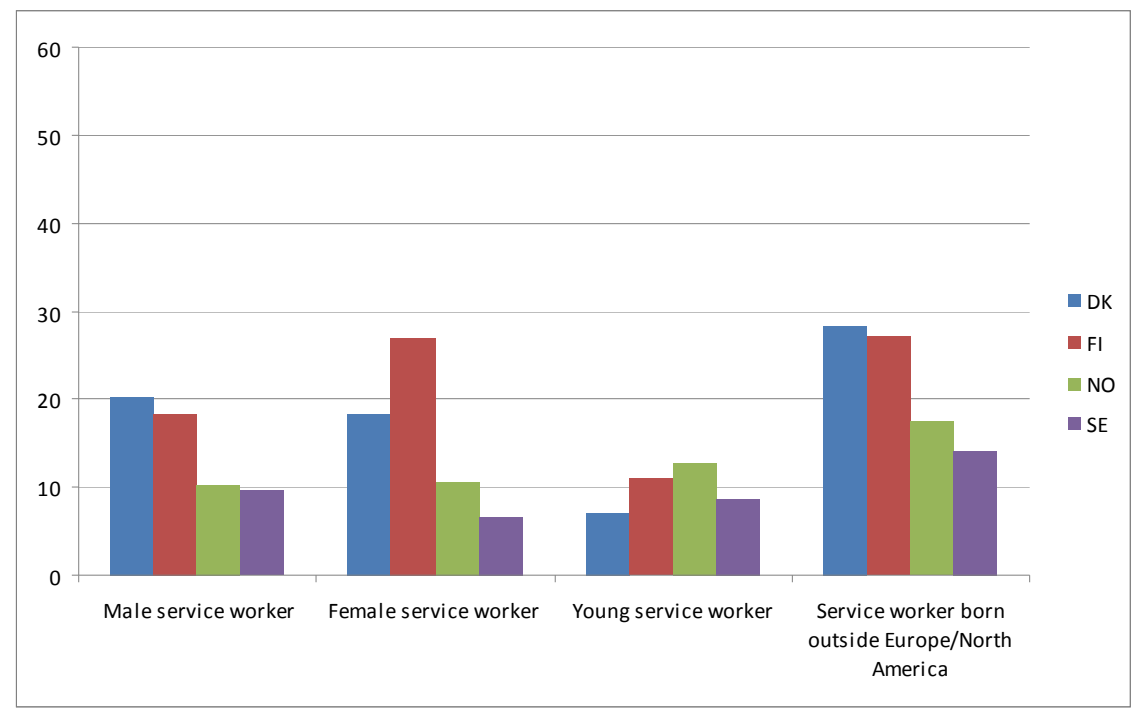

Diagram 6.5 Predicted probabilities for service workers transitions from temporary employment at $t$ to unemployment at $t+1$.percent.

Note: Male service worker model: man, 45-54 years old, married, primary education, full time work (35+ weekly hours), social and personal services, service worker, size of workplace $50+$, low county unemployment, no change in national unemployment rate. Female service worker model: male model but male replaced with woman with children and working time replaced with 20-29 hours per week. Young service worker model: male model but $45-54$ years replaced by 16-24 years and married replaced with single. Service worker born outside Europe or North America model: male model but native born replaced by born outside Europe or North America.

\subsection{Country differences}

So far we have investigated differences and similarities between the four countries when it comes to mobility to and from temporary employment, and we have in fact found a great deal of cross-national differences. This was especially evident when we calculated predicted probabilities for some of the transitions. In this last section of the chapter we will have a closer look at what happens when the data from all the regressions are run in the same model - just as we did in chapter 5. Again, the idea is to control for as much variation as possible caused by differences in characteristics of the workers, the industrial structure, the levels of unemployment in the countries etc. If there are still - after controlling for all these factors significant differences between the countries, then it may indicate that these differences can to be explained by the institutional arrangements in the four countries.

As in chapter 5, the following analyses also include three different models. In the first model only country is included. In the subsequent two models a larger number of control variables are stepwise taken in for the purpose of checking whether national differences can be explained that way. The reference category is the mean of odds for the four countries. As in chapter 5 we use another classification of county unemployment levels in model 3. We still have a distinction between low, medium and 
high unemployment levels but they are defined relative to the Nordic average (more about this in chapter 4).

Table 6.7 focuses on the transition from non-employment to temporary work. In model 1, where only country is included, we see that Sweden and Finland have higher odds than the mean for unemployed individuals making the transition to temporary work rather than permanent work, compared to both Denmark and Norway. We saw the same tendency in Table 6.2 in the beginning of the chapter. When control variables are included in models 2 and 3 a few changes in the odds take place. However, the overall picture remains the same - Sweden has the highest odds for non-employed persons moving to a temporary job rather than a permanent job, Finland is second, Denmark third and Norway fourth.

Table 6.7 Odds ratios for four Nordic countries regarding transitions from nonemployment (unemployed, student and inactive) to temporary employment, 20002006. Binomial logistic regression.

\begin{tabular}{llll}
\hline Country (ref.=mean of odds) & Model 1 & Model 2 & Model 3 \\
\hline Denmark & 0.66 & 0.67 & 0.70 \\
Finland & 1.39 & 1.47 & 1.23 \\
Norway & 0.55 & 0.52 & 0.61 \\
Sweden & 1.98 & 1.94 & 1.89 \\
\hline
\end{tabular}

No sign $=p<0.05$

Note: Model 1 includes only country as independent variable. Model 2 includes country and all the variables in Table 6.4 except county unemployment level and change in national unemployment. Model 3 includes country and all the variables in table 6.4 but with another classification of county unemployment rates.

Table 6.8 focuses on the transition from temporary work to permanent work. The three models are the same as in the previous table. In model 1 where only country is included, we see that Denmark and Norway have odds above the mean while Finland and Sweden have odds below the mean. This means that temporaries in Denmark and Norway have a greater chance of moving to permanent work than temporaries in Finland and Sweden. This was already revealed in Table 6.2 in the beginning of the chapter. When the control variables are added in models 2 and 3 there are some small changes in the odds ratios but the overall pattern remains the same. A temporary employee in Norway has the best opportunities of moving to permanent employment; then come Denmark, Sweden, and finally Finland where the temporary employees have the least chance of moving to permanent work. 
Table 6.8 Odds ratios for four Nordic countries regarding transitions from temporary employment to permanent employment, 2000-2006. Binomial logistic regression.

\begin{tabular}{llll}
\hline Country (ref.=mean of odds) & Model 1 & Model 2 & Model 3 \\
\hline Denmark & 1.42 & 1.41 & 1.39 \\
Finland & 0.52 & 0.48 & 0.55 \\
Norway & 1.91 & 2.05 & 1.77 \\
Sweden & 0.71 & 0.72 & 0.74 \\
\hline
\end{tabular}

No sign $=p<0.05$

Note: Model 1 includes only country as independent variable. Model 2 includes country and all the variables in Table 6.5 except county unemployment level and change in national unemployment. Model 3 includes country and all the variables in Table 6.5 but with another classification of county unemployment rates.

In the next two tables we have the transition from temporary employment to unemployment and inactivity. Starting with the transition to unemployment (Table 6.9) we see that when only country is in the model, Denmark and Finland are placed above the mean odds and therefore have higher risk of transition to unemployment. Norway is placed below the mean and Sweden is placed not significantly different from the mean odds. When the individual and work-related variables are included in model 2, the same pattern exists, except for the fact the Sweden is now placed significantly different below the mean odds. In the final model where the two unemployment measures are included, we still see the same pattern. In Denmark the highest risk of a temporary worker moving to unemployment is found, and then comes Finland which is placed very close to the level in Denmark. Sweden and Norway are placed below the mean (Norway lowest) with the least risk of a temporary employee becoming unemployed.

Table 6.9 Odds ratios for four Nordic countries regarding transitions from temporary employment to unemployment, 2000-2006. Binomial logistic regression.

\begin{tabular}{llll}
\hline Country (ref.=mean of odds) & Model 1 & Model 2 & Model 3 \\
\hline Denmark & 1.29 & 1.24 & 1.26 \\
Finland & 1.34 & 1.40 & 1.20 \\
Norway & 0.61 & 0.64 & 0.79 \\
Sweden & $0.95 \mathrm{~ns}$ & 0.90 & 0.84 \\
\hline
\end{tabular}

No sign $=p<0.05$, ns $=$ not significant

Note: Model 1 includes only country as independent variable. Model 2 includes country and all the variables in Table 6.6 except county unemployment level and change in national unemployment. Model 3 includes country and all the variables in Table 6.6 but with another classification of county unemployment rates.

In Table 6.10 we have the country analysis of the transition from temporary work to inactivity. In model 1 where only country is included in the model, Finland has the highest transition rate to inactivity, while Denmark is placed just under the mean odds. Norway and Sweden do not differ from the mean odds. In models 2 and 3 when the rest of the control variables are included, some odds ratios increase and some decrease. The overall picture is that Finland keeps having the highest transition rate to 
inactivity out of the four countries, Sweden and Norway have the lowest, and Denmark is placed not significantly different from the mean odds.

Table 6.10 Odds ratios for four Nordic countries regarding transitions from temporary employment to inactive (students included), 2000-2006. Binomial logistic regression.

\begin{tabular}{llll}
\hline Country (ref.=mean of odds) & Model 1 & Model 2 & Model 3 \\
\hline Denmark & 0.92 & $1.04 \mathrm{~ns}$ & $1.03 \mathrm{~ns}$ \\
Finland & 1.09 & 1.25 & 1.24 \\
Norway & $0.99 \mathrm{~ns}$ & 0.86 & 0.90 \\
Sweden & $1.01 \mathrm{~ns}$ & 0.90 & 0.87 \\
\hline
\end{tabular}

No sign $=p<0.05, n s=$ not significant

Note: Model 1 includes only country as independent variable. Model 2 includes country and all the variables in Table 6.7 except county unemployment level and change in national unemployment. Model 3 includes country and all the variables in Table 6.7 but with another classification of county unemployment rates.

The aim with this last section of the chapter has been to explore whether differences in transition rates to and from temporary employment exist when controlled for as much variation as possible. Throughout this section, we have learned that there are indeed differences between the countries. Firstly it is more normal, especially in Sweden but also in Finland, that non-employed persons enter employment in a temporary contract compared to a permanent one. In Denmark and especially Norway, it is easier for temporary employees to move into permanent work compared to Sweden and Finland. Regarding transitions from temporary employment to positions outside employment, Denmark and Finland have the highest scores and Norway and Sweden the lowest. Finnish temporaries are most likely to move to inactivity, and second most likely to move to unemployment. In Denmark it is the other way around.

\subsection{Conclusion}

The objective of this chapter has been to study transitions into and out of temporary employment in Denmark, Finland, Norway and Sweden. One of the main questions has been whether patterns of transitions differ across the four countries and whether differences can be explained with reference to the different institutional arrangements.

From this chapter we most certainly can conclude that patterns differ between the countries. We have learned that being a temporary employee is much more common in Finland and Sweden than in Denmark and Norway. It is also clear that temporary contracts play different roles in Finland and Sweden compared to Denmark and Norway.

In Finland and Sweden more people are likely to enter the labour market with a temporary rather than a permanent contract. Temporary employees are also less likely to move to permanent work in these two countries. When it comes to transitions out of temporary employment we do, however, see differences between Finland and Sweden. Swedish tempo- 
raries tend to stay in temporary employment while Finnish temporaries seem to move out to positions outside employment. Even though we find differences between the two countries here, it is still indicated that temporary employment can be associated with the "trap"metaphor to a larger degree in Finland and Sweden than in Denmark and Norway. At least it seems that in Finland and Sweden, there is a more segmented labour market with permanently employed insiders and temporarily employed outsiders.

In Denmark and Norway non-employed persons are less likely to enter the labour market in a temporary job than in Sweden and Finland. In Denmark where there is the lowest EPL, this was somehow expected since there is the smallest difference between the EPL for regular workers and temporary workers here. In Norway the restrictions on the use of temporary workers could be an explanation for the lower probability of starting on the labour market in a temporary job. Norway gives the best opportunities of all the four countries to move to permanent work. This result is in line with previous studies (i.e. Neergaard 2004). Denmark has the second highest probability of moving to permanent employment. When it comes to transitions to non-employment the two countries differ. In Norway the odds of a temporary employee becoming either unemployed or inactive are the lowest. However, in Denmark temporary employees have elevated odds compared to the other countries. But since Denmark is a rather mobile country where many move between employment, unemployment and inactivity, this transition may not be as severe in Denmark as in the other countries. This suggests that temporary employment in Denmark and Norway is associated with the "bridge" or "stepping stone" metaphor to a larger degree than in Finland and Sweden.

This said, however, it is also clear that temporary employment can be a springboard for some people in Finland and Sweden - just as temporary employment can be a trap for certain groups in Denmark and Norway. 



\section{Mobility in and out of part-time work}

\subsection{Introduction}

The focus of this chapter is on working hours and part-time work in the Nordic countries. Part-time work can be regarded as atypical in the same way as temporary employment, i.e. a type of employment that differs from the "standard or 'typical' model of full-time, regular, open-ended employment with a single employer over a long time span" (European industrial relations dictionary ${ }^{19}$ ). Part-time appointments may increase employer's flexibility, and are thus a factor in the flexicurity discussion. Here part-time tends to be placed in the category "internal numerical flexibility" (Employment in Europe 2006; Wilthagen et al. 2003; European Foundation 2008), as opposed to fixed-term appointments that result in external numerical flexibility. The concept of "working time flexibility" is also used. Employers achieve greater flexibility primarily through working hours (percent of a full position) being geared to the needs of the enterprise. But part-time employment can also offer employers greater flexibility because employees can be asked to work more as needed, and because part-time appointments can be used to meet labour requirements extending beyond normal working hours (evenings, weekends). In the latter case there will often be a close connection between part-time and other types of atypical work (on-call workers, students with extra jobs etc.).

The option of working part-time can make it easier for employees to combine economic activity with schooling, continuing education or the care of children, and thereby contribute to increased employment, especially among women. An example that is often cited is that of the Netherlands, which in the 1980s and 1990s experienced a substantial increase in employment when women moved from inactivity into part-time jobs (Visser 2002). Steps to facilitate part-time work have therefore been an important part of the EU employment strategy. Not the least of these has been ensuring equal treatment of part-time and full-time employees (see the EU Directive on part-time work). Employment in Europe 2008 also shows that growth has been far stronger for part-time than for full-time positions (European Commission 2008).

Although easing the way for part-time work is often regarded as a means of getting more people into work, part-time work poses a number of challenges. A not insignificant share of those who work part-time do

\footnotetext{
${ }^{19}$ http://www.eurofound.europa.eu/areas/industrialrelations/dictionary/definitions/atypicalwork.htm
} 
so because they are not offered a full-time position (involuntary parttime). Thus employees who do involuntary part-time work may be regarded as partly unemployed. Part-time work will also have consequences for the work situation of the individual employee: working environment, involvement in the workplace, salary, career, access to continuing education and further education, rights in the national insurance system and future pension. Part-time employees are normally heavily dominated by women, which means that women as a group will also be in a less favourable position with respect to salary, career and pension.

There are differences from country to country in how common parttime work is and how well part-time employees are integrated into working life, for example measured by the risk of exiting the labour market and the probability of switching to a full-time position (O'Reilly and Bothfeld 2002; Gash 2008). Although researchers place emphasis on institutional factors such as formal and informal barriers to part-time work in legislation and agreements (Visser 2002; Lind and Rasmussen 2008; Buddelmeyer et al. 2008), explanations relating to women's opportunities for working while they have small children are central in studies of part-time working. Good child-care schemes make it possible for mothers of small children to remain in work, thereby contributing to a high participation rate for women and a more stable labour market affiliation, also for those who work part-time. It may therefore be asserted that women's part-time work has been normalised, not only in that part-time work is common, but also in that part-time employees as such cannot be regarded as a marginal group in the labour market in the sense that they have an uncertain affiliation (see for example Ellingsæter 1995). However, factors such as the tax system and rules for unpaid parental leave will also affect the behaviour of women in the labour market in countries without this type of welfare state scheme. This applies not least to mobility into and out of work (O'Reilly and Bothfeld 2002). Preferences are also used as an explanatory factor in the discussion of part-time work by women, and it is pointed out that choice of working hours can be seen as a family compromise, where overall income and caring tasks in the home are the reason that women with children often elect to work part-time while the male spouse works full-time (for instance Fagan and O’Reilly 1998).

Other factors than women's labour market affiliation, will also affect the supply of part-time work in a labour market. A highpercentage of young people in secondary or tertiary education will for example normally mean a larger supply of relatively cheap and flexible labour wanting to work part-time (Buddelmeyer et al. 2008). This means that the share of part-time workers will increase when higher education becomes common for young adults in their 20s. A study of the Danish labour market shows that young employees make up an increasing share of part-time employees (Lind and Rasmussen 2008). 
In an international context, all the Nordic countries stand out as having good paid parental leave and subsidised child-care schemes. These are factors that prompt women to choose work (including part-time work) rather than to leave the labour market during the phase when they have small children. All the Nordic countries have implemented the EU parttime directive, which requires egalitarian treatment of part-time and fulltime employees. This has caused the removal or lowering of some thresholds for part-time employees with respect to rights in working life (Andersen, ed. 2003), and has caused the inclusion in the legislation of provisions prohibiting discriminatory treatment. Finland, Sweden and Norway also have provisions that entitle the parents of small children to reduced working time (part-time positions), while Denmark has had a special act on part-time work since 2004.

The issues discussed in this chapter are:

- How many people work part-time in the Nordic countries, and who are they?

- To what extent does the transition from inactivity to employment take place via part-time employment?

- Do part-time employees have greater mobility out of the labour market than full-time employees?

- How common is it for part-time employees to increase their working hours?

\subsection{Part-time and working hours - definitions}

There is no definitive definition of part-time work. A widely used approach is to say that part-time is normal/usual weekly working hours that are lower than those defined as constituting a full-time position in the industry or profession. This interpretation forms the basis for the EU Directive on part-time work. For the purposes of quantitative and comparative analysis, information from employees as to whether their position is full-time or part-time is often used as a basis for the definition. However, this type of information is not always available. Alternatively, a cut-off is made at for example 30 hours or 35 hours, and longer working hours than this are defined as full-time. ${ }^{20}$

In the Nordic countries, both legislation and collective wages agreements define normal working hours for full-time employees. Legislation sets the maximum average weekly working hours at 40 per week in Finland, Norway and Sweden, and 48 hours in Denmark (EIRO 2007a). The working hours laid down in the collective wages agreement (average

\footnotetext{
${ }^{20}$ See for example the OECD Glossary of Statistical Terms (http://stats.oecd.org/glossary /detail.asp?ID=3046). The OECD uses a cut-off of 30 hours in its analyses. Eurostat mainly uses information about whether the position is full-time or part-time, and therefore arrives at a substantially higher part-time share than that with which the OECD operates.
} 
weekly working hours) will be lower, on the whole, and may vary from sector to sector. Contractual working hours are normally 37.5 hours in Finland, Norway and Sweden, and 37 hours in Denmark. ${ }^{21}$ Employees who work shifts or do rotation work will have lower weekly working hours than is usual for similar daytime work, which means that employees with 32-33 working hours a week may have a full position. There is not sufficient information in our dataset to distinguish between full-time and part-time work in such cases. For Denmark, Finland and Norway we have information from employees as to whether they work full-time or part-time, while we have not included similar information for Sweden in the combined Nordic dataset. We have therefore chosen a classification based on number of hours with the starting point in agreed working hours or normal weekly working hours.

Our starting point is agreed or usual working hours in main employment. This means that work in an additional position is not included in our concept of working hours. For employees with a working hours agreement such that working hours vary from week to week (shift and rotation work), agreed/usual working hours refer to average weekly working hours. Our data for Norway and Sweden concerns agreed working hours - i.e. overtime and/or additional work are not included. For Denmark and Finland we have information about usual working hours. In the latter countries, overtime and additional time will be included if the employee usually works more than the agreed number of hours (see Chapter 4.6). In the analysis, we use the following classification of length of working hours:

- Short part-time (agreed/usual weekly working hours of 1-19 hours per week)

- Long part-time (agreed/usual weekly working hours of 20-34 hours per week)

- Full-time (agreed weekly/usual working hours of 35 hours or more per week)

This means that some employees in full-time positions will be classified as long part-time, and that some who have a part-timepercentage that is close to a full-time position (in most cases 90 per cent or more) may end up in the full-time category. The data from Denmark, Finland and Norway indicate whether the position is a full-time or part-time position in the Nordic dataset. The share of employees who state that they work fulltime, but who have weekly working hours of less than 35 hours (and are accordingly classified by us as part-time), varies from 9 per cent of those who are classified as working long part-time in Norway to 29 per cent in Finland.

\footnotetext{
${ }^{21} \mathrm{http} / / / w w w . e u r o f o u n d . e u r o p a . e u / e i r o / s t u d i e s / t n 0804029 s / t n 0804029 s . h t m \# h d 1$
} 
We also look at change in working hours over time, i.e. whether the employee has increased or reduced his or her weekly working hours. Our starting point here is the three main categories short part-time (1-19 hours), long part-time (20-34 hours) and full-time (35 hours or more). We consider whether the employee has changed his or her working hour status in the course of a year, for example changed from short part-time to long part-time, from full-time to long or short part-time etc. However, we make the requirement that the change in agreed/usual working hours must be at least 5 hours. This means that if employees change from shift/rotation work to daytime work this will generally not entail a change in classification, and minor changes in working hours that do not reflect major changes in job situation are not included. Changes within short part-time or within long part-time are not covered by the definition we have chosen to use either.

\subsection{A general overview: who works part-time?}

There are clear national differences in the scope of part-time work in the Nordic countries. In Chapter 2 (Figure 2.12) we showed that Finland differs from the other Nordic countries in having a low share of part-time workers. Norway has the highest share of part-time workers among people in employment (27-28 per cent) ${ }^{22}$, but Sweden and Denmark are also distinctly higher than the EU average. The part-time share in Table 7.1 is based on Eurostat data broken down by gender and age group. The share of part-time employees has increased substantially among young employees in all countries, particularly in Denmark (both genders) and among young women in Norway. However the increase for Norway is somewhat exaggerated by a change in 2003 in the manner in which Eurostat defines part-time. The part-time share for core-age employees (aged 25-59) is fairly stable for the period 2000-2006, with the exception of Sweden, where the part-time share increased for women.

\footnotetext{
${ }^{22}$ Eurostat does not use information on Norway supplied by informants in the Labour Force Survey as to whether positions are full-time or part-time. This results in a part-time work share that is approximately 1-2 percentage points lower for the period 2003-2008 than it would be if this information had been used. Note that there is a break in Eurostat's data series for Norway in 2003.
} 
Table 7.1 Difference in part-time share 2000 to 2006 , by gender and age.

\begin{tabular}{lrrrrrr}
\hline & & Aged 15-24 & & & Aged 25-59 & \\
& $\mathbf{2 0 0 0}$ & $\mathbf{2 0 0 6}$ & Difference & $\mathbf{2 0 0 0}$ & $\mathbf{2 0 0 6}$ & Difference \\
\hline Female & & & & & & \\
Denmark & 57.7 & 69.5 & 11.8 & 30 & 28.5 & -1.5 \\
Finland & 44.2 & 50.8 & 6.6 & 12.2 & 13.3 & 1.1 \\
Norway & 57.4 & 69.5 & 12.1 & 39.9 & 40 & 0.1 \\
Sweden & 49.4 & 57.7 & 8.3 & 33.3 & 36.8 & 3.5 \\
\hline Male & & & & & & \\
Denmark & 36.5 & 47.9 & 11.4 & 4.3 & 6 & 1.7 \\
Finland & 22 & 27.9 & 5.9 & 4.6 & 4.9 & 0.3 \\
Norway & 37.1 & 40.7 & 3.6 & 6 & 8.3 & 2.3 \\
Sweden & 27.6 & 28.3 & 0.7 & 6 & 7.4 & 1.4 \\
\hline Total & & & & & & \\
Denmark & 46.8 & 58.4 & 11.6 & 16.3 & 16.6 & 0.3 \\
Finland & 32.8 & 39.3 & 6.5 & 8.2 & 8.9 & 0.7 \\
Norway & 46.8 & 55.1 & 8.3 & 21.8 & 23.2 & 1.4 \\
Sweden & 38.3 & 42.2 & 3.9 & 19 & 21.3 & 2.3 \\
\hline
\end{tabular}

Source: Eurostat, Labour Force Surveys

In Diagram 7.1 we change to our Nordic dataset, which covers the period 2000-2006 (2005 for Denmark), and look at women's and men's working hours separately. The classification is based on agreed weekly working time (number of hours), and distinguishes between short and long parttime. There are only small differences between countries in the part-time share for men, albeit with a somewhat higher share for Norwegian men who claim to have agreed weekly working hours of less than 20 hours. The big differences are to be found among women. Finland stands out with a low share of women working part-time (22 per cent of women work less than 35 hours per week). Norway not only has a high share of part-time employees (46 per cent), but also a high number of women who work short part-time (1-19 hours per week). Denmark and Sweden have approximately the same share of part-time women employees (37-38 per cent in our underlying data), and long part-time predominates here (2034 hours per week). 


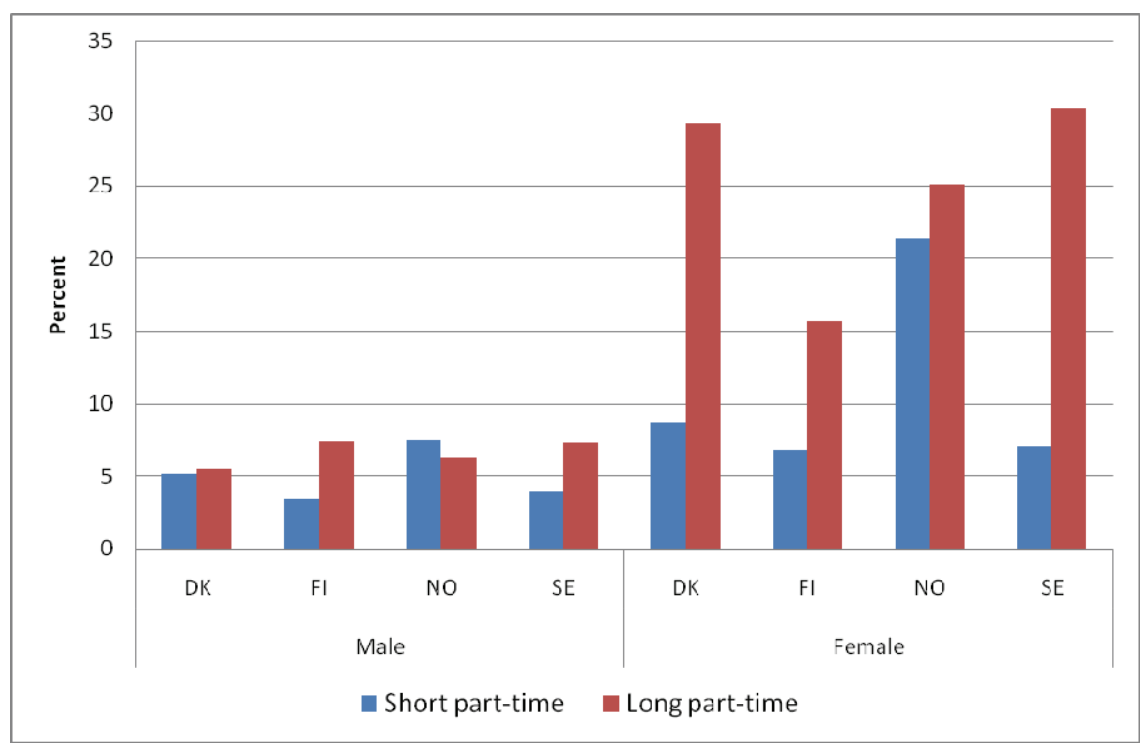

Diagram 7. 1 Agreed weekly working hours by gender and country, persons aged 16-63. Average for the period 2000-2006 (2000-2005 for Denmark). Share of employees with short part-time (1-19 hours per week) and long part-time (20-34 hours per week).

Part-time work is strongly associated with youth and entry into working life (Diagrams 7.2a and 7.2b), but this applies to a far greater extent to men than to women. Part-time work is also more usual among the oldest workers in our data - those in the age group 60-63. Again we see that there are small differences amongst the Nordic countries for men. Young Finnish men work full time more often than young men in the other Nordic countries, and Finnish men aged over 60 have working hours of less than 35 hours per week more often than others. One explanation may be the Finnish pension system, which makes it simpler to combine part-time work and a pension. The general pattern of the employment life-cycle of women, too, is fairly similar across the Nordic countries. Part-time is most common in the youth phase and increases again among the oldest employees. The part-time share for the age groups between 25-54 is fairly stable, and the difference in levels between countries is systematic - lowest in Finland and highest in Norway for all age groups. Part-time work is thus common for women aged 25-54 in the Nordic countries except, to some degree, Finland. 

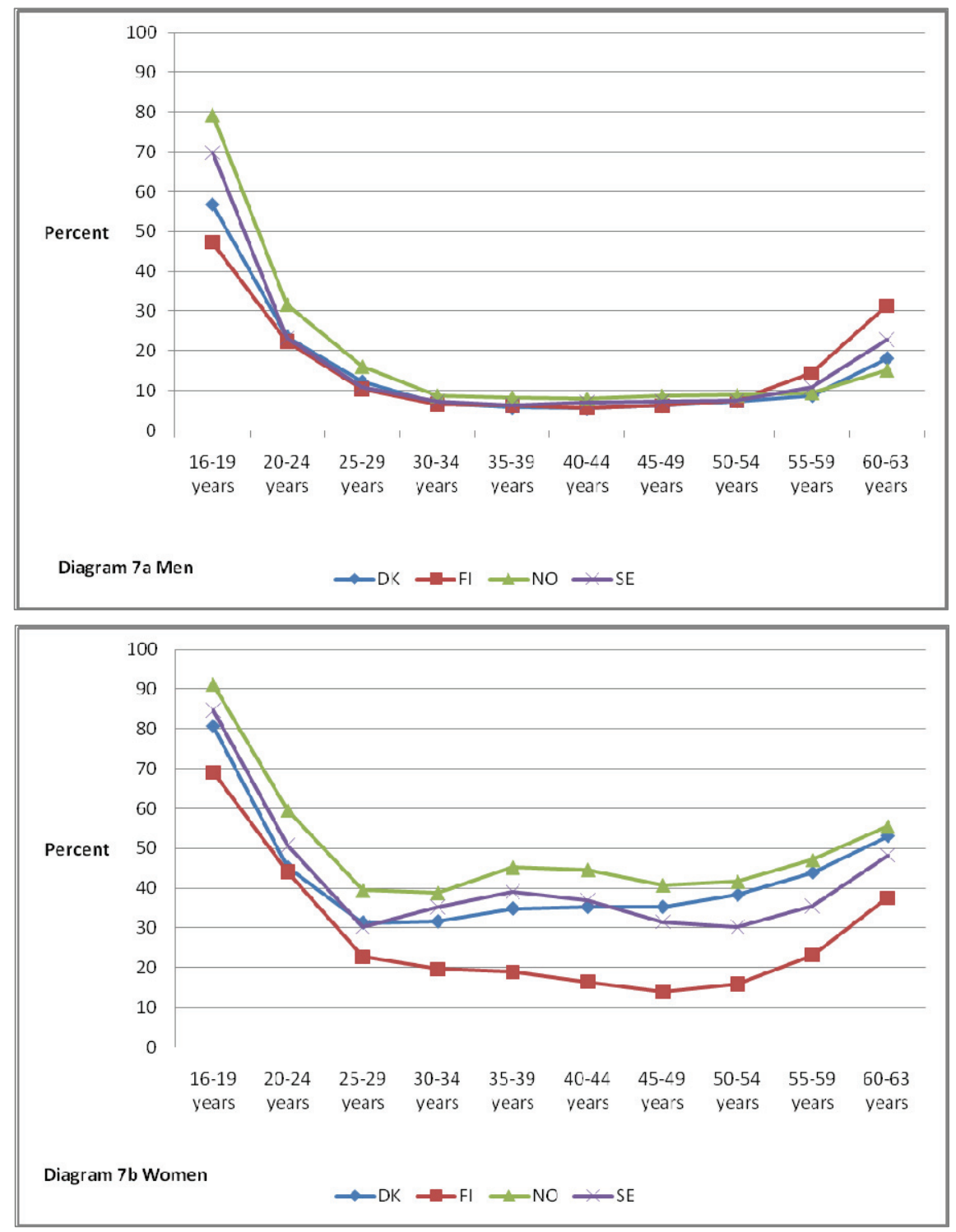

Diagrams 7.2a and 7.2b: Share of employees with agreed working hours of less than 35 hours per week (part-time), by age and country. Men (7.3a) and women (7.3b). 20002006 (2005 for Denmark).

\subsubsection{Who are the part-time workers - multivariate analysis?}

We performed a multivariate analysis (binary logistic regression) for each of the four countries, to investigate whether there is a common pattern for the probability of working part-time, or whether the various Nordic models vary with regard to who works part-time and what phase of working life they are in. We know that part-time can be a different matter for women and for men, and have therefore carried out separate analyses, by gender (Table 7.2). 
- The age effects seen in diagrams 7.2a and b continue to hold true when we control for other characteristics of the employee and the labour market. Employees aged under 25 work part-time far more often than the age group 25-54, and the oldest workers also have a higher probability of working part-time (less than 35 hours a week) than the reference category, which is $45-49$ years. This applies to all countries and both genders, but the difference between the youngest employees and the reference category is widest among Finnish and Norwegian men. Finland also differs in that the oldest workers have a high probability of working part-time.

- Being married or living in a partnership reduces the probability of men working part-time, while the effect is the opposite for women. Finland is the exception here: married women and women living in partnerships do not have a higher probability of working part-time than men. Having children at home increases the probability of women working part-time in all countries, while the effect of having children is smaller and less clear for men.

- The probability of men working part-time increases for non-natives, particularly outside Europe/North America. For women there is no such effect, except in Finland.

- The probability of women working part-time declines with the length of their education. The same applies to men in Finland. In the other Nordic countries, men with a secondary education have the lowest probability of working part-time.

- Some industries have a general tendency to be part-time industries in all the Nordic countries. For both men and women, the probability of working part-time is highest in service industries such as retail and wholesale trade, hotel and restaurant, health and social care, teaching and social and personal services. One characteristic of the Finnish labour market, however, is that Finnish women who work in health and social care do not stand out by working part-time more often, and the difference between retail and wholsesale trade and the hotel and restaurant sector on the one hand and other industries on the other is greater in Finland than in the other Nordic countries. This indicates that part-time work is largely restricted to private services in Finland. Finland also stands out in that there is a high probability of both men and women in the education sector working part-time. There is a low probability in all countries of part-time employment in the building and construction industry and public sector administration, all else being equal. The probability of working part-time in these sectors is lower than for manufacturing employees, the reference category.

- Service workers work part-time more often than other occupational groups, all else being equal. This applies to both women and men, and to all countries. Employees in managerial positions have a lower probability of working part-time. A characteristic of Finland is that 
professionals and semi-professionals have a greater tendency to work part-time. In the other countries, the opposite is true for professionals who, all else being equal, are less likely to work part-time than manual workers, who are the reference category.

- The probability of working part-time is higher for employees with a non-standard work contract. Temporary employees and selfemployed men have a higher probability than permanent employees of having working hours which we have defined as part-time. Women in temporary employment also have a higher probability of working part-time, with the exception of Danish women.

- For both men and women, part-time work is most usual for employees in the smallest companies, all else being equal.

- The national unemployment rate does not appear to affect the probability of women working part-time, with the exception of Finnish women, who have a higher probability of working full-time if unemployment is moderate or high. The effects for men do not follow a trend. Moderate and high unemployment reduces the probability of part-time work for Finnish men, while leading to a higher probability of part-time work among Danish men. For women we see that a rise in the unemployment rate, all else being equal, leads to a lower share of women in part-time work in all countries except Norway.

Table 7.2 shows that part-time employees in the Nordic countries have many features in common, although there are also distinctive national characteristics. Young employees, employees in private and public services, service workers and employees who only have primary school are highly likely to work part-time. Temporary employees also more often have working hours of less than 35 hours a week than others, and the probability of employees working part-time is highest in companies with less than 10 employees. We find in all the Nordic countries that women with children at home work part-time more often than women without children. The greatest differences between the Nordic countries therefore lie in the differences in the level of the share of part-time workers, from one country to the next and between women and men, not in that different types of employees are recruited to part-time work. 
Table 7.2 Effects of various factors on the probability of working part-time. Separate models for each country. Binomial logistic regression. Odds ratios. 2000-2006 (Denmark 2000-2005)

\begin{tabular}{|c|c|c|c|c|c|c|c|c|}
\hline & \multicolumn{4}{|c|}{ Men } & \multicolumn{4}{|c|}{ Women } \\
\hline & DK & FI & NO & SE & DK & FI & No & SE \\
\hline \multicolumn{9}{|l|}{ Children at home } \\
\hline Yes & $1.25^{\star *}$ & $0.92^{*}$ & - & 0.83 & $1.43^{\star \star}$ & $1.38^{\star \star}$ & $1.86^{\star \star}$ & $1.71^{\star \star}$ \\
\hline No (ref.) & 1 & 1 & - & 1 & 1 & 1 & 1 & 1 \\
\hline \multicolumn{9}{|l|}{ Marital status } \\
\hline $\begin{array}{l}\text { Married/cohabitant } \\
\text { (ref.) }\end{array}$ & 1 & 1 & 1 & 1 & 1 & 1 & 1 & 1 \\
\hline Single & $1.27^{\star \star}$ & $1.46^{\star \star}$ & $1.54^{\star *}$ & $1.28^{\star \star}$ & $0.82^{\star \star}$ & $1.20^{\star \star}$ & $0.72^{\star \star}$ & $0.70^{* *}$ \\
\hline \multicolumn{9}{|l|}{ Age } \\
\hline $16-24$ & $6.01^{* *}$ & $3.61^{* *}$ & $4.18^{* *}$ & $2.88^{\star \star}$ & $2.13^{\star *}$ & $3.93^{\star \star}$ & $2.42^{\star \star}$ & $2.64^{\star \star}$ \\
\hline $25-34$ & $1.40^{\star *}$ & 1.11 & 1.06 & 1.04 & $0.75^{\star \star}$ & $1.33^{\star *}$ & $0.68^{* *}$ & 1.00 \\
\hline $35-44$ & $0.83^{*}$ & $0.87^{\star}$ & $0.87^{*}$ & 0.95 & $0.80^{* *}$ & $1.10^{*}$ & $0.84^{\star *}$ & $1.17^{* *}$ \\
\hline 45-54 (ref.) & 1 & 1 & 1 & 1 & 1 & 1 & 1 & 1 \\
\hline $55-63$ & $1.99 * *$ & $3.03^{\star *}$ & $1.34^{\star *}$ & $2.10^{\star *}$ & $1.58^{\star *}$ & $2.19 * \star$ & $1.55^{\star \star}$ & $1.88^{* *}$ \\
\hline \multicolumn{9}{|l|}{ National origin } \\
\hline Natives (ref.) & 1 & 1 & 1 & 1 & 1 & 1 & 1 & 1 \\
\hline Other Nordic & 1.55 & 1.05 & $1.30^{*}$ & 1.02 & 1.00 & 1.04 & $0.78^{\star *}$ & $0.73^{* *}$ \\
\hline $\begin{array}{l}\text { Other European/N. } \\
\text { American }\end{array}$ & $1.36^{*}$ & 1.09 & 1.10 & $1.17^{\star}$ & 0.99 & $1.55^{\star \star}$ & 1.03 & $0.83^{\star *}$ \\
\hline Other & $1.56^{\star *}$ & $1.40^{*}$ & $1.36^{\star *}$ & 1.16 & 1.07 & $1.47^{\star \star}$ & 0.89 & $0.67^{* *}$ \\
\hline \multicolumn{9}{|l|}{ Education } \\
\hline Primary & 1.13 & $1.39 * *$ & 1.01 & $1.13^{*}$ & $1.15^{\star \star}$ & $1.37^{\star *}$ & $1.34^{\star *}$ & $1.32^{\star *}$ \\
\hline Secondary & $0.73^{\star *}$ & $1.17^{* *}$ & $0.87^{\star}$ & $0.67^{\star \star}$ & 0.95 & $1.10^{*}$ & 1.03 & $0.90 * *$ \\
\hline Tertiary (ref.) & 1 & 1 & 1 & 1 & 1 & 1 & 1 & 1 \\
\hline \multicolumn{9}{|l|}{ Occupational category } \\
\hline Managers & $0.42^{\star *}$ & $0.59 * *$ & $0.36^{\star *}$ & $0.55^{\star \star}$ & $0.46^{\star *}$ & $0.38^{\star \star}$ & $0.21^{* *}$ & $0.26^{\star \star}$ \\
\hline Professionals & $0.75^{\star *}$ & $1.44^{\star *}$ & $0.55^{\star \star}$ & $0.85^{\star}$ & 0.95 & $2.06^{\star *}$ & $0.55^{\star \star}$ & $0.75^{\star \star}$ \\
\hline Semi-professionals & 1.05 & $1.34^{\star *}$ & 0.88 & $1.13^{\star}$ & $1.93^{\star *}$ & $1.32^{\star \star}$ & $0.82^{*}$ & 0.97 \\
\hline Service workers & $2.87^{\star *}$ & $2.68^{\star *}$ & $2.47^{\star *}$ & $2.59 * \star$ & $3.03^{\star *}$ & $2.07^{\star \star}$ & $1.82^{\star \star}$ & $1.90^{\star *}$ \\
\hline $\begin{array}{l}\text { Manual workers } \\
\text { (ref.) }\end{array}$ & 1 & 1 & 1 & 1 & 1 & 1 & 1 & 1 \\
\hline \multicolumn{9}{|l|}{ Industry } \\
\hline Agriculture & 1.02 & $1.66^{\star *}$ & 1.10 & $1.46^{\star \star}$ & $1.69^{* *}$ & $2.24^{\star \star}$ & $2.05^{\star \star}$ & $2.37^{\star \prime}$ \\
\hline Manufacturing (ref.) & 1 & 1 & 1 & 1 & 1 & 1 & 1 & 1 \\
\hline Construction & $0.26^{\star \star}$ & $0.55^{\star \star}$ & $0.26^{* *}$ & $0.62^{\star \star}$ & 1.25 & $2.00 * *$ & 1.12 & $1.33^{*}$ \\
\hline Trade. etc. & $1.42^{\star \star}$ & $1.37^{\star \star}$ & $0.81^{\star *}$ & 0.93 & $1.67^{\star *}$ & $3.18^{\star \star}$ & $1.65^{\star \star}$ & $1.86^{* *}$ \\
\hline Transport. etc. & 1.12 & $1.34^{\star \star}$ & 0.70 ** & $1.14^{\star}$ & 0.99 & $1.81^{\star \star}$ & 0.89 & 1.10 \\
\hline Finance. etc. & 0.71 & 1.12 & $0.57^{\star *}$ & 1.05 & 0.88 & 1.02 & 0.94 & 1.14 \\
\hline Real estate. etc. & $1.51^{\star \star}$ & $1.46^{\star \star}$ & 0.85 & $1.21^{\star *}$ & $1.70 * *$ & $2.01^{\star *}$ & 1.07 & $1.21^{\star \star}$ \\
\hline Public administration & $0.69^{\star *}$ & $0.63^{\star \star}$ & $0.44^{\star \star}$ & 0.94 & 0.99 & 0.87 & $0.76^{\star \star}$ & $0.88^{*}$ \\
\hline Education & $3.27^{\star *}$ & $4.75^{\star \star}$ & $1.63^{\star *}$ & $1.68^{* *}$ & $2.08^{\star \star}$ & $3.39^{\star *}$ & $1.66^{\star \star}$ & $1.32^{\star *}$ \\
\hline
\end{tabular}


Table 7.2 continued

\begin{tabular}{|c|c|c|c|c|c|c|c|c|}
\hline Health care & $3.41^{* \star}$ & $2.26^{\star \star}$ & $1.64^{\star *}$ & $2.08^{* *}$ & $2.55^{\star \star}$ & $1.18^{*}$ & $1.89 * \star$ & $2.21^{\star \star}$ \\
\hline $\begin{array}{l}\text { Social \& personal } \\
\text { services }\end{array}$ & $2.75^{\star \star}$ & $2.94^{\star \prime}$ & 1.39 ** & $1.78^{* *}$ & $2.14^{\star \star}$ & $2.03^{\star *}$ & 1.51 ** & $1.99^{\star \star}$ \\
\hline \multicolumn{9}{|l|}{$\begin{array}{l}\text { Employment } \\
\text { contract }\end{array}$} \\
\hline Permanent (ref.) & 1 & 1 & 1 & 1 & 1 & 1 & 1 & 1 \\
\hline Temporary & $1.57^{\star \star}$ & $1.86^{\star *}$ & $2.49^{\star *}$ & 4.70 ** & 1.03 & $1.50^{* *}$ & 1.60 ** & $2.38^{* *}$ \\
\hline Self-employed & $1.44^{\star *}$ & $2.09 * *$ & $1.84^{\star *}$ & $1.98^{* *}$ & 0.94 & $1.42^{\star *}$ & $0.84^{*}$ & 0.92 \\
\hline \multicolumn{9}{|l|}{ Size of workplace } \\
\hline 1-10 (ref.) & 1 & 1 & 1 & 1 & 1 & 1 & 1 & 1 \\
\hline 11-19 & 0.93 & $0.77^{* *}$ & 0.91 & $0.68^{* *}$ & 1.05 & $0.76^{\star *}$ & $0.84^{\star *}$ & $0.87^{\star \prime}$ \\
\hline $20-49$ & $0.77^{\star *}$ & $0.82^{\star \star}$ & 0.94 & $0.66^{\star *}$ & $0.89 * \star$ & $0.76^{\star \star}$ & $0.88^{* *}$ & $0.84^{\star \star}$ \\
\hline $50+$ & $0.69 * *$ & $0.71^{* *}$ & 0.93 & $0.64^{* *}$ & $0.71^{* *}$ & $0.59^{* *}$ & $0.72^{\star *}$ & $0.73^{* *}$ \\
\hline Unknown & $2.09 * *$ & $1.93^{* *}$ & $2.03^{\star *}$ & $1.35^{\star \star}$ & $1.41^{* *}$ & $1.37^{\star \star}$ & 1.50 ** & $1.17^{\star *}$ \\
\hline \multicolumn{9}{|l|}{$\begin{array}{l}\text { County } \\
\text { unemployment }\end{array}$} \\
\hline Low (ref.) & 1 & 1 & 1 & 1 & 1 & 1 & 1 & 1 \\
\hline Medium & $1.19^{\star \star}$ & $0.88^{\star \star}$ & $1.14^{*}$ & 0.97 & 1.00 & $1.16^{\star \star}$ & 1.00 & $1.06^{\star}$ \\
\hline High & $1.38^{\star \star}$ & $0.89^{\star *}$ & 1.06 & 0.99 & 1.03 & $1.07^{*}$ & 0.97 & 1.00 \\
\hline $\begin{array}{l}\text { Annual change in } \\
\text { national unem- } \\
\text { ployment level }\end{array}$ & 0.98 & 0.94 & 0.96 & 1.00 & $0.95^{\star}$ & $0.90^{\star}$ & 1.01 & $0.94^{\star \star}$ \\
\hline Nagelkerke R2 & 0.26 & 0.22 & 0.26 & 0.24 & 0.17 & 0.20 & 0.20 & 0.19 \\
\hline $\mathrm{N}$ & 24874 & 42700 & 26435 & 53162 & 26632 & 26435 & 24091 & 52733 \\
\hline
\end{tabular}

\subsection{Labour market mobility into and out of part-time employment}

Are there differences across countries in the sort of working hours arrangement encountered by formerly non-employed persons who enter the labour market? For example, do formerly non-employed persons who enter the labour market often begin by working part-time in Norway, where it can be assumed that the supply of part-time positions is high compared with other Nordic countries? Or is entering part-time work, in contrast to full-time work, also common in countries where part-time work can be assumed to be more strongly associated with marginal labour market groups (Finland)? In the latter case, this could be analysed as a stage on the way into what is perceived as typical work, i.e. full-time.

If we consider formerly non-employed persons entering the labour market, there are distinct differences across countries with respect to the share that goes into full-time work (Table 7.3).

In all four countries, the unemployed constitute the group of nonemployed who most often go into a full-time position. The share that went into a full-time position varies from 57 per cent in Norway to 69 per 
cent in Denmark. However, it is noteworthy that the strong full-time tradition in Finland does not lead to unemployed Finns going into full-time positions more often than nationals in the other Nordic countries when they enter the labour market.

Students are often found in part-time positions, and tend to work short part-time. In other words, they have agreed/normal working hours of less than 20 hours a week. But here, too, there are considerable differences across countries. Finnish students most frequently get working hours equivalent to full-time, Norwegian students least often.

We also find substantial national differences among those defined as inactive and not students (inactive, others). This is a composite group, including among others persons who work in the home and those who are looking for work but are not classified as work-seekers. In Finland, 62 per cent of them move into positions which are equivalent to full-time work, compared with only 42 per cent in Norway. Please note that we are looking here only at the minority who move into work.

Norway distinguishes itself in that the share re-encountered in a category corresponding to short part-time work (less than 20 hours per week) is far higher than the rest of the Nordic countries. This applies to all groups who move into work from a position as non-employed.

Table 7.3 Transitions from non-employed to employment (working time categories). By labour market status one year earlier. 2000-2006 (2000-2005 for Denmark), 16-63 years. Per cent

\begin{tabular}{lrrrrr}
\hline & $\begin{array}{c}\text { Working time } \text { T }_{2} \\
\text { Short part } \\
\text { time }\end{array}$ & $\begin{array}{c}\text { Long part } \\
\text { time }\end{array}$ & Full time & Total & N \\
Status T $_{1}$ & 8 & 23 & 69 & 100 & 2266 \\
\hline Denmark & 38 & 19 & 43 & 100 & 1260 \\
Unemployed & 18 & 30 & 52 & 100 & 1232 \\
Inactive student & 62 & 18 & 20 & 100 & 2748 \\
Inactive other & 4 & 73 & 23 & 100 & 8138 \\
Short parttime & 1 & 5 & 94 & 100 & 36094 \\
Long partime & & & & & \\
Fulltime & 11 & 26 & 63 & 100 & 3238 \\
Finland & 27 & 20 & 52 & 100 & 2560 \\
Unemployed & 14 & 23 & 62 & 100 & 3119 \\
Inactive student & 58 & 17 & 24 & 100 & 3500 \\
Inactive other & 6 & 68 & 26 & 100 & 8657 \\
Short parttime & 1 & 3 & 96 & 100 & 71667 \\
Long partime & & & & &
\end{tabular}


Table 7.3 continued

\begin{tabular}{|c|c|c|c|c|c|}
\hline \multirow[b]{2}{*}{ Status $\mathrm{T}_{1}$} & \multicolumn{5}{|c|}{ Working time $\mathrm{T}_{2}$} \\
\hline & $\begin{array}{r}\text { Short part } \\
\text { time }\end{array}$ & $\begin{array}{r}\text { Long part } \\
\text { time }\end{array}$ & Full time & Total & $\mathrm{N}$ \\
\hline \multicolumn{6}{|l|}{ Norway } \\
\hline Unemployed & 30 & 14 & 57 & 100 & 976 \\
\hline Inactive student & 52 & 11 & 37 & 100 & 1749 \\
\hline Inactive other & 38 & 20 & 42 & 100 & 1085 \\
\hline Short parttime & 65 & 17 & 18 & 100 & 5464 \\
\hline Long parttime & 11 & 61 & 28 & 100 & 6705 \\
\hline Fulltime & 2 & 5 & 92 & 100 & 32021 \\
\hline \multicolumn{6}{|l|}{ Sweden } \\
\hline Unemployed & 14 & 20 & 66 & 100 & 2938 \\
\hline Inactive, student & 36 & 20 & 45 & 100 & 3535 \\
\hline Inactive, other & 20 & 29 & 51 & 100 & 1462 \\
\hline Short parttime & 54 & 24 & 22 & 100 & 4365 \\
\hline Long parttime & 4 & 75 & 21 & 100 & 18446 \\
\hline Fulltime & 1 & 5 & 94 & 100 & 76874 \\
\hline
\end{tabular}

We continue by looking at the factors that influence the probability of formerly non-employed persons who move into working life ending up in a part-time as compared to a full-time position. We have carried out logistic regressions for each country, controlling for characteristics of the individual such as age, gender, education etc., and also controlling for original labour market position and characteristics of the national labour markets.

Table 7.4. shows that the differences between the various categories of non-employed workers remain perceptible when we control for individual characteristics such as gender, age, education etc., and for the situation in the national labour markets. In all countries, those who come from a position as inactive (students or the collective category "other") have a greater probability than unemployed persons of going into a part-time position. The difference between the probabilities of various types of nonemployed persons going into part-time positions is smallest in Finland and largest in Denmark. This may indicate that part-time is less of an option in the Finnish labour market, whereas in Denmark there is greater differentiation between unemployed persons who often begin in full-time positions and students and other inactive groups who choose or are offered part-time work.

Women have a far higher probability of beginning in a part-time position than men in all countries, and with the exception of Finland, the risk of ending up in a part-time position is higher for women with children than for women without children. Young and older employees also have a higher probability of going into a part-time position than the reference 
category, which is persons aged 45-54. With the exception of in Sweden, we find the lowest probability of ending up in a part-time position for the age group 25-44.

National origin has little effect on the probability of ending up in a part-time job compared with a full-time position. In Norway, however, the category "other" has a greater probability of ending up in a part-time position than the other categories. In all countries except Denmark, employees with a high education (tertiary level) have a greater chance of ending up in a full-time position than employees with a lower education. Nor does the labour market situation, in the sense of whether the national unemployment rate is relatively high, moderate or low, appear to affect the odds of non-employed persons going into a part-time or a full-time position.

Thus we see that the general pattern we have observed for part-time work is also a determinant for whether inflow into the labour market is into full-time or part-time positions. Men, persons aged 25-54 and persons with higher education have the greatest probability of beginning in a full-time position. Women and young people are more often found in part-time positions.

Table 7.4 Effects of various factors on transitions. Transitions from non-employed into part-time employment as compared to full-time employment. Binomial logistic regression. Odds ratios

\begin{tabular}{|c|c|c|c|c|}
\hline & Denmark & Finland & Norway & Sweden \\
\hline \multicolumn{5}{|l|}{ Gender } \\
\hline Male (ref) & 1 & 1 & 1 & 1 \\
\hline Female, children & $3.02^{\star \star}$ & $2.65^{\star \star}$ & $4.30 \star \star$ & $4.59 \star \star$ \\
\hline Female, not children & $2.04^{\star \star}$ & $2.39 \star \star$ & $2.70 \star \star$ & $2.95^{\star \star}$ \\
\hline \multicolumn{5}{|l|}{ Age } \\
\hline $16-24$ & $1.59^{\star \star}$ & $1.24 * \star$ & 1.20 & $1.77^{\star \star}$ \\
\hline $25-34$ & $0.65^{\star *}$ & $0.71 * \star$ & $0.48^{\star \star}$ & 0.89 \\
\hline $35-44$ & $0.80^{\star}$ & $0.75^{\star \star}$ & $0.55^{\star \star}$ & 0.89 \\
\hline 45-54 (ref.) & 1 & 1 & 1 & 1 \\
\hline $55-63$ & $1.80^{\star \star}$ & $1.93^{\star \star}$ & 1.38 & $2.03^{\star \star}$ \\
\hline \multicolumn{5}{|l|}{ National origin } \\
\hline Natives (ref.) & 1 & 1 & 1 & 1 \\
\hline Other Nordic & 0.67 & 1.06 & 1.35 & 0.78 \\
\hline Other European/N.American & 1.22 & $1.88^{*}$ & 1.23 & $0.76^{\star}$ \\
\hline Other & 0.84 & 1.22 & $1.70 * \star$ & 1.06 \\
\hline \multicolumn{5}{|l|}{ Education } \\
\hline Primary & 1.09 & $1.74^{\star \star}$ & $1.86^{\star \star}$ & $2.25^{\star \star}$ \\
\hline Secondary & 1.03 & $1.15^{\star}$ & 1.18 & $1.21^{\star \star}$ \\
\hline Tertiary (ref.) & 1 & 1 & 1 & 1 \\
\hline \multicolumn{5}{|l|}{ Labour market posision } \\
\hline Unemployed (ref) & 1 & 1 & 1 & 1 \\
\hline Inactive, student & $1.94^{\star \star}$ & 0.99 & $1.53^{\star \star}$ & $1.68^{\star \star}$ \\
\hline Inactive, other & $2.49 * *$ & $1.28^{\star *}$ & $1.76^{\star \star}$ & $1.88^{\star \star}$ \\
\hline \multicolumn{5}{|l|}{ County unemployment } \\
\hline Low (ref.) & 1 & 1 & 1 & 1 \\
\hline Medium & 1.00 & 0.90 & 0.90 & 1.04 \\
\hline High & 1.14 & 0.96 & 0.93 & 0.98 \\
\hline $\begin{array}{l}\text { Annual change in national } \\
\text { unemployment }\end{array}$ & $0.85^{\star}$ & 0.98 & 0.96 & $1.09^{\star}$ \\
\hline Nagelkerke $\mathrm{R}^{2}$ & .14 & ,10 & .17 & .20 \\
\hline $\mathrm{N}$ & 4758 & 8917 & 3807 & 7932 \\
\hline
\end{tabular}

${ }^{*}=p<0.05,{ }^{* *}=p<0.01$. 


\section{Outflow}

We will now consider whether part-time work implies a greater probability of ending up as non-employed. An atypical affiliation may lead to increased risk of unemployment, contribute to periods of labour market inactivity and to long-term uncertainty when employees do not achieve permanent employment, the desired working hours and income or opportunities for development in the form of ongoing in-work training. The risk of ending up in dead-end jobs is particularly pronounced in connection with fixed-term positions, but part-time can also be regarded as a risk factor of this type (see for example the analysis in Employment in Europe 2002). In labour markets such as the Nordic ones, where part-time work has virtually become normal, it is reasonable to expect less difference between full-time and part-time employees with respect to the risk of involuntary exit from the labour market.

Table 7.3 shows that the great majority of part-time employees remain employed over time. But in all countries there is a clearly higher probability of employees with short part-time (agreed weekly working hours of less than 20 hours per week) leaving the labour force, not least in order to pursue or resume secondary or tertiary education. This is not surprising since it is common in all the Nordic countries for young people to combine education with part-time work, and means that in the majority of cases there is a planned transition rather than a dramatic change for the employees in question. Part-time employees also have a somewhat higher transition to unemployment than employees with a weekly working time of 35 hours or more. With the exception of Finland, we see that long parttime implies a stable labour market affiliation, and that the mobility pattern of this group deviates little from employees who work full-time. Between 89 and 92 per cent of this group are employed one year after our first observation, a rate which is only 3-4percentage points lower than that we find for full-time employees.

In Chapter 5 we saw that part-time employees in all four countries have greater mobility from the labour market to inactivity than full-time employees, also when controlling for other characteristics of the individual and the national labour markets. Except in Sweden, part-time employees also run a higher risk of unemployment. We consider more closely whether there are differences between the Nordic countries with respect to the factors that influence the probability of a part-time employee leaving the labour force compared with remaining employed after one year. We investigate this by means of multinomial logistic regression with inactivity, unemployment and continued employment (reference category) as the dependent variables. Table 7.5 shows the outcome of transitions from part-time employment to unemployment and inactivity respectively. As previously, we look at the characteristics of the employee, the job situation and the national labour market. 
Table 7.5 Effects of various factors on transitions from part-time employment. Multinomial logistic regression. Odds ratios.

\begin{tabular}{|c|c|c|c|c|}
\hline & \multicolumn{4}{|c|}{ To inactivity } \\
\hline & Denmark & Finland & Norway & Sweden \\
\hline \multicolumn{5}{|l|}{ Age } \\
\hline $16-24$ & $3.42^{\star \star}$ & $3.01^{\star \star}$ & $2.75^{\star \star}$ & $4.94^{\star \star}$ \\
\hline $25-34$ & $2.52^{\star \star}$ & $1.43^{\star \star}$ & $1.64^{\star \star}$ & $2.45^{\star \star}$ \\
\hline $35-44$ & 1.15 & 0.81 & 0.95 & 1.25 \\
\hline 45-54 (ref.) & 1 & 1 & 1 & 1 \\
\hline $55-63$ & $4.29 * \star$ & $2.62^{\star \star}$ & $2.07^{\star \star}$ & $3.14^{\star \star}$ \\
\hline \multicolumn{5}{|l|}{ Marital status } \\
\hline Married/cohabitant (ref.) & 1 & 1 & 1 & 1 \\
\hline Single & 0.99 & $1.24^{\star *}$ & $1.59^{\star *}$ & $1.19^{\star \star}$ \\
\hline \multicolumn{5}{|l|}{ Gender/children at home } \\
\hline Female. no children & $0.81^{*}$ & $1.26^{\star \star}$ & 0.86 & $0.81^{*}$ \\
\hline Female/children & 1.05 & 0.88 & $0.85^{\star \star}$ & 0.98 \\
\hline Male & 1 & 1 & 1 & 1 \\
\hline \multicolumn{5}{|l|}{ National origin } \\
\hline Natives (ref.) & 1 & 1 & 1 & 1 \\
\hline Other Nordic & 1.19 & 0.69 & 0.83 & 1.23 \\
\hline $\begin{array}{l}\text { Other European/N. Ameri- } \\
\text { can }\end{array}$ & 1.17 & $0.39 *$ & $1.45^{\star \star}$ & 1.09 \\
\hline Other & $2.02^{\star \star}$ & $1.75^{\star \star}$ & 1.31 & $1.57^{\star \star}$ \\
\hline \multicolumn{5}{|l|}{ Education } \\
\hline Primary & $1.45^{\star \star}$ & $1.43^{\star *}$ & 1.10 & $1.31^{\star *}$ \\
\hline Secondary & 1.18 & 1.12 & 0.85 & $1.16^{\star}$ \\
\hline Tertiary (ref.) & 1 & 1 & 1 & \\
\hline \multicolumn{5}{|l|}{ Industry } \\
\hline Agriculture & 1.15 & 0.97 & 1.36 & 0.82 \\
\hline Manufacturing (ref.) & 1 & 1 & 1 & 1 \\
\hline Construction & 0.65 & 1.30 & 1.04 & 1.03 \\
\hline Trade. Etc. & $0.74^{\star}$ & 1.01 & 1.00 & 0.94 \\
\hline Transport. etc. & $0.61^{*}$ & 1.23 & 1.01 & 0.84 \\
\hline Finance. etc. & $0.36^{\star}$ & 1.44 & 0.74 & 1.31 \\
\hline Real estate. etc. & 0.79 & $1.37^{*}$ & 1.12 & 1.05 \\
\hline Public administration & 0.96 & $1.54^{*}$ & 1.30 & 1.19 \\
\hline Education & 0.82 & $1.54^{\star *}$ & 1.01 & 1.11 \\
\hline Health care & 0.87 & $1.70 * \star$ & 1.02 & 0.89 \\
\hline Social \& personal services & 0.81 & 1.27 & 1.38 & 0.98 \\
\hline \multicolumn{5}{|l|}{ Working time } \\
\hline $1-19$ & $1.79 * \star$ & $1.35^{\star \star}$ & $1.76^{\star *}$ & $1.65^{\star \star}$ \\
\hline 20-34 (ref) & 1 & 1 & 1 & 1 \\
\hline \multicolumn{5}{|l|}{ Occupational category } \\
\hline Managers & 0.68 & $0.65^{\star}$ & 0.46 & 0.87 \\
\hline Professionals & $0.52^{\star \star}$ & $0.44^{\star *}$ & 0.71 & 0.84 \\
\hline Semi-professionals & $0.64^{\star *}$ & $0.67^{\star *}$ & $0.64^{\star *}$ & 0.83 \\
\hline Service workers & 0.87 & $0.68^{\star *}$ & 1.02 & 1.00 \\
\hline Manual workers (ref.) & 1 & 1 & 1 & 1 \\
\hline \multicolumn{5}{|l|}{ Employment contract } \\
\hline Permanent (ref.) & 1 & 1 & 1 & 1 \\
\hline Temporary & $2.53^{\star \star}$ & $2.33^{\star *}$ & $1.96 * \star$ & $2.65^{\star \star}$ \\
\hline Self-employed & 1.11 & 0.81 & $1.58^{\star \star}$ & $1.33^{\star \star}$ \\
\hline \multicolumn{5}{|l|}{ Size of workplace } \\
\hline $1-10$ (ref.) & 1 & 1 & 1 & 1 \\
\hline 11.19 & 0.96 & $0.83^{\star}$ & $0.82^{*}$ & $0.79 \star \star$ \\
\hline $20-49$ & 0.98 & 0.90 & 1.03 & $0.82^{\star \star}$ \\
\hline $50+$ & $0.73^{\star \star}$ & $0.72^{\star \star}$ & 0.88 & $0.83^{\star \star}$ \\
\hline Not classified & $1.27^{*}$ & $1.30 * *$ & $1.46^{\star *}$ & 1.08 \\
\hline \multicolumn{5}{|l|}{ County unemployment } \\
\hline Low (ref.) & 1 & 1 & 1 & 1 \\
\hline Medium & 1.04 & $1.16^{*}$ & 1.09 & 1.03 \\
\hline High & 1.11 & $1.25^{\star}$ & $1.16^{\star}$ & $1.15^{\star}$ \\
\hline $\begin{array}{l}\text { Annual change in national } \\
\text { unemployment }\end{array}$ & $1.24^{\star}$ & 1.07 & $1.16^{\star \star}$ & $1.21^{\star \star}$ \\
\hline
\end{tabular}


Table 7.5 Continued

\begin{tabular}{|c|c|c|c|c|}
\hline & \multicolumn{4}{|c|}{ To unemployment } \\
\hline & Denmark & Finland & Norway & Sweden \\
\hline \multicolumn{5}{|l|}{ Age } \\
\hline $16-24$ & 1.05 & $0.61^{*}$ & $1.95^{\star \star}$ & 1.00 \\
\hline $25-34$ & 1.05 & 0.78 & 1.36 & 0.93 \\
\hline $35-44$ & 1.15 & 0.76 & 1.18 & 1.08 \\
\hline 45-54 (ref.) & 1 & 1 & 1 & 1 \\
\hline $55-63$ & 1.08 & 0.91 & 0.93 & 1.01 \\
\hline \multicolumn{5}{|l|}{ Married/cohabitant (ref.) } \\
\hline Single & 1.23 & 1.59 ** & $1.97^{\star \star}$ & $1.48^{\star \star}$ \\
\hline Gender/children at home & 1 & 1 & 1 & 1 \\
\hline Female. no children & 0.92 & 0.95 & 0.88 & $0.71^{* *}$ \\
\hline Female/children & 0.83 & 0.87 & $0.61^{\star \star}$ & 0.99 \\
\hline Male & 1 & 1 & 1 & 1 \\
\hline \multicolumn{5}{|l|}{ National origin } \\
\hline Natives (ref.) & 1 & 1 & 1 & 1 \\
\hline Other Nordic & 1.61 & 0.96 & $2.20^{\star \star}$ & 1.49 \\
\hline $\begin{array}{l}\text { Other European/N. Ameri- } \\
\text { can }\end{array}$ & 0.97 & 1.44 & 1.61 & $2.25^{\star \star}$ \\
\hline Other & 1.39 & $1.99^{*}$ & $2.95^{\star *}$ & $1.99 * *$ \\
\hline \multicolumn{5}{|l|}{ Education } \\
\hline Primary & 1.21 & $1.78^{\star \star}$ & 1.52 & 1.27 \\
\hline Secondary & 1.09 & $1.49^{\star \star}$ & 1.22 & 1.14 \\
\hline \multicolumn{5}{|l|}{ Tertiary (ref.) } \\
\hline \multicolumn{5}{|l|}{ Industry } \\
\hline Agriculture & 0.61 & 0.77 & 0.49 & 0.93 \\
\hline Manufacturing (ref.) & 1 & 1 & 1 & 1 \\
\hline Construction & 1.09 & 1.59 & 0.60 & $1.76^{*}$ \\
\hline Trade. etc. & 0.97 & 0.88 & 1.15 & 1.21 \\
\hline Transport. etc. & 1.01 & 0.78 & 1.11 & 0.87 \\
\hline Finance. etc. & 0.63 & 0.23 & $3.22^{\star *}$ & 1.88 \\
\hline Real estate. etc. & 1.02 & 1.42 & 1.70 & 1.42 \\
\hline Public administration & 0.87 & 1.28 & 0.49 & 0.95 \\
\hline Education & 0.82 & 0.81 & 0.91 & 0.96 \\
\hline Health care & 0.68 & 1.39 & 0.66 & $0.60^{*}$ \\
\hline Social \& personal services & 1.00 & $1.55^{*}$ & 1.68 & 0.91 \\
\hline \multicolumn{5}{|l|}{ Working time } \\
\hline $1-19$ & 1.11 & 0.91 & 0.83 & $1.39^{* *}$ \\
\hline $20-34$ (ref) & 1 & 1 & 1 & 1 \\
\hline \multicolumn{5}{|l|}{ Occupational category } \\
\hline Managers & 1.28 & 0.56 & 0.25 & 0.70 \\
\hline Professionals & 0.85 & $0.45^{\star \star}$ & 0.44 & 0.81 \\
\hline Semi-professionals & 0.99 & $0.60^{\star *}$ & $0.54^{*}$ & $0.67^{*}$ \\
\hline Service workers & 1.22 & 0.81 & 0.87 & 0.84 \\
\hline Manual workers (ref.) & 1 & 1 & 1 & 1 \\
\hline \multicolumn{5}{|l|}{ Employment contract } \\
\hline Permanent (ref.) & 1 & 1 & 1 & 1 \\
\hline Temporary & $4.21^{\star \star}$ & $6.96^{\star \star}$ & $3.33^{\star \star}$ & $4.31^{\star \star}$ \\
\hline Self-employed & $0.48^{*}$ & $0.54^{\star *}$ & $1.85^{\star}$ & 0.78 \\
\hline \multicolumn{5}{|l|}{ Size of workplace } \\
\hline $1-10$ (ref.) & 1 & 1 & 1 & 1 \\
\hline 11.19 & $0.61^{\star \star}$ & $0.71^{*}$ & 0.72 & $0.69^{\star}$ \\
\hline $20-49$ & 0.78 & $0.72^{\star \star}$ & 0.78 & $0.72^{\star *}$ \\
\hline $50+$ & $0.53^{\star \star}$ & $0.51^{\star *}$ & 0.72 & $0.64^{\star *}$ \\
\hline Not classified & 1.08 & 1.07 & 0.99 & 0.79 \\
\hline \multicolumn{5}{|l|}{ County unemployment } \\
\hline Low (ref.) & 1 & 1 & 1 & 1 \\
\hline Medium & $1.40^{\star *}$ & $1.26^{\star}$ & 0.92 & $1.58^{\star *}$ \\
\hline High & $1.42^{\star \star}$ & $1.54^{\star \star}$ & 1.04 & $1.84^{\star *}$ \\
\hline $\begin{array}{l}\text { Annual change in national } \\
\text { unemployment }\end{array}$ & 1.15 & $1.35^{\star}$ & $1.52^{\star \star}$ & $1.29^{\star \star}$ \\
\hline Nagelkerke $\mathrm{R}^{2}$ & 0.14 & 0.20 & 0.17 & 0.20 \\
\hline $\mathrm{N}$ & 12722 & 14935 & 13779 & 25325 \\
\hline
\end{tabular}


- In all countries, it is the youngest and oldest part-time employees who most often move from working life to inactivity. It is reasonable to assume that many of the youngest have become students. But higher probabilites for leaving employment do not only apply to the youngest cohort. The odds of part-time employees in the age group 25-34 in all countries leaving working life are clearly higher than for the reference category, aged $45-54$. This reflects the fact that in this age group, too, we find many who combine education with part-time work. In contrast, there are no differences between age groups with respect to the probability of moving from part-time work to unemployment. The exception is Norway, where the youngest parttime employees have the highest probability of moving into unemployment.

- There is a slightly higher probability in Denmark and Sweden of men in part-time employment leaving the labour market than women with children. In Finland the opposite is true. Gender has little bearing on a transition from part-time employment to unemployment.

- There is a higher probability of unmarried persons moving from working life to inactivity in all countries apart from Denmark. In Finland and Sweden there is also a higher probability of singles moving into unemployment. One explanation may be that we are capturing characteristics of their life situation, for example that young singles are still finding their way in working life and between work and education to a greater extent than married persons or persons in partnerships.

- Part-time employees with a foreign background have a greater risk of leaving the labour market to inactiviy than natives. This applies in particular to the group "Other”. This group also have a higher risk of transition to unemployment than other part-time employees. However, there is no significant effect for Norway.

- In all countries, part-time employees with the lowest formal education have the highest risk of leaving the labour market for inactivity or unemployment. The exception is Norway, where we do not find that education has any significance for the probability of moving into inactivity. In Finland, there are also clearly higher odds on part-time employees without higher education moving into unemployment. In the other countries, the relationship between educational level and transition to unemployment is not significant.

- There are few signs that individual industries stand out because parttime employment implies more risk than other types of employment for a transition to inactivity or unemployment. When we control for characteristics of the labour (for example age), we do not find higher mobility into inactivity or unemployment from those segments of private services that are often indicated as exponents of high turnover and many part-time employees. One exception is Finland, where part- 
time employees in public-sector dominated industries have higher odds of moving to inactivity.

- The size of the workplace has a certain effect on the probability of a transition to inactivity and unemployment. Working in a somewhat larger workplace increases the probability of remaining in work.

- Fixed-term employees in part-time positions have a considerably higher risk of moving into inactivity and particularly into unemployment compared with permanent employees. In Norway and Sweden, self-employed persons also have a greater probability of moving from working life to inactivity, but the odds are clearly lower than for fixed-term employees. Employees with short part-time have a greater risk of transition to inactivity than those who work 20-34 hours a week, whereas only in Sweden does short part-time increase the risk of transition to unemployment.

- The labour market situation affects the probability of part-time employed moving into unemployment. The higher unemployment is at regional (county) level, the greater is the risk of transition to unemployment. The country employment rate is not significant for Norway, but an increase in national unemployment increases the risk of part-time employees moving into unemployment compared to long part-time and full-time.

The analysis shows that the Nordic countries share many common features with respect to which part-time employees have the highest odds for mobility out of work. The differences in the part-time share across countries appear to have had only moderate effects with respect to causing different categories of part-time employees to exit the labour market or to remain in work. In all countries it is the youngest and the oldest part-time employees who most often move into inactivity, and being temporarily employed or working short part-time increases the probability of transition. The same applies to having a background from countries outside Europe/North America. Mobility from part-time to unemployment is partly shaped by other characteristics of the employee and the job situation. It is only in Norway that young part-time employees have a higher risk than other age groups of moving into unemployment. But, as expected, fixed-term employment raises the risk of unemployment in all countries.

Another observation is that although there are clear differences between industries with respect to the odds of working part-time, there are no industries in which part-time employees have a higher risk of a transition to unemployment or inactivity than in other industries. For example, the probability of becoming unemployed is not significantly different for young part-time employees in retail trade compared with young part-time employees in manufacturing. Thus we see the same general tendency as for mobility from fixed-term employment to non-employment (Chapter 
6). The industry itself has little effect when we control for the type of employees recruited into this type of job.

\subsection{Working time mobility}

In this section we pose the question of what type of mobility we see with respect to agreed working hours in the sense of whether agreed working hours remain stable over time, or whether the employee increases or reduces the agreed working hours. We have chosen to take as our starting point the three main categories short part-time (1-19 hours), long parttime (20-34 hours) and full-time (35 hours or more), and to look at the mobility between them. Since the starting point is agreed or usual working hours, we can assume that changes in stated working hours also reflect a real change in the employment status of the individual. However, we have set as a requirement that the change must be at least 5 hours.

We consider the following categories.

- From short part-time to long part-time or full-time, and from long part-time to full-time (increased agreed working hours)

- From full-time to long part-time/short part-time or from long parttime to short part-time (reduced agreed working hours)

- We define those grouped in the same working time category at both times as having stable working hours. This includes those who have changed category, but where this has entailed a change of less than five hours in their weekly working hours.

Table 7.6 shows that the great majority of employees have stable agreed/usual working hours. The share varies from 87 per cent of all those who are employed at both times in Norway, to 93 per cent in Finland. We also see that a considerablepercentage of women work part-time on a stable basis, particularly in Norway, Sweden and Denmark. In Norway this applies to 32 per cent of all women who are in the labour market at both times. In Sweden and Denmark the shares of women in stable part-time work are 28 and 30 per cent, respectively. The exception is Finland, where 15 per cent of women are in stable part-time work, but where on the other hand a full 76 per cent of women are in stable fulltime work. We also note that Norway is distinguished by the fact that very short working hours (less than 20 hours) is a stable affiliation for a full 14 per cent of women in the working-age population. Few women in the other countries have such short weekly working hours over time. Men have more stable working hours than women in all countries, and Nordic men are in stable full-time work for the most part. 
Table 7.6 Share of employees with stable working hours, as apercentage of all those in work at times $T_{1}$ and $T_{2}$. By gender. 16-63 years. 2000-2006 (2005 for Denmark)

\begin{tabular}{llrrrr}
\hline \multirow{3}{*}{ Denmark } & Full-time & Long partime & Short parttime & $\begin{array}{r}\text { Stable wokring } \\
\text { hours, total }\end{array}$ \\
& Male & 88 & 3 & 3 & 95 \\
& Female & 59 & 25 & 5 & 89 \\
& Total & 73 & 14 & 4 & 92 \\
& Male & 89 & 5 & 2 & 95 \\
& Female & 76 & 11 & 4 & 90 \\
& Total & 83 & 8 & 3 & 93 \\
& Male & 85 & 4 & 4 & 92 \\
& Female & 48 & 18 & 14 & 81 \\
& Total & 68 & 11 & 9 & 87 \\
& Male & 87 & 5 & 2 & 94 \\
& Female & 59 & 25 & 3 & 87 \\
& Total & 73 & 15 & 3 & 91 \\
\hline
\end{tabular}

Diagram 7.3 shows that there is a certain amount of working time mobility in all countries in the sense that employees both reduce and increase their working hours. Women change their agreed working hours more often than men in all countries. Norwegian women have the highest working time mobility, and there are substantial transitions to both longer and shorter working hours. As many as 19 per cent of Norwegian women have changed their working hours over a period of one year - compared with 10 per cent of Finnish women. There are only minor differences in working hour mobility across the Nordic countries for men.

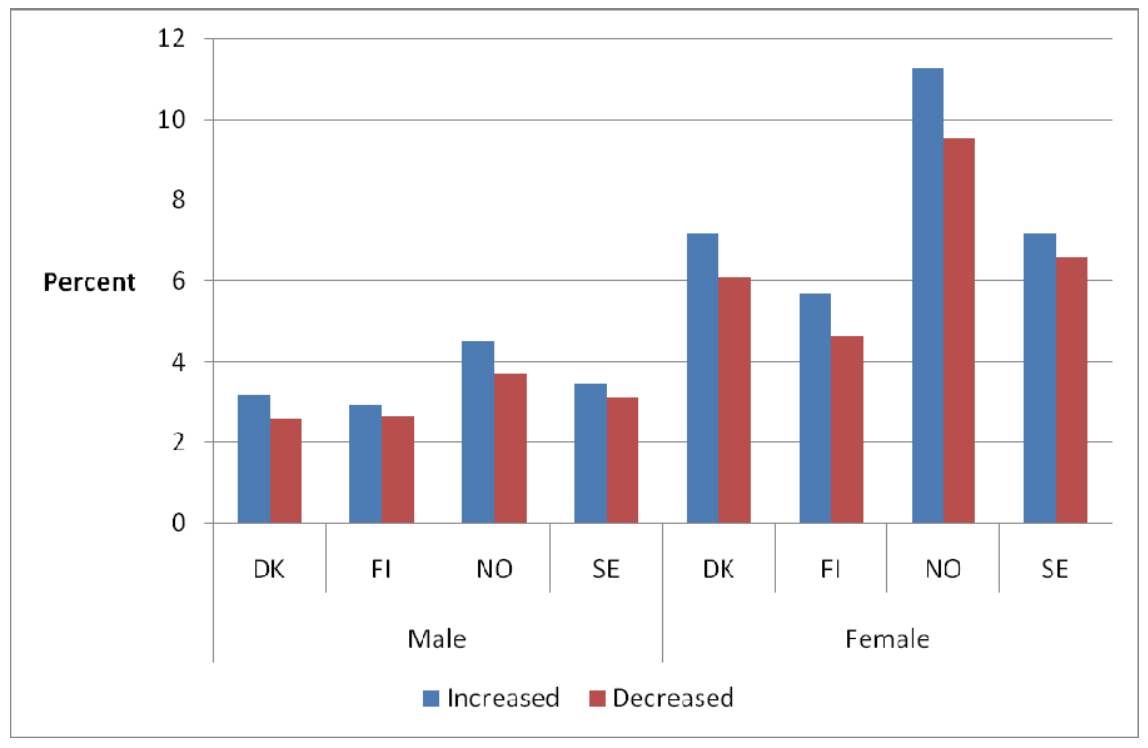

Diagram 7.3 Working time mobility.percentage of all employees who have reduced or increased their working hours. By gender. 2000-2006 (2005 for Denmark) 


\subsection{Part-time employees who increase their working hours}

The fact that part-time employees not only remain in the labour market, but in many cases also increase their working hours, is often regarded as an indicator of labour market integration. The fact that working hours increase over time may also indicate that in the course of time involuntary part-time workers achieve working hours in line with their wishes. We will now consider what characterises part-time employees who increase their working hours compared with those who work stable parttime or reduce their working hours. Diagram 7.4 shows the share of parttime employees who have increased their agreed working hours according to our definition (see previous section). The share of part-time employees who increase their working hours is highest in Finland and Norway, the two countries at the extremes with respect to share of part-time workers in the labour market. In all countries, it is employees with agreed weekly working hours of 1-19 hours who most frequently increase their working hours, which is not surprising since they can move to both a long part-time and a full-time position. Thus we see that this group is not only more unstable in the sense that more of them leave the labour market, but that many of them also increase their working hours. The impression that short part-time in Norway is a less unstable affiliation than others in the Nordic countries is reinforced in Diagram 7.4: whereas 40 per cent of Swedish employees and 37 per cent of Finnish employees with weekly working hours of 1-19 hours have increased their working hours over a one-year period, this only applies to 27 per cent of the Norwegian employees in the same situation.

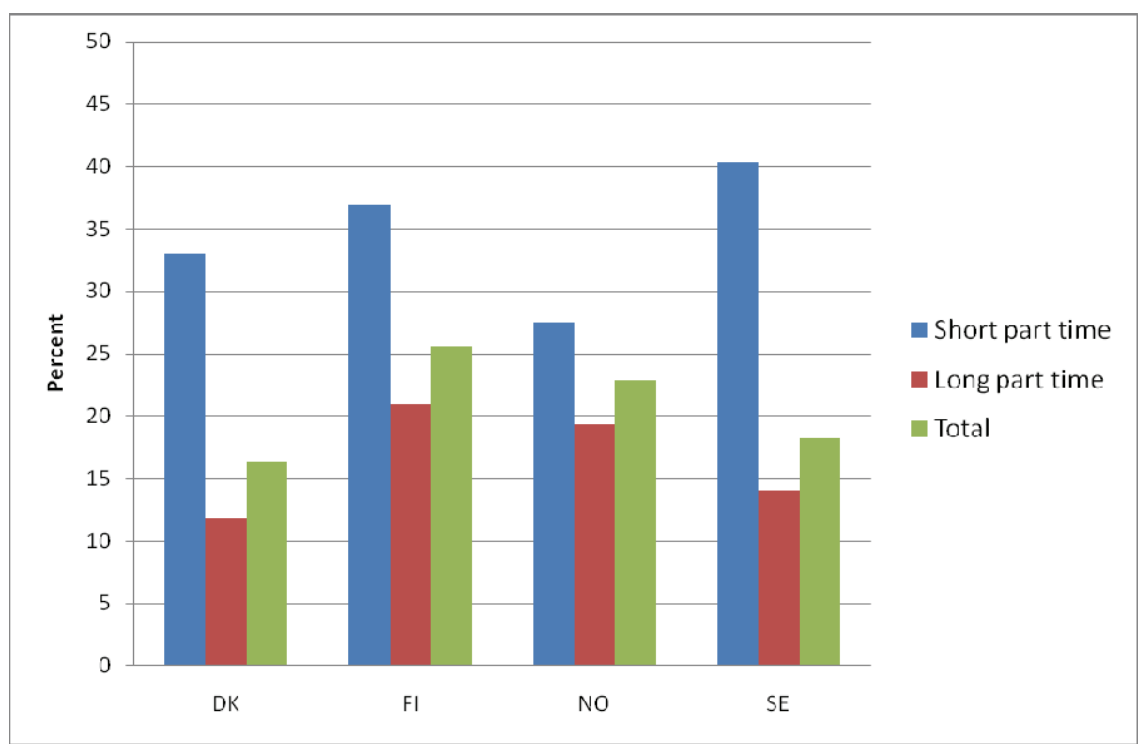

Diagram 7.4 Share of part-time employees who increase their working hours, by country and gender. Aged 16-63. 2000-2006 (2005 for Denmark). 
We take a closer look at the factors that influence the odds that part-time employees will increase their working hours (working time mobility) Binary logistic regression is used to look at the probability of part-time employees increasing their working hours as opposed to maintaining or reducing their weekly agreed working hours (Table 7.7).

In all countries, it is the younger part-time employees in particular who increase their working hours. Mobility to longer working hours is highest for the age group 25-35. This is the stage of life when many finish qualifying and switch from extra jobs to ordinary work. We do not find an age effect for Norway for the group aged 15-24 compared with the reference group, aged 45-54, which may indicate that the transition from extra jobs to ordinary work takes place somewhat later for young Norwegians. In all countries we also see that part-time is a stable status for employees aged 55-63. In Denmark, unmarried persons also have a greater probability of increasing their working hours than employees who are married or living in partnerships.

In all countries, part-time employed women with children have a substantially lower probability of increasing their working hours than men and women without children. For Finland, on the other hand, we find no significant differences between men and women without children, and the negative effect on the odds of a woman with children increasing her working hours is also less than in the other countries. This confirms the fact that, even when we control for characteristics of the individual employee and the workplace, Finnish women differ from their Nordic sisters in that part-time work can to a lesser extent be called a normal status for women. Finnish women do not remain part-time employees to the same extent as women in the other Nordic countries.

We find that nationality does not play a part (with the exception of the group "other" in Sweden). Consequently, it does not look as though parttime work is more than a temporary status for employees with a foreign origin, and we already know that nationality only has a moderate effect on the probability of working part-time.

In Norway and Sweden, part-time is more stable among those with a low education than the reference group, which has a high level of education (tertiary). Similarly, we find that in Finland and Sweden part-time employees in service occupations increase their working hours more seldom than employees in other occupations. In other words, part-time is a more stable employment status in these countries. In Sweden this also applies to the semi-professionals. In Denmark the professions are distinguished by the fact that part-time employees more often increase their working hours. 
Table 7.7 Effects of various factors on transitions to increased working time among part-time employes. Binomial logistic regression. Odds ratios .

\begin{tabular}{|c|c|c|c|c|}
\hline & Denmark & Finland & Norway & Sweden \\
\hline \multicolumn{5}{|l|}{ Gender/children at home } \\
\hline Women with children & $0.51^{* *}$ & $0.80^{* *}$ & $0.50^{* *}$ & $0.60^{* *}$ \\
\hline Women without children & $0.83^{* *}$ & 0.90 & $0.65^{\star \star}$ & $0.74^{\star *}$ \\
\hline Man (ref) & 1 & 1 & 1 & 1 \\
\hline \multicolumn{5}{|l|}{ Age } \\
\hline 15-24 years & $1.37^{\star \star}$ & $1.94^{\star \star}$ & 1.15 & $1.64^{* *}$ \\
\hline 25-34 years & $2.03^{\star *}$ & $1.94^{\star *}$ & $1.93^{\star *}$ & $1.93^{\star *}$ \\
\hline $35-44$ years & $1.62^{\star \star}$ & $1.35^{\star \star}$ & $1.43^{\star \star}$ & $1.52^{\star \star}$ \\
\hline 45-54 years (ref) & 1 & 1 & 1 & 1 \\
\hline $55-63$ years & $0.66^{\star *}$ & $0.36^{\star *}$ & $0.59^{\star \star}$ & $0.52^{\star \star}$ \\
\hline \multicolumn{5}{|l|}{ Marital status } \\
\hline Unmarried & $1.32^{\star *}$ & $0.87^{*}$ & 1.04 & 1.06 \\
\hline Married/cohabitant (ref) & 1 & 1 & 1 & 1 \\
\hline \multicolumn{5}{|l|}{ National origin } \\
\hline Other Nordic & 1.49 & 0.70 & 0.93 & 1.21 \\
\hline Other Europeans/North Americans & 0.87 & 0.70 & 1.23 & 1.13 \\
\hline Other world & 1.33 & 1.46 & 1.19 & $1.48^{* *}$ \\
\hline Native (ref) & 1 & 1 & 1 & 1 \\
\hline \multicolumn{5}{|l|}{ Education } \\
\hline Primary & 1.08 & 0.93 & $0.75^{\star \star}$ & $0.70^{* \star}$ \\
\hline Secondary & 1.04 & 0.90 & $0.86^{\star}$ & 0.92 \\
\hline Tertiary (ref) & 1 & 1 & 1 & 1 \\
\hline \multicolumn{5}{|l|}{ Industry } \\
\hline Agriculture & 1.32 & $1.72^{\star *}$ & $1.66^{\star \star}$ & 1.26 \\
\hline Manufacturing (ref) & 1 & 1 & 1 & 1 \\
\hline Construction & 1.34 & $2.17^{\star \star}$ & $1.59^{\star \star}$ & 1.90 \\
\hline Trade etc. & 0.91 & 1.04 & $1.45^{\star \star}$ & 1.14 \\
\hline Transport etc. & 1.17 & 1.18 & $1.63^{\star}$ & $1.47^{\star \star}$ \\
\hline Finance etc & 0.91 & 1.33 & 1.29 & 1.20 \\
\hline Real estate etc & 0.99 & $1.54^{\star *}$ & $1.64^{\star *}$ & $1.25^{\star \star}$ \\
\hline Public administration & 0.77 & $1.80^{* *}$ & $1.45^{\star}$ & 1.26 \\
\hline Education & 0.97 & 0.85 & $1.38^{\star *}$ & $1.34^{\star *}$ \\
\hline Health care & $0.70^{* *}$ & $1.50^{* *}$ & $1.27^{\star}$ & 1.13 \\
\hline Social and personal services & 0.89 & 0.87 & 1.06 & 1.08 \\
\hline \multicolumn{5}{|l|}{ Occupational status } \\
\hline Managers & $1.55^{\star}$ & 1.11 & $1.54^{*}$ & 1.16 \\
\hline Professionals & $1.74^{\star *}$ & 0.86 & 1.25 & 1.06 \\
\hline Semi-professonals & 1.05 & $0.79^{\star}$ & 1.05 & $0.74^{\star *}$ \\
\hline Service workers & 1.08 & $0.68^{\star *}$ & 0.87 & $0.63^{\star *}$ \\
\hline Blue collar worker (ref) & 1 & 1 & 1 & 1 \\
\hline \multicolumn{5}{|l|}{ Working time } \\
\hline Parttime 1-19 hours & $2.28^{\star \star}$ & $2.21^{\star *}$ & 1.52 & $2.41^{\star *}$ \\
\hline Part time $20-35$ hours (ref) & 1 & 1 & 1 & 1 \\
\hline \multicolumn{5}{|l|}{ Employment status } \\
\hline Temporary employee & $2.24^{\star *}$ & $1.93^{\star \star}$ & $1.43^{\star \star}$ & $2.17^{\star *}$ \\
\hline Self-employed & $2.55^{\star \star}$ & 1.12 & $1.66^{\star \star}$ & $2.09 * *$ \\
\hline Permanent contract (ref) & 1 & 1 & 1 & 1 \\
\hline \multicolumn{5}{|l|}{ Company size } \\
\hline $1-9$ (ref) & 1 & 1 & 1 & 1 \\
\hline $11-19$ & $0.71^{\star *}$ & 0.97 & 1.00 & 0.96 \\
\hline $20-49$ & 0.86 & 1.02 & 1.07 & 1.01 \\
\hline $50+$ & $0.74^{\star *}$ & 0.93 & 0.93 & 1.08 \\
\hline \multicolumn{5}{|l|}{ National unemployment rate } \\
\hline Low (ref) & 1 & 1 & 1 & 1 \\
\hline Medium & 1.00 & $0.84^{\star *}$ & 0.99 & 1.04 \\
\hline High & 0.92 & 1.12 & 1.05 & 1.03 \\
\hline Annual change in national unemployment & 0.93 & $0.75^{\star \star}$ & $1.16^{\star \star}$ & $0.93^{\star}$ \\
\hline Nagelkerke $\mathrm{R}^{2}$ & 0.16 & 0.15 & 0.09 & 0.18 \\
\hline $\mathrm{N}$ & 10299 & 9986 & 11697 & 20957 \\
\hline
\end{tabular}


There are no systematic industry-specific effects on the probability of employees increasing their working hours. In Norway we see that this takes place particularly in some private service sectors. In Sweden and Finland, part-time employment is a not very stable affiliation in the construction industry. The same applies to agriculture for Norway and Finland. We also see opposite effects for the health and social care sector. In Denmark this sector stands out because part-time employment is a more than usually stable status; in Finland we find the opposite. The size of the workplace tends not to have much effect. For example, part-time employees at large workplaces do not have the greatest probability of increasing their working hours.

We also see that employees who initially work short part-time are especially inclined to increase their working hours. Short part-time is an unstable affiliation in all countries, also when corrected for gender, age etc. Self-employed and temporary employees who work part-time also have a greater probability than others of increasing their working hours. In the case of self-employed persons this may also be partly attributable to the fact that they seldom have any agreed weekly working hours in the way that wage-earners do. This applies to all countries, but most strongly to Denmark and Sweden. It therefore appears that unstable part-time work may be more strongly associated with the type of contractual conditions in these two countries compared with Norway and Finland.

It is somewhat uncertain how the national unemployment rate can be expected to affect the working hours of part-time employees. But it is most reasonable to assume that in periods of low and/or falling unemployment there are higher odds of part-time employees being offered an opportunity to increase their weekly working hours. However, we find no clear relationship between the unemployment rate and the probability of migrating to longer working hours. In Finland and Sweden the probability of part-time employees increasing their working hours are reduced with rising unemployment. In Norway, somewhat surprisingly, we see the opposite pattern.

To better illustrate differences in transition rates, we have calculated the predicted probability of increased weekly working hours for two main groups of part-time workers: young people in the start-up phase in the labour market, and adult women in various industries/occupations. Diagram 7.5 shows young employees in temporary positions who work short part-time in industries such as retail and wholesale trade and the hotel and restaurant industry. Many of them will be students with extra jobs alongside their studies. We see here that the share who increase their working hours is higher in Denmark and Finland than in Sweden, and lowest of all in Norway. Young men have a somewhat higher probability of increasing their working hours than young women. 


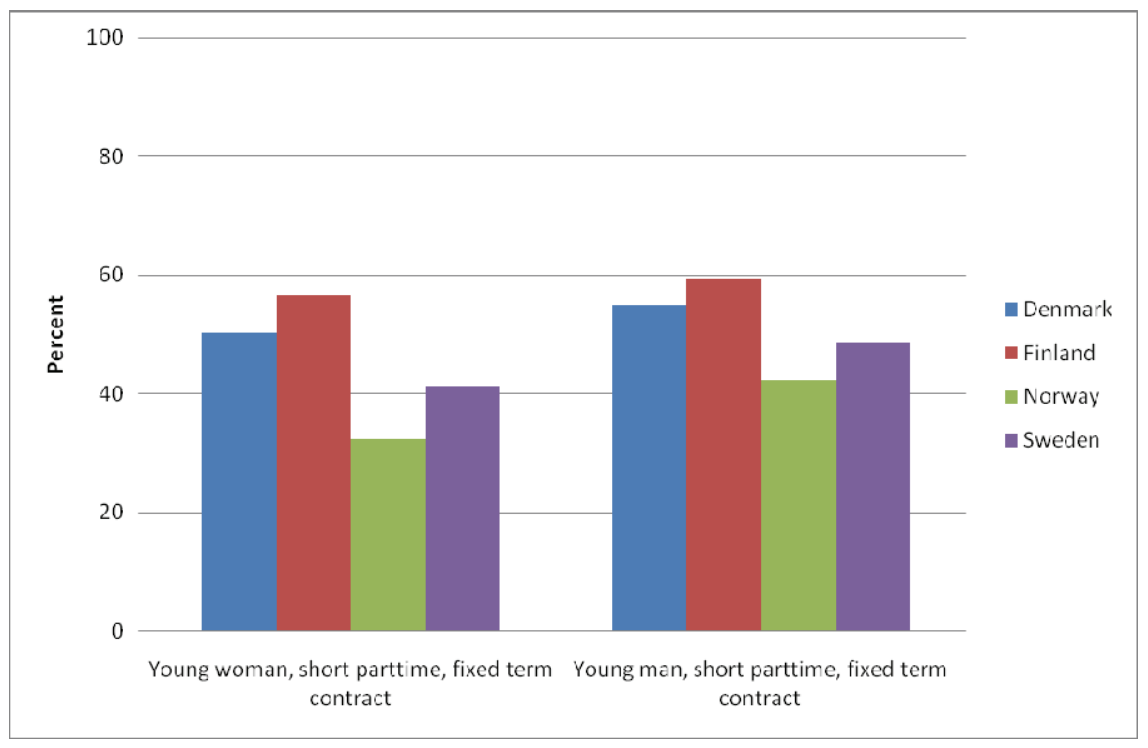

Diagram 7.5 Predicted probabilities of various categories of part-time employees at $T_{1}$ having increased their working time at $T_{2}$

Note: Young men: aged 15-24, single, natives, primary education, short part-time, fixed term contract, service worker, in retail and wholesale trade etc, employed in a company with 10-19 employees, no change in national unemployment rate moderate county unemployment. Young women: apart from gender and no children, all variables the same as those for the previous category.

Quite another type of part-time employee is adult women with children who work long part-time (20-34 hours a week). This group has far more stable working hours in all countries than we find for young part-time employees (Diagram 7.6). The probability of a woman who works part-

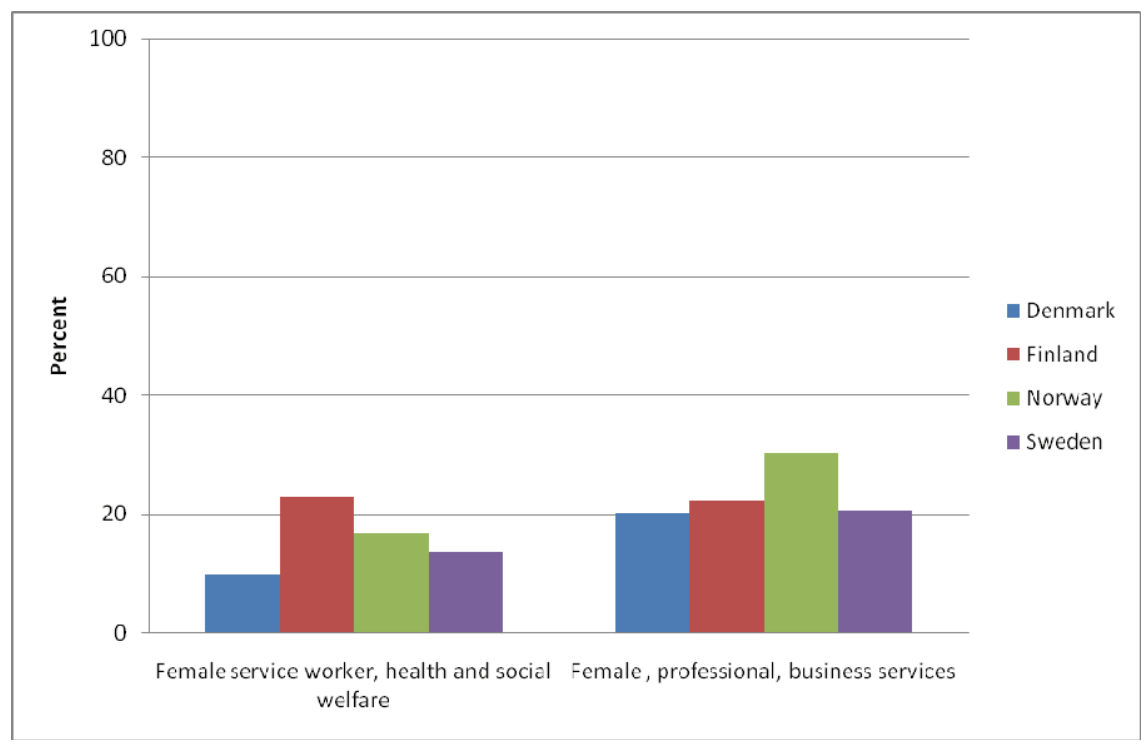

Diagram 7.6 Predicted probability of various categories of part-time employees at $T_{1}$ having increased their working time at $T_{2}$

Note: Female service workers in health and social welfare: aged 35-44, married with children, natives, primary education, employed in company with 50+ employees, permanent contract, long part-time, no change in national unemployment rate, moderate country unemployment. Female professionals in business services, same but with tertiary education. 
time increasing her working hours to full time is higher for highly educated women in business services, an industry where the part-time share is generally low, than for service workers in health and social services without higher education. The exception is Finland, where there is no difference between the two categories of part-time employees.

\subsection{Country differences}

In this section we look at national differences in mobility by applying regression analysis to all four countries. By including factors such as age, gender, industry, level of education, unemployment rate etc., we also control for differences in the composition of the labour force and industry structure in the different countries. Our question is whether national differences in mobility patterns persist after such factors have been controlled for. The reference category is the mean of the odds for the four countries. Here we show only the effect of country (odds ratio) in a model where country is the only variable (Model 1). We then control for characteristics of the employee and the job situation (Model 2) and finally the unemployment rate and changes in the unemployment rate (Model 3). In the same way as in Chapters 5 and 6, we use a measure of the unemployment rate that reflects whether the unemployment rate is low, moderate, or high in a Nordic (not national) context.

\subsubsection{Entry into the labour market - part-time or full-time?}

In this chapter we have seen that there are differences between countries in the odds of ending up in part-time rather than full-time work in connection with mobility from non-employment (inactive as well as unemployed) to employment. This is confirmed in Table 7.8, where Norway and Finland are opposites with respect to the probability of "newcomers" moving into part-time employment (Model 1). Denmark also distinguishes itself through the somewhat lower probability of going into a part-time position compared with a Nordic average. This pattern persists when we control for various characteristics of those who move from nonemployment to employment, including whether they are students, inactive for other reasons and unemployed (Model 2). The differences between the Nordic countries with respect to mobility from nonemployment into employment therefore cannot be explained through national differences. The pattern is also the same when we include information about the labour market situation measured by the rate of and change in unemployment (Model 3). 
Table 7.8 Odds ratios for four Nordic countries regarding transitions from nonemployment to part-time employment, 2000-06 (2005 for Denmark). Binomial logistic regression. Only persons in employment at $T_{2}$.

\begin{tabular}{llll}
\hline Country (ref.=mean of odds) & Model 1 & Model 2 & Model 3 \\
\hline Denmark & $0,85^{\star *}$ & $0,92^{\star *}$ & $0,91^{\star *}$ \\
Finland & $0,78^{\star *}$ & $0,75^{* *}$ & $0,75^{* *}$ \\
Norway & $1,51^{\star *}$ & $1,40^{* *}$ & $1,41^{* *}$ \\
Sweden & 1,00 & 1,03 & 1,03 \\
\hline
\end{tabular}

Note: In Model 1, country is the only independent variable. Model 2 includes country and all variables in Table 7.4 except unemployment rate and change in national unemployment rate. Model 3 includes the variables in Model 2 , change in national unemployment rate and another classification of county unemployment rates.

\subsubsection{Mobility out of part-time employment}

Our next question is, in which country is there greatest risk of part-time employees leaving the labour market? In Table 7.9 we look at the probability of part-time employees leaving the labour market, for either unemployment or inactivity. When we look only at differences across countries (Model 1), we see that the probability of a part-time employee becoming unemployed is highest in Finland and lowest in Norway. When we control for characteristics of the employee and the workplace, i.e. take account of the differences across countries with regard to who the parttime employees are, we see that the odds of a part-time employee moving into non-employment are highest in Denmark, and that the transition rate is lowest in Sweden (Model 2). This pattern continues to apply when we include information about the unemployment rate and changes in the unemployment rate in the analysis (Model 3).

Table 7.9 Odds ratios for four Nordic countries regarding transitions from part-time work into non-employment, 2000-06 (2005 for Denmark). Binomial logistic regression.

\begin{tabular}{llll}
\hline Country (ref.=mean of odds) & Model 1 & Model 2 & Model 3 \\
\hline Denmark & 1,02 & $1,27^{\star *}$ & $1,29^{\star *}$ \\
Finland & $1,40^{\star *}$ & $1,28^{\star *}$ & $1,19^{\star *}$ \\
Norway & $0,89^{\star *}$ & $0,86^{\star *}$ & $0,94^{\star}$ \\
Sweden & $0,78^{\star *}$ & $0,72^{\star *}$ & $0,69^{\star *}$ \\
\hline
\end{tabular}

Note: In Model 1, country is the only independent variable. Model 2 includes country and all variables in Table 7.5 except unemployment rate and change in national unemployment rate. Model 3 includes the variables in Model 2 , change in national unemployment rate and another classification of county unemployment rates.

\subsubsection{National differences in working time mobility?}

We have also been concerned with whether employees change their agreed working hours, and in particular the extent of any increase in agreed working hours among part-time employees. We consider employees with short and long part-time separately. The probability of part-time 
employees with short part-time increasing their working hours is lower in Norway than in the other Nordic countries, all else being equal (Table 7.10). This also holds true when we control for characteristics of the individual (Model 2) and when we include information on the labour market (unemployment rate and change in unemployment rate, Model 3). Mobility from short part-time to longer working hours is highest in Sweden.

One explanation for this pattern may be that short part-time is a less marginal labour market affiliation in Norway than in the other Nordic countries (cf. the relatively high share of Norwegian women who work short part-time). As a result, a larger number of employees keep to their original working hours in Norway. In the other Nordic countries, short part-time is a far more unstable affiliation.

However, Norwegian employees with long part-time have a higher probability than their colleagues in other Nordic countries of increasing their working hours (Table 7.10).

Table 7.10 Odds ratios for four Nordic countries regarding transitions to increased working hours, employees working short part-time (1-19 hours per week) and from long part part-time (20-34 hours per week). 2000-06 (2005 for Denmark). Binomial logistic regression

\begin{tabular}{|c|c|c|c|}
\hline Country (ref.=mean of odds) & Model 1 & Model 2 & Model 3 \\
\hline & \multicolumn{3}{|c|}{ From short part-time $T_{1}$} \\
\hline Denmark & $0,93^{*}$ & 0,98 & 0,98 \\
\hline Finland & $1,09^{* *}$ & $1,11^{\star *}$ & 1,08 \\
\hline Norway & $0,78^{\star \star}$ & $0,82^{\star \star}$ & $0,83^{\star \star}$ \\
\hline \multirow[t]{2}{*}{ Sweden } & $1,27^{\star \star}$ & $1,12^{\star \star}$ & $1,13^{\star \star}$ \\
\hline & \multicolumn{3}{|c|}{ From long part-time $T_{1}$} \\
\hline Denmark & $0,74^{\star \star}$ & $0,83^{\star \star}$ & $0,83^{\star \star}$ \\
\hline Finland & $1,23^{\star \star}$ & $0,94^{*}$ & $0,94^{*}$ \\
\hline Norway & $1,25^{\star \star}$ & $1,39^{\star \star}$ & $1,38^{\star \star}$ \\
\hline Sweden & $0,88^{\star *}$ & $0,93^{\star \star}$ & $0,93^{\star \star}$ \\
\hline
\end{tabular}

Note: In Model 1, country is the only independent variable. Model 2 includes country and all variables in table 7.7 except working time, unemployment rate and change in national unemployment rate. Model 3 includes the variables in Model 2 , change in national unemployment rate and another classification of county unemployment rates.

We also consider the probability of employees reducing their working hours, either from full-time to part-time or from long part-time to short part-time. Although only a small share of the full-time employees and employees working long part-time reduce their agreed working hours (36.5 per cent), this still amounts to a considerable number of persons. Table 7.11 shows that the probability of reducing working hours is highest in Norway and lowest in Finland when controlled only for country (Model 1). This pattern is reinforced when we control for characteristics of individuals (Model 2) and persists after controlling for the labour market 
situation in the form of unemployment rate and change in unemployment rate.

Table 7.11 Odds ratios for four Nordic countries regarding transitions to reduced working hours, employees working long part-time (20-34 hours per week) or full-time (35 hours per week or more). 2000-06 (2005 for Denmark). Binomial logistic regression

\begin{tabular}{llll}
\hline Country (ref.=mean of odds) & Model 1 & Model 2 & Model 3 \\
\hline Denmark & $0,84^{\star \star}$ & $0,86^{\star *}$ & $0,86^{\star *}$ \\
Finland & $0,76^{\star \star}$ & $0,69^{\star \star}$ & $0,68^{\star \star}$ \\
Norway & $1,52^{\star \star}$ & $1,71^{\star \star}$ & $1,74^{\star *}$ \\
Sweden & 1,03 & 0,99 & 0,98 \\
\hline
\end{tabular}

Note: In Model 1, country is the only independent variable. Model 2 includes country and all variables in table 7.7 except working time, unemployment rate and change in national unemployment rate. Model 3 includes the variables in Model 2 , change in national unemployment rate and another classification of county unemployment rates.

\subsubsection{Summary - country differences}

In this section we have considered national differences in mobility into and out of part-time work. Earlier in this chapter we noted that there are large differences in part-time shares across the Nordic labour markets, and that the probability of working part-time is clearly highest in Norway and lowest in Finland. We see this pattern again when we consider the sort of working hours we find among those who have entered the labour market. Thus there appear to be distinct national patterns associated with the demand side of the labour market, or national traditions for full-time or part-time work. The pattern for part-time employees also mirrors the pattern observed for the labour markets generally with respect to the risk of exiting the labour market, with highest outflows in Denmark and Finland and lowest mobility out of the labour market in Sweden.

Working time mobility is highest in Norway (where the part-time share is also highest) and lowest in Denmark. In Finland there is little probability of a reduction in working hours, but nor do we find any stronger probability of increasing working hours in Finland than in Sweden or Denmark. One explanation is that in the Finnish labour market there is a lesser stock of part-time employees who are ready to work longer hours if they get the offer or can fit it into their day. However, a high part-time share in itself does not result in high working time mobility. In the Danish labour market - which also has a large number of parttime employees - the probability of employees changing their working hours is lower than the Nordic average. 


\subsection{Conclusion}

The focus of this chapter has been on part-time work in the Nordic countries. There are substantial differences across countries in the share of part-time employees. Finland distinguishes itself clearly by having a low share of employees working part-time, while Norway has the highest part-time share in the sense of thepercentage of employees who have weekly working hours of less than 35 hours per week. Norway also distinguishes itself in having a high share of part-time employees with short weekly working hours (less than 20 hours a week), and in that a short working week appears to be a stable status to a greater extent than in the other Nordic countries. In all countries, women predominate strongly in part-time work. We also see that part-time work is common among young people, and that there is a higher probability of the oldest cohorts in the labour market working part-time. There are many similarities among the Nordic countries with respect to which factors increase the probability of part-time work. For example, we find somewhat the same part-time industries in all four countries.

The most important Nordic difference in part-time work is the national differences in the share of adult women who work part-time. In all countries, men work full-time for the most part, at least if the youngest and to some extent the eldest cohorts in the labour market are excluded. For a considerable share of these women, part-time is also a stable status in the sense that they maintain their working hours in the course of the one-year period surveyed.

Is part-time work a bridge into working life for those who are not employed at the outset? A substantial share of non-employed who enter the labour market end up in part-time work. This applies in particular to students. It is reasonable to suppose that many of them look for part-time work in order to be able to combine paid work with studies. For the great majority of them, part-time work will not be a permanent status when they enter working life in earnest. But the share of unemployed and other groups of non-employed persons who move into part-time work is still clearly higher than the share of part-time work in the labour market as a whole.

We see the national differences in shares of part-time unemployed again when we look at the non-employed who enter the labour market. The probability of moving into a job with working hours that correspond to part-time employment is clearly highest in Norway and lowest in Finland, all else being equal.

The discussion regarding the role of part-time work also covers the question of whether there is a greater possibility of part-time employees leaving the labour market, and the extent to which part-time employees move into full-time work or increase their working hours, which is usually perceived as a transition to a more integrated position in working life. 
In all countries, the great majority of part-time employees remain in the labour market during the period we have surveyed (one year), and parttime employees with long part-time employment have almost as stable a labour market status as full-time employees. In the Nordic countries this type of part-time work can therefore not be regarded as involving a substantially higher risk of leaving the labour market. Finland can be regarded as a slight exception, which indicates that the strong Finnish tradition for full-time work heightens the distinction between full-time and part-time work, and that part-time work is regarded to a greater extent as marginal. In all countries, employees with short part-time probably have a higher probability of leaving the labour market, not least in order to pursue an education. Here, too, we see that the risk of transition to the status of non-employed follows the national patterns we have seen for those employed generally (see Chapter 5), with highest mobility out of the labour market for part-time employees in Denmark and lowest in Sweden and Norway, all else being equal.

As regards the transition to longer working hours, we do not find it surprising that the share of employees who increase their working hours is highest in Norway, which not only has the highest share of part-time employees, but also the largest number of employees who work short part-time. But Norway also has the highest mobility the other way (reduction of working hours), which may indicate that the Norwegian labour market generally is characterised by higher working time mobility. As a general rule we nevertheless find a common Nordic pattern when it comes to the types of part-time employees who increase their working hours. Young employees, fixed-term employees or self-employed persons and men are over-represented in all countries among part-time employees who increase their working hours. Adult women with children distinguish themselves by increasing their working hours far less than other groups in the labour market - all else being equal. However, no industries stand out as having especially high or low working time mobility, nor do we find any clear signs that mobility to longer working hours can be linked to employees' level of education or nationality. Thus the transition from part-time to longer working hours can be linked more strongly to phase of life than to a two-track labour market with industries/occupations where employees are locked into part-time employment and industries and occupations where there is a rapid transition to longer working hours.

There is little to indicate that working time mobility is part of the Danish flexicurity model. Part-time employees in Denmark have a lower probability of either increasing or reducing their working hours compared with Norway, all else being equal, nor does the transition to working life proceed more often via part-time work in Denmark than it does in the other Nordic countries. It therefore appears that part-time work can be regarded as somewhat more marginal in Denmark than, for example, in Norway. 



\section{Mobility between Workplaces, Occupations and Industries}

\subsection{Introduction}

In the previous chapters, much of our focus has been on transitions between labour market states - with the exception of changing one's working hours or type of contract. In the present chapter, we move on to study transitions within employment. How common is it for the employed in our countries to have a more or less significant career change?

The transitions studied in this chapter are changes of workplace, occupation, and industry. We also look at how often the three mobility types combine with another. As in all analyses in this report, we look at annual transitions on an individual level.

The outline of the chapter and the most important questions raised are as follows:

In the remainder of the introductory section, we first consider the relevance of the studied transitions, and briefly present some previous research. Then we have a look at general definitions used when studying these types of mobility. Finally, we list some hypotheses about flexicurity and the three types of mobility studied. What effects do we expect the flexicurity institutions described in Chapter 3 to have on these mobility types?

The empirical part of this chapter is twofold. First, we present the main results of our mobility indicators. Section 8.2 answers some of our most important questions: how large are the flows between workplaces, occupations, and industries in our four countries? How do the countries differ from each other and how have the rates changed over time? We also look at combinations of the three types: how do mobility-related situations differ between the countries, and are there more differences in some combinations than others? Finally, we link the analyses to those presented in Chapter 5 by looking at a measure of "total mobility".

After finding large differences between countries in section 8.2, we then move on to the other part of our empirical analyses. Each of the three mobility types is analysed in two multivariate settings similar to those used in other chapters of this report. First, we look at parallel country models. What are the most important determinants of workplace, occupational, and industrial mobility in our four countries? Are they similar or different for the three mobility types and the four countries? Second, we use combined models with country as a variable. The aim is to see if the country differences can be explained by the variables we control for. 
Thus, section 8.3 consists of three sub-sections, one of each mobility type, where we first look at mobility determinants in parallel models and then at a combined model.

The chapter is concluded by section 8.4 , where we summarize the most important findings and discuss what may lie behind them. Finally, we revert to the hypotheses presented earlier and see if we have been able to back up or reject them.

\subsubsection{Relevance and previous research}

Workplace and occupational mobility are often in focus in discussions about flexibility. Facilitating transitions between workplaces, industries and occupations is one of the key rationales behind flexicurity.

Industrial mobility differs from the other two types in the sense that, apart from being an individual transition, it can also happen on a corporate level: either there is a fusion or the company changes its line of business. In those cases, the change may or may not have effects on the individual employees.

Facilitating mobility is often seen as an especially difficult task in the future, as the workforce ages. It is thought that an older workforce will be less willing to make the necessary transitions. Further, as the average educational level increases, it may be thought that the "skill walls" between occupations rise higher, and this also reduces mobility. However, these arguments are not necessarily valid. For instance, in the USA mobility increased substantially at the same time when the age and education of the workforce increased. Also in Finland we saw an increase in mobility at a time when the workforce was ageing. (Tomkins and Twomey 2000, Työministeriö 2006, Kambourov and Manovskii 2004, Virjo et al. 2007, Aho et al. 2009).

In policy discussions, it seems often to be thought that the rule "the more the better" applies to mobility. However, it is clear that mobility can be negative as well as positive. In essence, workplace, occupational and industrial mobility may be labelled as reallocation of human capital. As human capital can be very specific for an occupation or even for a job, it is obvious that mobility can both destroy and help utilise human capital.

Recently, the transferability of human capital has been the topic of several studies. Tenure within an occupation increases earnings markedly, a result that can of course be expected - experience is rewarded. However, tenure within a job or an industry has little independent effect, when occupational tenure is controlled for. Simultaneously, occupational mobility often leads to decreased earnings, which is thought to indicate that human capital is specific to occupation. (Sullivan 2006, Kambourov and Manovskii 2009a, Kambourov et al. 2009). The latter result could also be interpreted otherwise: it may indicate that the reasons for chang- 
ing one's occupation are often other than the prospect of getting a better salary.

It seems also clear that individually motivated mobility may cause changes that the society needs to adapt to. More generally we can say that mobility also can be analyzed in terms of "winners" and "losers" - be they regions, occupations, individuals, or societies.

At least in theory, we can distinguish between different types of mobility-related situations on a macro level and from the point of view of the individual. On the individual level, we can roughly distinguish between four situations related to mobility: involuntary mobility ("push"), voluntary mobility ("pull”), voluntary immobility ("stay”), and involuntary immobility ("stuck").

On the macro level, we may distinguish between mobility demanded by structural change ("necessary mobility"), mobility driven by individual factors rather than structural demand ("unnecessary mobility"), and the situation where mobility is driven by individual factors and it is in conflict with structural demand ("harmful mobility").

\subsubsection{Hypotheses from the flexicurity standpoint}

The main question in this report is whether flexicurity has effects on mobility in the four countries. In chapter 3 , the "flexicurity profiles" of the countries have been discussed. Based on that, we can list the following expected findings when it comes to workplace, occupational, and industrial mobility.

Strict employment protection legislation (EPL) is expected to have by raising the threshold for hiring and firing - a negative effect on workplace and industrial mobility, and possibly on external occupational mobility as well.

Further, the effect of economic cycles on workplace mobility may be greater in countries with stricter EPL. The explanation would be that beside the alternatives on the labour market (vacancies), employees' exit decisions are also determined by the relative value of the present job. This reasoning is obviously valid only for voluntary job mobility. In any case, we can expect to see greater changes with business cycles in countries with strict EPL, and especially Sweden with its seniority rules.

As strict EPL and seniority rules provide an incentive to staying with the same employer, we expect to find a positive effect - at least in relative terms - on internal occupational mobility.

Generous unemployment benefits encourage risk-taking and provide incentives for career shifts. Thus, we expect them to have positive effects on all three forms of mobility.

One of the aims of active labour market policy measures (ALPM) is to encourage people in vulnerable positions on the labour market (unemployed or at risk of unemployment) to make the kind of career shifts that 
are in focus in this chapter. Thus, we expect that the scope of ALPM has positive effects on workplace, industrial, and occupational mobility. However, in this study we can only detect a very small part - if any - of such an effect. This is because we are studying mobility during a oneyear period, which is too short for most of the career change processes involving ALPMs. In most cases, the process of e.g. becoming unemployed, being directed to an active measure and becoming re-employed will take more time. This is especially true for occupational mobility.

Further, we expect investments in lifelong learning to have positive effects on occupational mobility.

One interesting comparison involves the forms of flexibility. It is often claimed that temporary employment contracts (and temporary work agencies) are a functional alternative to flexibility. Temporary employment is much more common in Finland and Sweden than it is in Denmark and Norway (chapter 2, see also Virjo 2006). It is a reasonable assumption that people with temporary employment contracts are more mobile than others. Thus, we could hypothesize that the mobility levels between the countries are not necessarily very different, but mobility is channelled via different routes.

The labour markets are different geographically as well. Denmark has a much smaller area than the three other countries, and thus has a much denser labour market. This might be an important factor. In Finland, Sweden, and Norway, the lack of possibilities and/or will for geographical mobility may well reduce workplace, occupational or industrial mobility.

Obviously, it can be difficult to study these hypotheses in practice, as they may yield contradictory predictions. For instance, we could expect Sweden to have high workplace mobility because of its relatively generous unemployment benefits. On the other hand, its strict EPL is expected to have opposite consequences.

\subsubsection{Definitions in general}

As labour flows partly take place back and forth between workplaces, occupations, and industries, the main indicator for mobility is gross mobility. It is defined as the proportion of people employed at two consecutive points of time who change workplace / industry / occupation in between (at least once).

Another concept is net mobility, which can be defined as the change of occupational / industrial structure that is caused by gross mobility. Net mobility is calculated for each occupation / industry (gross inflow minus gross outflow). Aggregate net mobility is the sum of absolute values of net mobility for all occupations / industries, divided by two so that each transition is counted only once. The difference between gross and net is often referred to as "churning”. (See Moscarini and Vella 2002.) Regret- 
tably, studying net mobility could not be done within the framework of this report.

The concept of gross mobility in itself is incomplete, as it leaves out people who were not employed during one of the points of measurement. It is, however, essential to know whether labour flows mainly are between occupations or industries, or whether their direction from some occupations is to unemployment or outside the labour force - and vice versa for some other occupations.

"Total mobility" would mean that we also include inflow/outflow from/to other labour market states (unemployment, outside the labour force). On an aggregate level, these flows are dealt with in chapter 5. In this chapter, section 8.2.2 complements those analyses.

Occupational mobility does not necessitate change of workplace / employer or vice versa. Transitions within the same workplace are called internal mobility, whereas external mobility refers to transitions including a change of workplace. Career advancement often manifests as a change of work tasks and occupational status. Especially those working for large multinational companies have access to considerable "internal labour markets” (Cf. Cheng and Kalleberg 1996, Shniper 2005). Further, it is also possible to change industry without changing employer - this is the case when a firm changes line of business, or e.g. merges with another firm.

\subsection{Mobility levels}

In this section we take a look at our main indicators: what are the mobility levels in our four countries, and how have they changed over the study period? Before moving on to the results, we should be made aware of some possible underlying factors and reminded of others. Many of these aspects are also taken up when interpreting the results.

Previously, the term applied to job changes has often been job-to-job mobility. However, the definition of a job is not self-evident, and a wide range of indicators have been used to measure job-to-job mobility. Because they often are not comparable with each other or with the indicators used in our study, we have decided to use a more precise term. In three of the countries - Denmark, Finland, and Norway - the LFS measure used refers very precisely to the change of physical workplace. As the LFS in Sweden instead measures change of employer, a precise term would be "workplace / employer mobility". For convenience, we use the shorter term of workplace mobility.

Further, we should remember the lessons from Chapter 4, some of which we recapitulate now.

There are some methodological differences between the countries, especially when it comes to workplace mobility. As mentioned, the Swed- 
ish LFS measures change of employer, while the others measure change of physical workplace. This will make the Swedish figure lower in comparison. On the other hand, the Swedish indicator is based on a cumulative measure, which will probably make it higher than it would be with a single retrospective question.

Also, interview methodology may have an effect on the observed mobility levels - perhaps especially by raising some of the rates for Norway.

We also studied what possible effect the way the data sets have been constructed may have on the results in this chapter. Our conclusion was that for all three mobility types, the Swedish and Norwegian mobility rates are probably somewhat underestimated when compared with Finland and Denmark. This is because the two latter countries' data sets include mobility starting throughout the year - most importantly, people working seasonally during the summer. At most - concerning workplace and occupational mobility - the rates in Norway and Sweden should probably be multiplied by around 1.1. As this is just an educated guess, we have not done such a calculation. Instead, this should be kept in mind when interpreting the results. Also, we must keep in mind that the different data structures can have some bearing on the effects of independent factors in multivariate analyses.

Another issue to consider is that the indicators we use are not at all free from cultural influence. This may especially have bearing on occupational mobility, as the concept of occupation can depend on who is defining it. Obviously, the LFS is thought to measure it in a similar manner in all countries, taking into account actual work tasks, etc.

However, we cannot exclude that local practices or even passing fads may have an impact on our measurements. For instance, it is possible that there are different practices at workplaces regarding when a person is given a new job title - and receiving a new job title is something that could affect the possibility of change of occupation in the next LFS interview, even in a situation where one's tasks have remained almost or completely the same. It is possible that the differences observed below are partly caused by e.g. Norwegians more often than Swedes giving a new title when a person gets a salary increase.

Further, technical development, reorganizations, or internationalization may result in new job titles. For instance, it may be the case that no actual change takes place when a salesman ("försäljare”) becomes a "key account manager". There may thus be "title inflation" on the labour market, at least periodically. Especially in the private sector, job titles can be freely chosen. A more "fancy" title can be given to a person as a reward, or in order to make an impression on the company's clients.

Having said this, we should note that job title should not determine one's occupation in the LFS. It is the actual tasks performed that should be behind the decision when deciding the occupational code. However, we cannot exclude the possibility that a new job title affects the way a 
person describes his/her work tasks. Thus, increased occupational mobility during some time period can perhaps be partly explained by a wave of giving people new, more fashionable job titles.

With our data, we cannot study how permanent the observed changes are. Previously, Kambourov and Manovskii (2004) have found that changes of occupation are rather permanent. Only about 20 per cent of the changers returned to their earlier occupation or industry within four years, and the return rate to an occupation/industry which is close to their earlier (same on 1-digit level) was 30 per cent.

\subsubsection{Descriptive statistics}

In Tables 8.1-8.3, the general gross mobility levels between workplaces, occupations, and industries in our four countries are described. In Table 8.1, we have given two measurements for Norway. In short, the primary variable is constructed in a way more comparable to Sweden while the alternative is very similar to the measures used in Finland and Denmark (see chapter 4 and Appendix B).

The mobility rates are highest in Denmark, which is also expected from a flexicurity standpoint. Perhaps surprisingly - especially when considering its strict EPL - Norway has high mobility rates as well, being not far behind Denmark. To some extent this may be due to methodology. However, Norway is overall so much above Finland and Sweden that the difference cannot be attributed solely to small discrepancies in the way mobility is measured. Further, we must bear in mind that mobility in Norway and Sweden probably is underestimated in comparison because of data structure issues. Overall, Sweden tends to have the lowest rates, while Finland ranks third.

The overall labour market mobility in Denmark seems to be on a very high level indeed, considering that there are also many transitions between employment and non-employment. About 22\% of employed Danes changed occupation during a year, while $16 \%$ switched workplace and $10 \%$ industry. Occupational mobility is especially high: during the peak year in 2002-03, more than one in four employed Danes changed from one occupation to another.

When looking at the different forms of mobility separately, the picture changes in some respects. For instance, the differences between countries and over time are much smaller with industrial mobility than they are with occupational mobility. Until 2003, Finland and Sweden had a similar industrial mobility rate, 2-3percentage points lower than that of Norway and Denmark, which were very similar to each other. After that, Denmark has the highest and Sweden the lowest industrial mobility, with Finland and Norway in between. The difference between Sweden and Denmark increases markedly after 2003, being over fourpercentage points in 2005. 
With occupational mobility, we see much larger differences between the countries. Sweden and Finland have a relatively stable occupational mobility rate around 10 per cent, with a slight increase towards the end of the period. Considering the possible effect of data structure, we can conclude that Finland has the lowest occupational mobility of the four countries. Danes are constantly extremely mobile, even though there are large differences between the years - most notably between 2001 and 2002.

The most interesting development can be seen in Norway. In the beginning of the period, occupational mobility is on the same level as in Denmark. After 2001, it decreases clearly, and towards the end of the period Norway is more similar to Finland and Sweden than it is to Denmark.

For workplace mobility, we have two indicators from Norway. All indicators seem to be strongly correlated, with a pro-cyclical pattern.

Ranking the countries is partly difficult because of the differences in methodologies used. We can certainly say that Sweden has the lowest amount of workplace transitions and Denmark the highest. Our conclusion is that the low workplace mobility in Sweden cannot be attributed to methodology. On one hand, LFS in Sweden measures changes of employer and not workplace. This along with data structure issues may cause an underestimation. On the other hand, the measurement in Sweden is cumulative, which should have the opposite effect.

Norway ranks second when using the hybrid indicator. However, when comparing levels in Norway to Finland and Denmark, the alternative variable is preferable, since it is constructed in a similar manner as the indicators for those two countries. With that indicator, Norway's workplace mobility level is very similar to that of Finland. As the alternative indicator measures mobility between second quarter of $t$ and second quarter of $t+1$, it probably does not underestimate mobility in the way that the general construction of Norwegian data does. Thus, our conclusion is that Norway and Finland have a similar workplace mobility rate.

Perhaps the most striking finding here is that workplace mobility in Sweden has had a very steep decline between 2000 and 2004. The rate has probably increased a bit again in 2005-06, as have the other two mobility forms. In any case, the Swedish development is remarkable, because in the other countries, workplace mobility levels are relatively stable. What caused the stagnation of workplace mobility in Sweden after 2001? One explanation is the combination of very strict EPL and seniority rules and the rising unemployment during the studied years. In a harsh economic environment, the seniority acquired in the present job is valued very highly, which promotes risk-aversive behaviour. 
Table 8.1 Gross workplace mobility. Two alternative measures for Norway.

\begin{tabular}{lrrrrr}
\hline & Denmark & Finland & $\begin{array}{r}\text { Norway } \\
\text { primary }\end{array}$ & $\begin{array}{r}\text { Norway } \\
\text { alternative }\end{array}$ & Sweden \\
\hline Average of available years & $15.7 \%$ & $\mathbf{1 1 . 1 \%}$ & $\mathbf{1 4 . 0 \%}$ & $\mathbf{1 0 . 9 \%}$ & $\mathbf{7 . 9 \%}$ \\
2000 & $16.9 \%$ & $11.5 \%$ & $16.1 \%$ & $12.9 \%$ & $9.7 \%$ \\
2001 & $15.6 \%$ & $10.6 \%$ & $15.6 \%$ & $11.8 \%$ & $9.0 \%$ \\
2002 & $15.1 \%$ & $10.5 \%$ & $13.6 \%$ & $9.8 \%$ & $7.6 \%$ \\
2003 & $14.7 \%$ & $10.0 \%$ & $11.2 \%$ & $9.5 \%$ & $6.8 \%$ \\
2004 & $15.9 \%$ & $10.9 \%$ & $12.8 \%$ & $10.7 \%$ & $6.6 \%$ \\
2005 & $16.0 \%$ & $11.6 \%$ & $\mathrm{n} / \mathrm{a}$ & $\mathrm{n} / \mathrm{a}$ & $\mathrm{n} / \mathrm{a}$ \\
2006 & $\mathrm{n} / \mathrm{a}$ & $12.2 \%$ & $\mathrm{n} / \mathrm{a}$ & $\mathrm{n} / \mathrm{a}$ & $\mathrm{n} / \mathrm{a}$ \\
\hline
\end{tabular}

Table 8.2 Gross occupational mobility.

\begin{tabular}{|c|c|c|c|c|}
\hline & Denmark & Finland & Norway & Sweden \\
\hline Average of available years & $22.3 \%$ & $9.2 \%$ & $16.6 \%$ & $10.1 \%$ \\
\hline 2000 & $\mathrm{n} / \mathrm{a}$ & $\mathrm{n} / \mathrm{a}$ & $20.4 \%$ & $11.6 \%$ \\
\hline 2001 & $19.1 \%$ & $\mathrm{n} / \mathrm{a}$ & $20.7 \%$ & $10.9 \%$ \\
\hline 2002 & $25.8 \%$ & $8.7 \%$ & $17.1 \%$ & $10.0 \%$ \\
\hline 2003 & $21.6 \%$ & $8.2 \%$ & $15.7 \%$ & $9.0 \%$ \\
\hline 2004 & $22.5 \%$ & $9.1 \%$ & $15.4 \%$ & $8.2 \%$ \\
\hline 2005 & $22.5 \%$ & $9.6 \%$ & $14.2 \%$ & $10.8 \%$ \\
\hline 2006 & $\mathrm{n} / \mathrm{a}$ & $10.6 \%$ & $12.5 \%$ & $10.9 \%$ \\
\hline
\end{tabular}

Table 8.3 Gross industrial mobility.

\begin{tabular}{|c|c|c|c|c|}
\hline & Denmark & Finland & Norway & Sweden \\
\hline Average of available years & $9.6 \%$ & $7.7 \%$ & $9.6 \%$ & $7.0 \%$ \\
\hline 2000 & $\mathrm{n} / \mathrm{a}$ & $8.9 \%$ & $12.4 \%$ & $9.0 \%$ \\
\hline 2001 & $10.4 \%$ & $7.8 \%$ & $10.9 \%$ & $7.8 \%$ \\
\hline 2002 & $9.1 \%$ & $7.2 \%$ & $9.4 \%$ & $\mathrm{n} / \mathrm{a}$ \\
\hline 2003 & $8.8 \%$ & $6.3 \%$ & $8.4 \%$ & $6.4 \%$ \\
\hline 2004 & $9.9 \%$ & $7.2 \%$ & $8.4 \%$ & $5.7 \%$ \\
\hline 2005 & $9.9 \%$ & $8.0 \%$ & $8.4 \%$ & $5.7 \%$ \\
\hline 2006 & $\mathrm{n} / \mathrm{a}$ & $8.8 \%$ & $9.2 \%$ & $6.8 \%$ \\
\hline
\end{tabular}

Overall, the three mobility types are correlated with each other within countries, and to some extent between countries as well. Our time frame is very limited, but from what we can see it appears that for the most part they are pro-cyclical. This has been the case in earlier studies as well. Mobility is usually observed to be higher during an economic upturn and low unemployment (Virjo et al. 2007, Aho and Virjo 2009, Furåker and Berglund 2009, Moscarini and Vella 2002, Kambourov and Manovskii 2004, Isaoglu 2006, Frederiksen and Westergaard-Nielsen 2007, Moscarini and Thomsson 2007). With these results in mind, it is reasonable to assume that the overall mobility levels studied here have declined strongly after the last year in our data (2006) because of the financial crisis.

\subsubsection{Total mobility}

In Figure 8.1, we look at a "total mobility" picture. In the other analyses in this chapter, mobility figures reflect gross mobility. That is, they only include people who have been employed at both $t$ and $t+1$. In Figure 8.1, we also include entrants to employment from unemployment and from 
outside the labour force. (Industrial mobility has been left out of this analysis in order to avoid complicating it too much.) Unfortunately, we cannot say whether the entrants have changed occupation or not.

Let us give an example of how to read the figure. First, it should be noted that the population the calculations are based on includes those employed at time $t+1$. Thus, the years given in the figure refer to that year, instead of year $t$ as in most of our analyses. In Finland in 2007, about 24 per cent of all employed had made at least one of the transitions described during the preceding year. A bit less than 10 per cent had been either unemployed (3.4\%) or outside the labour force (6.2\%) in 2006. Within employment we have those who changed physical workplace but not occupation (5\%), occupation but not workplace (3.5\%), and both workplace and occupation (6\%).

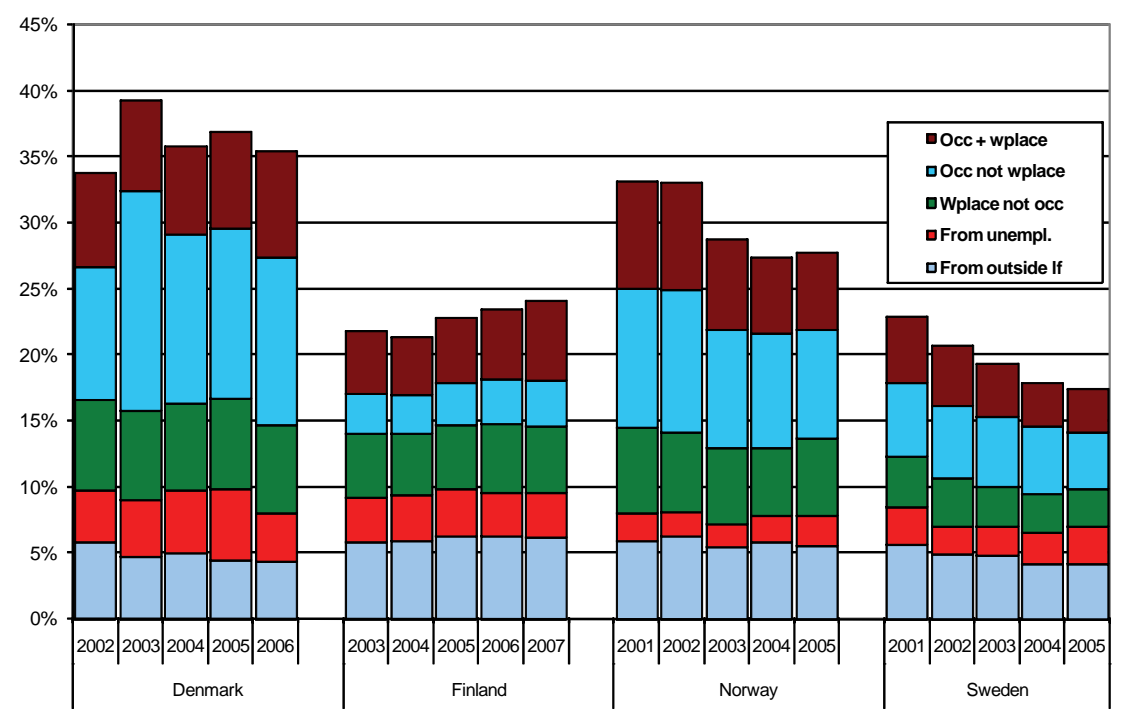

Figure 8.1 Total mobility in four countries with regard to occupational and workplace mobility. Those employed at time $t+1$ : status one year earlier. Displayed are years where data are available, partly different for the countries.

Figure 8.1 further stresses the fact that there are large differences in mobility levels between the countries. The employed in Denmark and to some degree in Norway are much more mobile than their counterparts in Finland and Sweden. Of those employed in 2005, over 35\% had been mobile in one way or another in Denmark. In Sweden, the corresponding figure was $17 \%$ - less than half of the Danish figure, with a difference of 18percentage points or nearly one-fifth of all employed! For Finland, the figure was around $23 \%$, and for Norway around $28 \%$.

When the data are studied this way, we can also see some interesting developments over time. In Norway and Sweden, total mobility has clearly decreased over the period studied. In Norway, this has mostly been due to the rapid decrease in occupational mobility not associated with a workplace change. In Sweden, the change has to do both with de- 
creasing workplace mobility and, until 2004, also with a decreasing flow into employment from non-unemployment. From chapter 5, we know that this flow has increased again since then.

In Finland the development goes in the opposite direction: total mobility has increased somewhat. In Denmark the trend is not clear.

Here, we should keep in mind the double nature of mobility. The figure can of course also be read as an indicator of stability by looking at those not included in its categories. Viewing it in that way, we can say that the share of those with a stable position - employed in the same workplace and occupation - has increased markedly in Sweden (from 77 to 83 per cent) and Norway (from 67 to 72 per cent) in 2001-05, while it has decreased somewhat in Finland.

\subsubsection{How the types of mobility combine with each other}

In this section, we look at how often the three types of mobility take place separately, and how often they are combined with each other. These kinds of combinations are interesting, as they give us tools to look at specific mobility-related situations, such as internal and external occupational mobility.

It should be noted, however, that the methodological difficulties and possible cultural differences described earlier in this chapter will be even more problematic when combining the indicators. In other words, uncertainties related to a single indicator will accumulate when looking at a combination of two or three indicators.

This is especially true when we combine workplace mobility with the two other forms of mobility. Workplace mobility is measured in a different manner than the other mobility forms. As workplace mobility relies (at least partly) on a retrospective question, there may be some discrepancy of measurement when compared to the other forms of mobility. For Norway, we have to use the primary workplace mobility indicator, as it is the only one referring to the same time period as the occupational and industrial mobility indicators.

The combinations are only calculated for the years when the information is available in the country in question. These are partly different periods for different countries. Combinations of the three mobility forms have been presented in Table 8.4.

Table 8.4 Combinations of different forms of gross mobility (employed at both $t$ and $t+1$ ).

\begin{tabular}{lrrrr}
\hline & Denmark & Finland & Norway & Sweden \\
\hline Only workplace & $5.5 \%$ & $4.0 \%$ & $4.6 \%$ & $2.1 \%$ \\
Only occupation & $13.6 \%$ & $2.7 \%$ & $8.9 \%$ & $4.3 \%$ \\
Only industry & $1.0 \%$ & $1.0 \%$ & $1.0 \%$ & $0.9 \%$ \\
Workplace + occupation & $2.1 \%$ & $1.4 \%$ & $1.8 \%$ & $0.9 \%$ \\
Workplace + industry & $2.0 \%$ & $1.5 \%$ & $1.8 \%$ & $1.5 \%$ \\
Industry + occupation & $0.7 \%$ & $0.9 \%$ & $1.3 \%$ & $1.2 \%$ \\
Workplace + occupation + industry & $5.8 \%$ & $4.2 \%$ & $5.8 \%$ & $3.5 \%$ \\
Total (at least one form of mobility) & $30.8 \%$ & $15.6 \%$ & $25.1 \%$ & $14.4 \%$ \\
\hline
\end{tabular}


It is obvious that the large differences in general mobility rates concentrate more in some mobility situations than in others. The high occupational mobility in Denmark and Norway is very much due to a situation where people change occupation but not workplace or industry. This type of mobility is much rarer in Sweden and especially in Finland.

It must be noted, though, that occupational mobility in combination with changing workplace, industry or both is also more common in Denmark and Norway than it is in Sweden and Finland. The difference observed is just much smaller than it is when looking at occupational mobility within the same workplace and industry.

When studying occupational mobility in Finland (Aho and Virjo 2009), we were surprised that so much of it took place without a workplace change. Now we can see that internal occupational mobility is even more common in the other Nordic countries. In fact, it is in general much more common to change occupation within a workplace than in combination with a workplace change (see Figure 8.2).

Clearly, this result raises questions for further research. How does occupational mobility within a workplace look like, and what is its function in the structural change of the society? How often is the situation in fact "only" a promotion, and how often does it entail large changes of tasks performed? A brief comparison of occupational mobility with and without a change of workplace in Finland indicated that changing occupation within a workplace is rather common in all occupational groups, but more common in higher occupational statuses (Aho and Virjo 2009).

For Sweden, we see that it is especially rare to change only workplace without changing occupation or industry at the same time. Only one in four workplace changers did not change occupation or industry at the same time - which makes a very small absolute figure, as Sweden has a low general workplace mobility.

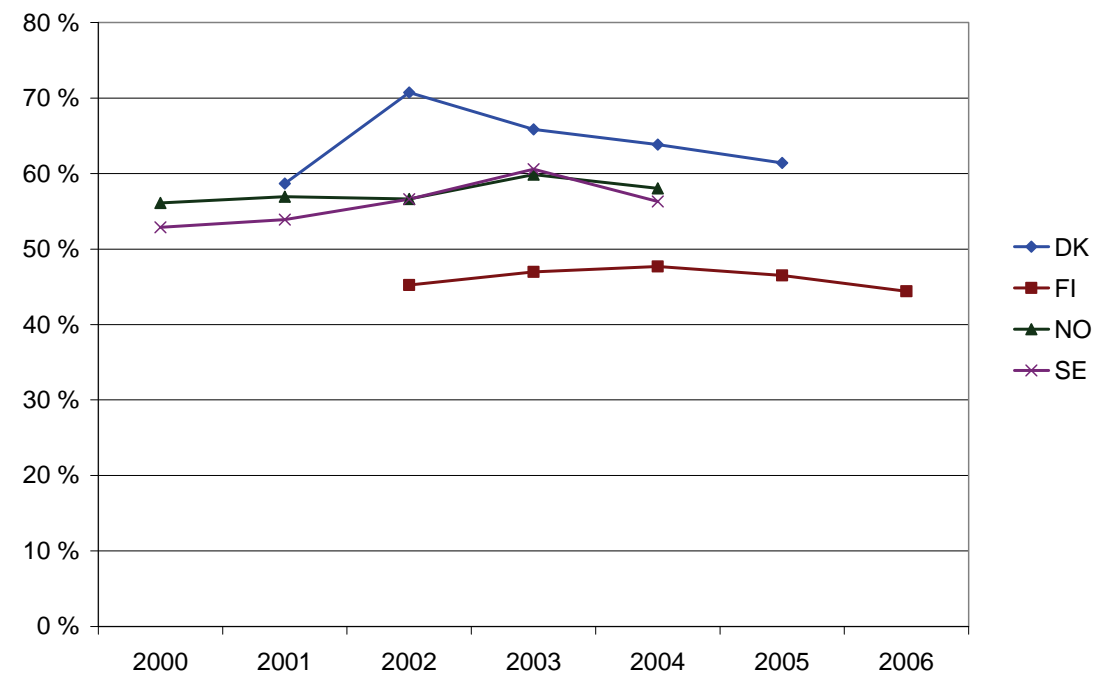

Figure 8.2 Internal occupational mobility. (Share of occupation-changers who did not change workplaces simultaneously.) 


\subsection{Factors affecting mobility: multivariate analyses}

In this section, factors affecting the three types of mobility are studied in a multivariate setting. The approach is similar to that applied in other chapters of this report. However, we have chosen to apply binomial logistic regression, as it seems best suited for the analyses here.

The analyzed population includes the gross mobility population, that is, those employed both at $t$ and $t+1$. The dependent variable in the analyses has two values: the person either has been mobile, or is still employed in the initial position. For instance, we model the probability of changing occupation compared to being employed in the same occupation.

In a first phase, models have been fitted for each country separately. This way we can see what the predictors of workplace, occupational, and industrial mobility are on an individual level in each of our countries. We can e.g. see whether country of origin affects the odds of mobility when the other variables in the model are controlled for, and whether the effect is similar between the four countries.

The country models are fitted for the time period available for the country in question. As information on the different mobility types is available for different periods in the four countries, there are slight differences in the periods included for each country and mobility type. We assume that this does not have a large effect on the results for two reasons. Firstly, it is not probable that the effect of individual factors would change considerably in only a year or two. Secondly, yearly unemployment change on national level and relative regional unemployment level are included in the country models. These two variables should control for business trends, thus making the other coefficients more "trendneutral”.

Rather than trying to find an optimal model for each country, we have made identical models in order to make the results as comparable as possible. The independent variables are the same in all models in this chapter. Because we only have information about children for women in Norway, a combination variable of gender and children has been used in the models. We present only the final model here, but the models have been fitted stepwise, and information on that process is used in some of the commentary.

In a second phase, we take a closer look at the large cross-national differences seen in the mobility levels. Again, the approach is similar to that in other chapters of this report. We fit binomial logistic regression models for the mobility types with combined data, having country as an independent variable. This way, we test what happens to the differences between countries, when a number of factors are controlled for. In order to fit the comparative models, we need to have data from all countries. Thus, the time period for these models has been chosen so that all countries have data from the exact same years. 
The independent variables, all of which refer to time $t$, can be seen as groups. First, you have a number of individual and family variables (gender-children, marital status, country of origin, age, education). Then there are two variables relating to employment contract at time $t$ : type of contract and regular working time. Third, you have variables relating to the individual's workplace and position on the labour market (occupational and industrial categories, size of workplace). Finally, you have structural variables concerning regional unemployment, unemployment change, and population density.

To be noted is that regional unemployment is measured in two ways: in the parallel models, we use a relative measure, which states that the region has low/medium/high unemployment compared to other regions within the country. In the combined models, we use an absolute measure, where the low/medium/high status is given compared to other regions in the Nordic countries. Thus, the categories for unemployment level have different cutpoints depending on the setting. For cut-points, see Appendix B.

An obvious direction for further research is to study combinations of the mobility types - e.g. no mobility / only occupational mobility / only workplace mobility / both - in a multivariate setting. The scope and time table of this report did not allow such analyses.

\subsubsection{Workplace mobility}

In Table 8.5, we see the results for logistic regressions on workplace mobility in the four countries. Note that we have used the primary indicator for Norway in the models, as the alternative variable is not available for the time period that the independent variables refer to.

We see some similar patterns, but also differences between the countries. An interesting feature is that the model seems to have much more explanatory power in Finland than in the other countries. This is probably due to the fact that two powerful independents - age and temporary employment - have the largest odds ratios in Finland.

Overall, age is by far the most powerful predictor of workplace mobility. This is an expected finding, as in almost all previous studies it has been found that mobility decreases with age (Shniper 2005, Kambourov and Manovskii 2004, Parrado et al. 2005, Moscarini and Vella 2002 \& 2008, Virjo et al. 2007, Aho and Virjo 2009, Isaoglu 2006). This cannot be explained by generational differences, as age decreases the probability of mobility also within the same cohort (Gabriel 2003) - even though there have been findings about large differences between cohorts in their mobility behaviour (Moscarini and Vella 2008). 
Table 8.5 Effects of various factors on workplace mobility, binomial regression (separate models for each country). Odds ratios for change of workplace vs. still employed in the same workplace. Time 2000-06 (available years not same for all countries). ${ }^{*}=$ $p<0.05,{ }^{* *}=p<0.01$.

\begin{tabular}{|c|c|c|c|c|}
\hline & Denmark & Finland & Norway & Sweden \\
\hline \multicolumn{5}{|l|}{ Gender / children (ref. man) } \\
\hline Woman no children & 0.95 & 0.98 & 0.92 & 0.98 \\
\hline Woman with children & 0.96 & $0.91^{*}$ & $0.82^{\star *}$ & $0.91^{\star}$ \\
\hline \multicolumn{5}{|l|}{ Marital status (ref. married) } \\
\hline Cohabitant & $1.18^{\star \star}$ & $1.12^{\star *}$ & 0.98 & $1.13^{\star \star}$ \\
\hline Single & $1.30 * *$ & $1.16^{\star \star}$ & 1.07 & $1.12^{\star \star}$ \\
\hline \multicolumn{5}{|l|}{ Country of origin (ref. country) } \\
\hline Nordic & 1.32 & 0.94 & 1.18 & $1.36^{\star *}$ \\
\hline European/North American & 1.06 & 1.13 & 1.05 & $0.78^{\star *}$ \\
\hline World & $1.22^{*}$ & 0.86 & 1.05 & 0.95 \\
\hline \multicolumn{5}{|l|}{ Age (ref. 35-44 years) } \\
\hline $15-19$ & $1.29 * *$ & $4.53^{\star *}$ & $2.64^{\star *}$ & $2.15^{\star \star}$ \\
\hline $20-24$ & $1.86^{\star *}$ & $2.67^{\star *}$ & $2.90^{* *}$ & $2.11^{\star *}$ \\
\hline $25-29$ & $1.50^{* *}$ & $1.71^{* *}$ & $1.94^{\star *}$ & $1.69 * *$ \\
\hline $30-34$ & $1.31^{\star *}$ & $1.34^{\star *}$ & $1.46^{\star *}$ & $1.32^{\star *}$ \\
\hline $45-54$ & $0.68^{\star *}$ & $0.63^{\star *}$ & $0.67^{* *}$ & $0.65^{\star *}$ \\
\hline $55-63$ & $0.36^{\star *}$ & $0.35^{\star *}$ & $0.43^{\star *}$ & $0.37^{\star \star}$ \\
\hline \multicolumn{5}{|l|}{ Education (ref. primary or unknown) } \\
\hline Secondary & 1.08 & 1.00 & 1.03 & $1.20^{* *}$ \\
\hline Tertiary & 1.10 & 1.04 & 1.11 & $1.52^{\star *}$ \\
\hline \multicolumn{5}{|l|}{ Regular working time per week (ref. $35+$ hours) } \\
\hline $1-19$ & $2.32^{\star *}$ & $2.04^{* *}$ & $1.62^{\star \star}$ & $2.78^{\star \star}$ \\
\hline $20-29$ & $1.36^{\star *}$ & $1.40^{* *}$ & 1.09 & $1.89^{\star *}$ \\
\hline $30-34$ & 1.09 & $1.43^{\star \star}$ & 1.00 & $1.32^{\star \star}$ \\
\hline \multicolumn{5}{|l|}{ Type of contract (ref. permanent) } \\
\hline Temporary & $4.11^{\star *}$ & $5.92^{* *}$ & $2.62^{\star *}$ & $3.65^{\star \star}$ \\
\hline Self-employed & $0.40^{\star *}$ & $0.38^{\star *}$ & 0.99 & $0.53^{\star *}$ \\
\hline \multicolumn{5}{|l|}{ Occupational category (ref. manual worker) } \\
\hline Manager & $0.82^{*}$ & $0.85^{\star}$ & 1.15 & $1.25^{\star \star}$ \\
\hline Professional & $0.88^{\star}$ & $0.75^{\star *}$ & $1.19^{\star}$ & 1.02 \\
\hline Semi-professional & $0.81^{* *}$ & $0.69^{* *}$ & 1.13 & 0.91 \\
\hline Service worker & 0.95 & $0.75^{\star *}$ & $1.19^{* *}$ & 0.91 \\
\hline \multicolumn{5}{|l|}{$\begin{array}{l}\text { Industry category (ref. manufacturing, mining, electricity, } \\
\text { gas and water) }\end{array}$} \\
\hline Agriculture, forestry, fishing & $1.24^{*}$ & $1.33^{\star *}$ & $1.71^{\star *}$ & 1.18 \\
\hline Construction & $1.31^{\star *}$ & $2.24^{\star *}$ & 1.03 & 1.14 \\
\hline Trade, hotels and restaurants & $1.23^{\star *}$ & $1.52^{\star *}$ & $1.21^{\star *}$ & $1.24^{\star *}$ \\
\hline Transport and communication & 1.07 & $1.37^{* *}$ & 1.10 & $1.32^{\star *}$ \\
\hline Finance, insurance & 0.90 & 1.05 & 0.81 & $0.74^{\star}$ \\
\hline Real estate, business services & $1.20^{* *}$ & $1.96^{\star *}$ & $1.52^{\star *}$ & $1.52^{\star *}$ \\
\hline Public administration & $0.80^{\star *}$ & 1.02 & 1.05 & $0.64^{\star *}$ \\
\hline Education and research & $0.76^{\star \star}$ & 1.02 & $0.81^{*}$ & 0.95 \\
\hline Health care & 1.05 & $1.31^{\star *}$ & 0.92 & $0.84^{\star *}$ \\
\hline Social and personal services & 1.01 & $1.53^{\star \star}$ & 1.19 & $1.31^{\star *}$ \\
\hline \multicolumn{5}{|l|}{ Number of employees (ref. 1-10) } \\
\hline $11-19$ & $0.86^{* *}$ & $0.77^{\star *}$ & 0.92 & $0.83^{\star *}$ \\
\hline $20-49$ & $0.82^{\star *}$ & $0.72^{\star *}$ & 0.93 & $0.84^{\star *}$ \\
\hline $50+$ & $0.71^{\star *}$ & $0.58^{\star *}$ & $0.79^{\star *}$ & $0.68^{\star *}$ \\
\hline \multicolumn{5}{|l|}{ Regional population density (ref. over $60 / \mathrm{km}^{2}$ ) } \\
\hline $1-20$ & $\mathrm{n} / \mathrm{a}$ & 0.92 & 0.96 & $0.92^{*}$ \\
\hline $21-60$ & $0.91^{*}$ & 0.92 & 0.93 & 0.90 \\
\hline \multicolumn{5}{|l|}{ Relative regional unemployment within country (ref. low) } \\
\hline Medium & 0.97 & 0.99 & 1.02 & 0.89 \\
\hline High & 0.95 & 1.04 & 0.93 & $0.72^{\star *}$ \\
\hline Unemployment change (national,percentage points) & $0.94^{\star}$ & $0.76^{\star \star}$ & $1.20^{\star}$ & $0.80^{\star \star}$ \\
\hline Nagelkerke $\mathrm{R}^{2}$ & 0.16 & 0.27 & 0.14 & 0.16 \\
\hline $\mathrm{N}$ & 47113 & 71135 & 31897 & 75502 \\
\hline
\end{tabular}

While age is very important in all countries, there are significant differences between them. The age pattern is strongest in Finland, where the youngest age group is over four times more, and the oldest group about three times less, likely to be mobile than the reference group. Data struc- 
ture - that summer workers are not included in the Norwegian and Swedish data - may explain to some extent why the odds ratios for the younger age groups are lower in these countries than in Finland. However, it cannot explain why the age effect is clearly the weakest in Denmark, with a very strong effect only for the oldest age group. Overall, the difference between Finland and the other countries is strongest for the youngest group. For 20-29-year-olds, the odds are highest in Norway.

For those older than the reference group of 35-44-year-olds, the effect of age is similar in all countries: we see a clear decline in mobility probability. This effect is somewhat weaker in Norway.

After age, the strongest independent variable is type of contract. Having a temporary employment contract at $t$ heavily increases the odds of changing workplace during the following year - especially in Finland, where the probability is six-fold when compared to those with a permanent contract.

Interestingly, temporary contract has a stronger effect in Finland than in Sweden, although both are countries with many temporaries. Temporary contracts in Sweden may be longer than in Finland, or else they are more often made permanent over time (which seems to be the case - see chapter 6).

Perhaps surprisingly, the effect is also very strong in Denmark, even though the difference between fixed-term and open-ended contracts in a legal sense is weakest there.

Being self-employed also has a strong but opposite effect on the probability of changing workplace in all countries but Norway. Norway is an interesting exception, as self-employment has no effect on the probability of mobility there.

Women with children are significantly less mobile than men in all countries but Denmark, even though the difference is not very large. This effect is strongest in Norway. Women without children do not differ significantly from men. Regarding the other individual and family variables we see some interesting results. Marital status seems to matter in all countries except Norway. Both cohabitants and singles have a higher probability of mobility than married persons, especially in Denmark. To the extent family variables have an effect, it is an expected one: the more family ties and responsibilities one has, the less likely one is to be mobile.

In a family setting, mobility decisions often concern more than one person, which may render them harder to make. Also, people with children may be less willing to take risks. The country differences raise questions, though. Why does having children not reduce the probability of mobility in Denmark, whereas being married certainly does?

Country of origin has significance only in Sweden and to a small extent in Denmark. In Sweden, those with a background in other Nordic countries are more likely to be mobile than natives, whereas people originating from elsewhere in Europe or North America are less likely to be 
mobile. In Denmark, we see an effect for the non-European/North American group: they are more likely to be mobile than natives.

Education is another factor where Sweden stands out: higher education increases the probability of mobility. People with tertiary education are 50 per cent more likely to be mobile than the reference group. Perhaps surprisingly, we do not see a significant effect of education in any of the other countries. We considered the probability that this would occur because occupational category is also included in the model - however, removing one of these two variables does not noticeably affect the odds ratios of the other, nor does it affect those of other variables in the model.

Working hours also affect the probability of mobility. This effect is largest for short part-time: people working less than 20 hours a week are much more likely to be mobile than full-time workers in all countries. The overall result pattern fits well to our understanding of how institutionalised part-time work is in these countries. Working part-time is most normal in Norway, which makes it understandable that only short parttime has an effect on mobility there. In Finland and Sweden, on the other hand, all those working less than full-time are more likely to be mobile. Thus we can conclude a main result that having a "non-normal" working time entails higher odds for changing workplace.

With regard to occupational group, there are some clear differences. In Finland, all other groups are significantly less mobile than the reference group of manual workers. A similar but weaker pattern can be seen for Denmark with the exception of service workers. In Norway and Sweden, the variable is less powerful. However, when we see an effect, its direction is the opposite of the Finnish and Danish pattern. In Sweden managers, and in Norway professionals and service workers, are more likely to change workplace than manual workers.

When it comes to industrial category, similarities in all four countries concern people working in real estate / business services, and trade, hotels and restaurants; they are more likely to be mobile than the reference group. Otherwise, the variable has different effects for the countries. The only case with opposite significant results is health care. In that sector, workplace change is more probable than in the reference group in Finland, whereas it is less probable in Sweden.

A large workplace lowers the odds of changing workplace in all countries. This is an expected result, as people in large workplaces obviously have more possibilities of adapting their work to their wishes by e.g. changing tasks or working hours. The effect of this variable is weakest in Norway, where only the largest category - a workplace with at least 50 employees - differs significantly from the reference group of up to 10 employees. In the other countries, the effect is coherent already with medium-sized workplaces. This effect is somewhat stronger in Finland than it is in Sweden and Denmark. 
Regional variables have a relatively small effect on mobility. Perhaps surprisingly, the regional unemployment rate - which should reflect labour demand in the region - has no significant effect in three of the countries, and only a moderate effect in Sweden. Regional population density is not significant at all in Norway and Finland, and has only a relatively small effect in Denmark and Sweden.

Yearly unemployment change on the national level is thought to give an estimate of the effect of business cycles. As we only have one figure per year per country, and a very limited number of years, it must be remembered that this variable may reflect other underlying factors specific to a year or some years. In Finland, Sweden, and to some extent in Denmark, mobility decreases with increasing unemployment - a result in line with previous studies mentioned earlier. However, in Norway we get the opposite result: probability of mobility increases somewhat as unemployment rises - a result that is unexpected when considering how the relation of mobility to unemployment appears on a descriptive level.

With descriptive statistics, we saw that Denmark had the highest workplace mobility rate, followed in order by Norway (we are referring to the primary indicator), Finland, and Sweden. This can also be clearly seen in the first column of Table 8.6, where a model with only country as an independent variable is fitted. Denmark has a much higher odds ratio than the mean of the four countries, and Sweden the lowest.

Table 8.6 Odds ratios for four Nordic countries regarding workplace mobility 2000-04 (start years for mobility). Binomial logistic regression. All country odds $p<0.01$.

\begin{tabular}{llcc}
\hline Country (ref. = mean of odds) & Model $\mathbf{1}$ & Model 2 & Model 3 \\
\hline Denmark & 1.41 & 1.53 & 1.50 \\
Finland & 0.89 & 0.84 & 0.85 \\
Norway & 1.23 & 1.26 & 1.22 \\
Sweden & 0.65 & 0.63 & 0.64 \\
\hline
\end{tabular}

Note: Model 1 includes only country as independent variable. Model 2 includes country + individual, family, and workrelated variables (gender-children, marital status, age, origin, educational level, occupational and industrial categories, number of employees, type of contract and working time). Model 3 includes model $2+$ unemployment and regional population density variables. (Yearly unemployment change on national level, absolute regional unemployment rate divided into three categories, regional population density divided into three categories.)

The new feature of the analyses comes in the following two columns, when controls are added. We also tried adding the controls in smaller steps, but this had no effect on the overall picture. The overall result is that adding controls does not reduce the differences between the countries. Rather, if anything, Denmark appears to move further away from the mean when controls are added. Thus, the differences in workplace mobility rates between the countries cannot be explained e.g. by demographic dissimilarities or other factors included in our models. 


\subsubsection{Occupational mobility}

The models of occupational mobility presented in Table 8.7 reveal expectedly that the independent variables to a large extent have similar patterns here as when predicting workplace mobility. There are, however, some considerable differences.

Overall, the variables in our model are somewhat less successful in predicting occupational mobility than they were with workplace mobility. This is especially true for Norway and Denmark. The explanation may simply be that in countries with very high mobility rates, mobility is something that concerns all kinds of people and all sectors of the economy. Such a broad phenomenon is harder to explain in a model.

Age is still a very important independent variable, particularly in Finland, but the effects are for the most part smaller than with workplace mobility. Especially in Denmark, the effect of age on occupational mobility is relatively small and partly even insignificant. This may have to do with the fact that the major part of occupational mobility is internal to a workplace. In an earlier study, occupational mobility with a workplace change was much easier to model in Finland, and age had a clearer effect on it than on occupational mobility without a workplace change (Aho and Virjo 2009).

Same story with employment contract: the effect is important and expected, but much weaker than with workplace mobility. Having a temporary contract is much more important in Finland and Sweden than it is in Denmark or Norway. Finland and Sweden have the largest share of temporaries, so this may be an expected finding. Being self-employed reduces the odds of occupational change - again, with the exception of Norway - but the effect is much smaller than with workplace mobility.

Norway also stands out when it comes to gender and family. Women are less likely than men to change occupation in Norway. Also, being a cohabitant or single as opposed to married reduces the odds of occupational mobility in Norway. In Denmark and Sweden, being single increases the odds of changing occupation.

As with workplace mobility, having a higher education increases the probability of mobility in Sweden and is insignificant in the other countries. Country of origin has significant effects only in Sweden, and even there they are small.

With working time we see a roughly similar pattern than with workplace mobility: a "non-normal" working time increases the odds for mobility - and in Norway, 20-29 hours can be considered normal.

It might be an expected finding that occupational category at $t$ is very significant for the odds of occupational mobility. This is only partly true, however. The broad group labelled as "managers" is more mobile than the reference group in all countries - much more so in Norway and Sweden, though. 
Table 8.7 Effects of various factors on occupational mobility, binomial regression (separate models for each country). Odds ratios for change of occupation vs. still employed in the same occupation. Time 2000-06 (available years not same for all countries). ${ }^{*}=p<0.05,{ }^{* *}=p<0.01$.

\begin{tabular}{|c|c|c|c|c|}
\hline & Denmark & Finland & Norway & Sweden \\
\hline \multicolumn{5}{|l|}{ Gender / children (ref. man) } \\
\hline Woman no children & 0.94 & 0.99 & $0.80^{\star \star}$ & 1.04 \\
\hline Woman with children & 0.96 & 0.97 & $0.72^{\star *}$ & 0.96 \\
\hline \multicolumn{5}{|l|}{ Marital status (ref. married) } \\
\hline Cohabitant & 1.07 & 1.04 & $0.75^{\star \star}$ & 1.05 \\
\hline Single & $1.17^{\star *}$ & 1.04 & $0.84^{\star \star}$ & $1.08^{*}$ \\
\hline \multicolumn{5}{|l|}{ Country of origin (ref. country) } \\
\hline Nordic & 1.23 & 0.88 & 1.11 & 1.02 \\
\hline European/North American & 1.01 & 0.84 & 1.05 & $0.88^{*}$ \\
\hline World & 1.10 & 0.90 & 0.99 & 0.93 \\
\hline \multicolumn{5}{|l|}{ Age (ref. 35-44 years) } \\
\hline $15-19$ & $1.18^{\star}$ & $3.90^{* *}$ & $1.78^{\star \star}$ & $1.99 * \star$ \\
\hline $20-24$ & $1.36^{\star *}$ & $2.67^{\star *}$ & $1.97^{\star \star}$ & $1.72^{\star *}$ \\
\hline $25-29$ & 1.05 & $1.68^{* *}$ & $1.49^{\star *}$ & $1.30^{* *}$ \\
\hline $30-34$ & 1.05 & $1.36^{\star *}$ & $1.14^{\star *}$ & $1.09^{\star}$ \\
\hline $45-54$ & $0.88^{\star \star}$ & $0.69 * *$ & $0.75^{\star \star}$ & $0.73^{\star \star}$ \\
\hline $55-63$ & $0.78^{\star *}$ & $0.47^{* *}$ & $0.60^{\star *}$ & $0.53^{\star *}$ \\
\hline \multicolumn{5}{|l|}{ Education (ref. primary or unknown) } \\
\hline Secondary & 0.98 & 1.00 & 1.04 & $1.09^{\star}$ \\
\hline Tertiary & 0.92 & 1.08 & 1.09 & $1.28^{\star \star}$ \\
\hline \multicolumn{5}{|l|}{ Regular working time per week (ref. $35+$ hours) } \\
\hline $1-19$ & $2.07^{\star *}$ & $1.91^{\star *}$ & $1.59^{\star *}$ & $1.99 * *$ \\
\hline $20-29$ & $1.19^{\star *}$ & $1.48^{* *}$ & 1.06 & $1.28^{\star \star}$ \\
\hline $30-34$ & 1.03 & 1.09 & 0.96 & 0.97 \\
\hline \multicolumn{5}{|l|}{ Type of contract (ref. permanent) } \\
\hline Temporary & $1.62^{\star \star}$ & $3.03^{* *}$ & $1.89 * *$ & $2.65^{\star \star}$ \\
\hline Self-employed & $0.85^{\star \star}$ & $0.71^{\star *}$ & 0.98 & $0.85^{\star \star}$ \\
\hline \multicolumn{5}{|l|}{ Occupational category (ref. manual worker) } \\
\hline Manager & $1.39 * \star$ & $1.43^{\star *}$ & $2.38^{\star *}$ & $2.12^{\star *}$ \\
\hline Professional & $0.89^{*}$ & 0.94 & $1.42^{\star *}$ & 0.99 \\
\hline Semi-professional & $1.28^{\star \star}$ & $1.16^{\star}$ & $1.32^{\star *}$ & $1.12^{\star *}$ \\
\hline Service worker & 1.08 & 1.05 & $1.26^{\star \star}$ & 1.04 \\
\hline \multicolumn{5}{|l|}{$\begin{array}{l}\text { Industry category (ref. manufacturing, mining, } \\
\text { electricity, gas and water) }\end{array}$} \\
\hline Agriculture, forestry, fishing & $0.81^{*}$ & 1.04 & $1.61^{\star *}$ & 0.98 \\
\hline Construction & $0.51^{\star \star}$ & 0.97 & $0.68^{\star \star}$ & $0.70^{* *}$ \\
\hline Trade, hotels and restaurants & $0.74^{\star *}$ & 0.91 & $0.81^{\star *}$ & $0.92^{*}$ \\
\hline Transport and communication & $0.66^{\star \star}$ & 0.91 & $0.84^{\star *}$ & $0.86^{* *}$ \\
\hline Finance, insurance & $0.82^{\star \star}$ & 0.87 & $0.58^{\star \star}$ & $0.75^{\star \star}$ \\
\hline Real estate, business services & $0.79^{\star *}$ & $1.23^{\star *}$ & 0.94 & 1.03 \\
\hline Public administration & $0.84^{\star \star}$ & $0.81^{*}$ & $0.88^{*}$ & $0.76^{\star \star}$ \\
\hline Education and research & $0.58^{\star *}$ & $0.77^{* *}$ & $0.63^{\star *}$ & $0.63^{* *}$ \\
\hline Health care & $0.32^{\star *}$ & $0.52^{\star *}$ & $0.47^{\star \star}$ & $0.38^{\star *}$ \\
\hline Social and personal services & $0.70^{\star *}$ & 0.93 & $0.84^{\star}$ & $0.85^{\star \star}$ \\
\hline \multicolumn{5}{|l|}{ Number of employees (ref. 1-10) } \\
\hline $11-19$ & 1.02 & $0.81^{* *}$ & 0.98 & 0.94 \\
\hline $20-49$ & $0.92^{*}$ & $0.79^{* *}$ & 0.95 & 1.03 \\
\hline $50+$ & 0.95 & $0.78^{\star *}$ & 0.95 & 1.01 \\
\hline \multicolumn{5}{|l|}{ Regional population density (ref. over $60 / \mathrm{km}^{2}$ ) } \\
\hline $1-20$ & $\mathrm{n} / \mathrm{a}$ & 1.04 & $0.84^{\star \star}$ & 0.98 \\
\hline $21-60$ & 0.94 & 0.93 & $0.92^{\star}$ & $0.93^{\star *}$ \\
\hline \multicolumn{5}{|l|}{$\begin{array}{l}\text { Relative regional unemployment within country } \\
\text { (ref. low) }\end{array}$} \\
\hline Medium & 0.97 & 0.94 & 0.95 & $0.90 * *$ \\
\hline High & $0.93^{\star}$ & 0.85 & $0.89 * \star$ & $0.85^{\star \star}$ \\
\hline $\begin{array}{l}\text { Unemployment change (national,percentage } \\
\text { points) }\end{array}$ & $1.06^{\star \star}$ & $0.68^{\star \star}$ & $1.26^{\star \star}$ & $0.86^{\star \star}$ \\
\hline Nagelkerke $\mathrm{R}^{2}$ & 0.07 & 0.14 & 0.08 & 0.11 \\
\hline $\mathrm{N}$ & 38858 & 58960 & 44066 & 99456 \\
\hline
\end{tabular}


"Semi-professionals" are also significantly more mobile than manual workers. Overall, Norway stands out as the country where occupational category plays a large role for the probability of occupational mobility.

When it comes to industrial category, it is Denmark's turn to stand out with significant, partly very low odds for all categories in the model when compared to the reference group of manufacturing, mining, electricity, gas and water. This result stands for two things. Firstly, it is clear that the mobility probability in the reference group is exceptionally high in Denmark. Secondly, the differences between the other industrial categories are large there as well.

People working in public sector industries, such as public administration, education, and research and health care, are significantly and quite strongly less likely to change occupation than the reference group. An interesting discrepancy can be found for the group "real estate and business services", which is more mobile than the reference group in Finland, but less mobile in Denmark. Those working in construction are significantly more likely to be mobile than the reference group in all countries but Finland.

Interestingly, the size of establishment has considerable significance only in Finland, where we see the same pattern as with workplace mobility. That is, people in large workplaces are less likely to change occupation. Probably this has something to do with the fact that occupational mobility is more often linked with a change of workplace in Finland than in the other countries. Internal occupational mobility is essentially more common in the other three countries, also when taking into account the differences in firm sizes.

The structural variables included in the model have more significance for occupational mobility than for workplace mobility. In Denmark, Norway and Sweden, higher unemployment reduces the odds for mobility. So does living in a less densely populated area in Norway and Sweden. Both results are to be expected, as possibilities for a career change are less often present in scarcely populated areas and/or in areas with high unemployment. High unemployment also indicates that the risks combined with changing one's occupation are high.

The unemployment change variable proved to be an especially strong independent in these analyses, with interesting results. In Sweden and especially in Finland, unemployment change has a strong negative effect on occupational mobility. That is, when unemployment rises, mobility decreases, and vice versa. In Norway and to some extent in Denmark the opposite applies, when the other factors in the model are controlled for.

Next, we look at how country differences react when controls are introduced into the model (Table 8.8). As expected, we see very high odds for Denmark in model 1. Changing occupation is about twice as probable for a Dane than it is on average in our four countries. Norway is somewhat over average, whereas Sweden and Finland have rather low odds. 
Table 8.8 Odds ratios for four Nordic countries regarding occupational mobility 2002-05 (start years for mobility). Binomial logistic regression. All country odds $\mathrm{p}<0.01$.

\begin{tabular}{llll}
\hline Country (ref. = mean of odds) & Model 1 & Model 2 & Model 3 \\
\hline Denmark & 1.97 & 2.11 & 2.05 \\
Finland & 0.62 & 0.58 & 0.62 \\
Norway & 1.21 & 1.20 & 1.18 \\
Sweden & 0.68 & 0.68 & 0.67 \\
\hline
\end{tabular}

Note: Model 1 includes only country as independent variable. Model 2 includes country + individual, family, and workrelated variables (gender-children, marital status, age, origin, educational level, occupational and industrial categories, number of employees, type of contract and working time). Model 3 includes model $2+$ unemployment and regional population density variables. (Yearly unemployment change on national level, absolute regional unemployment rate divided into three categories, regional population density divided into three categories.)

Introducing individual, family and work-related control variables makes both Finland and Denmark move further away from the mean. Thus, e.g. age or education of the population certainly does not explain the large differences between the countries, nor do differences in establishment size etc. In model 3, structural and cyclical variables are introduced. Regional unemployment and population density along with yearly unemployment change bring all countries except Sweden slightly towards the mean, but in essence the differences remain similar or in Denmark's case even stronger than without controls at all.

\subsubsection{Industrial mobility}

The odds ratios in the country models for industrial mobility are for the most part similar to either workplace or occupational mobility, depending on the variable. New patterns emerge as a rule only for Norway. This may be due to methodology, as Norway is the only country where industry is also defined solely on the basis of the respondent's answer. In the other three countries, industry code is usually derived from registers based on information about the employer. However, we saw in Table 8.3 that this had not resulted in a larger share of people changing only industry (but not workplace or occupation) in Norway - in fact, this share was smaller in Norway than the other countries.

In any case, age and the type of employment contract remain the most powerful independent variables. Age pattern is not quite as strong as the one seen with workplace mobility, but for all countries except Finland, it is much stronger than with occupational mobility. Regarding the type of contract, the odds ratios resemble the ones we got with occupational mobility - with one large exception. Namely, in Norway being selfemployed increases the probability of changing industry. Partly this may be due to methodology, as it may be that especially self-employed persons describe their line of business differently from one year to another. To be noted is, however, that also with workplace and occupational mobility, we saw a difference for self-employed people between Norway and the other countries. 
Table 8.9. Effects of various factors on industrial mobility, binomial regression (separate models for each country). Odds ratios for change of industry vs. still employed in the same industry. Time 2000-06 (available years not same for all countries). * $\mathrm{p}<0.05$, bold $=\mathrm{p}<0.01$.

\begin{tabular}{|c|c|c|c|c|}
\hline & Denmark & Finland & Norway & Sweden \\
\hline \multicolumn{5}{|l|}{ Gender / children (ref. man) } \\
\hline Woman no children & $0.86^{\star \star}$ & 0.97 & $0.85^{\star \star}$ & 0.97 \\
\hline Woman with children & $0.90^{*}$ & $0.91^{*}$ & $0.72^{\star \star}$ & $0.87^{\star \star}$ \\
\hline \multicolumn{5}{|l|}{ Marital status (ref. married) } \\
\hline Cohabitant & $1.13^{\star}$ & $1.13^{\star \star}$ & 0.96 & 1.05 \\
\hline Single & $1.28^{\star *}$ & $1.11^{*}$ & 1.03 & $1.14^{\star *}$ \\
\hline \multicolumn{5}{|l|}{ Country of origin (ref. country) } \\
\hline Nordic & 1.35 & 1.17 & 1.02 & 1.11 \\
\hline European/North American & 0.95 & 1.02 & 1.07 & $0.81^{*}$ \\
\hline World & $1.36^{* \star}$ & 0.84 & 0.97 & 1.01 \\
\hline \multicolumn{5}{|l|}{ Age (ref. 35-44 years) } \\
\hline $15-19$ & $1.49^{* \star}$ & $3.23^{\star \star}$ & $1.90^{* *}$ & $2.04^{\star \star}$ \\
\hline $20-24$ & $1.88^{\star *}$ & $2.45^{\star \star}$ & $2.40^{\star *}$ & $1.83^{\star *}$ \\
\hline $25-29$ & $1.29 * *$ & $1.68^{\star \star}$ & $1.75^{\star \star}$ & $1.53^{\star *}$ \\
\hline 30-34 & $1.16^{\star}$ & $1.30^{\star *}$ & $1.31^{\star *}$ & $1.19^{\star *}$ \\
\hline $45-54$ & $0.72^{* *}$ & $0.70^{\star *}$ & $0.67^{\star *}$ & $0.67^{\star *}$ \\
\hline $55-63$ & $0.47^{\star *}$ & $0.45^{\star \star}$ & $0.45^{\star \star}$ & $0.37^{\star *}$ \\
\hline \multicolumn{5}{|l|}{ Education (ref. primary or unknown) } \\
\hline Secondary & 1.08 & 1.06 & 0.95 & $1.17^{\star \star}$ \\
\hline Tertiary & $1.17^{*}$ & $1.13^{*}$ & 0.99 & $1.29 * *$ \\
\hline \multicolumn{5}{|c|}{ Regular working time per week (ref. 35+ hours) } \\
\hline $1-19$ & $2.37^{\star \star}$ & $2.33^{\star \star}$ & $2.16^{\star \star}$ & $2.07^{\star \star}$ \\
\hline $20-29$ & $1.63^{\star *}$ & $1.73^{\star \star}$ & $1.48^{\star *}$ & $1.60^{\star *}$ \\
\hline $30-34$ & $1.19^{*}$ & $1.29 * *$ & 1.00 & 1.05 \\
\hline \multicolumn{5}{|l|}{ Type of contract (ref. permanent) } \\
\hline Temporary & $2.65^{\star *}$ & $3.48^{\star *}$ & $2.46^{\star \star}$ & $3.13^{\star *}$ \\
\hline Self-employed & $0.59^{* *}$ & $0.65^{\star *}$ & $1.27^{\star *}$ & $0.63^{\star *}$ \\
\hline \multicolumn{5}{|c|}{ Occupational category (ref. manual worker) } \\
\hline Manager & 0.91 & 0.96 & $1.27^{\star \star}$ & $1.48^{* *}$ \\
\hline Professional & $0.69^{\star *}$ & $0.77^{\star \star}$ & 1.04 & 0.98 \\
\hline Semi-professional & 0.92 & $0.85^{\star \star}$ & 1.04 & 0.95 \\
\hline Service worker & 1.10 & 0.93 & $1.36^{\star \star}$ & 1.03 \\
\hline \multicolumn{5}{|c|}{$\begin{array}{l}\text { Industry category (ref. manufacturing, mining, } \\
\text { electricity, gas and water) }\end{array}$} \\
\hline Agriculture, forestry, fishing & $0.57^{\star \star}$ & $0.83^{\star}$ & 1.06 & 1.08 \\
\hline Construction & $0.39^{* *}$ & $0.79^{\star *}$ & $0.60^{* *}$ & $0.76^{\star *}$ \\
\hline Trade, hotels and restaurants & $0.76^{\star \star}$ & 0.93 & $0.77^{\star *}$ & 1.01 \\
\hline Transport and communication & $0.76^{\star \star}$ & $0.86^{*}$ & 0.98 & 1.06 \\
\hline Finance, insurance & $0.35^{\star \star}$ & 0.97 & $0.73^{\star}$ & 1.03 \\
\hline Real estate, business services & 0.96 & $1.50 \star \star$ & $1.37^{\star \star}$ & $1.37^{\star *}$ \\
\hline Public administration & $0.49^{* *}$ & $0.77^{\star \star}$ & $0.83^{\star}$ & $0.85^{\star}$ \\
\hline Education and research & $0.45^{\star *}$ & $0.68^{\star *}$ & $0.64^{* *}$ & $0.69^{\star *}$ \\
\hline Health care & $0.25^{\star *}$ & $0.35^{\star \star}$ & $0.31^{* *}$ & $0.66^{\star *}$ \\
\hline Social and personal services & $0.65^{\star *}$ & 1.09 & 0.99 & 1.09 \\
\hline \multicolumn{5}{|l|}{ Number of employees (ref. 1-10) } \\
\hline $11-19$ & 0.91 & $0.76^{\star \star}$ & 0.97 & $0.80^{* *}$ \\
\hline $20-49$ & $0.77^{\star *}$ & $0.75^{\star \star}$ & $0.89^{*}$ & $0.82^{\star *}$ \\
\hline $50+$ & $0.68^{\star *}$ & $0.62^{\star *}$ & $0.83^{\star *}$ & $0.69^{* *}$ \\
\hline \multicolumn{5}{|c|}{ Regional population density (ref. over $60 / \mathrm{km}^{2}$ ) } \\
\hline $1-20$ & $\mathrm{n} / \mathrm{a}$ & 0.90 & 0.91 & 0.94 \\
\hline $21-60$ & 0.96 & 0.99 & 0.99 & $0.89 * *$ \\
\hline \multicolumn{5}{|c|}{$\begin{array}{l}\text { Relative regional unemployment within country } \\
\text { (ref. low) }\end{array}$} \\
\hline Medium & 0.94 & $0.80 * *$ & 1.01 & $0.87^{\star *}$ \\
\hline High & 0.94 & 0.93 & $0.85^{\star *}$ & $0.80^{\star *}$ \\
\hline $\begin{array}{l}\text { Unemployment change } \\
\text { (national,percentage points) }\end{array}$ & $0.93^{*}$ & $0.74^{\star \star}$ & $1.07^{\star \star}$ & $0.86^{\star *}$ \\
\hline Nagelkerke $\mathrm{R}^{2}$ & 0.13 & 0.17 & 0.14 & 0.14 \\
\hline $\mathrm{N}$ & 35197 & 71248 & 44101 & 82011 \\
\hline
\end{tabular}

For temporary employees, the odds are similar but stronger than those seen with occupational mobility. Overall, the effect of having a tempo- 
rary contract is more similar between countries when it comes to industrial mobility than it is with the other two mobility types discussed in this chapter.

Being single - and in Denmark and Finland also being a cohabitant increases the odds for industrial mobility in all countries but Norway. Women with children are less mobile than men in all countries, as are women without children in Norway and Denmark. Higher education increases the odds of changing industry especially in Sweden, but to some extent also in Finland and Denmark. Country of origin does not have any significant effect in Finland and Norway. In Sweden, the finding is similar to what we saw with occupational mobility: those with a European / North American background are slightly less mobile than natives. In Denmark, the picture is similar to that seen with workplace mobility: background outside Europe and North America strongly increases the odds for industrial mobility.

Working time has roughly the same effect on industrial mobility as it did on the other two mobility types. However, the effect of long part-time work is now significant also for Norway.

Overall, occupational category is less important as an independent variable here than it was with the two other mobility types. In all countries, we see that people working in the public-sector-dominated industries, as well as construction, are significantly less mobile than the reference group. Size of establishment is a strong predictor of industrial mobility, having a very similar pattern as the one observed with workplace mobility. With larger workplaces, the probability of industrial mobility decreases.

Again, the structural regional variables play a relatively small role. Population density has some significance only in Sweden. Living in a region with medium or high unemployment also has most effect in Sweden, but does have some effect also in Finland and Norway. Unemployment change is significant for all countries. Again, Norway is the exception with a positive odds ratio.

For the three types of mobility studied here, the differences between countries are smallest with industrial mobility, which can be seen in Table 9 as well. All countries differ only moderately from the mean. Introducing controls, especially the structural ones in model 3 , also has the expected effect of bringing the countries closer to the mean - which it did not have with workplace or occupational mobility. In essence, Finland and Norway move closer to the mean when controls are introduced, whereas the positions of Denmark and Sweden as the most and least mobile remain. 
Table 8.10. Odds ratios for four Nordic countries regarding industrial mobility in years 2001 and 2003-05 (start years for mobility). Binomial logistic regression. All country odds $\mathrm{p}<0.01$.

\begin{tabular}{llll}
\hline Country (ref. = mean of odds) & Model $\mathbf{1}$ & Model 2 & Model 3 \\
\hline Denmark & 1.24 & 1.33 & 1.26 \\
Finland & 0.89 & 0.85 & 0.94 \\
Norway & 1.14 & 1.13 & 1.06 \\
Sweden & 0.80 & 0.79 & 0.80 \\
\hline
\end{tabular}

Note: Model 1 includes only country as independent variable. Model 2 includes country + individual, family, and workrelated variables (gender-children, marital status, age, origin, educational level, occupational and industrial categories, number of employees, type of contract and working time). Model 3 includes model $2+$ unemployment and regional population density variables. (Yearly unemployment change on national level, absolute regional unemployment rate divided into three categories, regional population density divided into three categories.)

\subsection{Conclusions}

Summing up, the main finding in this chapter is that there are very large differences in the mobility types studied between the four countries. They become even more obvious when taking a "total mobility" approach, i.e. including even entrants to employment in the analysis.

The differences are by far largest with occupational mobility and very large also when it comes to workplace mobility. With industrial mobility, the countries are much more alike, but the general pattern can be seen there as well. Overall, Denmark is the most mobile country. Norway ranks second, Finland third, and Sweden tends to have the lowest mobility. However, with occupational mobility the picture changes somewhat and we find that Finland has the lowest mobility.

With occupational mobility, the differences are very large indeed: the lowest yearly figure is $8.2 \%$ (FI 2003 and SE 2004), while the highest $25.8 \%$ - is over three times higher (DK 2002). While there admittedly are some issues with the indicators used, it is our understanding that methodological issues cannot to any great extent lie behind these results. This standpoint is supported by the fact that the huge differences remain similar when studying occupational mobility on a less detailed level using two or one digits, of the occupational code, or between the five broad occupational categories used in our models. The large occupational mobility taking place without workplace change prevails in analyses with less detail as well. Thus, changing to a completely different occupation is also much more common in Denmark than it is in Finland.

The country differences are more prominent with certain mobility related situations than with others. In particular, they are striking when comparing occupational mobility without a workplace change. Further, Sweden stands out with its low workplace mobility, which is especially low in the last few years of data and when considering workplace change without a simultaneous change of occupation. 


\subsubsection{Factors affecting mobility}

Some common factors affecting the probability of mobility were found in the models. The two most powerful predictors were age and type of employment contract. There were differences in the power of the age effect, but in all countries and with all mobility types, mobility decreased with age.

In all countries and with all types of mobility, temporary employment contract increased the probability of mobility. Being self-employed, on the other hand, tends to reduce mobility especially between workplaces. This is of course not a surprising finding in itself. There was however a striking exception to the rule. In Norway, self-employment had no effect on occupational and workplace mobility, and in fact increased the probability of industrial mobility.

Another point where Norway is different concerns the effect of unemployment change. In general, we found the expected result in the other countries: increasing unemployment decreases mobility - but the opposite in Norway.

Further, having a working time that is different from the norm in the country increased the probability of mobility in all countries. What can be considered normal is, as seen in chapter 7 , slightly different from one country to another. With workplace and industrial mobility, we also saw that being employed in a larger workplace reduced the probability of mobility. This is an expected result, as larger firms obviously provide more possibilities for internal mobility. For occupational mobility, this effect was observed only in Finland.

\subsubsection{Country differences prevail with controls}

The main result of this chapter has to be that there are very large differences in mobility rates between the countries. They were largest with occupational mobility, and very large with workplace mobility as well. With industrial mobility, the differences were considerably smaller. These main results became even stronger in a multivariate setting, where we found that differences between countries did not disappear when control variables were introduced. In fact, with occupational and workplace mobility, they grew stronger. With industrial mobility, Finland and Norway moved somewhat towards the Nordic average when controls were introduced. In any case, the main result is that differences in mobility cannot be explained by any of the variables included in the models: unemployment, age and education of the population, etc.

As this is a strong result, it was tested further. Two things in particular can be thought to have an effect on mobility rates. To begin with, we have age, as it is a very important independent factor in the country models - and especially with regard to the youngest and oldest groups. Secondly, the fact that Denmark is geographically very different from the 
other three countries may play a role here, even though population density proved for the most part to be a weak independent variable.

To test the effect of age structure and density of the labour market in the countries, we fitted the stepwise comparative models for each mobility type in two additional settings. Firstly, we chose only regions with more than 60 people per square kilometre to the model. Secondly, we tested a model with only the prime-age (25-54 years) workforce of these relatively densely populated regions.

The first variant resulted in country odds very similar to those reported earlier in this chapter. The second variant resulted in some changes with regard to industrial and occupational mobility. The difference between Finland and the others when it comes to occupational mobility became clearer in a model with only prime-age workforce in dense regions. This result is probably due to the very high occupational mobility of Finnish youth. With industrial mobility, Sweden and Norway came closer to the mean when only prime-age workforce in dense regions is taken into the analysis - whereas Finland moved further away from the mean. The overall picture - that country differences do not disappear when adding controls - prevailed also in these analyses.

\subsubsection{Some considerations outside our data}

Thus, it appears that the different mobility rates are caused either by cultural and structural differences between the countries that our data do not cover, or by differences in institutions. Let us consider some possible explanations not covered by our data.

It has been hypothesised that greater wage inequality would explain higher mobility (see Kambourov and Manovskii 2009b). This is of course plausible, as general wage inequality most likely also means larger wage differences between occupations, industries, and workplaces. Thus, a change of position could be associated with a more significant increase in wages.

As our models do not include wages, we can only speculate on an aggregate level. Within the OECD, Denmark and Sweden are the two countries with most equal wages (both had similar gini coefficients below 0.25 in 2005; see OECD 2008, 285) - and they are also the countries in this study with highest and lowest mobility rates. It is hard to see any apparent connections between our mobility results and the figures about wage inequality and its development reported by the OECD. Of course, this picture could change if we had individual data on income. However, on an aggregate level, it does not seem likely that income inequality could explain the differences between countries.

Another thing to remember is that cross-border mobility cannot be observed with the LFS panel at all. It has been speculated that a large inflow of foreign workforce would especially be an issue in Norway, where la- 
bour-related immigration skyrocketed from just a few thousands per year in 2003 to about 20,000 in 2006 (Statbank of SSB). This might be one large explanation for the Norwegian decline of mobility observed in this study; within-country labour force mobility has been partly replaced by the inflow of foreign workforce.

It should also be noted that we cannot completely rule out the role of geography with the analyses where only relatively dense regions were included. To begin with, the size of the region whose density has been recorded varies considerably between the countries, meaning that the internal composition of the regions can vary as well. Further, our analyses do not control for the fact that Denmark as a whole is a dense labour market. It is, after all, different to live in a densely populated area within a country than to live in a densely populated country. Thus, the fact that Denmark is geographically very different from the three other countries can at least partly explain its high mobility rates.

\subsubsection{What about the expected flexicurity-related findings?}

Finally, let us look at how our flexicurity-related hypotheses fared in the analyses.

We anticipated that a strict EPL would have a negative effect on mobility. This was partly supported, as Denmark with its liberal EPL has by far the highest mobility, and Sweden with a strict EPL in most cases the lowest, with Finland in between as expected. However, Norway as a strict EPL country had the second-highest mobility rates, which makes it difficult to draw any straightforward conclusions.

A more specific hypothesis was that business cycles would have a stronger effect on workplace mobility in countries with a strict EPL. This hypothesis was at least partly supported, as the largest relative changes in workplace mobility were observed in Sweden. Mobility decreased rapidly in a time of increasing unemployment. At the same time, workplace mobility was on a remarkably stable level in liberal-EPL Denmark despite changes in unemployment.

We also expected that strict EPL and seniority rules would have a positive effect on internal occupational mobility. Compared to other forms of mobility, this type of mobility is relatively high in Sweden, partly supporting the hypothesis. It is also high in Norway, another country with a strict EPL. However, internal occupational mobility is by far highest in Denmark with a low EPL - and by far rarest in Finland with its relatively strict EPL. Overall, internal occupational mobility is the mobility type with largest differences in mobility rates between the countries differences that are also hardest to explain.

Generous unemployment benefits were anticipated to have positive effects on all forms of external mobility. Again, Denmark's high mobility supports this. However, second-ranking Norway is not as generous. 
Finland is the least generous of all, but still tended to have higher mobility rates than Sweden.

When looking at EPL-UB combinations, it is very much expected that Denmark has the highest mobility figures. However, looked at in this way the results from Norway are unexpected. Also, Sweden's rather generous UB does not seem to play any role at all - if not in the fact that occupational mobility is higher than in Finland.

We also expected that the scope of active labour market policies would have a positive effect on mobility, but that we would not be able to notice this effect because of the limited time frame for mobility. From this viewpoint, Denmark's very high mobility is expected, as Danes spend the most in ALPMs. However, Sweden is the second-largest spender but has the overall lowest mobility rates.

Further, we expected investments in lifelong learning to have positive effects on occupational mobility. This hypothesis was not supported at all. Sweden has the most participants in adult education, but far less occupational mobility than Denmark or Norway. Norway in turn has the lowest LLL score but a very high occupational mobility.

One hypothesis was that strict EPL and/or wide use of temporaries would channel mobility into different routes. Overall, this hypothesis was not supported. Temporary employment is most common in Finland and Sweden. These are the countries with lowest overall mobility - also when looking at "total mobility" including flows from unemployment and outside the labour force. Moreover, having a temporary contract increased the odds of mobility significantly not only in Finland and Sweden, but also in Norway and Denmark. The effect in Denmark was strong even though the legal difference between a temporary and an open-ended contract is smallest there.

All in all, we found some support for the idea that the mobility types studied are affected by flexicurity-related institutions. Most obviously, Denmark's profile as a flexicurity land and its high mobility fit the pattern. Both Sweden and Finland also fit our expectations to some degree, even though there are puzzling exceptions. In many respects, Norway is the country that "does not fit", having high mobility, but being far from the flexicurity ideal in many ways. Clearly, our results should be studied further. 



\section{Conclusion}

\subsection{Introduction}

The purpose of the present study has been to investigate patterns of labour market mobility that characterise four Nordic countries: Denmark, Finland, Norway and Sweden. In many studies and discussions of labour markets and welfare states the Nordic countries are regarded as constituting a specific Nordic regime with great internal similarities. However, in the wake of the interest in the Danish flexicurity model, questions have been raised as to whether it is only a Danish phenomenon or whether flexicurity is something that also characterises other Nordic countries. In international comparisons evaluating flexicurity profiles, similarities in the institutional frameworks of the Nordic countries have been found (European Commission 2006; Muffels 2008). Yet when studying the institutional framework in more detail, important differences emerge between the countries that could affect the flexibility and security on the four labour markets.

The study gives some answers to these questions through a comparative study of labour market mobility. Concentrating on mobility, it is mainly the flexibility aspect of the flexicurity concept that has been in focus. Therefore, this study has mostly given a picture of labour market dynamics, i.e. what characterises and determines the flows on the four labour markets.

How these flows affect the wider economy has not been the scope of the study. In general, however, labour market mobility is evaluated as a quite positive phenomenon, as it is a prerequisite for changes of the economic structure. The ability to change and adapt is said to be an important quality for national economies in a global environment of technological change and international competition. Some theories also suggest that mobility is demanded in a more individualized society with less standardized labour market biographies for individuals (i.e. career breaks, occupational changes and adult retraining). However, mobility can be negative as well. For the individual, it may entail risks such as income insecurity and social disintegration. For firms, costs of employee turnover can be high. On a societal level, negative effects may include e.g. costs for unemployment benefits, other social security systems, and retraining.

Some of the mobility types studied here can be looked upon from a security perspective. Mobility from unemployment or inactivity to employment, or from fixed-term to open-ended contracts, may be a sign of employment security. On the other hand, high rates of mobility from employment to unemployment may indicate job insecurity. However, the 
question of security cannot be answered solely by analysing mobility rates. It is to a great deal a question of how the institutions connected with the labour market are constructed and functioning to secure jobs or help individuals back to work. Furthermore, the question of security needs to be supplemented by more subjective data on individuals' perceptions of security.

In this study, we have used the panel structure of the Labour Force Surveys in order to create mobility measures in a way which to our knowledge has not been used before. Our measures compare the respondent's labour market situation during a reference week at two points in time with 12 months in between. These indicators are more reliable than measures relying on retrospective questions. Furthermore, the fact that LFS is highly standardized is an advantage in international comparisons.

The main limitations of the present study are, firstly, that the panels are not constructed in exactly the same way in the four countries (see chapter 4). However, we have only found limited effects of this on the mobility indicators used. The second limitation has to do with the indicator of workplace mobility. This is less standardized between the countries, which may affect the results somewhat (underestimatation of workplace mobility in Norway and Sweden). All in all, there is more potential in LFS for mobility research than has been utilized in this study. In future research this should be paid attention to.

The analyses focus on some of the most central transitions on the labour markets. These are transitions between employment, unemployment and inactivity (Ch. 5), into and out of temporary contracts (Ch. 6) and part-time employment (Ch. 7), and transitions between workplaces, occupations and industries (Ch.8). All mobility types are compared in the four countries in terms of mobility rates and underlying factors affecting mobility. One of the main aims is to control for the effects of business cycles (measured as unemployment) and the compositions of national labour markets (e.g. age structure) in the analyses of mobility rates.

This concluding chapter will firstly focus on the determinants of the different forms of labour market mobility. Secondly, the results concerning mobility rates will be presented. Thirdly, the main findings regarding the significance of labour market and welfare state institutions for labour market transitions are discussed. Finally, we take up the question whether flexicurity should be regarded as a solely Danish phenomenon or as a more common Nordic feature.

\subsection{Determinants of labour market mobility}

In the analyses of the transitions in focus, there are some factors with general impact on mobility that have been revealed. These findings are to a great extent in line with previous research (see overview in Chapter 
1). However, there are also some results that are of significance in particular countries and explained by specific features of the national labour markets.

Two factors that have previously been shown to affect mobility are gender and age. However, gender has few effects on the transitions studied here, although there are some exceptions. Women have a greater risk than men of leaving the labour force (i.e. transitions into inactivity). This pattern certainly has to do with gender roles related to family responsibilities. On the other hand, when women are unemployed, they have greater chances than men of being employed one year later. Still, there is a greater risk for women than for men that this is a transition into parttime work or a temporary contract.

Age is an important factor in relation to labour market mobility. Evidently, many different kinds of transitions - between workplaces and occupations and industries, out of the labour force and into employment are structured by age, and in most cases the young are more mobile. This pattern is expected, because young people have a motive to scan the labour market to find jobs that suit their competences and expectations. In general, the young may be more risk-taking than the older, which makes them more prone to voluntary mobility. However, many of these transitions may not be entirely voluntary. The young, therefore, constitute a category on the labour market that to a great extent bears the expenses for adjustments to the demand for labour in changing business cycles, i.e. the costs for numerical flexibility.

A related factor that is important for mobility patterns is the type of contract. Those employed on temporary contracts have a higher risk of unemployment or of leaving the labour force. They also change workplaces, occupations and industries to a higher degree than permanent employees. In general, the difference in risks between permanent and temporary employees for these transitions is somewhat greater in Finland and Sweden than in Denmark and Norway. Some of the analyses also indicate that young people's labour market risks (from employment to unemployment) are structured to a higher extent by the use of temporary contracts in Finland and Sweden.

Another factor with importance for labour market risks is national origin. This factor affects mobility between employment and unemployment and between employment and inactivity. The general pattern is higher risks of falling out from employment and smaller chances of getting into employment for people not native to the country. This pattern is amplified if you are born outside Europe or North America. Comparing the four countries, there is a tendency to less difference in relative risks between native-born and people born outside Europe/North America in Denmark concerning mobility between employment and unemployment (both directions). On the other hand, there is a larger difference in relative risks in Denmark regarding mobility between employment and inactivity. 
Looking at workplace, occupational and industrial mobility, there are few significant effects of the variable. In Denmark there are higher chances for people born outside Europe/North America than native-born for workplace mobility and industrial mobility. In Sweden the chances for workplace mobility are lower for this group.

If we look at the significance of working time, there are some general patterns. There are greater risks of mobility to inactivity, between workplaces, occupations and industries for part-time workers than for full-time workers. Furthermore, part-time workers in temporary contracts have a higher risk of becoming inactive than full-time workers in temporary contracts. These patterns are found in all four countries, which indicates that part-time workers are somewhat less attached to the labour market. However, there are some results that complicate this interpretation. Only in Denmark and Finland do part-time workers (short part-time) have a higher risk than full-time workers of becoming unemployed. And only in Sweden do part-time workers on temporary contracts have less probability than full-time workers on temporary contracts of mobility into permanent contracts.

The size of the workplace has impact on mobility from employment to unemployment or to inactivity, and on mobility between workplaces and industries. The direction of the relationship is negative, i.e. the larger the workplace the less risk of these transitions. This indicates that larger workplaces entail more stable employment relations. In fact, this seems to be the case also when the individual is employed on a temporary basis. However, we have not studied whether larger workplaces have more internal mobility, i.e. mobility between jobs and positions at the same workplace.

Educational level has, in most of the countries, the same effect on central transitions. The risk of transitions from employment to unemployment or to inactivity becomes smaller with higher level of education. The inverse pattern is found for transitions from unemployment to employment or from inactivity to employment. However, in Denmark the differences in risk between educational categories for transitions from employment to unemployment are smallest, and there are no significant differences for transitions from unemployment to employment. Furthermore, in Denmark there are smaller differences between educational categories for the risk of unemployment, even though the analyses are delimited to those employed with temporary contracts. These results indicate more equal labour market risks between educational categories in Denmark than in the other three countries. Concerning workplace and occupational mobility, a divergent pattern is found in Sweden. The risk of mobility becomes greater with higher educational level. This pattern is especially visible when workplace mobility is analysed. There is no straightforward explanation for this pattern, but it may indicate that voluntary mobility (which constitutes a great part of these forms of transitions) is more struc- 
tured by human capital in Sweden than in the other countries, i.e. there is less risk of failed transitions (into unemployment) for people with higher education, which makes them more prepared for mobility.

The unemployment rates on county level and changes in national unemployment rates have impacts on mobility between employment and unemployment in expected directions (despite some statistically insignificant results in Norway). The main explanation for these effects is that changes in the business cycle, which are indicated by unemployment levels, determine the rate of job openings and job closings on the labour market, and that this affects the probability of finding and losing a job.

For workplace, occupational and industrial mobility, regional unemployment rates have relatively small effects on mobility. Unemployment change on national level has more often a stronger effect. For the most part, when we observe such effects they are as expected - that is, more unemployment means less mobility. There are some exceptions, however. Most notably, rising unemployment has a positive effect on all three mobility types in Norway and on occupational mobility in Denmark.

In Finland and Sweden, we also find that the county unemployment level affects temporary employees' chances of getting a permanent job. The explanation for this may be that there are fewer job opportunities with open-ended contracts in these areas and that the employers become reluctant to employ on a permanent basis when county unemployment is high. Why this pattern is found only in Finland and Sweden is not easy to answer. However, the measure of county unemployment is constructed as a relative measure (see chapter 4 ) because of great differences in unemployment levels between the countries. Therefore, in Finland and Sweden there are greater variations in county unemployment level than in Denmark and Norway, i.e. there are areas with much higher unemployment levels in those two countries.

\subsection{Mobility rates in the four Nordic countries}

One main purpose of this study has been to compare mobility rates between the countries. This has been done in several ways. Firstly, the gross mobility rates have been presented and compared. Secondly, predicted probabilities for certain categories have been produced. Thirdly, the country differences have also been studied in a multivariate setting, i.e. differences in labour market composition and business cycle (unemployment rates) have been controlled for in statistical analyses (see Table 9.1).

The analyses of transitions between main labour market statuses, i.e. employment, unemployment and inactivity, have in general shown high figures in Denmark. In particular, transitions from employment to unemployment are more common in Denmark than in the other three countries. The picture is even strengthened when compositional and business cycle 
effects are put under statistical control. This result implies that it is easier to lose a job in Denmark, i.e. job insecurity is higher. For example, the estimated probability for a male manual worker to lose his job in one year is close to $4 \%$ in Denmark and about $1.5 \%$ in Sweden, where the risk is lowest (see Diagram 5.5). One central premise in the flexicurity system is that the job insecurity should be compensated for by employment security, i.e. high flows (back) into employment. The figures are quite high for transitions from unemployment to employment in Denmark, but they are not the highest figures, which instead are found in Norway. The difference between Denmark and Norway becomes somewhat smaller in a multivariate setting. Finland and Sweden have clearly lower levels of transitions from unemployment to employment compared to the other two countries.

Table 9.1 Odds ratios (ref. = mean of odds) for four Nordic countries regarding different types of mobility in a model with controls. For model details see "model 3 " in chapters 5-8.

\begin{tabular}{lllll}
\hline & Denmark & Finland & Norway & Sweden \\
\hline Employment to unemployment & 1.53 & 0.99 n.s. & 0.82 & 0.81 \\
Employment to inactivity & 1.14 & 1.32 & 0.96 n.s. & 0.69 \\
Unemployment to employment & 1.17 & 0.71 & 1.39 & 0.87 \\
Inactivity to employment & 1.36 & 0.94 & 1.02 n.s. & 0.76 \\
Workplace & 1.50 & 0.85 & 1.22 & 0.64 \\
Occupational & 2.05 & 0.62 & 1.18 & 0.67 \\
Industrial & 1.26 & 0.94 & 1.06 & 0.80 \\
Non-employment to temporary & 0.70 & 1.23 & 0.61 & 1.89 \\
Temporary to permanent & 1.39 & 0.55 & 1.77 & 0.74 \\
Temporary to unemployment & 1.26 & 1.20 & 0.79 & 0.84 \\
Temporary to inactive & 1.03 n.s. & 1.24 & 0.90 & 0.87 \\
Non-employment to part-time & 0.91 & 0.75 & 1.41 & 1.03 n.s. \\
Part-time to non-employment & 1.29 & 1.19 & 0.94 & 0.69 \\
Increased working hours (from short part-time) & 0.98 n.s. & 1.08 n.s. & 0.83 & 1.13 \\
Increased working hours (from long part-time) & 0.83 & 0.94 & 1.38 & 0.93 \\
Decreased working hours & 0.86 & 0.68 & 1.74 & 0.98 n.s. \\
\hline
\end{tabular}

However, the picture of the transitions between employment and unemployment has to be supplemented by the transitions between employment and inactivity. In this regard, controlling for compositional and business cycle effects, Denmark stands out with the highest estimated inflows from inactivity to employment. Concerning mobility from employment to inactivity, Finland has the highest rates and Denmark the second highest. The Swedish pattern is very distinctive in the Nordic context, with very low rates of transitions between employment and inactivity during the studied period.

Beside these general labour market flows there are also transitions between workplaces, industries and occupations. Gross workplace mobility rates are highest in Denmark and second highest in Norway. Finland is in 
third place and Sweden has the lowest workplace mobility rates. This order of the countries is also found in a multivariate setting. Looking at occupational mobility, the same order of the countries is found except that Finland and Sweden share the lowest rate of occupational changes. When it comes to industrial mobility, Denmark and Norway share the highest rate when gross mobility is studied. In a multivariate analysis the same order is found as for workplace mobility.

In an analysis of total mobility - defined as any changes (i.e. from inactivity or from unemployment, changes of job or changes of occupation, except industry) for employed persons compared to the situation one year earlier (see Figure 8.1) - there are higher mobility figures in Denmark than in the other three countries. During 1 year between 35 and $40 \%$ of employed Danes have had at least 1 transition. In Norway the interval is around 30\%, in Finland just below 25\% and in Sweden around 20\%.

Looking at transitions into and out of so-called atypical employment, we find huge differences between the four countries. Firstly, there are transitions into and out of temporary contracts. Denmark and Norway have distinctly different patterns compared to Finland and Sweden. In the first two countries there is less risk of ending up in temporary contracts when making the transition from non-employment (unemployed or inactive) to employment. The risk is clearly highest in Sweden. And if you have a temporary contract the chance is greater in Denmark and especially Norway of making a transition to a permanent contract. These patterns are significant also in a multivariate setting.

Secondly, there are transitions into and out of part-time jobs. In this regard, we find clearly different regimes for the use of part-time jobs on the labour market. The greatest share of part-timers is found in Norway and the smallest in Finland. Denmark and Sweden are found somewhere in between. As expected, the highest transition rates into part-time jobs when coming from unemployment or inactivity are found in Norway. The lowest transition rates is found in Finland. If we instead look at the risks of transitions out of employment for part-time workers, they seem to be somewhat lower in Sweden and Norway than in Denmark and Finland. In Norway, we also find the highest rates of working time mobility (except increased working hours from short part-time).

\subsection{The significance of welfare and labour market institutions}

Which conclusions can be drawn if the results presented here are evaluated from the perspective of the overall question that guides this study: Do the patterns described above reveal anything about the significance of the labour market and welfare institutions that characterise the four coun- 
tries (see chapter 3)? Are any of the differences between the countries a consequence of the institutional frameworks?

If we first look at how the independent variables studied affect the different forms of mobility, there are some patterns that indicate the significance of institutions. The first one is the impact of forms of contract in the four countries. Norway and Sweden have the most strict employment protection legislation of the four countries. However, these two countries differ in the regulation of regular and temporary employees (see Figure 3.3), where the Swedish legislation is more strict concerning permanent employees but more liberal concerning temporary employees than the Norwegian. Consequently, the use of temporaries is more common in Sweden than in Norway. Furthermore, there is some evidence that it is harder in Sweden than in Norway to make the transition out of a temporary into a permanent contract. This may indicate that the liberal use of temporary contracts and the strong protection of permanent employees in Sweden create higher thresholds into the primary labour market, leaving many temporary employees in a secondary labour market with insecure employment. This appears to be avoided in Norway.

If the figures from Finland also are taken into consideration, the argument is strengthened for the significance of the legislation. Finland has the second most liberal EPL of the four countries in the OECD ranking. However, this is largely a consequence of their liberal approach to temporary employees. If only permanent employees are considered, the strictness is on the same level as the Norwegian. This indicates that the design of the EPL has relevance for explaining the high numbers of temporaries in Finland. Denmark has low figures of temporary employment, and the differences from permanent employees regarding unemployment risks are small compared to Finland and Sweden. This is in line with theoretical expectations of the effects of the institutions, i.e. liberal employment protection legislation both for permanent and temporaries lessens the differences between the categories. A contradictory result is the small difference in unemployment risks that is found also in Norway.

In relation to the institutions studied here, EPL may have an impact on how age affects mobility patterns. Sweden has the most explicit rules for priority orders and - together with Finland and Norway - time of notice, whereas the rules in Denmark vary a lot on the labour market but in general are more liberal. These rules build upon seniority, which may affect the age structure of mobility, especially transitions from employment to unemployment. The young should have a higher risk of mobility to unemployment in the countries with stricter EPL, and the age differences in risk of unemployment should be smallest in Denmark. These risks interplay with the type of contract and, as has been discussed above in analyses without type of contract, the differences in risks for different age groups are smallest in Denmark. 
Concerning the effects of education on mobility between employment, unemployment and inactivity, the distinctive pattern found in Denmark compared to the other three countries may be due to its extensive use of ALMP. One would expect that human capital (e.g. educational level) should play a greater role on the less regulated Danish labour market, i.e. the employers can to a higher degree pick and choose employees they want to hire or fire. However, educational level is not so significant for mobility between employment and unemployment in Denmark compared to the other three countries, which contradicts this expectation. The explanation for this may be found in the great differences in Denmark between educational levels when it comes to mobility between employment and inactivity. The group outside the labour force is a very broad category, and some of the participants in ALMP are usually found here. The explanation for the small effects of education on mobility into unemployment could be a selection process where the unemployed with the lowest human capital go into measures that count as inactivity, although we have not been able to test this hypothesis directly in this study. However, in a special analysis of mobility from employment to inactivity (not shown) we tried to rule out most of the effects of the educational and pension systems in the countries through separate analyses of individuals aged 25 to 54 making the transition from employment to inactivity. The largest differences in odds for educational categories were still found and somewhat strengthened in Denmark.

The second approach that has been used to trace the effects of institutions is to utilize country as a variable in multiple regressions. However, country as a variable in regression analyses can be regarded as a "Black Box" containing many unmeasured properties. The strategy used here has been to control for as many central characteristics as possible in the analyses. The remaining impact is certainly not a pure effect of institutions but containing cultural differences in values and preferences, and other non-measured characteristics of the labour markets.

With these limitations in mind, what are the most conspicuous characteristics of the estimated effects of country on transitions that have been found? If we look at the findings from the perspective of the theoretical considerations and hypotheses in chapter 3 , some conclusions can be drawn.

Firstly, we expected that Denmark should have a higher mobility rate from employment to unemployment than the other three countries. The explanation is a combined effect of less strict EPL and rather generous UB. The analyses confirm this expectation: the probability of making this transition is higher in Denmark than in the other countries.

Secondly, when it comes to mobility from unemployment to employment, we also expected the highest rates in Denmark as a combined effect of less strict EPL and the large scope of ALMPs used in the country. In this regard the results are not as unambiguous as above. The highest esti- 
mated transition rate from unemployment to employment is found in Norway. Denmark is ranked second, distancing Sweden and Finland. The analysis indicates that there is a higher probability of making the transition in Norway than in Denmark.

However, in Denmark the transitions into and out of employment are also complemented by high outflows to and inflows from inactivity. A possible explanation for this is the extensive use of ALMPs in Denmark. Many unemployed may be counted as inactive in LFS, for example when they participate in labour market training. In a special analysis (not shown) of the transitions between employment and non-employment (i.e. both unemployment and inactivity), the figures are highest in Denmark in both directions. The analysis was even qualified to a subset of the population aged 25-54 to make sure that the rates were not affected by other institutional systems, mainly the school and pension systems in the countries. The rank-order of the transitions out of employment was Denmark, Finland, Norway and Sweden - and into employment Denmark, Norway, Finland and Sweden. Consequently, the analysis indicates that people in inactivity are not as far from the labour market in Denmark as in the other three countries.

In Sweden there seems to be a wider cleavage between inactivity and employment, with very low levels of transitions from inactivity to employment during the studied period. The discussion in Sweden, especially during the election campaign in 2006, focused on wedges created by social security systems, unemployment benefits and the tax system, making wage labour less profitable. The present study gives some support to the notion of low mobility rates between employment and inactivity in Sweden compared to the other three countries. However, there is no unequivocal explanation for this pattern. For example, the social security systems and unemployment benefits are in many ways at least as generous in the other countries as the Swedish and we do not find the same effects.

A further comment about the transitions from unemployment to employment is that the unemployment benefits in Denmark do not seem to undermine the transition rate into employment, which is one theoretical expectation about generous unemployment benefits when entitled to a long duration time. However, we cannot make a guess how the transition rate into employment should be affected by less generous UB in Denmark. But during the studied period, the benefits are somewhat less generous in the other three countries, and it is only Norway that has higher transition rates from unemployment to employment. The unemployment benefit in Finland has a special feature through the so-called Labour Market Support, with no maximum duration, which may affect the low outflow from unemployment.

The rates of workplace mobility also vary considerably between the countries. Theoretically, we expected that workplace mobility is facili- 
tated by less strict EPL, generous UB (replacement rate), and the effectiveness of the matching process through the public employment services (PES). The greatest institutional differences that are found between the countries have to do with EPL, where the EPL is less strict in Denmark. Consequently, we expected a higher rate of workplace mobility in Denmark compared to the other three countries. And, certainly, the highest rate was found in Denmark, Norway the second highest and Finland the third. The Swedish rate was on a very low level during the studied period (see chapter 8 for some methodological issues). These figures consist of both workplace mobility that is involuntary because of job losses and workplace mobility that is voluntary. We are not able to distinguish between these forms in the analysis, although a fair guess is that both are quite common on the Danish labour market.

Following the hypothesis, the results give support to the claim that the low EPL in Denmark affects the high rate of workplace mobility. And there are many possible mechanisms behind this effect. Most obviously, low employment protection increases the risk of losing one's job, which produces both higher transition rates into unemployment and higher workplace mobility. These rates are much higher in Denmark than in the other three countries. Another possible mechanism is that low EPL makes employers more apt to employ because of less potential costs involved if there are dismissals later on. This could create more job openings, which also should facilitate voluntary job mobility. Moreover, the lack of seniority rules in EPL implies that the employee cannot invest in security through staying at the same employer. This restraining force will be smaller in Denmark, especially compared to Sweden.

However, a main factor behind voluntary mobility is the safety net that exists if the transition fails when leaving a job, i.e. becoming unemployed. The general levels of unemployment benefits are, in international terms, quite high in all Nordic countries. However, the Danish UB is more generous compared to the other three countries concerning the combination of duration, coverage and replacement rate, especially for people with low income (see Appendix A for more details). This could affect the perception of security in the Danish labour force in a positive way and thereby the willingness to make risky transitions, e.g. changing workplace.

An alternative hypothesis for why we find such high figures of workplace mobility in Denmark compared to the other countries is that Denmark has a much higher population density. This would create a denser labour market, where jobs are easier to find closer to the residence. However, we did not find proof of this hypothesis in an analysis where thinly populated areas in the other three countries were excluded: the differences between countries prevailed (not shown). It must be noted, though, that such analysis cannot exclude the possibility that Denmark's dense labour market still plays a role here. After all, it is a different thing to live 
in a densely populated area in an otherwise thinly populated country, than to live in a more uniformly populous country with short distances.

In the analyses of the transition rates into and out of temporary employment, there are also clear signs of the effects of the institutional framework. Finland and Sweden have a much greater transition rate into temporary contracts than Denmark and Norway. And as discussed above, this has to do with EPL, i.e. how liberal it is and to what degree it allows for temporary contracts.

\subsection{Is flexicurity a Danish or a general Nordic phenomenon?}

To answer this question we will start by referring back to chapter 3 and Appendix A, where the institutional frameworks of the countries are presented. These presentations surely show many commonalities between the countries, especially in an international light. From this perspective, all the countries apparently make substantial efforts on active labour market policies, have quite generous unemployment benefits and see the importance of lifelong learning.

Nonetheless, one factor varies substantially between the countries and that is the employment protection legislation, where Denmark is conspicuous with its liberal and Sweden with its quite strict legislation. Finland and Norway stand somewhere in between when it comes to the protection of permanent employees, but they differ in their regulation of temporaries.

However, taking a closer look at the institutional frameworks there are internal differences concerning the other systems that, in combination, may have significant effects on mobility. And even on this closer inspection, Denmark stands out. First of all, the Danish unemployment insurance system seems to be the most generous in the Nordic context, especially when it comes to the compensation rate for lower incomes. The maximum possible duration is also long, and there is an extensive coverage compared to the other countries. Furthermore, measured as the percent of GNP that is used on UB perpercent point unemployed, Denmark is the most ambitious. If we continue to look at the active labour market policies, Denmark is also in this regard the most ambitious user, measured both as percent of GNP spent on ALMPs and per unemployed. In Denmark, a lot of people are also involved in LLL activities - only Sweden has a greater share.

Taking these institutions in combination, Denmark certainly has an institutional nexus that differs in a Nordic context (see Figure 3.8). The present study gives evidence for the conclusion that the Danish flexicurity system goes hand in hand with high figures of labour market mobility. The study cannot point out exactly how the different institutions 
work, but there are clear indications that the low EPL is important. Low EPL may lead to high figures of involuntary mobility, i.e. you lose your job and are forced to find a new one. This mechanism should explain some of the high figures found in Denmark. However, the flexicurity system should mean not only numerical flexibility for the employers, but also security for employees. The high costs for passive and active measures in Denmark certainly indicate that there is a safety net which catches up people who lose their job and helps them back to work. However, this study cannot tell whether the safety net also affects voluntary mobility in a positive way.

A main conclusion from this study is that flexicurity is a Danish phenomenon and it affects the high levels of mobility on the Danish labour market. Yet the study has revealed that there are high levels of labour market mobility also in Norway. And Norway diverges greatly from the flexicurity nexus of low EPL and very grand efforts on ALMP. One explanation for the high mobility figures may be that Norway has had a strong economy for many years now, which to some extent is a consequence of its oil income. A hypothesis, which cannot be tested here, is that there are high levels of voluntary mobility on the Norwegian labour market. The mobility patterns in Norway may be regarded as the levels we would find on a labour market characterized by full employment. Full employment was also a characteristic of the Swedish labour market during the 1980s, and there are therefore reasons to expect similar mobility patterns during this period. However, there could also be other, nonmeasured, characteristics of the Norwegian labour market (e.g. industrial relations, regional and decentralization policies or cultural traits) that affect the high transition rates.

In a Nordic context, there is quite clear evidence from this study that most mobility rates during the period are low in Finland and very low in Sweden. The labour market in these two countries seems somehow to have frozen during the studied period, especially in Sweden. What is the reason for this? However, we have not studied the mobility patterns for a long time period. Perhaps the low mobility rates in these two countries are a more or less constant feature in the Nordic context explained by broader cultural differences than the institutional frameworks. Another answer may be the unemployment crises in the 1990s. This can be regarded as a watershed in Finland and Sweden that may have affected people's perception of security on the labour market in a profound way, and in addition reduced the willingness to make risky transitions.

However, if we go back to the focus of this study and relate the two countries' institutional characteristics to the flexicurity model, additional explanations may be found. The first factor that falls into view is the level of EPL. Sweden has the strictest EPL in the Nordic context, which can affect mobility between employment and unemployment, and between jobs. But a fact that somewhat contradicts this conclusion is that Finland 
has the second most liberal EPL of the four countries and still has quite low mobility rates. If we instead look at the unemployment benefits, both Finland and Sweden do not have as generous benefits as Denmark. Furthermore, Denmark uses ALMPs more ambitiously, especially compared to Finland. If we look at these measures in more detail, Denmark uses more of these resources to subsidise jobs (see Figure 3.6). Finland and Sweden use a relatively more limited scope of measures.

This study indicates that there are two possible ways to increase labour market mobility in a Nordic context. The first way is to follow the flexicurity path taken by Denmark. One of the most central features of this institutional nexus is the low level of employment protection legislation. However, it is important to notice that the flexicurity path also includes generous unemployment benefits and great efforts on ALMPs. That is the trade-off to recreate security when job security is missing. In 2004 the total cost for these measures in Denmark was 3.46\% of GNP compared to 2.32 in Finland, 1.49 in Norway and 2.27\% of GNP in Swe$\operatorname{den}^{23}$. These figures arose in a situation with quite low levels of unemployment. If, for example, Sweden decides to take this path, the main objective may therefore be to restore unemployment benefits to a more generous level and to expand the scope of ALMPs that are used. In this way people's perception of security may increase, which in itself can increase voluntary transitions. And this may perhaps be a precondition for liberalising EPL. Without efforts on UB and ALMP, a liberalising of EPL would turn the labour market more into an Anglo-American model.

The second path is the Norwegian, which could be called a "fullemployment model”. By pressing down unemployment, this model creates employment security and thereby individuals' inclination for mobility on the labour market. A traditional way in a Nordic context to press down unemployment has been through public investments and the creation of public sector jobs. This could be regarded as an alternative use of public funds rather than costs for UB and ALMP.

In this study, we have focused on the differences between the Nordic labour markets and their welfare regimes. However, it is important to remember that in international comparisons the Nordic welfare states have much in common, making it reasonable to speak of a Nordic welfare, employment or flexicurity regime. Looking in more detail there are, however, differences that affect mobility patterns. Whether these divergences have grown larger over time, and how they are affected by the present economic turmoil, are research questions that still need to be answered.

\footnotetext{
${ }^{23}$ The costs are a summation of the share of GNP in 2004 used for programmes 2-8 in Table J, Statistical Annex (OECD 2008).
} 


\section{References}

Aho, .S, Virjo, I., Tyni, P. \& Koponen, H. (2005) Työttömät ja palvelutarve. Työttömille kohdistetun kyselyn ja työnhakusuunnitelmien analyysin tuloksia. Työministeriö:Työpoliittinen tutkimus 271.

Aho, S. \& Arnkil, R. (2008) "Suomen työvoimapolitiikan ja työvoimapalvelujen kehityksen käänteet pohjoismaisessa kontekstissa.” In T. Heiskanen, A. Järvensivu, M. Leinonen and S. Aho (eds.): Kohti uutta työelämää? Tutkimuksen näköala työelämän kehitykseen. Tampere: Tampere University Press, pp .46-77.

Aho, S. \& Vehviläinen, J. (1997) Activating the Young Unemployed into Education? Studies on the effects of a recent policy in Finland and on the hidden rationalities among uneducated young people. University of Tampere, Research Institute for Social Sciences, Work Research Centre: Working Papers 53.

Aho, S. (2004) Kroonisen työttömyyden laajuus, rakenne ja syntytausta. Studies in Labour Policy 261. Helsinki: Ministry of Labour.

Aho, S. Virjo, I. \& Koponen, H. (2009) Ammatillinen liikkuvuus Suomessa 1989-2007. Helsinki: Prime Minister's Office Publications 5/2009.

Aho, S., Koponen, H. \& Virjo, I. (2006) Työnhakusuunnitelmien toteutumisen seuranta. Työministeriö: Työpoliittinen tutkimus 319.

Andersen, Søren Kaj (red) 2003, EU og det nordiske spil om lov og aftale. De nordiske lande og de europæiske aftaler/direktiver om deltid og tidsbegrærnset ansettelse. SALTSA Report NO 2

Andersen, T. Haahr, J. H. Hansen, M. E. \& Holm-Pedersen, M. (2008) Job Mobility in the European Union: Optimising its Social and Economic Benefits. Copenhagen: Danish Technological Institute.

Anxo, Dominique (2006) Contribution to the EEO Autumn Review 2006
Flexicurity (Sweden). European Employment Observatory. Brussels.

Anxo, Dominique (2007) "Sweden”. In European Employment Observatory Review: Autumn 2007, 157-161.

Arnkil, R., Karjalainen, V., Pitkänen, S., Saikku, P. \& Spangar, T. (2008) Kohti työelämälähtöisiä integroivia palveluja Työvoimatoimistojen ja työvoiman palvelukeskusten arviointitutkimus. Työ- ja elinkeinoministeriö: Julkaisuja, Työ ja yrittäjyys 18 .

Arnkil, R., Spangar, T. , Lyytinen, S., Karjalainen, V., Lahti, T. \& Aho, S. (2004) Yhteispalvelusta palvelukeskuskonseptin kehittämiseen. Työministeriö: Työhallinnon julkaisu 339.

Atkinson, J. (1984): Flexibility, Uncertainty and Manpower Management. IMS Report No. 89, Institute of Manpower Studies, Brighton.

Atkinson, J. and Meager, N. (1986) Changing Working Patterns: How companies achieve flexibility to meet new needs. Institute of Manpower Studies, National Economic Development Office, London.

Boeri, T. (1999) "Enforcement of employment security regulations, onthe-job search and unemployment duration." European Economic Research, 43(1), pp. 65-89.

Boone, J. (2004) "Unemployment Insurance and Workers’ Mobility.” Journal of Institutional and Theoretical Economics, 160, pp. 275-93.

Booth, A. L.,Francesconi, M. \& Frank, J. (2000a) Temporary jobs: who gets them, what are they worth and do they lead anywhere? University of Essex.

Booth, A. L., Francesconi, M. \& Frank, J. (2000b) Temporary jobs: Stepping Stones or Dead Ends? IZA: Discussion paper No. 205.

Bredgaard, T., Larsen, F., Madsen, P. K. \& Rasmussen, S. (2009) Flexicurity and atypical employment in Denmark. CARMA: Research paper 2009:1.

Bredgaard, T., Larsen, F., Madsen, P.K. (2005) The flexible Danish labour market 
- a review. CARMA, Aalborg University, CARMA Research Papers, 2005:01.

Bredgaard, T., Larsen, F; Madsen, P.K., Rasmussen, S.(2009) Flexicurity på Dansk, CARMA Research Paper 2009:2, Center for Arbejdsmarkedsforskning, Aalborg Universitet.

Buddelmeyer, H., G. MOurre and M. Ward (2008) Who do Europeans work part-time? A cross-country panel analysis. European Central Bank. Working Paper Series No 872/February 2008.

Bylund, Bo \& Viklund, Lars (2006) Arbetsrätt i praktiken. En handbok 13:e upplagan. Stockholm: Norstedts förlag.

Calmfors, L., Forslund, A., and Hemström, M., (2001) "Does active labour market policy work? Lessons from the Swedish experiences." Swedish Economic Policy Review, 8 (2001), pp. 61-124.

Carling, K., Edin, P-A., Harkman, A. and Holmlund, B. (1996) "Unemployment duration, unemployment benefits, and labor market programs in Sweden”, Journal of Public Economics 59, pp. 313-334.

Cheng, M. M. \& Kalleberg, A. L. (1996) "Labor Market Structures in Japan: An Analysis of Organizational and Occupational Mobility Patterns." Social Forces, Volume 74, Issue 4, pp. 1235-1260.

de Luna, X., Forslund, A., Liljeberg, L. (2008) Effekter av yrkesinriktad arbetsmarknadsutbildning för deltagare under perioden 2002-04 IFAU: RAPPORT 2008:1.

EIRO (2008): Working time developments - 2007

http://www.eurofound.europa.eu/eiro/ studies/tn0804029s/tn0804029s.htm\#hd1

Ellingsæter, Anne Lise (1995), ”Kjønn, deltid og fleksiblitet i arbeidsmarkedet. Det norske eksemplet”. In Dag Olberg. (Eds)., Endringer i arbeidslivets organisering. Fafo-rapport 183

Ericson, T. (2006) Trends in the pattern of lifelong learning in Sweden: towards a decentralized economy. Göteborg University: Working Papers in Economics, no. 188.

Eriksson, T. \& Jensen, P. (2003) Tidsbegränsade anställningar - danske erfarenheter. Department of Economics, Aarhus School of Business: Working paper 03:15.

Esping-Andersen, G. (1996[1990]) The Three Worlds of Welfare Capitalism. Cambridge: Polity Press.

European Commission (2007) Communication from the Commission to the European Parliament, the Council, the European Economic and Social Committee and the Committee of the Regions. Towards Common Principles of Flexicurity: More and better jobs through flexibility and security. Brussels, 2007, COM(2007) 359 final.

European Commission (2008) European Employment Observatory, Review: Autumn 2007

European Commission, (2002) Employment in Europe 2002. Luxembourg: Office for Official Publications of the European Communities.

European Commission, (2003) Employment in Europe 2003. Luxembourg: Office for Official Publications of the European Communities.

European Commission, (2006) Employment in Europe 2006. Luxembourg: Office for Official Publications of the European Communities.

European Commission, (2007) Employment in Europe 2007. Luxembourg: Office for Official Publications of the European Communities.

European Commission, (2008) Employment in Europe 2008. Luxembourg: Office for Official Publications of the European Communities.

European Foundation for the Improvement of Living and Working Conditions ( 2007a) Part-time work in Europe

European Foundation for the Improvement of Living and Working Conditions ( 2007b) Varieties of flexicurity: reflections on key elements of flexibility and security. Background Paper

Fagan, Colette and Jacqueline O’Reilly (1998)."Conceptualising part-time work" in O’Reilly and Fagan, eds: Part-time prospects.An international comparison of part-time work in Europe, North America and the Pacific Rim.London: Routledge

Frederiksen, A. \& Westergaard-Nielsen, N. (2007) "Where did they go? Modelling transitions out of jobs.” Labour Economics, Elsevier, Volume 14, Issue 5, pp. 811-828. 
Fredriksson, P. \& Johansson P. (2003) Employment, mobility, and active labor market programs. IFAU: Working Paper 2003:3.

Furåker, B. \& Berglund, T. (2009) "Changes of Employer, Employment Protection and Labour Market Attachment: An Analysis of Swedish Data from 1972 to 1998.” In Blanpain, R. (ed.), The Modernization of Labour Law and Industrial Relations in a Comparative Perspective. The Netherlands: Walters Kluwer, pp. 211-231.

Furåker, B. (2005) Sociological Perspectives on Labor Markets. Houndmills, Basingstoke, Hampshire: Palgrave Macmillan.

Furåker, B. (2009) "Unemployment and Social Protection.” In Giugni, M. (ed.), The Politics of Unemployment in Europe. Farnham: Ashgate.

Furåker, B. and Blomsterberg, M. (2009) “Arbetsmarknadspolitik.” In Berglund, T. and Schedin, S. (eds.), Arbetslivet. Lund: Studentlitteratur.

Furåker, B., Håkanssson, K. and Karlsson, J. Ch. (2007) Flexibility and Stability in Working Life. New York: Palgrave Macmillan.

Furåker, Bengt (2006) “Anställningsform och inställning till rörlighet: en analys av data från tre svenska undersökningar” s. 63-91 i Daniel Rauhut \& Björn Falkenhall (red) Arbetsrätt, rörlighet och tillväxt. Östersund: Institutet för tillväxtpolitiska studier.

Gabriel, P. E. (2003) “An examination of occupational mobility among fulltime workers.” Monthly Labor Review, September 2003, pp. 32-26.

Gallie (2007) Employment Regimes and the Quality of Work. Oxford: Oxford University Press.

Gash, V. (2005) The labour market outcomes of atypical employment in Ireland and Denmark. Combat Poverty Agency: Working Paper 05/03.

Gash, V. (2008) "Bridge or trap? Temporary workers' transition to unemployment and to the standard employment contract.” European Sociological Review, Volume 24, Issue 5, pp. 651-668.

Gash, Vanessa (2008): "Preference or constraint? Part-time workers' transitions in Denmark, France and the
United Kingdom”. Work, Employment \& Society 2008; 22; 655-675

Gjerding, A. N. (2006) The Danish Welfare Commission. Main assumptions and overall proposals. Mimeo, Faculty of Social Science, Aalborg University.

Graversen, E. Ekeland, A. Solum, N. H. Åkerblom, M. Virtaharju, M. Ratkic, A. Svanfeldt, C. \& Harðardson, Ó. (2003) Mobility of Human Capital - the Nordic countries, 1988-1998. Oslo: STEP, Report 11-2003.

Håkansson, K. \& Isidorsson, T. (2009) "Tillfällig arbetskraft och arbetsvillkor." In T. Berglund \& S. Schedin (eds.), Arbetslivet. Lund: Studentlitteratur.

Håkansson, K. (2001) Språngbräda eller segmentering? Et longitudinell studie av tidsbegränsat anställda. IFAU: Rapport 2001:1.

Hakola, T. \& Määttänen, N. (2009) Pension systems, unemployment insurance and employment at older ages in Finland. Helsinki: Prime Minister's Office Publications 2/09.

Hall, P.A. \& Soskice, D. (eds.) (2001) Varieties of Capitalism: The Institutional Foundations of Comparative Advantage. Oxford: Oxford University Press.

Harðardson, Ó. (2003) Some methodological issues using labour force survey data for mobility research. Oslo: STEP, Report 14-2003.

IAF/Arbetsförmedlningen (2009), Arbetssökande med och utan arbetslöshetsersättning. Report 2009:7. Prepared for the Swedish Government.

Isaoglu, A. (2006) "Occupational Mobility in Germany.” Paper presented at IZA European Summer School in Labor Economics.

http://www.iza.org/conference_files/SU MS2006/isaoglu_a2651.pdf

Jonsson, D. (2007) "Flexibility, Stability and Related Concepts.” In Furåker, B., Håkanssson, K. and Karlsson, J. Ch., Flexibility and Stability in Working Life. New York: Palgrave Macmillan.

Kalleberg, A. L. (2000) "Nonstandard employment relations: part-time, temporary and contract work." Annual Review of Sociology, Volume 26, pp. 341-365.

Kambourov, G. \& Manovskii, I. (2004) "Rising Occupational and Industry Mobility in the United States: 1968-1993.” Discussion Paper 1110. Bonn: IZA.

Kambourov, G. \& Manovskii, I. (2009a) "Occupational Specificity of Human 
Capital.” International Economic Review, Volume 50, Issue 1, pp. 63115.

Kambourov, G. \& Manovskii, I. (2009b) "Occupational Mobility and Wage Inequality.” Review of Economic Studies, Volume 76, Issue 2, pp. 731-759.

Kambourov, G., Manovskii, I. \& Plesca M. (2009) "Returns to Government Sponsored Training.” Mimeo, University of Pennsylvania. http://www.chass.utoronto.ca/ gkamb our/research/training/training.pdf. Version retrieved October 2009.

Keller, Berndt \& Hartmut Seifert, 2005 "Atypical Employment and Flexicurity,” management revue. The International Review of Management Studies, Rainer Hampp Verlag, vol. 16(3), pages 304-323. (

Kjellberg, Anders (2006) “The Swedish unemployment insurance - will the Ghent system survive? s. 87-98 i Transfer nr 12006.

Korpi, W. \& Palme, J (1999) "Robin Hood, Matteus eller strikt likhet? En jämförande studie av välfärdsstatens institutioner och strategier för att minska ojämlikhet och fattigdom i västländerna.” Sociologisk Forskning 1/99: 53-92.

Lag (1982:80) om anställningsskydd tabellerna

Lag (1997:238) om arbetslöshetsförsäkringen

Lag (1997:239) om arbetslöshetskassor

Layard R., Nickell, S. and Jackman. R. (1991) Unemployment: Macroeconomic Performance and the Labour Market. Oxford: Oxford University Press.

Lind, J and E. Rasmussen (2008): "Paradoxical Patterns of Part-Time Employment in Denmark?” Economic and Industrial Democracy 2008; 29; 521-540

Lindbeck, A. (2003) An Essay on Welfare State Dynamics. Stockholm: Research Institute of Industrial Economics.

Löfgren, Anna-Kirsti (2006) Gemensam arbetslöshetsförsäkring? Stockholm: LO.

Long, J. S. (1997) Regression Models for Categorical and Limited Dependent Variables. London: SAGE
Madsen, P. K. (2006) “How can it possibly fly? The paradox of a dynamic labour market in a Scandinavian welfare state." In J. L. Campbell, J. A. Hall and O. K. Pedersen (eds.), National Identity and a Variety of Capitalism: The Case of Denmark, Montreal: McGill University Press, pp. 321-355.

Magnusson, L., Jørgensen, H. and Dølvik, J. D. (2008) The Nordic approach to growth and welfare. European lessons to be learned? Brussels: ETUI.

Martin, J. P. \& Grubb, D. (2001) What Works and for Whom: A Review of OECD Countries' Experiences with Active Labour Market Policies. Uppsala: Office of Labour Market Policy Evaluation. Working paper 2001:14.

Mortensen, D. T. (1977) "Unemployment insurance and job search decisions.” Industrial and labor relations review, 30(4), pp. 505-17.

Moscarini, G. \& Thomsson, K (2007) "Occupational and job mobility in the US.” Scandinavian Journal of Economics, Volume 109, Issue 4, pp. 807-836.

Moscarini, G. \& Vella, F. (2002) “Aggregate Worker Reallocation and Occupational Mobility in the United States: 1971-2000.” Working Paper 2002/08. Yale: Institute for Fiscal Studies.

Moscarini, G. \& Vella, F. (2008) "Occupational Mobility and the Business Cycle.” Working Paper No. 3369. Bonn: IZA.

Muffels, R. (2008) "Pathways to Flexicurity in Europe: Do They Affect Male and Female Labour Market Transitions Patterns?” In Ester, P, Muffels, R., Schippers, J and Wilthagen, T. (eds.), Innovating European Labour Markets. Dynamics and Perspectives. Cheltenham: Edgar Elgar.

Nätti, J. (1993) “Temporary employment in the Nordic Countries: A 'Trap' or a 'bridge'?” Work, Employment \& Society, Volume 7, Issue 3, pp. 451-464.

Neergaard, K. (2004) Atypisk arbeid. Midlertidige ansettelser og deltidsarbeid i Norge. FAFO: Rapport 430.

Nickell, S. (1997) "Unemployment and Labour Market Rigidities: Europe versus North America.” Journal of Economic Perspectives, 11(3), pp. 55-74.

Nordlund, M. \& Strandh, M. (2008) “Göra illa för att hjälpa eller hjälpa till att göra illa. Arbetslösas reservationslöner, jobbchanser och återanställningsinkomster.” 
Sociologisk Forskning, 2008(3), pp. 32-54.

O’Reilly, Jacqueline and Silke Bothfeld (2002): "What happens after working part time? Integration, maintenance or exclusionary transitions in Britain and western Germany" Cambridge Journal of Economics 26:409-439 (2002)

OECD (2002) Employment outlook. Paris.

OECD (2003) Employment Outlook. Paris.

OECD (2004) Employment Outlook. Paris.

OECD (2006) Employment Outlook. Paris.

OECD (2007) Benefits and Wages 2007, Paris

OECD (2008) Employment Outlook. Paris.

OECD (2008) Growing unequal? Income distribution and poverty in the OECD countries. Paris: OECD.

Parrado, E. Caner, A. \& Wolff, E. (2005) “Occupational and Industrial Mobility in the United States 196993.” Working Paper 416. New York: The Levy Economics Institute.

Räisänen, H. \& Skog, H. (1998) Towards a better functioning labour market. Helsinki: Ministry of labour.

Rasmussen, E., J. Lind and J. Visser (2004) "Divergence in Part-Time Work in New Zealand, Denmark and the Netherlands", British Journal of Industrial Relations 42(4): 637-58

Rosholm, M. \& Svarer, M. (2008) “The Threat Effect of Active Labour Market Programmes.” Scandinavian Journal of Economics, Volume 110, Issue 2, pp. 385-401.

Sabirianova, K. Z. (2000) “The Great Human Capital Reallocation: An Empirical Analysis of Occupational Mobility in Transitional Russia.” Working Paper 309, William Davidson Institute: Ural State University.

Salvanes, K.G. (2007) “Omstilling i

Norge: Muligheter og utfordringer for den skandinaviske modellen.” Søkelys på arbeidslivet, 3/2007.

Schmid, G. (2008) Full Employment in Europe. Managing Labour Market Transitions and Risks. Edward Elgar. Shniper, L. (2005) Occupational Mobility, January 2004. Monthly Labor Review, December 2005, pp. 30-35.
Sianesi, B. (2004) "An evaluation of the Swedish system of active labor market programs in the 1990s.” The Review of Economics and Statistics, 86(1), pp. 13355.

Sibbmark, K. (2007) Arbetsmarknadspolitisk översikt 2006. IFAU: Rapport 2007:27.

Skedinger, P. (2008) Effekter av anställningsskydd. Vad säger forskningen? Stockholm: SNS Förlag.

SO Arbetslöshetskassornas Samorganisation (2006) Historik om arbetslöshetsförsäkringen. www.samorg.org

SO Arbetslöshetskassornas Samorganisation (2008) What you need to know about unemployment insurance.

www.samorg.org

Solga, H. (2001) "Longitudinal Surveys and the Study of Occupational Mobility: Panel and Retrospective Design in Comparison.” Quality and Quantity, Volume 35, Issue 3, pp. 291-309.

Sullivan, P. (2006)" Empirical Evidence on Occupation and Industry Specific Human Capital.” Munich Personal RePEc Archive Paper 863, posted November 17 2006. Online at http://mpra.ub.unimuenchen.de/863/.

the European Union: Optimising its Social and Economic Benefits. Danish Technological Institute.

Tomkins, J. M. \& Twomey, J. (2000) “Occupational mobility in England.” Applied Economics, Volume 32, Issue 2, pp. 193-209.

Työministeriö (2006): Hyvää työtä ja osaavaa työvoimaa.Työministeriön tulevaisuuskatsaus ensi hallituskaudelle. Helsinki: Ministry of Labour.

Työllisyyskertomus vuodelta 2007 (2008) Työ- ja elinkeinoministeriö: Julkaisuja, Työ ja yrittäjyys 12 .

Venn, D. (2009) “Legislation, Collective Bargaining and Enforcement. Updating the OECD Employment Protection Indicators.” OECD Social, Employment and Migration Working Papers, No. 89, Paris.

Virjo, I. \& Aho, S. (2002) Ikääntyvien työllisyys 1990-luvulla. Tutkimus yli 50vuotiaiden erityisongelmista työmarkkinoilla. Studies in Labour Policy 242. Helsinki: Ministry of Labour.

Virjo, I. (2006) Employment Rate Potential in the Nordic Countries: an Overview. TemaNord 2006:569. Copenhagen: The Nordic Council of Ministers. 
Virjo, I. Aho, S. \& Koponen, H. (2007) "Työvoiman toimialaliikkuvuus Suomessa 1995-2003.” In Rekrytointiongelmat, työvoiman tarjonta ja liikkuvuus. Helsinki: Prime Minister’s Office Publications 5/2007.

Visser, J. (2002) “The First Part-Time Economy of the World: A Model to Be Followed?”, Journal of European Social Policy 12(1)

Wilthagen, T. \& Tros, F. (2004) "The concept of "flexicurity": A new approach to regulating employment and labour markets.” Transfer, European
Review of Labour and Research, 10(2): 166-87.

Wilthagen, T. (1998) "Flexicurity - A new paradigm for labour market policy reform?” Berlin: WZB Discussion Paper, FSI, pp. 98-202.

Wilthagen, Ton C.J.M., F.H. Tros and Harm Van Lieshout (2003) Towards 'Flexicurity'? Balancing Flexibility and Security in EU Member States (September 2003). Paper.

Åberg, R. (2001) "Equilibrium unemployment, search behavior and unemployment persistency.” Cambridge Journal of Economics, 25, pp. 131-47. 


\section{Sammanfattning}

Denna studie undersöker rörligheten på arbetsmarknaden under perioden 2000-2006 i fyra nordiska länder: Danmark, Finland, Norge och Sverige. Syftet är att studera vilka faktorer som påverkar rörligheten på ländernas arbetsmarknader, samt vilken betydelse som olika arbetsmarknads- och välfärdsinstitutioner har för rörligheten.

Under de senaste decennierna har det funnits ett intresse för hur olika arbetsmarknads- och välfärdsinstitutioner skall organiseras för att underlätta rörlighet på arbetsmarknaden. Speciellt de senaste åren har en modell förts fram som går under benämningen "Flexicurity”. Denna modell sägs kunna befrämja både flexibilitet och trygghet på arbetsmarknaden. I detta sammanhang ses Danmark som ett exempel på ett land som lyckats skapa en arbetsmarknad kännetecknad av flexicurity. Men i kölvattnet bakom intresset för den danska flexicurity-modellen har frågan rests om flexicurity endast är ett danskt fenomen eller om flexicurity också är något som kännetecknar de andra nordiska länderna. I flera internationella studier av nationella flexicurity-profiler hittar man tillräckliga likheter för att gruppera länderna tillsammans. Undersöker man arbetsmarknads- och välfärdsinstitutionerna mer noggrant finner man dock olikheter som kan påverka flexibiliteten och tryggheten på arbetsmarknaderna. Danmark utmärker sig genom sitt svaga anställningsskydd, generösa arbetslöshetsförsäkring och stora satsningar på aktiva arbetsmarknadspolitiska åtgärder. Endast ifråga om livslångt lärande framstår Sverige som ett ungefär lika ambitiöst land som Danmark. Vid en jämförelse framstår således den danska kombinationen av institutioner kring arbetsmarknaden också som speciell i ett nordiskt sammanhang.

Denna rapport fokuserar på rörlighet. Därmed är det framförallt flexibilitetsaspekten av flexicuritybegreppet som sätts i centrum. De övergripande frågeställningar som väglett studien är följande:

- Vilken omfattning har olika former av övergångar på arbetsmarknaden? I vilken utsträckning skiljer sig olika kategorier av individer åt i fråga om rörlighet?

- Vilka faktorer påverkar individers övergångsbenägenhet? Har de nationella institutionella ramverkan någon betydelse?

- Hur kan nationella skillnader i rörlighet på arbetsmarknaden förklaras? Är de relaterade till skillnader i de institutionella ramverken?

Tre övergripande former av rörlighet på arbetsmarknaden är i fokus: 
- Rörlighet mellan sysselsättning, arbetslöshet och att vara utanför arbetskraften.

- Rörlighet till och från s.k. "atypiska arbeten”, dvs. tillfälliga anställningar och deltidsarbete.

- Rörlighet mellan arbetsplatser, yrken och näringsgrenar.

Studien undersöker inte geografisk rörlighet. Ett viktigt påpekande är att alla dessa övergångar dock kan innebära en rörlighet i rummet - inom länder och mellan. Det empiriska material som analyseras är arbetskraftsundersökningarna (AKU) i de fyra länderna. Dessa undersökningar har sammanförts i en gemensam datamatris med AKU:s panelstruktur intakt. I de flesta fall undersöks rörligheten mellan två undersökningstillfällen med 12 månaders mellanrum.

Den första formen av rörlighet som studerats är mellan sysselsättning, arbetslöshet och att vara utanför arbetskraften. Två av de viktigaste faktorerna bakom dessa former av rörlighet är ålder och typ av anställningskontrakt. I de flesta fall har yngre en högre övergångssannolikhet än äldre. Anställda på tillfälliga kontrakt tenderar i högre utsträckning än anställda på tillsvidarekontrakt att röra sig från sysselsättning till arbetslöshet eller att falla utanför arbetskraften. Jämför vi länderna finner vi en högre sannolikhet att röra sig från sysselsättning till arbetslöshet i Danmark. Den högsta sannolikheten att röra sig från arbetslöshet till sysselsättning finns i Norge. Danmark har dock en hög rörlighet till sysselsättning bland dem som i utgångsläget står utanför arbetsmarknaden. I Sverige hittar vi för de flesta av dessa övergångar den lägsta rörligheten.

När det gäller rörlighet mellan arbetsplatser, yrken och näringsgrenar finner vi också att rörligheten är högst i Danmark. Speciellt gäller detta arbetsplats- och yrkesrörlighet. Rörlighet mellan näringsgrenar skiljer sig mindre mellan länderna, men den är fortfarande högst i Danmark. Finland och Sverige har generellt lägst rörlighet i dessa avseenden. Också för dessa former av rörlighet är ålder och typ av kontrakt viktiga bestämmande faktorer.

Länderna skiljer sig mycket åt med avseende på användningen av tillfälliga kontrakt på arbetsmarknaden. Den största andelen tillfälliga kontrakt finner vi i Finland och Sverige. Analyserna visar att unga, födda utomlands och arbetande inom servicesektorn har i störst utsträckning har denna kontraktsform. Om man övergår till sysselsättning efter att ha varit arbetslös eller utanför arbetskraften, så är risken störst i Finland och Sverige att hamna i en tillfällig anställning. I dessa två länder är sannolikheten också minst att röra sig från en tillfällig till en tillsvidareanställning. Sannolikheten för detta är störst i Norge.

Den sista formen av övergångar som studerats avser rörlighet mellan heltids- och deltidsanställning. Vi finner också här tydliga skillnader. I Norge är deltidsanställningar vanligast - mellan 25-30 procent av de sysselsatta har en deltidsanställning. I Finland är det bara mellan 10-15 
procent. Danmark och Sverige ligger därimellan (20-25 procent). Som förväntat är också sannolikheten störst i Norge för att få en deltidsanställning om man varit utan sysselsättning ett år innan. Risken för att som deltidsanställd bli arbetslös eller att befinna sig utanför arbetskraften ett år senare är minst i Sverige och störst i Danmark vad gäller arbetslöshet och i Finland för att hamna utanför arbetskraften.

Den huvudsakliga slutsatsen av denna studie är att Danmark har en speciell kombination av institutioner kopplade till arbetsmarknaden också i ett nordiskt sammanhang. Detta flexicurity-system är sammankopplat med en hög rörlighet på arbetsmarknaden. Studien har dock inte kunnat avgöra exakt hur betydelsefulla institutionerna är för rörligheten. Med stor säkerhet spelar dock det låga anställningsskyddet en väsentlig roll. Härigenom ökar risken för anställda att förlora arbetet och detta medför i sin tur ökad risk för vissa former av rörlighet. Förutom detta har generositeten $\mathrm{i}$ arbetslöshetsförsäkringen och den omfattande användningen av aktiva åtgärden betydelse för att skapa trygghet på arbetsmarknaden och därmed större benägenhet till frivillig rörlighet, t.ex. i form av arbetsplatsbyten.

De tre övriga länderna skiljer sig under studieperioden från det danska flexicurity-systemet på flera punkter. Framför allt Norge och Sverige har ett betydligt strängare anställningsskydd. Finland och Norge har en mindre generös arbetslöshetsförsäkring och Finland satsar minst på aktiva åtgärder per arbetslös.

Studien visar att rörligheten på arbetsmarknaden också är tämligen hög i Norge. En förklaring till detta kan vara att Norge har haft en stark ekonomi under flera år. Rörligheten på den norska arbetsmarknaden kan kanske ses som typisk för en arbetsmarknad karaktäriserad av i det närmaste full sysselsättning, men det kan också finnas andra förhållanden (t.ex. partsrelationer, regionalpolitik, kulturella särdrag) som förklarar den höga rörligheten. 



\title{
Appendix A National descriptions of institutional frameworks
}

\author{
Employment protection legislation
}

\section{Denmark}

It is generally emphasised that the overall level of employment protection in Denmark is at a low level and comparable to liberal labour markets like that of the United Kingdom. Furthermore, this low level of protection is a long-standing feature of the Danish labour market dating back to the General Agreement between the social partners that was the outcome of a general strike in 1899. This so-called September Agreement defined the right for the employers to manage the workplace (including the right to hire and dismiss workers), while the employers on the other hand recognized the trade unions as legitimate counterparts in negotiations about wages and work conditions. One of the characteristics of the Danish labour market, which is in contrast to for instance the situation in Sweden, is that this low level of employment protection has been intact until present times.

Regulating individual employment protection and setting rules concerning dismissals is therefore mainly left to the social partners. As a result of this, a closer look at the employment protection found on the Danish labour market will reveal that the level of protection against dismissals varies between different groups and between different sectors. For example, in the construction sector dismissal periods can be only one day, while other blue-collar workers have an employment protection similar to that of salaried workers. The overall assessment of employment protection in Denmark is however that the protection level is in the lower end of the spectrum.

As an important exception, the dismissal of salaried workers is regulated by a special piece of legislation (Lov om retsforholdet mellem arbejdsgivere og funktioncrer). But even for salaried workers the term of notice is rather short, depending however on the seniority of the employee. During the first 6 months of employment the notice period is one month. Thereafter, for a seniority of less than three years, the notice period is three months. The maximum notice period is six months after at least nine years of employment. For some groups the employer also must present a concrete reason for the dismissal, based on circumstances re- 
lated to either the employee or the firm. In itself the law on salaried workers covers employees doing office work or similar work. However, a number of collective agreements have stipulated that the employees covered by the agreements should have the same protection as that found in the law, even if their tasks are of a non-clerical nature. The de facto coverage of the law is therefore rather wide, in both the public and the private sector.

An interesting trait is that there are no special regulations of the public employees, which are in general subject to the same rules as in the private sector. The exemption is the minority of public employees who still have a special status as public servants, although the tendency over the last decades has been to phase out this category of public employees.

A final observation to be made is that the low level of employment protection is correlated with a relatively small share of employees having an employment contract of limited duration. According to the labour force survey for 2007 only $8.8 \%$ of the employees have such a contract. The share is highest - at about 20\% - for young persons aged 15-29 years, among whom one will find many students having some form of temporary job. For the EU-27 the average share of employees with fixed-term contracts was $14.4 \%$ in 2006.

Fixed-term contracts are regulated by laws and collective agreements. Except for standard terms of notice, fixed-term workers are generally covered by the same collective agreements and by the same legislation as permanent employees (e.g. holidays, seniority, salary during sickness etc.).

Since 2003, all fixed-term workers are furthermore covered by the law on fixed-term contracts (Lov om Tidsbegrcensede Anscettelser). This law stems from an EU directive from 1999. The main objective is to improve the quality of fixed-term contracts in all the EU countries by ensuring that fixed-term workers have the same possibilities and rights as employees in standard contracts. This means, for instance, that fixed-term workers must be given access to continuing vocational training on the same terms and conditions as permanent employees, and that employers are obliged to inform fixed-term workers of vacant positions in the company in order for the fixed-term worker to achieve a permanent position. Another important objective of the law is to protect the fixed-term workers against employers' improper use of successive renewals. Therefore a fixed-term contract can only be renewed due to objective conditions such as maternity leave or sickness or because a longer contract is needed in order to complete the task. In some areas of the labour market (like teaching and scientific work) only two renewals can be given before the fixed-term contract terminates. 


\section{Finland}

In Finland, the previously tense industrial relations were relaxed with the “Engagement of January” between the employers' and employees' organizations in the middle of the Winter War in 1940, which was the beginning of Finnish Corporatism. Since the first comprehensive collective agreement ("TUPO") in 1968, the labour market relations have been shaped towards a tripartite cooperation that has become an important basis of the welfare state development.

The most important regulations of employment protection are the Employment Contracts Act (reformed in 2001) and the Act on Co-operation within Undertakings (1978, recently revised). Collective agreements may include minor branch-specific amendments, but mainly employment protection is based on this legislation.

In principle, employment contracts are valid indefinitely and can be terminated by the employer only on the basis of a "proper and weighty reason". Apart from reasons due to the employee, the employer can terminate the employment contract if work that the employer has available has been reduced "permanently and substantially because of economic or production-related reasons" (including reorganization). In cases of unjust employment termination, the employee has a right to compensation. The minimum notice period before the termination of employment varies according to the duration of employment, between 14 days (one year or less duration of employment) and six months (over 12 years duration of employment relationship).

The contract can be made for a fixed term, if the employee is hired for a limited trial period or works as a substitute or trainee or if the task is seasonal or otherwise has a specific character and limited duration. A fixed-term contract can be terminated without notice at the end of the predetermined period. There are regulations defining when a person having several successive fixed-term contracts with the same employer should be considered as a permanent employee. Fixed-term contracts are relatively common in the public sector (where sacking of permanent employees is at least politically if not formally more difficult than in the private sector), arousing continuous discussion and dispute.

A temporary lay-off is a rather usual method of quantitative flexibility in Finland, when the employer faces a reduction of demand. A lay-off may be valid until further notice or for a defined period. During a lay-off, the employee is qualified for the unemployment benefits and ALMP measures like any unemployed person, but the employment contract is not formally terminated.

Employees with a very long employment history and qualification for UI had a right to severance pay until 2002. This benefit was not paid by the individual employer but by a fund financed by employers collectively. This benefit is nowadays replaced by a right to an increased unemployment insurance benefit for a limited period. 
Concerning collective dismissals (or other essential changes of employment contract), the employers have an obligation to negotiate with the representatives of the employees. If at least ten employees are affected by the planned change, a minimum of six weeks for negotiations is required before the changes can take place.

In 2005, a right to special measures ("transition security") came into force concerning those who have been dismissed for economic or production-related reasons or became unemployed after having served the same employer under temporary contracts for about three years. After the reform, the concerned group is entitled to free time with full wage for job search during 5-20 days (depending on employment history), to an action plan with the employment office, and eventually as a part of this plan to a maximum of 185 days of increased benefit during training. A first evaluation (Arnkil et al. 2008) suggests that this reform had some modest positive impact on the re-employment probability of the target group.

\section{Norway}

Individual dismissals as well as collective redundancies are mainly regulated through legislation (Working Environment Act). A collective redundancy involves at least 10 employees without being warranted by reasons related to the individual employees.

Dismissals have to be "objectively justified on the basis of circumstances relating to the undertaking, the employer or the employee". If the dismissal is grounded in rationalization processes etc., the employer also has to consider whether other suitable work is available. Collective dismissals/redundancies are subject to special procedures; among other things, the employer is obliged to discuss the situation with the employee representatives.

There are relatively strict technical requirements of which procedures employers have to follow in dismissal cases.

Norwegian legislation is not very specific regarding which employees should be chosen in the case of a dismissal warranted by reasons such as restructuring processes or a general need to downsize. However, it is recognized that the selection of redundant employees should be based on some type of more generally applicable and known considerations/criteria. A court will place weight on seniority, as well as on relevant qualifications. Dismissals warranted by reasons linked to the individual should also be justified, and case-law has been important in defining in which situations such a dismissal is justified or not.

In both types of dismissals the period of notice varies from 1 month (up to 5 years' employment) to 3 months (10 years' employment in the establishment). The period of notice is higher for older employees with 10 years' employment or more (up to 6 months for employees aged 60 
years or more). These provisions might be deviated from through collective agreements. There are no legal provisions for severance pay.

Collective agreements add to the legal regulations in several respects. Firstly, agreements add to the procedures for how collective dismissals should be handled. Secondly, agreements will often state that the seniority principle should apply if an enterprise has to downsize (other things being equal). Thirdly, in the private sector a moderate severance pay scheme exists for employees who have become 50 years old or more. More important, downsizing processes will normally be discussed with union representatives and may also lead to special agreements where redundant employees are given compensation for voluntary resignations, possibilities for early retirement etc. Collective agreements might also give other provisions regarding the period of notice. In the private sector this will mainly be regulated through company level agreements. In the municipal sector as well as some parts of the private sector (we do not know how common this is), the minimum period of notice will be 3 months (for both parties) for employees with permanent employment.

Temporary lay-offs ("permitteringer") are an alternative to (collective) dismissals in situations where the enterprise expects to take the employees back. The lay-off institution is regulated by the LO-NHO Basic Agreement, normally used in sectors such as manufacturing and construction, and employees that are temporary laid off will have to seek employment in order to get unemployment benefits.

Generally speaking, the Norwegian regulations on when a dismissal can take place are not very strict as long as the employer can justify this on objective grounds such as the need to downsize due to economic reasons. The employer will have to apply generally applicable principles when choosing which employees to dismiss (not just pick and choose). In practice, the principle of seniority is often applied, although other criteria may also be taken into consideration. An employer may offer early retirement or encourage voluntary resignations through economic compensation in order to bypass such principles, or to avoid dismissals in cases where downsizing is deemed necessary.

Even if Norwegian employers can resort to dismissals if this is seen as necessary/justified, relatively strict technical procedures will have to be followed. Employees can demand that negotiations take place, can take cases to court, and will have the right to stay in employment until the case is determined (unless the court finds it unreasonable that employment should continue while the case is in progress). Dismissed employees will also have priority to new employment in the enterprise if the dismissal is based on the need to downsize (applicable for a period one year after the dismissal).

In Norway temporary employment is mainly regulated by legislation. ${ }^{24}$ Norway has relatively strict regulations on temporary employment

\footnotetext{
${ }^{24}$ Working Environment Act, Section 14-9.
} 
in an international as well as Nordic context (measured by the EPLindex). Permanent employment is the rule, and fixed-term contracts ("midlertidig ansettelse") can only be used in connection with a temporary replacement for another person/persons or when "warranted by the nature of the work and the work differs from that which is ordinarily performed in the undertaking”. In addition, temporary employment contracts can be used for trainees, for persons on labour market schemes and for certain types of jobs within organized sports. The regulations cover all sectors with the exception of state employees. Here the relevant legislation (the Act related to Civil Servants) opens up for the use of temporary contracts also in situations where the employee is only needed for a specific period or to carry out a specific assignment, or if the work has not yet been defined as permanent, and staffing needs are therefore uncertain. The implication is that restrictions on temporary employment are less strict in the state sector than in the private or municipal sector. Probation time (prøvetid) is allowed in both permanent and temporary contracts.

The regulations on fixed-term contracts were slightly tightened in 1996 (when it was stressed that the type of work should differ from what ordinarily was performed when a fixed-term contract was justified by "the nature of the work"). The legislation on temporary contracts has not undergone any substantial changes since $1996 .{ }^{25}$ One exception is a change from 2006 which introduced a maximum period of 4 years before an employee is considered as permanently employed.

In Norway, collective agreements do not play any major role regarding the regulation of temporary contracts.

Even if the Norwegian regulations on fixed contracts are rather strict in an international context, these forms of contracts are rather widespread, and there are few cases where the question of the legality of such contracts is taken to court. Fixed-term contracts/temporary employment is usual among young employees, both among students and in the first job. Surveys indicate that most fixed-term contracts are for relatively shortterm appointments, but that the total period that an employee is on temporary contracts is longer, indicating that it is common to have several consecutive temporary assignments.

Temporary employment, and especially fixed-term/temporary contracts, has been much debated in Norway. In 2005 the regulations on temporary contracts were relaxed after extensive debate and deliberations. However, the changes of government in October 2005 meant that the new regulations never were implemented. The arguments in favour of changing the legislation have mainly been grounded in positive effects of

\footnotetext{
${ }^{25}$ In connection with the revision of the Working Environment Act in 2005, a majority in the Parliament voted in favour of new legislation that would have opened up for temporary contracts for a period of up to one year without any special justification. The change of Government in October 2005 (to a Labour-led government) meant that the new legislation on fixed-term contracts never was implemented.
} 
a deregulation of the employment possibilities among groups with a weak labour market position, as well as in the belief that this will lead to more jobs. The majority of the trade union movement has fought against a deregulation, fearing that this will lead to more fixed-term jobs and an insecure situation for young employees and others who may end up in longer periods as temporarily employed.

\section{Sweden}

The December Compromise between the labour market parties in 1906 serves as some sort of starting point for the employment protection legislation in Sweden. As a result of the compromise, workers were given the right of association in exchange for employers' right to manage the work place. In reality this meant that employers could hire and fire without restraint, which led to great insecurity among the workforce and made it difficult for unions to predict future activities. The so-called "Saltsjöbaden Agreement" in 1938 obliged employers to give advance notice of dismissal, but without further legal rights or means it was nevertheless hard for unions to affect the arbitrary power of employers by collective bargaining. Hence it was after a period of massive union pressure that the Swedish Parliament sharpened the labour legislation in the 1970s against the will of the Opposition Parties and the Employers (Bylund and Viklund 2006).

The Employment Protection Act (Lagen om Anställningsskydd, LAS) dates back to 1974. It rests upon three cornerstones: contracts of employment (duration), objective grounds for dismissal, and order of priority in connection with termination of employment. To begin with, an employment contract is open-ended unless otherwise agreed. Openended contracts are the guideline whereas fixed-term contracts are allowed as an exception to the main rule. From the beginning the possibilities of signing fixed-term contracts were limited to a rather narrow range of circumstances.

Since then the law has in some parts been liberalized, in particular regarding fixed-term contracts. In 1982 it became easier to hire on trial or for a short term during intense working periods. In 1993 it also became legal for private temporary employment agencies to rent out labour force to other employers (Bylund and Viklund 2006:43; Furåker 2006:68). In 1997 an amendment regarding the rules of so-called agreed fixed-term employment was introduced, which allowed employers to contract employees for a short term without having to specify any particular reason (no more than five such contracts at the same employer were accepted). In 2007 agreed fixed-term was replaced by so-called general fixed-term employment which, as before, entitled employers to sign short-term contracts without having to specify a motive. In addition to that, fixed-term contracts are allowed under the following circumstances since 2007: sub- 
stitute employment, seasonal employment, and temporary employment when the person has attained the age of 67. Furthermore, the law does not stipulate a maximum number of temporary contracts at the same employer any more.

Another key component of the Employment Protection Act is that notice of termination, which always shall be given in writing, must be based on objective grounds. Shortage of work is in general viewed as a legitimate cause for dismissal. Furthermore, employers are obliged to give advance notice of redundancy and/or dismissal (varsla om uppsägning) and employees are entitled to pay and other benefits during the period of notice. The order of priority stipulates that employees with longer times of employment are entitled to longer periods of notice (Furåker and Berglund 2009). After being laid off, workers have the right to priority of reemployment at their previous workplace, on condition that they meet the criteria for getting re-hired. In Sweden, there is no system to subsidise temporary lay-offs ("permitteringar") any more. It disappeared in the 1990s.

A third and vital ingredient of the law is the order of priority in connection with termination of employment on the grounds of shortage of work. For several years, time of notice and rules of priority in connection with layoffs were based on age, but since 1997 these rules depend on length of service instead. In accordance with the "last in, first out" principle, employees with longer employment time have priority over employees with shorter employment time in cases of redundancy. The same applies for time of notice, which is gradually built up with length of employment. The minimum time of notice is one month if the individual has been employed less than two years, and increases thereafter gradually to at most six months after more than ten years of employment (Furåker and Berglund 2009; Bylund and Viklund 2006).

In 2000-2001 the Swedish Parliament undertook yet another amendment to the law, stipulating that an employer with a maximum of ten employees is allowed to exempt at most two employees from the priority order who, in the employer's opinion, are of particular importance to the company.

Taken together, continuity rather than change stands out when looking at the law over time (Furåker and Berglund 2009). The underlying principle is the same as from the beginning, i.e. to protect people who are already employed. In short, the most important changes have occurred along the following lines. Firstly, employers' right to conduct fixed-term contracts has expanded. Secondly, time of notice and rules on priority are no longer based on age, but on length of employment. Thirdly, small employers have been given the right to deviate from the rules on priority in cases of redundancy (Furåker 2006:68-70).

Due to the negotiable nature of Swedish labour law it is also necessary to look at the relationship between law and collective agreement, plus the 
content of collective agreements, when trying to estimate the total effect of labour market regulations (Anxo 2006). Employment protection may be revised both upwards and downwards by collective agreements at industry level as well as company level (Bylund and Viklund 2006). Because of this, the actual amount of employment protection is related to collective agreements in those sections of the law which are wholly or partly optional and open for negotiation. In the Employment Protection Act, the rules on objective grounds for dismissal are not negotiable, whereas the rules regarding contracts of employment (duration) and order of priority in connection with layoffs are flexible and possible to deviate from by collective agreements (Bylund and Viklund 2006).

Table 1. Overview of Employment Protection Legislation 2000-2006

\begin{tabular}{|c|c|c|c|c|}
\hline & \multicolumn{4}{|c|}{ Regulations of Regular (Permanent) Employees } \\
\hline & Denmark & Finland & Norway & Sweden \\
\hline $\begin{array}{l}\text { Dismissals } \\
\text { can be } \\
\text { employed } \quad . .\end{array}$ & $\begin{array}{l}\text { Depending on the } \\
\text { content of the } \\
\text { relevant collective } \\
\text { agreement and the } \\
\text { coverage of the } \\
\text { law on salaried } \\
\text { workers. For the } \\
\text { latter, the em- } \\
\text { ployer has to } \\
\text { present an objec- } \\
\text { tive reason for the } \\
\text { dismissal. Special } \\
\text { protection for } \\
\text { pregnant women. }\end{array}$ & $\begin{array}{l}\text {... when justified } \\
\text { by a "proper and } \\
\text { weighty reason", } \\
\text { incl. if available } \\
\text { work has been } \\
\text { reduced "perma- } \\
\text { nently and sub- } \\
\text { stantially because } \\
\text { of economic or } \\
\text { production-related } \\
\text { reasons". }\end{array}$ & $\begin{array}{l}\text { Have to be objec- } \\
\text { tively justified on } \\
\text { the basis of } \\
\text { circumstances } \\
\text { relating to the } \\
\text { undertaking, the } \\
\text { employer or the } \\
\text { employee. }\end{array}$ & $\begin{array}{l}\text { Have to be } \\
\text { justified on } \\
\text { objective } \\
\text { grounds, for } \\
\text { example short- } \\
\text { age of work. }\end{array}$ \\
\hline $\begin{array}{l}\text { Time of } \\
\text { notice (min- } \\
\text { max - usual) }\end{array}$ & $\begin{array}{l}\text { Varies according } \\
\text { to collective } \\
\text { agreements and } \\
\text { whether the } \\
\text { employee is a } \\
\text { salaried worker. }\end{array}$ & $\begin{array}{l}\text { From } 14 \text { days to } 6 \\
\text { months depending } \\
\text { on tenure of } \\
\text { employment. } \\
\text { (Tenure less than } \\
\text { a year }=14 \text { days } \\
\ldots \text { over } 12 \text { years = } \\
6 \text { months). }\end{array}$ & $\begin{array}{l}\text { Usual: } 1-3 \\
\text { months, varies by } \\
\text { length of service. } \\
\text { For older employ- } \\
\text { ees ( } 50+\text { ) up to } 6 \\
\text { months. Collec- } \\
\text { tive agreements } \\
\text { may set } 3 \text { months } \\
\text { as minimum/ } \\
\text { Usual. }\end{array}$ & $\begin{array}{l}\text { Minimum } 1 \\
\text { month if less } \\
\text { than two years of } \\
\text { employment. } \\
\text { Increases gradu- } \\
\text { ally to at most } 6 \\
\text { months after } \\
\text { more than ten } \\
\text { years of em- } \\
\text { ployment. }\end{array}$ \\
\hline $\begin{array}{l}\text { Principle for } \\
\text { choosing } \\
\text { which em- } \\
\text { ployees to } \\
\text { dismiss }\end{array}$ & $\begin{array}{l}\text { The employer has } \\
\text { discretion to } \\
\text { choose which } \\
\text { workers to dismiss } \\
\text { as long as objec- } \\
\text { tive causes can be } \\
\text { stated. Discrimina- } \\
\text { tion according to } \\
\text { race, religion etc. } \\
\text { is not permitted. }\end{array}$ & $\begin{array}{l}\text { No regulation } \\
\text { (except against } \\
\text { discrimination) but } \\
\text { firm-specific } \\
\text { practices may } \\
\text { exist. Because the } \\
\text { oldest workers } \\
\text { have right to UI } \\
\text { until pension, they } \\
\text { are often dis- } \\
\text { missed first. }\end{array}$ & $\begin{array}{l}\text { Seniority principle } \\
\text { strong in CAs, but } \\
\text { may be deviated } \\
\text { from by qualifica- } \\
\text { tions and social } \\
\text { considerations. }\end{array}$ & $\begin{array}{l}\text { Seniority princi- } \\
\text { ple "last in, first } \\
\text { out!" Small } \\
\text { employers (10 or } \\
\text { less) can exempt } \\
2 \text { employees } \\
\text { from priority } \\
\text { rules. Deviations } \\
\text { through collec- } \\
\text { tive agreements. }\end{array}$ \\
\hline $\begin{array}{l}\text { Main type of } \\
\text { regulation }\end{array}$ & $\begin{array}{l}\text { Collective agree- } \\
\text { ments }\end{array}$ & Legislation & $\begin{array}{l}\text { Legislation. CAs } \\
\text { add to legislation }\end{array}$ & Legislation, CA \\
\hline $\begin{array}{l}\text { Collective vs } \\
\text { individual } \\
\text { dismissals }\end{array}$ & $\begin{array}{l}\text { Same regulations } \\
\text { apply for the } \\
\text { individual workers, } \\
\text { but collective } \\
\text { dismissals also } \\
\text { have to be re- } \\
\text { ported in advance } \\
\text { to the PES. }\end{array}$ & $\begin{array}{l}\text { Same regulations, } \\
\text { but collective } \\
\text { dismissals must } \\
\text { be negotiated with } \\
\text { personnel. }\end{array}$ & $\begin{array}{l}\text { Same period of } \\
\text { notice }\end{array}$ & $\begin{array}{l}\text { Same period of } \\
\text { notice. } \\
\text { Consultations } \\
\text { with workers } \\
\text { representatives. }\end{array}$ \\
\hline
\end{tabular}




\begin{tabular}{|c|c|c|c|c|}
\hline \multirow[t]{3}{*}{$\begin{array}{l}\text { Changes in } \\
\text { regulations } \\
\text { over the last } \\
10-15 \text { years }\end{array}$} & $\begin{array}{l}\text { No substantial } \\
\text { changes }\end{array}$ & $\begin{array}{l}\text { Law on "transition } \\
\text { security" given in } \\
2005 \text {, providing } \\
\text { support for job } \\
\text { search and for } \\
\text { improvement of } \\
\text { employability }\end{array}$ & $\begin{array}{l}\text { No substantial } \\
\text { changes during } \\
\text { the last } 10-15 \\
\text { years }\end{array}$ & $\begin{array}{l}\text { The basis for } \\
\text { priority rules } \\
\text { changed from } \\
\text { age to tenure } \\
1997 \\
\text { Small employers } \\
\text { have possibility } \\
\text { to exempt } 2 \\
\text { employees from } \\
\text { priority rules } \\
\text { (2000-2001). }\end{array}$ \\
\hline & \multicolumn{4}{|c|}{ Regulations of Temporary Employees } \\
\hline & Denmark & Finland & Norway & Sweden \\
\hline $\begin{array}{l}\text { Temporary } \\
\text { contracts can } \\
\text { be used ... }\end{array}$ & $\begin{array}{l}\text { In accordance with } \\
\text { both collective } \\
\text { agreements and } \\
\text { EU regulations (cf. } \\
\text { the directive from } \\
\text { 1999). There may } \\
\text { therefore be restric- } \\
\text { tions on the num- } \\
\text { ber of consecutive } \\
\text { contracts. }\end{array}$ & $\begin{array}{l}\text {...in case of trial } \\
\text { period or tempo- } \\
\text { rary substitutes or } \\
\text { trainees, or if the } \\
\text { task is seasonal } \\
\text { or otherwise has } \\
\text { a specific charac- } \\
\text { ter and limited } \\
\text { duration. After } \\
\text { several succes- } \\
\text { sive fixed-term } \\
\text { contracts with the } \\
\text { same employer, } \\
\text { the employment } \\
\text { should be con- } \\
\text { sidered as per- } \\
\text { manent. }\end{array}$ & $\begin{array}{l}\text { For temporary } \\
\text { replacement or } \\
\text { when warranted } \\
\text { by the nature of } \\
\text { the work. For } \\
\text { labour market } \\
\text { schemes, train- } \\
\text { ees etc. } \\
\text { No regulations on } \\
\text { maximum period } \\
\text { or number of } \\
\text { consecutive } \\
\text { contracts until } \\
2006 \text { when } \\
\text { principle of } \\
\text { maximum } 4 \\
\text { years was } \\
\text { adopted. }\end{array}$ & $\begin{array}{l}\text {...without having } \\
\text { to specify any } \\
\text { particular reason } \\
\text { No more than five } \\
\text { such contracts at } \\
\text { the same em- } \\
\text { ployer are ac- } \\
\text { cepted (except } \\
\text { substitutes). } \\
\text { (Changed 2007). } \\
\text { If an employee } \\
\text { has been em- } \\
\text { ployed as a } \\
\text { substitute at the } \\
\text { same employer } \\
\text { for more than } 3 \text { of } \\
\text { the last } 5 \text { years, } \\
\text { the contract will } \\
\text { be changed to an } \\
\text { open-ended } \\
\text { (permanent) } \\
\text { contract. } \\
\text { (Changed 2007.) }\end{array}$ \\
\hline $\begin{array}{l}\text { Changes } \\
\text { over the last } \\
10-15 \text { years }\end{array}$ & $\begin{array}{l}\text { A special law on } \\
\text { temporary con- } \\
\text { tracts was intro- } \\
\text { duced in } 2003 \\
\text { implementing the } \\
\text { EU directive from } \\
\text { 1999. The law } \\
\text { stipulates minimum } \\
\text { rights for those } \\
\text { employees not } \\
\text { covered by collec- } \\
\text { tive agreements }\end{array}$ & $\begin{array}{l}\text { No important } \\
\text { changes. }\end{array}$ & $\begin{array}{l}\text { More strict } \\
\text { regulations } \\
\text { introduced in } \\
\text { 1996, maximum } \\
\text { period of } 4 \text { years } \\
\text { introduced from } \\
2006\end{array}$ & $\begin{array}{l}\text { Successively } \\
\text { liberalized since } \\
\text { 1982. In 1993, } \\
\text { Temporary } \\
\text { Employment } \\
\text { Agencies were } \\
\text { allowed. In } 1997 \\
\text { up to } 5 \text { temporar- } \\
\text { ies without speci- } \\
\text { fying any particu- } \\
\text { lar reason. } \\
\text { In } 2007 \text { no regu- } \\
\text { lations of maxi- } \\
\text { mum numbers of } \\
\text { temporaries. }\end{array}$ \\
\hline $\begin{array}{l}\text { Main type of } \\
\text { regulations }\end{array}$ & $\begin{array}{l}\text { Law and collective } \\
\text { agreements }\end{array}$ & Legislation & $\begin{array}{l}\text { Legislation } \\
\text { (Working Envi- } \\
\text { ronment Act). } \\
\text { CAs play mi- } \\
\text { nor/no role }\end{array}$ & LAS and CA \\
\hline
\end{tabular}




\section{Unemployment benefits}

\section{Denmark}

Both when it comes to income support for the unemployed and to active labour market policy, the Danish organisation of labour market policies is based on a division between those unemployed that are members of an unemployment insurance fund and those who are uninsured. In the event of unemployment, the latter must apply for means-tested social assistance (cash benefits) that is administered by the municipalities. Also, when it comes to the active programmes, the municipalities handle the group of uninsured unemployed, while the insured unemployed are in the public employment system administered by central government. ${ }^{26}$ The vast majority (79\% in 2007) of the unemployed are members of an unemployment insurance fund.

While the two-tier character of both active and passive measures has been and still is an important feature of Danish labour market policy, the system has experienced a number of reforms since the early 1990s having as their main characteristics:

- The introduction of a two-period benefit system for the insured unemployed with an initial "passive" and a subsequent "activation" period. Over the years, the passive period has been gradually shortened from initially four years to the present nine months for older unemployed and six months for unemployed aged less than 30 years. The total duration of unemployed benefits is now four years, thus implying that the "activation period" is now a little more than three years.

- A strong emphasis on "rights and duties" for the individual unemployed, who has the right to get an individual "job-plan" spelling out the activities to be undertaken to get back to employment, but also the duty to take part in the different programmes of the employment service.

- A decentralisation of policy implementation to regional and local authorities, which were to some degree empowered to adjust programme design to fit local needs.

- The removal of the connection between job-training and the unemployment benefit system, implying that any employment with a wage subsidy no longer increases the duration of the period when an unemployed is eligible for unemployment benefits.

\footnotetext{
${ }^{26}$ From August 1, 2009, the insured unemployed will also be transferred to the municipalities, thus marking a formal abolition of the state-run public employment service. However, the legal distinction between the insured and the non-insured unemployed will remain, and they will still differ with respect to the activation regime and the income support that they receive.
} 
From 2007 the two systems for the insured and the non-insured unemployed have been integrated in new local "job centres". However, the legal distinction between the insured and the non-insured unemployed remains, both when it comes to participation in active labour market programmes and to income support during unemployment. Thus the insured unemployed still get their income support from the unemployment insurance funds, while the non-insured receive cash benefits from the municipalities.

The Danish system of unemployment insurance is based on the socalled Ghent system. It consists of 31 state-recognized unemployment insurance funds. Four of them are unemployment funds for both employees and self-employed persons. One unemployment insurance fund only admits self-employed persons as members. When a person moves from one unemployment insurance fund to another, either due to a shift in occupation or because s/he decides to do so, the right to unemployment benefits is transferred at the same time.

Most of the unemployment insurance funds are affiliated with one or more trade unions. This is often taken as an explanation of the high union density of about $80 \%$ on the Danish labour market. While membership of an unemployment insurance fund is independent of being a member of a trade union, most workers conceive the membership of the trade union and the affiliated unemployment insurance fund as a package. This is probably due to the long historical bonds between the two kinds of institutions and to the fact that trade unions do little to advertise the formal difference between the two sorts of membership. Also, of course, membership of a trade union offers some advantages which are unrelated to receiving unemployment benefits, like support in local wage negotiations and in conflicts with the employer.

The present version of the system for income support for the unemployed dates back to the last large reform of the unemployment benefit system in 1970, where the state took over the responsibility for financing the extra costs of unemployment benefits that were caused by increases in unemployment (the principle of public financing "at the margin"). The members of the unemployment insurance funds are therefore only obliged to pay a fixed membership contribution, independent of the actual level of unemployment.

This mechanism for financing unemployment insurance implies that the share of public funding depends on the total number of unemployed. In periods of high unemployment as in the early 1990s, the Government's share rises to $80 \%$, while it falls to less than $50 \%$ during economic upswings.

Apart from those who have exhausted their right to unemployment benefits, the group of non-insured consists of those who are not members of an insurance fund in the first place. This group of people consists of those who voluntarily choose not to become a member of the insurance 
funds, or those who do not meet the membership conditions (cf. the list of criteria presented below). This group of unemployed must apply for cash benefits administered by local government (the municipalities). As explained in more detail below, cash benefits are means-tested and the amount depends on the family situation of the unemployed.

Membership of an unemployment insurance fund is voluntary. Members have to fulfil the following criteria:

- A member must stay and reside in Denmark. However, departures are made from this rule if the person resides in another EEA country.

- They must be between 18 and 63 years of age when they join the unemployment insurance fund. They must have employment as an employee or as a self-employed person or assisting spouse in a company owned by a self-employed person.

- A person can also be admitted as a member of an unemployment insurance fund if the person has completed a vocational training course of at least 18 months' duration when applying for membership not later than 2 weeks after completion of the training course.

Both full-time and part-time employees can become members of an unemployment insurance fund. Part-time insurance is an option for persons working less than 30 hours per week. Both membership contribution and unemployment benefits are lower for this group. Thus benefits cannot be higher than two-thirds of the benefits for a full-time insured person.

The membership contribution amounts to:

- A flat-rate compulsory contribution to the unemployment insurance, which is the same for all members and in 2008 amounts to 3,372 DKK per year (453 Euro27)

- A flat-rate contribution to finance the Labour Market Supplementary Pension Scheme (the so-called ATP scheme)

- An administrative fee, which varies (considerably) between the individual unemployment insurance funds

- A voluntary early retirement contribution for the Voluntary Early Retirement Scheme. The yearly retirement contribution in 2008 amounts to DKK 4,920 (660 Euro) for full-time insured members.

All membership contributions are tax-deductible, which implies that the net cost to the member is about two-thirds of the gross cost.

To be entitled to unemployment benefits, the unemployed must in general fulfil the following conditions:

\footnotetext{
${ }^{27}$ Due to Denmark's membership of the European Exchange Rate Mechanism (ERM) the Danish currency is stable at the rate of 7.45 DKK to 1 Euro. This rate is therefore applied in all currency conversions in the chapter.
} 
- Have been a member of an unemployment insurance fund for at least one year

- For persons insured on a full-time basis, the employment requirement means that they must have had employment to such an extent that it altogether corresponds to employment during the full, normal working hours of the trade or profession for a minimum of 52 weeks within the past 3 years. If the full, normal working hours are 37 hours a week, the employment requirement for full-time insured members will amount to a total of 1,924 hours of work within the past 3 years.

Furthermore, the unemployed must look actively for work and is subject to the rules and regulations of active labour market policy (cf. below). In principle an unemployed person who has been unemployed for more than 3 months must accept any job offered by the PES that the person could perform. By example an unemployed academic must willing to work as a postman. However, in practice the job centres are not very strictly implementing this rule, because of the expected lack of motivation of the unemployed if actually employed in the job.

Taking part in labour market training or being employed with a wage subsidy will not make the unemployed eligible for an extension of the benefit period. The benefit rate is individual and depends on the size of the previous earned income. Unemployment benefits can, at a maximum, amount to $90 \%$ of previous earnings. The maximum benefit rate in 2006 is 667 DKK (90 Euro) per day for full-time insured members. Unemployment benefits are paid out for 5 days a week. The maximum yearly benefit is therefore 173,420 DKK (23,278 Euro). Special rates apply for persons who have just graduated from a vocational education without having any work record.

Once eligible for unemployment benefits, an unemployed person may collect them for a total period of four years, if s/he follows the directions concerning active job-seeking and participation in active labour market programmes. After the end of the four-year period, the unemployed loses the right to unemployment benefits and will have to apply for cash benefits as an "uninsured" unemployed; cf. below. The right to benefits is also automatically lost at the age of 65 years, when the person will qualify for old-age pension.

Apart from those who have exhausted their right to unemployment benefits, the group of "non-insured" unemployed consists of those unemployed who do not fulfil the criteria for becoming eligible for unemployment benefits in the first place (cf. the list of criteria presented above). This group of unemployed must apply for cash benefits administered by local government (the municipalities). These benefits are thus considered as parts of social policy and regulated by a separate law under the supervision of the Ministry of Employment. Financing is shared between national Government and the municipalities. 
Cash benefits are means-tested and the amount depends on the family situation of the unemployed. For example, a person aged 25 and more and having children will receive 139,500 DKK per year (18,725 Euro), while a young person aged 24 and less will receive 67,656 DKK per year (9,081 Euro). Like unemployment benefits, cash benefits are taxable income. The duration of cash benefits is not limited, but again the person will have to accept the offers from the municipality to participate in active programmes. Otherwise, cash benefits may be reduced or abolished altogether.

\section{Finland}

The Finnish unemployment compensation system consists of three benefits: Unemployment Insurance (UI), Unemployment Allowance (UA) and Labour Market Support (LMS). Type of benefit is decided by an employment requirement and by membership in an unemployment fund. Those fulfilling the later specified employment requirement will receive regular unemployment benefit, i.e. either UI or UA. Members of an unemployment fund will receive UI if they have been members during the time they fulfilled the employment requirement. Non-qualifiers and those whose UI/UA has been exhausted receive LMS.

Unemployment funds are traditionally linked to trade unions, and most members belong to a union. The link is not based on any law or rule, even though this fact has not been advertised much by the unions. Recently, an independent unemployment insurance fund has gained a considerable amount of members, but they are still a small minority. Even though fund membership is obligatory in order to receive UI, only a small fraction of the actual costs of UI is paid by the funds.

Until 2002, the employment requirement for UI/UA was 10 months' employment during an observation period of 24 months (on average at least 18 hours per week). From 2003, the requirement has been 10 months' employment during an observation period of 28 months for firsttime qualifiers. For those who have previously qualified, the renewal condition is eight months of employment during an observation period of 24 months. Certain types of ALMPs are counted wholly or partly as employment in relation to the UB system. The observation period is usually the time directly preceding unemployment, but it can be prolonged for a number of reasons (sickness, military service, parental leave, etc.).

The maximum duration of the UI/UA benefit is about 24 months (500 working days). The LMS benefit has no maximum duration. All benefits may be lowered or stopped if the person does not comply with rules about activation and being available for work. There is a self-risk period of seven working days before one can receive benefits after becoming unemployed. The self-risk is counted only once during the 500-day period. 
Only a minority of the Finnish unemployed receive an earningsrelated benefit. The coverage of UI is about $42 \%$ of the unemployed (annual average 2003). About $8 \%$ receive UA and $50 \%$ are on LMS.

The UA and LMS benefits are both flat-rate and of the same amount, about $530 €$ a month. There is an increase if the person is supporting minors. The main difference between UA and LMS is that UA is not meanstested, whereas LMS is steeply reduced if household earnings are high. There are two exceptions where means-testing is not applied. When a person receives LMS because of UI/UA exhaustion, the benefit will not be means-tested for the first 180 days. Means-testing does not apply to those who are at least 55 years old, either.

The amount of UI will be determined from stable income during the time the person last fulfilled the employment requirement. Benefit amount is basic benefit with possible child supplements plus $45 \%$ of the difference between earnings and the basic benefit. The percentage is smaller (20\%) for the part of earnings that exceeds about $2200 €$. Roughly, the net replacement rate of UI is around 60\%. However, it is higher for those with low income and considerably lower for those with a high income.

Until 2002, people with a very long work history (20 years) were entitled to a "redundancy pay". From 2003, they have instead been eligible for a higher UI benefit during the first 150 days of unemployment.

The main exceptions to the above-mentioned rules concern the ageing long-term unemployed on one hand and young labour market entrants on the other.

If UI/UA benefit has not been exhausted when the receiver turns 59, he or she will be entitled to extended benefit until the start of old-age pension (at the age of 62-67 according to individual choice). For those born 1949 or earlier, age limit is 57 with a right to unemployment pension at the age of 60 .

Those under 25 will qualify for LMS only if they have vocational education or have applied to at least three such schools. Even if they have applied for training, labour market entrants without vocational training will have to wait five months before qualifying for LMS. Those living with their parents will also receive a reduced amount of the benefit.

Many unemployed, especially those on UA or LMS, also qualify for other means-tested benefits, such as housing support or social assistance. Last-resort social assistance should be available also in cases where no unemployment benefit is paid, regardless of the reason.

\section{Norway}

The Norwegian unemployment compensation system consists mainly of the daily subsistence allowance issued by the Norwegian labour and welfare administration (NAV). In addition to this main benefit, persons who 
are under vocational rehabilitation (“yrkesrettet attføring”, i.e. measures to obtain new employment or retain former employment) have the right to rehabilitation benefits.

Unemployed persons get daily subsistence allowance as a replacement for loss of work income. To get daily subsistence allowance the unemployed person must have his or her working hours reduced by at least $50 \%$, and he or she must have had an income of at least 105,384 NOK the last completed calendar year, or at least 210,768 NOK during the last three calendar years (2008). Workers will also get a daily subsistence allowance at the level of the unemployment benefit if they are temporarily laid off by their employer during brief periods of work shortage ("permittert"), if an unemployed person is starting his or her own business, if the person is unemployed after serving his military duty, or if the unemployed person's own company went bankrupt.

Daily subsistence allowance is based on the duty to actively seek employment and a willingness to take up employment on short notice, to take any type of employment, and also to take jobs in other parts of the country. NAV might also ask an unemployed job-seeker to participate in training activities.

The duration of the daily subsistence allowance depends on the unemployed person's previous income. Everyone who earned more than 104,512 NOK last calendar year or at least 210,768 NOK during the last three calendar years is entitled to daily subsistence allowance for a maximum of 104 weeks. Those with lower incomes are entitled to daily subsistence allowance for at most 52 weeks. In 2004 the maximum period a person can get employment benefits was reduced from 152 to 104 weeks, and from 76 to 52 weeks for the group with low income in the period previous to the unemployment period.

The duration of the rehabilitation benefits may be up to 3 years. Vocational rehabilitation might include some kind of school/studies or work practice or a combination.

Persons that have been on long-term sick leave (52 weeks) may also be granted a rehabilitation benefit. This is a short-term benefit (maximum 52 weeks), and the aim is to improve the chances of coming back to employment.

Those who apply for daily subsistence allowance get benefits from day four of the period they are granted money for (i.e. no benefits are paid for the first 3 days as unemployed). The daily subsistence allowance is on average $62.4 \%$ of the person's former wage, before taxes. If an unemployed person provides for children, a small additional compensation is granted.

The size of the rehabilitation benefits depends on former income and on whether the person provides for children. Those who have their income ability reduced by $100 \%$ will receive maximum rehabilitation bene- 
fits. Those who have their income ability reduced between 50 and $100 \%$ will receive graded (reduced) rehabilitation benefits.

There are some exceptions to the general rule concerning the maximum duration of the daily subsistence allowance. The most important in our context would be that persons 64 years old or older can keep their benefits until age 67 , which is the general retirement age.

Persons who have recently done their military service can receive daily subsistence allowance for maximum 26 weeks, while those who are temporarily laid off can receive daily subsistence allowance for a maximum of 30 weeks within an 18-month period.

Persons who receive daily subsistence allowance for the maximum period, 104 weeks, could until 2008 get a waiting benefit ("ventestønad") if still without a job. The waiting benefit was removed from the benefit system at the beginning of 2008.

The rules regarding unemployment benefit (“dagpenger”) have been changed during the period 2000-2006. The changes have mainly been in the direction of more strict regulations on when and for how long an unemployed person can receive unemployment benefits. The maximum period an unemployed person can receive unemployment benefit was reduced from 3 to 2 years (104 weeks) for persons with the highest qualification basis (highest income level over the last 3 years) and from 1.5 years to 1 year (52 weeks) for persons with low qualification basis (lowest income over the last 3 years). The new regulations were applied from 1 January 2004. In addition, unemployment benefits would be paid only if the working time is reduced by $50 \%$ (earlier by $40 \%$ ), and the income qualification requirement (former income) was increased somewhat. ${ }^{28}$ The number/percentage of registered unemployed persons who do not receive unemployment benefits has increased over time (1990-2006). Among the explanations are new regulations/routines that require more groups to register as job-seekers in order to receive other types of public support/benefits (even if they do not qualify for unemployment benefits). There is no information on how much of the increase is related to new groups registering and how much is explained by changes in the unemployment benefit scheme (see Reiersen and Årethun 2007).

\section{Sweden}

In Sweden during 2007 there were 34 recognized unemployment insurance funds. With the exception of the independent "Alfa-kassan" all insurance funds are affiliated with trade unions. The membership fees cover only a small part of the unemployment benefit whereas the degree of state subsidy is about $90 \%$ (Kjellberg 2006:94).

\footnotetext{
${ }^{28}$ Tormod Reiersen and Torbjørn Årethun (2007): En lavere andel arbeidsledige mottar dagpenger. In Arbeid og velferd No.2, 2007.
} 
There have been some legal regulations surrounding the UB since 1935. However, the first law regulating unemployment benefits, the Unemployment Insurance Act, dates back to 1974. In 1998 the Unemployment Insurance Act from 1974 was abolished and replaced by the present law.

Since 1998 the unemployment insurance consists of two main elements: a basic insurance for those who fulfil a work requirement but not a membership condition, and an optional income-related insurance for those who satisfy both the work requirement and the membership condition for the unemployment insurance fund. In order to enter the unemployment insurance a minimum of four weeks' work during an uninterrupted period of at least five weeks is required. Moreover, you must have worked on average at least seventeen hours per week and still be working at least the same amount of hours (SO 2008).

The membership requirement involves at least 12 months' continuous membership of an unemployment insurance fund, whereas the work requirement implies (from 1997) at least 70 hours' employment per month for at least 6 calendar months during the last 12 months. In 2007 this was changed to 80 hours' employment per month for at least 6 calendar months during the last 12 months. To get benefit from the basic insurance it is enough to satisfy the work requirement, on condition that you live up to the basic conditions of the unemployment insurance. This involves among other things to register as a job-seeker at the local employment office and to be able and willing to take a suitable job. If you do not apply for a job or a programme which the employment office has decided is suitable for you, your benefit may gradually be reduced or even suspended (SO 2008:7). In Sweden during 2004, around 64\% of the registered unemployed received the income-related benefit and about $9 \%$ the basic insurance (IAF/Arbetsförmedlingen 2009).

The maximum duration of the unemployment benefit has been 300 days since 1974. Until 2001, people aged 55 years or older were entitled to 450 days. Thereafter this age distinction was abolished. However, the duration of the benefit is also affected by requirements for requalification. In the 1980s it became possible to qualify for a new benefit period via employment programmes as an alternative to regular work. In 2001, the government decided to abolish this re-qualifying condition linked to employment programmes. At the same time some deviations from the rule of work requirement were accepted, which in practice gave workers right to additional benefit periods (300 days). Since 2007, the length of the benefit period is at most 300 days. However, if a job-seeker has children who still have not attained the age of 18 when the benefit-period is about to end, it will be extended with an extra 150 days. Each new benefit period begins with a waiting/qualifying period before benefits are payable. The length of the waiting/qualifying period was changed from five to seven days in 2008. 
In short, the amount of benefit that the unemployed receives from the unemployment insurance relates to the number of hours worked, the number of hours per week that he or she can and is willing to work, and the number of hours per week for which he or she is unemployed. If entitled to income-related insurance, the benefit also depends on the average income that the unemployed had before the lay-off (SO 2008:6). In 1993, during the depression, the income-related benefit was reduced from $90 \%$ to $80 \%$ of previous earnings. In 1996 it was once again reduced from $80 \%$ to $75 \%$, only to be restored to $80 \%$ of previous earnings a year later. In 2007 the benefit level was changed again. During the first 200 days it is, as before, $80 \%$ of previous earnings, but from day 201 to day 300 it is lowered to $70 \%$.

In 2001 and 2002 the income-ceiling was increased during the first 100 days of benefit (from 680 to 730 SEK per working day). In 2007 the income-ceiling was restored to the level of 2001. However, since the upper limit for benefits has not been indexed for 15 years the actual benefit level is being hollowed out, that is to say, the ceiling of the insurance is not in step with the wage increase. As a result less than $50 \%$ of the unemployed who are entitled to income insurance do actually receive $80 \%$ of their previous earnings (Kjellberg 2006:97; SO 2006). Due to this, the demand for supplementary insurances, collective but also individual, has increased (Andersson et al. 2006). The basic insurance is at most 320 SEK per working day. 
Table 2. Overview of UB systems 2000-2006

\begin{tabular}{|c|c|c|c|c|}
\hline & Denmark & Finland & Norway & Sweden \\
\hline $\begin{array}{l}\text { Coverage of wage- } \\
\text { related UB } \\
\text { (Percent of regis- } \\
\text { tered unemployed) }\end{array}$ & 79\% (2007) & $42 \%(2003)$ & $\begin{array}{c}60 \% \\
\text { (Estimate 2000-2006) }\end{array}$ & Сa 64\% (2004) \\
\hline \multicolumn{5}{|l|}{$\begin{array}{l}\text { Net replacement } \\
\text { rates of wage- } \\
\text { related UB in the } \\
\text { beginning of unem- } \\
\text { ployment }\end{array}$} \\
\hline $\begin{array}{l}\text { - Single person } 67 \% \\
\text { APW }\end{array}$ & $84 \%$ & $73 \%$ & $65 \%$ & $82 \%$ \\
\hline $\begin{array}{l}\text { - Single person } \\
100 \% \text { APW }\end{array}$ & $61 \%$ & $60 \%$ & $66 \%$ & $77 \%$ \\
\hline $\begin{array}{l}\text { - Single person } \\
150 \% \text { APW }\end{array}$ & $47 \%$ & $48 \%$ & $53 \%$ & $55 \%$ \\
\hline $\begin{array}{l}\text { - Two-earner mar- } \\
\text { ried couple with } 2 \\
\text { children, or lone } \\
\text { parent with } 2 \text { chil- } \\
\text { dren } 100 \% \text { APW } \\
\end{array}$ & $76-77 \%$ & $79-80 \%$ & $83 \%$ & $88 \%$ \\
\hline $\begin{array}{l}\text { Maximum duration } \\
\text { of wage-related UB }\end{array}$ & 48 months & 24 months & 24 months & $\begin{array}{l}28 \text { months }(14+ \\
14 \text { months) }\end{array}$ \\
\hline $\begin{array}{l}\text { Conditions for } \\
\text { receiving wage- } \\
\text { related UB }\end{array}$ & $\begin{array}{l}12 \text { months' } \\
\text { employment } \\
\text { during preced- } \\
\text { ing } 36 \text { months, } \\
\text { membership } \\
\text { in a fund for at } \\
\text { least } 12 \\
\text { months }\end{array}$ & $\begin{array}{l}\text { 8-10 months' } \\
\text { employment } \\
\text { during preced- } \\
\text { ing } 24 \text { months, } \\
\text { membership } \\
\text { in a fund } \\
\text { during said } \\
\text { employment }\end{array}$ & $\begin{array}{l}\text { An income of at least } \\
105,384 \text { NOK the last } \\
\text { completed calendar } \\
\text { year, or at least } \\
210,768 \text { NOK during } \\
\text { the last three calendar } \\
\text { years. } \\
\text { Working hours must be } \\
\text { reduced by at least } \\
50 \% .(2008) \text {. }\end{array}$ & $\begin{array}{l}70 \text { hours' em- } \\
\text { ployment per } \\
\text { month for at least } \\
6 \text { calendar months } \\
\text { during the last } 12 \\
\text { months. } 12 \\
\text { months' continu- } \\
\text { ous membership } \\
\text { in a Ul fund. }\end{array}$ \\
\hline $\begin{array}{l}\text { Main alternative } \\
\text { benefit if one does } \\
\text { not qualify for wage- } \\
\text { related UB coverage } \\
\text { (Percent of unem- } \\
\text { ployed) }\end{array}$ & $\begin{array}{l}\text { Cash benefits, } \\
\text { depending on } \\
\text { age and family } \\
\text { situation } \\
\text { ( } 21 \% \text { of } \\
\text { unemployed in } \\
2007)\end{array}$ & $\begin{array}{l}\text { Labour market } \\
\text { support, 50\% } \\
\text { of the unem- } \\
\text { ployed in } \\
2003 . \\
\text { Additional } \\
\text { social assis- } \\
\text { tance com- } \\
\text { monly } \\
\text { needed. }\end{array}$ & $\begin{array}{l}\text { General financial social } \\
\text { benefit (sosialhjelp). } \\
\text { Participants in labour } \\
\text { market measures will } \\
\text { get a basic grant (if they } \\
\text { do not qualify for } \\
\text { unemployment or } \\
\text { receive other state } \\
\text { benefits) }\end{array}$ & $\begin{array}{l}\text { Basic UB, } \\
\text { In } 2004 \\
\text { ca } 9 \% \text { of unem- } \\
\text { ployed } \\
\text { If not qualifying for } \\
\text { Basic UB, then } \\
\text { social benefits }\end{array}$ \\
\hline $\begin{array}{l}\text { Conditions for } \\
\text { receiving main } \\
\text { alternative benefit }\end{array}$ & $\begin{array}{l}\text { The benefit is } \\
\text { means-tested. } \\
\text { The recipient } \\
\text { must be } \\
\text { actively } \\
\text { looking for } \\
\text { work if he/she } \\
\text { is considered } \\
\text { employable by } \\
\text { the social } \\
\text { authorities. }\end{array}$ & $\begin{array}{l}\text { Registered } \\
\text { job-seeker } \\
\text { available for } \\
\text { work. If under } \\
25 \text { years old, } \\
\text { special } \\
\text { requirements } \\
\text { (see text). }\end{array}$ & $\begin{array}{l}\text { Financial social benefit } \\
\text { is means-tested. }\end{array}$ & $\begin{array}{l}70 \text { hours' em- } \\
\text { ployment per } \\
\text { month for at least } \\
6 \text { calendar months } \\
\text { during the last } 12 \\
\text { months. } \\
\text { Social benefits are } \\
\text { means-tested }\end{array}$ \\
\hline $\begin{array}{l}\text { Amount of alterna- } \\
\text { tive benefit in EUR } \\
\text { for a single person } \\
\text { per month }\end{array}$ & $\begin{array}{r}1278 \text { Euro per } \\
\text { month (tax- } \\
\text { able) }\end{array}$ & $530 €$ & $\begin{array}{l}\text { None, but meant to be } \\
\text { short-term. }\end{array}$ & $\begin{array}{l}\text { For Basic UB ca. } \\
700 €\end{array}$ \\
\hline $\begin{array}{l}\text { Possible maximum } \\
\text { duration of alterna- } \\
\text { tive benefit }\end{array}$ & None & None & None & $\begin{array}{l}\text { For Basic UB } 28 \\
(14+14) \text { months }\end{array}$ \\
\hline
\end{tabular}

Source: OECD benefits and wages. Figures are for 2004. Quoted $21^{\text {st }}$ Oct 2008 at http://www.oecd.org/dataoecd/25/28/ 34008439.xls.

Sources for coverage calculations: Denmark: Databanks of Statistics Denmark (www.statistikbank.dk, table AUL01); Finland: statistics of the Ministry of Employment and the Economy. Shares of benefit types are annual averages for 2003 Norway: NAV Arbeid og velferd Nr. 2-2007; Sweden: IAF/Arbetsförmedlingen 2009. 


\section{Active labour market policies}

\section{Denmark}

As mentioned above, an important feature of the present system of labour market policy is its two-tier nature, which follows the dividing lines in the unemployment insurance system. At the individual level, the dividing line is therefore between those unemployed who are members of an unemployment insurance fund and those who are not and therefore are eligible for means-tested social welfare.

As shown in Figure 1, active programmes cover about 70,000 fulltime persons per year, which can be compared to a workforce of about 2.9 million persons. This figure does not include participants in the socalled flexi-jobs, which are jobs with a permanent wage subsidy for persons with lastingly reduced work-capacity. Their number has been rapidly rising and in 2007 amounted to 44,000 persons.

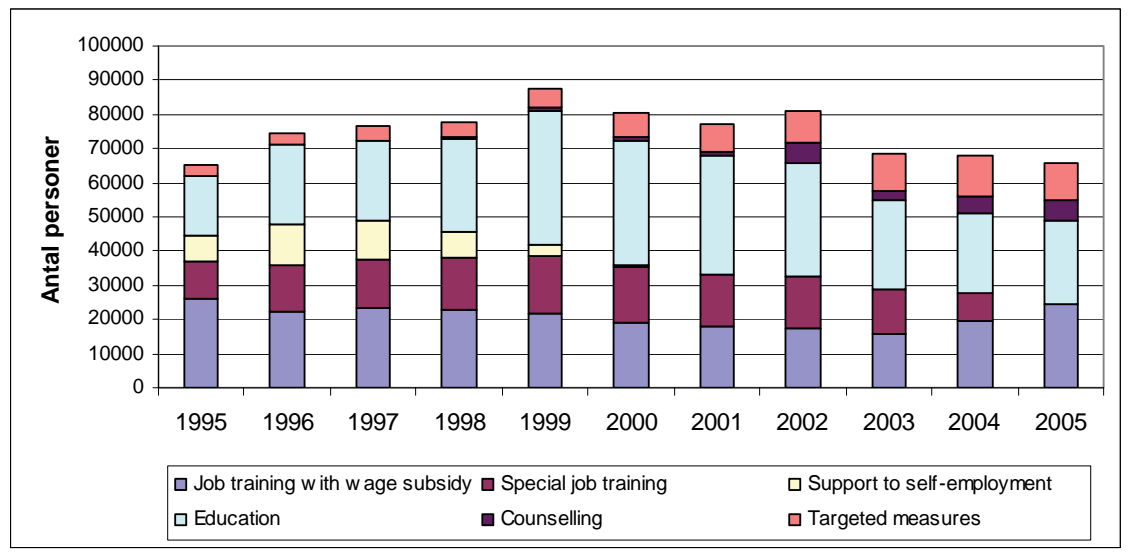

Figure 1: Number of participants (full-time equivalents) in active labour market policy measures, 1995-2005.

Source: Databanks of Statistics Denmark.

The figure has information about the main programmes of Danish ALMP:

- Job training with a wage subsidy implies that the unemployed is paid a normal wage from a public or private employer for a limited time period (up to one year).

- Special job training is for weaker groups of unemployed and will typically take place in special projects in the public sector.

- Support to self-employment (a three year subsidy equal to $50 \%$ of benefits) was phased out from 1998. The programme is now closed.

- Education covers a wide range of education and labour market training with duration up to one year.

- Counselling includes job search activities etc. 
- Targeted measures are programmes targeted at special groups like immigrants or older workers.

To keep up unemployment benefits or cash benefits for the unemployed, participation in ALMP is mandatory. The regime differs somewhat for insured and non-insured unemployed people.

\section{An insured unemployed}

When an insured individual (a member of an unemployment insurance fund) becomes unemployed, he or she must from the first day of unemployment register either at the local job centre or at the local office of the unemployment insurance fund. This can be done via the Internet, if so wished.

Within the first month of unemployment, the unemployed must make a CV describing his/her qualifications, work experience and the field of work that he/she is interested in. This CV is entered into a nationwide "job-bank" on the Internet (operated by the National Labour Market Authority). The unemployed person can get assistance in filling out the CV from the job centre or the unemployment insurance fund.

The unemployed must every week enter the "job-bank" and confirm that he/she is still actively looking for work. This is done via the Internet.

After one month of unemployment, the unemployed has to have an interview at the unemployment insurance fund, where the CV is discussed along with the possible employment options for the unemployed person, who will be given advice with respect to job search and maybe also get information about specific jobs that are available. The unemployed is informed that he/she must apply for at least four jobs per week in order to be "on the safe side", when it comes to be considered as an active jobseeker, which is again a condition for keeping the right to unemployment benefits.

After the first interview, the unemployed person will have to have interviews with both the unemployment insurance fund and the job centre (or one of its partners) every three months. The focus of the interview with the unemployment insurance fund will be to test the availability for work of the unemployed, while the interview with the job centre is more focused on the employment options of the unemployed person. In practice there may be some overlap in the focus of the two interviews due to the fact that the unemployment insurance funds also to an increasing degree are giving guidance with respect to job search.

After nine months of unemployment, the unemployed person is considered a "long-term" unemployed and will therefore be subject to mandatory activation. ${ }^{29}$ The content hereof is decided by the job centre after

\footnotetext{
${ }^{29}$ For persons aged less than 30 years or between 60 and 64 years, the job-plan and mandatory activation starts after 6 months of unemployment (cf. below).
} 
an interview with the unemployed person. The activation to be undertaken is described in a so-called job-plan, which is signed by the job centre and the unemployed person. The active measures will have the form of job training, employment with a temporary wage subsidy, further guidance or upgrading of skills (cf. the above overview of active measures).

The mandatory activation continues until the unemployed person gets a job or loses the entitlement to unemployment insurance benefits after four years of unemployment. Hereafter he/she can apply for means-tested cash benefits (social assistance) and will be subject to the regime of a non-insured unemployed as described below.

\section{A non-insured unemployed}

A non-insured person who wants to apply for cash benefits due to unemployment must report in person to the local job centre for an interview. Here it will be decided whether the individual has a potential for getting into employment, and whether the person is eligible for benefits (the means-testing). ${ }^{30}$ If the person is considered eligible for cash benefits as an unemployed, he/she will have to fill in a CV for the job-bank along the same lines as an insured unemployed (that is, after one month). The CV will have to be checked regularly by the unemployed in order to prove the availability for work.

For a non-insured unemployed there will also be regular interviews with the job centre; the first interview takes place after one month of unemployment. The exact interval between the interviews is however not formally stipulated.

For the non-insured unemployed there is furthermore a right and duty to take part in active measures, although the rules differ somewhat from those for the insured unemployed, leaving some freedom for the local initiative of the municipalities. For example, some municipalities practise what is labelled "instant activation" for some groups (e.g. young unemployed) and thus enrol them in a mandatory programme from their very first day of unemployment. However, in general, the timing of the mandatory offers is similar to those for the insured unemployed. Thus a person aged 30 years or more is obliged to take part in active programmes after 9 months of unemployment. Thereafter the person is obliged to take part in an active programme every 6 months.

If a person is absent from activation or refuses to take a job, cash benefits are reduced by one third and - in the event of recurrent refusals may be cancelled altogether.

\footnotetext{
${ }^{30}$ If the person is not assessed as being employable, he/she may still be eligible for cash benefits and may also take part in various activities to improve the chances of getting a job. However, the person is not registered as unemployed per se.
} 


\section{Finland}

In Finland, active labour market policies have for long been an essential part of policies aiming at increasing employment and reducing unemployment. The goals and practices of ALMP were reshaped and specified with "comprehensive reform of the labour market policy" in 1998 (Aho \& Arnkil 2008). The most important aims of the reform were "to improve the functioning of the labour market" and to intensify "activation" of the unemployed (Räisänen \& Skog 1997). The reform was partially inspired by similar kinds of pursuits in Denmark and e.g. the UK. The "rights and duties" of the unemployed were clarified; the duties include active search for employment and obligation to co-operate in increasing one's employability. "Individual action plans" to be made by the job-seekers and PES case workers together, as well as job-seeking guidance measures (jobseeking courses and "job clubs"), were extensively introduced and became essential parts of policy ever since. However, there are no formal rules about how intensively job-seekers should search for a job. Also, the practices concerning how often they have to confirm their availability to work and be interviewed by PES officer vary a lot locally.

In Finland, activation of those under age 25 without secondary education is sanctioned in a unique way. They are not qualified for unemployment benefits (LMS) if they do not apply for or if they interrupt secondary education. However, they can still get benefits while participating in ALMP measures (or if they have fulfilled the employment condition for UI). This has facilitated participation in secondary education and in ALMP, but also created a problem: some students are not actually motivated for the education they participate in (Aho \& Vehviläinen 1997).

An individual job-seeking plan should be made before unemployment has lasted five months (for those under 25, before three months) and to be revised if unemployment continues. The plan has the character of a contract between the job-seeker and PES, and it should be signed by both parties. Failure to fulfil actions included in the plan can lead to sanctions. The plan identifies the immediate goals and steps to be taken in order to find employment or to increase employability in the long run. The plan should be the basis for participation in activation measures. However, actual participation is often not mentioned in the plan, and conversely not all planned participations actually take place (Aho \& al. 2006). Special procedures are applied for e.g. able-to-work social assistance receivers (“activation plans") and immigrants ("integration plans”).

A rather recent evaluation shows that only about half of the plans are drawn up or revised inside the time-limit given as the goal, seemingly due mainly to insufficient resources. For a person that becomes unemployed for the first time, the plan is usually made soon, but if unemployment continues or is repeated, the revision of the plan is often delayed or does not take place at all. About half of the goals of the plans are achieved during the following twelve months (although unemployment may con- 
tinue, implying the setting of a further goal). The plans are not considered as important (or not even recognised) by a majority of the job-seekers. However, if made properly, the plans seem to be helpful for at least a part of the job-seekers. The plans also make the service process more transparent and support it (Aho et al. 2006).

Participation in ALMP has in general not been obligatory, and a great majority of participants have participated willingly (Aho \& al. 2005). In principle, the unemployed who need it have a right to participate, but actual possibility to participate depends on availability of measures, i.e. on resources allocated for them in the annual state budget. Long-term unemployed are in principle obliged to participate, when this is considered beneficial for improvement of their employability. Sanctions are possible in case of refusal; no published information is available on how often such sanctions are actually implemented, but obviously not very often. In 2006, participation in ALMP was made in principle obligatory for long-term unemployed LMS-receivers (although dependent on availability of measures). There is no proper information on how often sanctions based on denial or failure to participate in activation are actually implemented in relative terms, but several thousands of sanctions are implemented annually.

The general activation rate in Finland during the period we study was $20-22 \%$ and has not varied much according to the type of the received unemployment benefit or the length of unemployment (Aho 2005). If unemployment continues or is repeated, almost all participate in the long run (with the exception of the elderly with extended right to UI benefit). Repetitive participation is very common. There are no formal rules concerning when participation should take place. Many participate quite early, but also many only after long or repeated unemployment spells. Of those who became unemployed for the first time in 2001, about $29 \%$ had started a measure within six months, 36\% within 12 months and $60 \%$ within three years, if unemployment continued or was repeated. On average, participation is repeated after 1.5 years after the previous participation, but individual variation is large here. Often ALMP measures form "paths" of two or more combined measures (e.g. training followed by subsidised employment) (Aho \& Koponen 2008).

In spite of the clear emphasis on improving the employability of the participants, ALMP in Finland also has other goals. One of them is to prevent "social exclusion", which is also mentioned as a goal of ALMP in the European Employment Strategy. Subsided employment in municipalities and in the "third sector" seem often to serve also social-political goals. This seems to be especially true in the case of "combined subsidy" which was introduced in 1998 and is nowadays called "additional wage subsidy for the least employable”. This subsidy is initially higher and can be paid in a reduced amount for a much longer time than "normal" subsidies, and the official goal is "to prevent exclusion from the labour mar- 
ket”. The share of the receivers of this subsidy has during recent years been about $45 \%$ of all subsidised employment. (Työllisyyskertomus vuodelta 2007, 74-76.)

A great share of all ALMP in Finland is training. Most of it is vocational, and often leads to generally acknowledged formal qualifications. Also a great deal of training has the character of guidance or coaching, aiming at identifying proper additional means to increase employability. Also special courses on EDB-skills, languages etc. are provided. Training can also be tailored according to the needs of employers who are going to recruit new workforce (then the employer pays part of the cost). The duration of training is typically several months, but can also be only some weeks or even a couple of days, and in some rare cases training can last even $2-3$ years.

Another widely used measure is trainee work or coaching for working life. This takes place in ordinary work places, mainly without a work contract - the participant receives no wage but somewhat increased unemployment benefits (labour market support). This measure is typically provided for the young and lasts three months (it can be repeated).

Wage subsidies for private sector employers and to a lesser degree municipalities, as well as job creation in state service, are also used. In these cases the participant receives a normal contractual wage.These subsidies last usually six months. "Combined subsidy", already mentioned above, is also a wage subsidy, but its duration is usually one year, and can be extended with decreased subsidy up to two years. The employer is usually a "third sector" actor and working hours are less than full-time.

Job sharing, job rotation and start-up grants for starting entrepreneurs also belong to the repertoire of ALMP.

While unemployment decreased quite slowly also after the reform of 1998, the reduction of "structural unemployment" was raised to the forefront of policies. Since then, the aim of the reforms has been to differentiate the services, in order to make them more effective. An important step was taken with the introduction of experimental "Joint Service Centres" in 2002. These centres provided "single gateway" multi-professional services for long-term unemployed and combined the efforts and expertise of PES, municipal social agencies and the Social Insurance Institution (state agency for administration of universal social benefits including LMS and, for example, various rehabilitation measures and benefits). Health and rehabilitation services, training providers and organisations of the "third sector" were also involved in the provision of services and activation measures (Arnkil et al. 2004).

This experiment was followed in 2005 by establishment of regular "Labour Force Service Centres" (LAFOS) with a very similar profile as "Joint Service Centres". This reform is a part of a general differentiation of PES services between "ordinary" and "targeted" services, aiming at developing both of them. LAFOS are established only in densely popu- 
lated areas of the country. During the period of our study, there were 127 local PES offices and from 2005 onwards 39 LAFOS centres (many of them are regional, i.e. operating in an area of several PES offices).

LAFOS centres do not automatically serve all job-seekers with employability problems - customers are assigned to LAFOS by the local PES or municipal social agency on the basis of need evaluation. LAFOS centres are able to serve only a part of those who seem to be in need of this kind of service, and the service process is typically quite long (a couple of years or longer). The aim is that LAFOS should cover about $10 \%$ of unemployed job-seekers in the future, but the share of those with severe employability problems is much higher. This has led to selection problems and long waiting times before access to LAFOS (Arnkil et al. 2008).

\section{Norway}

Until the 1990s changes in welfare politics in Norway were focused on limiting the growth in public expenses through moderate cuts in public welfare benefits. Since the 1990s, the connection between labour market politics and welfare/social politics has also been more prominent (see Fløtten et al. 2007 for an account of the development in politics as well as welfare system reforms). The public policy changes in Norway over the last ten to fifteen years is in many ways a part of an international trend connected with "workfare" policies, even though one has not lowered the level of welfare benefits in order to make the economic incentives work better. Instead the policy has been to introduce measures of activation in order to avoid long-term or permanent inactivity among persons on the borderline of the labour market. A number of step-wise reforms have been introduced to make the working life more "inclusive", among others by encouraging employers to adjust the working place/the job for employees with health problems (among others through the so-called Inclusive Working Life Agreement and new measures introduced under this scheme). Further reforms are in the pipeline or have been implemented after 2006/2007, mainly aimed at groups with long-term/substantial problems in the labour market because they either are in danger of leaving the labour market or have not been able to get employment (temporary disabled, long-term social benefit, occupationally handicapped persons etc.).

The Norwegian employment services have been under reorganization over the last decade, with the establishment of NAV in July 2006 as a milestone. During the period 2000-2006 Aetat was the public employment service. Aetat/NAV is in charge of the public employment service for job-seekers and employers as well as for different labour market measures for ordinary job-seekers in need of such assistance and measures for the occupationally handicapped ("yrkeshemmede"). The last group of job-seekers are "persons who have had their ability to execute income yielding work reduced, or have had their possibilities to choose 
profession or place of work significantly reduced. The reason for this may be illness, injury or defect, or social maladjustments" (Forskrift om arbeidsmarkedstiltak) ${ }^{31}$. Aetat/NAV is also responsible for the administration of the state finances' unemployment benefit, rehabilitation benefit and other benefits for job-seekers.

Over the period (2000-2007) the Norwegian employment service (Aetat, later NAV) reallocated more of its resources to the groups of unemployed persons most in need of assistance or training in order to enter the labour market, i.e. a stronger prioritisation within the group of unemployed (NOU 2004: 13 En ny arbeids- og velferdsforvaltning, chapter 3.3). Unemployed persons who most probably would find new employment through active job-seeking were encouraged in job-seeking activities through job clubs and counselling, but would normally not be offered any labour-marked measures. After about 6 months of unemployment some type of training (or other measures) will be considered also for this group. In addition, the traditional division between measures for occupationally handicapped job-seekers and ordinary unemployed persons was toned down, among others through the introduction of a common statute covering measures for both groups in 2002 (Forskrift om arbeidsmarkedstiltak). Over time the number of occupationally handicapped job-seekers has increased, among others because of the government's ambition to reduce the number of persons on permanent disability benefits.

\section{Organisation}

In the period 2000-2006 Aetat was reorganised from a 3-level to a 2level organisational structure (the county level units were removed), and in 2004 Aetat consisted of the central level Aetat Arbeidsdirektoratet and 164 Aetat service offices around the country (NOU 2004: 13 En ny arbeids- og velferdsforvaltning). In 2006 NAV (the Norwegian Labour and Welfare Service) was established, which is the merger of Aetat and the state-run National Insurance Service (Trygdeetaten).

\section{Labour market measures}

Aetat (as well as NAV today) had several measures intended to give different persons and groups of persons labour-marked training and occupational rehabilitation. Some of the measures can be used both for ordinary job-seekers with problems finding a job and for people classified as occupationally handicapped ("yrkeshemmede"). Other measures are restricted to the last group. The detailed design of the measures will vary over time, and the funds allocated to labour market measures will vary

\footnotetext{
${ }^{31}$ Definition in English from Directorate for Education, Education Policy Committee, Group of National Experts on Special Needs Education, Country Report for Norway. Pathways for disabled students to tertiary education and employment.
} 
with the situation at the labour market. Job-clubs, counselling and other initiatives to encourage job-seeking are not listed here.

- Wage subsidies (“tidsbegrenset lønnstilskudd”) are given a timelimited wage contribution to secure a lasting work relationship (they can be used up till 12 months). The measure is intended to help marginalised groups of job-seekers to be employed on normal wage and work conditions, and both private and public enterprises can get such subsidies.

- Work practice (“arbeidspraksis”) is adjusted work training with active follow-up from Aetat/NAV. Work practice can take place in ordinary enterprises as well as in labour market enterprises, and the measure can be used both for ordinary job-seekers and the occupationally disabled.

- Labour market training (AMO, arbeidsmarkedsopplæring): A measure which qualifies ordinary job-seekers and vocationally handicapped for available jobs.

- Temporary employment measures (“Midlertidig sysselsetting”, among others "vikarplass") give work experience to persons who are in danger of being permanently excluded from the labour market.

- Assisted work (“arbeid med bistand”) provides assistance in order to secure the integration of vocationally handicapped persons within the labour market. It involves help in getting suitable employment and adapted working conditions, and training in work-related and social skills. The person will be working within an enterprise and the arrangement can last for a maximum of 3 years.

- Measures in Labour Market Enterprises ("arbeidsmarkedsbedriftene") offers temporary measures, among others clarifying work abilities, work training and qualifying. The labour-marked enterprises are reserved for the occupationally disabled, and the goal is to give training and support to enable these persons to transfer to ordinary jobs or to the educational system.

- Lasting adjusted work within the Labour Cooperation Enterprises (“arbeidssamvirkebedriftene/vekstbedriftene”), for those who are not expected to be able to transfer to ordinary work (persons on disability pensions). Sheltered employment (as provided by the Labour cooperation enterprises) may also take place in ordinary enterprises (but this is not common).

There are not many measures connected with job creation.

Of these measures the majority of participants (ordinary unemployed) participated in training (AMO) and work practice measures (20002006/7). Wage subsidies were also used, although less common than training and work practice. Among the occupationally handicapped, the 
great majority of participants take part in work practice measures and training.

\section{Recruitment into ALMP}

The government prioritizes some groups in ALMP. Among these groups are persons with reduced working capacity, long-term unemployed, young unemployed, long-term social benefits receivers and immigrants. The prioritization principles are set in the annual state budgets, which also allocate funds for labour market measures, and also earmark funding for measures for the occupationally handicapped. NAV will base their policy on the prioritization criteria given by the Government, and seek to prioritise persons who need new qualifications or support/training in order to find employment. Participation in the labour market measures is not an individual right. Aetat/ NAV will make an individual assessment of whether or not a person needs to participate in some type of labour market measure to get employment. Job-seekers on unemployment benefits are obliged to participate in different activation programmes if requested to do so by the authorities.

Over the period 2000-2006 the number of participants on ordinary labour market measures (annual average, measures for the occupationally handicapped not included) varied between 9300 and 17000. Over the same period the number of unemployed persons (ordinary job-seekers, annual average) varied from 62500 till 92600 persons. The number of occupationally handicapped persons (annual average) increased from 57000 in 2000 to 93000 in 2005. The majority of these were in some type of labour market measure (2/3 in 2006), mainly work practice and training and also lasting adjusted work ("varig tilrettelagt arbeid") and assisted work.

\section{Sweden $^{32}$}

The employment offices are central for the organisation of active labour market measures in Sweden. Before 2008 they were organised on a local, regional and national level. The name of the national organisations was AMS (Arbetsmarknadsstyrelsen). In 2008 there was a reorganisation with the replacement of AMS by the National Employment Office (Arbetsförmedlingen). The new organisation is divided in four larger regions (North, South, West and East) and 68 labour market areas with local employment offices. These areas are defined by natural local labour markets.

The purpose of the employment office is to facilitate the matching between job-seekers and employers. Until 2007, the employers were obliged by law to report vacancies to the employment office. This law was repealed in 2007 and it is now done on a voluntary basis. Vacancies

\footnotetext{
${ }^{32}$ Furåker \& Blomsterberg 2009; Sibbmark 2007.
} 
are published in journals (Platsjournalen) and in databases (Platsbanken). The qualifications and competences of the unemployed are also scanned and offered for the employers in a database (Mitt CV). Furthermore, the employment officials try to actively match job-seekers and employers. They can request job-seekers to search for specific jobs. If the job-seeker ignores the request, the consequence may be a reduction in the unemployment benefit. However, until 2007 the unemployed had the right during the first 100 days to deny a request that involved a job in a geographically distant location. Since 2007 this right has been abolished.

An unemployed person with unemployment insurance is obliged to register at the employment office in order to have the right to unemployment benefits. Furthermore, he/she has to be actively searching for a new job, which is checked up on by the employment office.

A newly registered job-seeker at the employment office should be appointed a meeting with an employment official to screen the job-seeker's qualifications, needs and wants on the labour market. An individual action plan describing activities to find a job has to be settled before 3 months after registration (earlier for people under 25 years). The plan specifies activities to improve the job-seeker's employability.

There are many different measures that the employment office may request for the job-seeker. It is obligatory to participate in the measures, or there may be a reduction in the unemployment benefit.

One type of measures, Activities within Councelling Guidance $(27,500),{ }^{33}$ aims at the unemployed who risk long-term unemployment (no employment during the last 2 years) with the purpose of activating the unemployed in their job-search efforts, for example through organized job-seeking meetings. In 2007 this measure was replaced by the Job and Development Guarantee.

One central type of measures is labour market training. The main measures used are Vocational Training $(9,300)$, Work Experience $(11,613)$ and Preparatory Training Courses $(13,267)$. The latter measure gives orientation to the labour market and the Swedish society for immigrants and other groups that have been outside the labour market for a long time.

Other measures are different kinds of subsidies for employment. Recruitment Incentives can be given to employers that employ long-term unemployed people. The main recruitment incentives used during 20002006 are General $(5,505)$, Extended $(10,795)$ and Special $(10,301)$. General Recruitment Incentives were aimed at those unemployed that had been registered as job-seekers for 12 months, and gave the employer a subsidy of $50 \%$ of the salary for 6 months. Extended and Special Recruitment Incentives targeted the unemployed who had been registered job-seekers for 24 months, and gave 75 and $85 \%$ of the salary as a subsidy during 18 months. These subsidies were abolished in 2007. Only

\footnotetext{
${ }^{33}$ Number of participants in January 2006 (Sibbmark 2007).
} 
Special Recruitment Incentives remain (with a reduction in the length of the subsidy to 12 months). However, the new government introduced two new types of subsidies: Step-in jobs (Instegsjobb) which give the employer a subsidy of $75 \%$ of the salary (for 6 months at a time up to 24 months) when employing a newly arrived immigrant, and New Start jobs (Nystartsjobb) which subsidises the employer through no payroll tax when employing a long-time unemployed person.

Another subsidy during the period and still applied is Start-up Grants $(4,867)$ for the unemployed who start a business. For a short time period (2005-2006) it was also possible to make a Career Break $(11,750)$, i.e. to take 1 year off from the job with the income from the unemployment benefit. The employed person taking a career break was to be replaced by a registered unemployed person.

In the arsenal of active labour market measures there are some that have been specially aimed at young unemployed people. The municipalities have been responsible for creating full-time activities for youths under age 20 in so-called Municipal Youth Programmes (5,935). For youths aged 20-24 years that have been unemployed for 90 days or more, a similar measure called Youth Guarantee $(7,549)$ was offered. These programmes were replaced in 2007 by the Job Guarantee for Youth for young people 16-24 years old who have been unemployed at least 3 months.

An important part of the active labour market policies are measures to support persons with functional disorders. There are many different measures that are used, for example wage subsidies and sheltered public employment. A total of 63,449 persons participated in these kinds of measures. 
Table 3. Overview of ALMP systems.

\begin{tabular}{|c|c|c|c|c|}
\hline & Denmark & Finland & Norway & Sweden \\
\hline $\begin{array}{l}\text { Public em- } \\
\text { ployment } \\
\text { services and } \\
\text { administra- } \\
\text { tion: Organi- } \\
\text { sation of the } \\
\text { public em- } \\
\text { ployment } \\
\text { services and } \\
\text { general } \\
\text { measures }\end{array}$ & $\begin{array}{l}\text { The PES is } \\
\text { organised in } \\
\text { local jobcentres } \\
\text { in the munici- } \\
\text { palities. Re- } \\
\text { gional and } \\
\text { national authori- } \\
\text { ties have a } \\
\text { supervisory role. }\end{array}$ & $\begin{array}{l}\text { PES as regionalised } \\
\text { state authority is } \\
\text { mainly responsible } \\
\text { for ALMP. } \\
2005 \text { LAFOS centres } \\
\text { for least employable } \\
\text { as joint office of PES, } \\
\text { municipali-ties and } \\
\text { other actors. } \\
\text { In } 2006 \text {, the respon- } \\
\text { sibility of municipali- } \\
\text { ties increased for } \\
\text { activation of long- } \\
\text { term unemployed. }\end{array}$ & $\begin{array}{l}\text { Until 2006, Aetat, } \\
\text { public employment } \\
\text { service office in } 164 \\
\text { municipalities (of ca. } \\
450 \text { ), i.e. some } \\
\text { offices cover more } \\
\text { than one municipal- } \\
\text { ity. } \\
\text { After 2006, gradual } \\
\text { introduction of one } \\
\text { office (NAV) which } \\
\text { administers unem- } \\
\text { ployment benefits, } \\
\text { social benefits and } \\
\text { pensions. }\end{array}$ & $\begin{array}{l}\text { The PES was } \\
\text { organised on } \\
\text { a local, } \\
\text { regional and } \\
\text { national level. } \\
\text { In } 2008 \text { a new } \\
\text { organisation } \\
\text { was estab- } \\
\text { lished. }\end{array}$ \\
\hline $\begin{array}{l}\text { Labour } \\
\text { market } \\
\text { training } \\
\text { measures }\end{array}$ & $\begin{array}{l}\text { 1. Counselling. } \\
\text { 2. Many forms of } \\
\text { education and } \\
\text { training lasting } \\
\text { up to one year. } \\
\text { 3. Special } \\
\text { programmes for } \\
\text { "weaker groups" }\end{array}$ & $\begin{array}{l}\text { 1. Job-seeking } \\
\text { guidance. } 2 \text {. Prepara- } \\
\text { tory courses aiming } \\
\text { at finding ways to } \\
\text { increase employabil- } \\
\text { ity. 3. Courses on } \\
\text { specific skills (lan- } \\
\text { guages, EDB, etc.). } \\
\text { 4. Occupational } \\
\text { training and educa- } \\
\text { tion. } 5 \text {. Recruitment } \\
\text { training or skill raising } \\
\text { in cooperation with } \\
\text { employers }\end{array}$ & $\begin{array}{l}\text { 1) Clarification. 2) } \\
\text { Work practice. } \\
\text { 3) Training. } \\
\text { 4) Work with assis- } \\
\text { tance. } \\
\text { 5) Labour-marked } \\
\text { enterprises. }\end{array}$ & $\begin{array}{l}\text { Counselling, } \\
\text { Vocational } \\
\text { Training, } \\
\text { Work Experi- } \\
\text { ence, } \\
\text { Preparatory } \\
\text { Training } \\
\text { Courses }\end{array}$ \\
\hline $\begin{array}{l}\text { Subsidised } \\
\text { employment } \\
\text { and rehabili- } \\
\text { tation }\end{array}$ & $\begin{array}{l}\text { Job training with } \\
\text { a wage subsidy } \\
\text { in the public or } \\
\text { private sector }\end{array}$ & $\begin{array}{l}\text { 1. Wage subsidies for } \\
\text { private and public } \\
\text { employers, incl. third } \\
\text { sector actors special- } \\
\text { ised in least employ- } \\
\text { able; } 2 \text {. trainee work / } \\
\text { coaching for working } \\
\text { life; } 3 . \text { apprenticeship } \\
\text { subsidies; } 4 \text {. start-up } \\
\text { grants for entrepre- } \\
\text { neurship; } 5 \text {. job- } \\
\text { sharing measures; } 6 \text {. } \\
\text { rehabilitative work } \\
\text { activity for least } \\
\text { employable }\end{array}$ & $\begin{array}{l}\text { 1) Wage contribu- } \\
\text { tion. } \\
\text { 2) Work with assis- } \\
\text { tance. } \\
\text { 3) Labour coopera- } \\
\text { tion enterprises }\end{array}$ & $\begin{array}{l}\text { Recruitment } \\
\text { Incentives for } \\
\text { long-term } \\
\text { unemployed. } \\
\text { Wage subsi- } \\
\text { dies for } \\
\text { persons with } \\
\text { functional } \\
\text { disorders. } \\
\text { Start-up } \\
\text { grants for } \\
\text { business } \\
\text { enterprises. }\end{array}$ \\
\hline $\begin{array}{l}\text { Job creation } \\
\text { measures }\end{array}$ & Rarely used. & $\begin{array}{l}\text { Subsidies for em- } \\
\text { ployment in social } \\
\text { enterprises for dis- } \\
\text { abled and long-term } \\
\text { unemployed (not } \\
\text { widely used) }\end{array}$ & $\begin{array}{l}\text { 1) Temporary } \\
\text { employment meas- } \\
\text { ures }\end{array}$ & $\begin{array}{l}\text { Sheltered } \\
\text { public em- } \\
\text { ployment for } \\
\text { persons with } \\
\text { functional } \\
\text { disorders }\end{array}$ \\
\hline $\begin{array}{l}\text { Participation } \\
\text { in ALMP } \\
\text { obligatory? }\end{array}$ & $\begin{array}{l}\text { Yes. Legislation } \\
\text { has deadlines } \\
\text { for different } \\
\text { groups of } \\
\text { unemployed. } \\
\text { Main deadline is } \\
\text { after } 9 \text { months } \\
\text { of unemploy- } \\
\text { ment. }\end{array}$ & $\begin{array}{l}\text { In principle yes, if } \\
\text { considered so by the } \\
\text { PES. Sanctions } \\
\text { seldom applied. } \\
\text { Since } 2006 \text { obligatory } \\
\text { activation for long- } \\
\text { term unemployed } \\
\text { LMS-receivers, } \\
\text { selective targeting } \\
\text { depending on re- } \\
\text { sources }\end{array}$ & $\begin{array}{l}\text { Everyone is obliged } \\
\text { to participate in } \\
\text { different activation } \\
\text { programmes if so } \\
\text { requested by } \\
\text { Aetat/NAV (i.e. an } \\
\text { obligation to job- } \\
\text { seeking activites). } \\
\text { No formal criteria } \\
\text { involved }\end{array}$ & $\begin{array}{l}\text { Yes, if re- } \\
\text { quested by } \\
\text { the official. } \\
\text { Otherwise } \\
\text { possible } \\
\text { reductions in } \\
\text { unemploy- } \\
\text { ment benefits. }\end{array}$ \\
\hline
\end{tabular}




\section{Life-long learning}

\section{Denmark}

In Denmark, life-long learning (LLL) can be divided into public LLL, which is an integrated part of the public educational system, and private LLL, which is provided by private commercial training companies, private organisations, trade unions, employers' organisations etc.

In 2005 about 1,156,000 persons took part in LLL, whereof 883,000 persons (including 751,500 aged 25+) in public LLL and 273,000 persons in LLL provided by private companies and organisations (including trade unions and employers' organisations). These figures can be compared to a total workforce in 2005 of 2,845,000 persons. Thus, the number of participants was equal to about $40 \%$ of the total workforce. Furthermore, one should mention that an important part of LLL takes place as training provided directly in the workplace. It is estimated that more than $60 \%$ of the workforce (employed and unemployed) in 2004 took part in some form of LLL, including in-house training in the workplace. Measured in full-time training, public LLL had 45,900 participants in 2005. Of those, 34,200 persons were older than 24 years. On average, a person thus takes part in training activities that last a little more than two weeks. For 2004 the number of full-time participants in private LLL has been estimated at between 33,100 and 43,600, while the number of full-time participants in in-house training activities is estimated to be between 33,100 and 41,300.

An important part of LLL has the form of labour market training and education ("AMU" in Danish). In 2005 the total number of participants in AMU was 560,900 persons, or 9,900 persons when measured on a fulltime basis. AMU thus accounts for about two-thirds of the adult participants aged 25 and above taking part in public LLL, but only for one quarter of the full-time participants, thus indicating that this form of training mainly has the form of training activities of limited duration.

By international comparison, LLL plays an important role in the Danish labour market. Thus, according to Eurostat (Labour Force Survey), 29.2\% of the Danes aged 25 to 64 stated in 2006 that they received education or training in the four weeks preceding the survey. Among the EU27 this number is surpassed only by Sweden. The EU-27 average is 9.6\%.

Publicly financed adult learning can be roughly subdivided into three main categories:

- Adult liberal education (folk high schools, evening schools etc.).

- General adult education (primary and secondary level - or special courses at levels that cannot be indicated precisely).

- Vocationally oriented adult education and training from vocational education (VET) level to the highest academic level (continuing vocational education and training - CVT). 
- The adult education system furthermore "mirrors" the general educational system in the sense that it is divided into two levels of education:

- Basic Adult Education in the form of educational programmes, which give the same competences as ordinary youth educational programmes up to and including the level of vocational education.

- Advanced education levels, which are comparable with ordinary education levels, but different from these as regards organisation and content; short, medium-term and long higher education programmes.

The Ministry of Education administers a major part of the public system of LLL. In the case of specialised institutions for labour market training (AMU), the social partners have a strong involvement in the design and implementation of the training activities.

The total cost of the public LLL system amounts to approximately DKK 5,000 million (EUR 671 million), including both the operational costs and the cost of compensation to the participants, who are normally paid an amount equal to the unemployment benefit when they take part in public LLL with a vocational target. Employers contribute with about DKK 1,000 million to compensate costs to the participants. A fee to cover participation in most education and training programmes is paid by participants or employers, the latter being the most frequent contributor in the case of training with a vocational content.

A vast majority of those taking part in LLL are in employment. Among the total number of those in public LLL, $74.5 \%$ are wage earners and $2.6 \%$ are self-employed. The share of unemployed is $9.6 \%$. For those taking part in labour market training (AMU), the share in employment (including self-employment) is $82.0 \%$ and the share of unemployed is $10.7 \%$.

The educational background of persons taking part in public LLL is as follows. The share of participants having only a basic education amounts to $25.7 \%$, while $6.5 \%$ have a secondary education. About $47.3 \%$ have a vocational education and the remaining $21.5 \%$ have some form of higher education. For the specialised labour market training, the share of persons with basic education and vocational education is somewhat higher.

Measured as a share of the workforce with different educational attainment, the unskilled workers have a smaller rate of participation in LLL than other groups. In general, one finds that the propensity to participate in LLL increases with the person's educational level. The rate of participation is also lower for employees from smaller firms. Furthermore, persons employed in the construction sector or in trade and restaurants/hotels have a lower propensity to participate in LLL. On the other hand, participation is high among employees in large companies and innovative sectors. 
About $45 \%$ of the firms in the private sector have not had any employees taking part in formal internal or external training during the last year. The same goes for $11 \%$ of the public institutions.

Persons with reading disabilities participate in LLL to a lesser degree than others. This is also related to educational background because unskilled persons and persons with a basic vocational training have a larger chance of showing reading disabilities than others. This also applies to persons with a foreign background.

The private supply of LLL is characterised by small private commercial providers of a wide range of training activities. In spite of this, a few larger providers dominate the private LLL market. In 2004 about half of the training days were supplied by providers with more than 100 employees. A characteristic feature of the private providers of LLL is their focus on "softer" subjects like "management and organisation", "personal development" and "cooperation and communication".

In 2006 about 274,000 persons took part in training provided by private suppliers of LLL. The majority of the participants had a medium or long-cycle further education. Most were top-level or mid-level salaried employees.

According to present legislation, participants in adult education and training programmes may receive public financial support to cover their costs of living.

Economic support is normally given at a level corresponding to the maximum level of unemployment benefit for participation in a full-time education and training programme on certain conditions. Most important is the criterion that the person is aged 25 years and above. In some cases it is also demanded that the participant must not have passed upper secondary level or has a vocational education.

For those participants that are in employment, the employee will normally receive his or her normal wage during the training period. The employer will then receive a subsidy equal to the amount of maximum unemployment benefit (equal to about 472 Euro per week). For a normal wage level for an unskilled worker, this will cover about $60-70 \%$ of the wage cost. For low-skilled adults there are also possibilities of receiving support for participation in part-time education and training.

For basic public adult education, minor user fees apply. The user fees will normally be paid by the employer, or by the job centre in the case of unemployed participants. A mixture of user fees and "taximeter-funding" finances prevails in advanced public adult education, where the balance can vary considerably depending on the character of the programme. Private CVT is mainly financed by user fees, which will normally be paid by the employer.

Finally one should mention that the general agreements between employers' organisations and trade unions most often will have a provision that gives the employees the right to participate in adult education and 
training for a certain period during a year (normally between 2 and 4 weeks). At present this right is rarely used, but in principle it gives the employee an important option for taking part in adult education and training at his or her own initiative.

\section{Finland $^{34}$}

Systematic policy aiming at facilitation of adult education started in Finland in the 1970s. Labour market organizations were involved from early on. The goal is to provide educational and training opportunities widely to everybody corresponding to their needs, notably selfdevelopment, the upgrading of qualifications and the upgrading of competences. Current developments and reforms aim at contributing to occupational mobility, prolonging careers, raising the employment rate and improving productivity. During recent years, especially apprenticeshiptype training and possibilities to get formal acknowledgement of qualifications acquired in whatever way have been developed. One of the official goals is to raise the yearly participation rate in adult education to $60 \%$.

Formal education at all levels is in principle open to all age groups, and a great variety of liberal adult education is available. Labour market training is provided for the unemployed or those threatened by it (see section on active labour market policy). Personnel training is widely arranged by the employers for their staff. Education aiming at formal qualifications is mainly provided free of charge, and the state also subsidises other forms of training.

In Finland, the participation rate in adult education is high in international comparison (see Figure 2.6 above). According to the European Adult Education Survey for 2006, 55\% of those aged 25-64 had participated in formal or non-formal education or training during the preceding 12 months (Sweden 73\%, Norway 55\%, Denmark no information). In formal education (aiming at formal qualifications) the participation rate was $10 \%$ (Norway $10 \%$, Sweden 13\%) and in non-formal education $51 \%$ (Sweden 69\%, Norway 51\%). In European comparison, Sweden has by far the highest participation rates, and Finland, Norway and the UK come next with clearly better than average figures (Denmark is not included in this survey).

In Finland in 2006, 18\% of all participation in adult education was not work-related; $57 \%$ of employed wage earners took part in education or training supported by the employer.

\footnotetext{
${ }^{34}$ Adult Education Survey 2006, European comparison. Statistics Finland: Education 2009; Aikuiskoulutuksen vuosikirja. Tilastotietoja aikuisten opiskelusta 2006. Opetusministeriön julkaisuja 2008:22; Ammatillisesti suuntautuneen aikuiskoulutuksen kokonaisuudistus. AKKU-johtoryhmän väliraportti. Opetusministeriön työryhmämuistioita ja selvityksiä 2008:20; Education and Science in Finland. Ministry of Education publications 2008:25; NOSTE-ohjelman vuosiraportti 2007. Opetusministeriön julkaisuja 2008:35
} 
In Finland, females participate in all forms education clearly more often than males. Participation is also heavily dependent on the level of earlier education - the more education you already have, the more often you participate; the yearly adult education participation rate of those with tertiary education is twice as high as of those with only primary education. In 2006, the participation rate in adult education was $60 \%$ among the employed, $29 \%$ among the unemployed and 34\% among the inactive. There was also some regional variation, participation being relatively higher in southern Finland and urban areas.

According to a recent survey of employers with 10 or more employees, participation in personnel training was somewhat higher in industry than in services. The variation between industries was wide, from $21 \%$ in textiles and clothing to $62 \%$ in finance and insurance. Participation increased with the size of the employer: if the number of employees was $10-19$, the participation rate in personnel training during the past 12 months was $25 \%$, but if the number of employees was 1000 or more, this rate was $51 \%$. (In this survey, the average participation rate was $39 \%$.)

Since 2003, a programme called LIFT (NOSTE, Kunskapslyftet) has been targeted to those with no more than primary education in order to provide incentives and increased opportunities for further education. In 2003-2007 the programme reached about 22,000 persons, which is clearly less than intended.

\section{Norway}

Life-long learning (LLL) and competence development entered the political/labour market parties' agenda from the early 1990s onwards. A number of reforms were implemented, and the labour market parties put LLL on the collective bargaining agenda as well as for co-operative measures. LLL in Norway is characterised by measures such as improved access to education for adults, adapted education for adults, and better appreciation of experience gained in a wide array of learning contexts among others validation of informal learning, so-called "realkompetanse" (Ure 2003). ${ }^{35}$ The labour market parties, especially LO and NHO, strongly influenced the first part of the so-called competence reform (1999 onwards), and stressed the importance of informal learning/the workplace as a learning arena (validation).

The responsibility for LLL lies with the Ministry of Research and Education (Kunnskapsdepartementet). Special focus has been directed against adults with low formal qualifications, among others through the establishment of VOX (Norwegian Institute for Adult Learning). Another institution, Norgesuniversitetet (Norway Opening Universities), has been established with the objective to stimulate the development of life-long

\footnotetext{
${ }^{35}$ http://www.fafo.no/pub/rapp/20030/20030.pdf
} 
and flexible learning in higher education as well as generating and sharing knowledge.

The concept of life-long learning (Norway) covers all organised and unorganised learning throughout life, including formal and informal learning in work and at other arenas. Life-long learning (LLL) often is divided into formal education (continuous or further education that is recognised as part of the formal system of education) and non-formal training. The last type of LLL will include a number of activities and providers, and will among others include shorter courses arranged by adult-education organisations, trade unions, other interest organisations, in-house training provided by employers or suppliers etc.

The main source for number of participants in LLL is the Adult Education Survey (AES) ${ }^{36}$ According to the AES, $10 \%$ of the population (25-64 years) reported having participated in formal education, whereas $51 \%$ participated in non-formal education over the last 12 months in 2007. Figures for the previous years (2003-2006) show a relatively stable level of LLL in Norway. During the last twelve months in 2007, 58\% of all employees had participated in training, compared to a fifth of those who were not employed. A substantial part of the LLL is defined as jobrelevant, and job-relevant education is often organised at the workplace/during working hours. In 2007, 47\% of the population (25-64 years) had participated in work-related training during the last 12 months. Participants in non-formal training have on average 78 hours of training over the last 12 months (compared to 73 hours in Sweden and 95 hours in Finland).

Universities and university colleges have a number of adult students both in their regular programmes and in programmes specially adapted for adult students (for instance part-time studies and distance studies), as well as by offering courses that can be defined as continuous or further vocational training (EVU) and which normally will be financed by the participants or most commonly their employers. The last type of programmes does not require that the participant is admitted as a student at the university/university college.

The number of so-called EVU-students has varied between 120,000 and 144,000 over the period 1998-2007; however, the statistics are not very good and may underestimate the number of EVU-students. ${ }^{37}$ In addition approximately $1 / 4$ of the students (ordinary full-time programmes) are adults, i.e. 30 years old or more.

As part of the so-called competence reform, adults without formal university admission certification may now be admitted as students, based on a combination of previous education and informal competence/training (by a system where prior learning is assessed).

\footnotetext{
${ }^{36} \mathrm{http}: / / w w w . s s b . n o / v i s / m a g a s i n e t / a n a l y s e / a r t-2008-11-12-01 . h t m l$

${ }^{37} \mathrm{http}: / /$ norgesuniversitetet.no/artikler/2005/deltakelse-UH og Tilstandsrapport om livslang lering $i$ Norge http://www.regjeringen.no/upload/KD/Vedlegg/Kompetanse/Livslang_\%20laring_ \%20Norge2007.pdf
} 
Adults without such education also have a statutory right to primary and upper secondary education. The number of persons using these rights are limited, especally with regard to primary education. With regard to upper secondary education the number of adult students is higher (approximately 20,000 per year).

Persons with problems on the labour market (unemployed, in rehabilitation etc.) will also be offered training by NAV (former Aetat) if this is seen as necessary in order to re-enter/stay in the labour market. Such training will vary from shorter courses to training for a new type of occupation. Such training will normally be financed by NAV, and a variety of providers (public as well as private) will be used.

Private providers of LLL vary from a few private universities/ university colleges (mainly within business economics, administration etc.) via traditional adult education organisations ("studieforbund") to different types of commercial actors selling programmes/courses to employers or the labour market authorities (NAV). The adult education organisations have long traditions in Norway and are mainly financed by the state.

Surveys such as the AES show that almost $50 \%$ of the training activities (informal learning, measured by hours) among employed persons were provided by the employer or by suppliers. Public and private educational institutions or course providers accounted for 14 and $15 \%$ of the job-related training measures (measured by hours of training) whereas adult education organisations, trade unions etc. accounted for $8 \%$.

The issue of how to finance LLL was much debated in the period 1999-2001/2002, where the competence reform was high on the agenda of the social partners. Although all employees had a statutory right to educational leave (up to 3 years), the issue of how to finance cost of living while on leave was never resolved. The employers' organisations refused the idea of establishing a fund co-financed by the social partners and the state. A reform of the State Educational Loan Fund secured equal treatment of adults and other students, and the loan scheme was adapted to adult students.

Informal LLL (courses etc.) will normally be partly or fully financed by the employers (for taking part during working hours, the employers pay the fees, the employee gets time off to participate etc.). The unemployed and persons in need of rehabilitation etc. will have their cost of living financed by NAV (unemployment benefits, other types of benefits).

There are no figures on the total costs of LLL in Norway. 
Sweden $^{38}$

Sweden has a long tradition of adult education, starting in the $19^{\text {th }}$ century with adult colleges and evening schools run by the popular movements. Formal adult education was stipulated in 1968 as a task for the municipalities. In 1997 under the slogan "Knowledge lift" the government made a grand effort on adult education. This programme especially targeted low-skilled workers with the purpose of lifting their formal education to a three-year secondary level (Ericson 2006). This special effort ended in 2002.

The formal adult learning system is organised by several actors on different levels, by private and public providers and aiming at different groups. Komvux is the name of the adult education organized by the municipalities and aiming at upgrading the participants' formal education up to a secondary level (Gymnasium). In 2005/06 the number of participants was 228,000. However, 150,000 (66\%) of these were 25 years or older (Skolverket). There is also education for adults with learning disabilities (Särvux) aiming at formal education up to secondary level. These courses are adapted to the special needs of the participants. In 2005/06 Särvux had around 5000 participants. Since 2002 the Swedish adult learning system also includes a programme for Advanced Vocational Training (Kvalificerad yrkesutbildning) which is a post-secondary education combined with workplace training (32,600 participants in 2006). Swedish for immigrants (SFI) provides basic knowledge in the Swedish language for adult immigrants. In 2005/06, SFI had around 48,000 participants. The adult learning system also includes adult colleges (folkhögskolor). They are run as independent foundations and often provide education up to a secondary level beside some speciality, for example art. In 2006 there were 15,000 adults $(25+)$ in these colleges. Some parts of the general ALMP in Sweden also contribute to the adult learning system. Labour Market Training has the purpose of giving basic vocational training for job-seekers. These programmes had 47,000 participants (25+) in 2006.

Around $4 \%$ of the total population between 25 and 64 years in 2005/06 were participants in formal adult learning systems. If informal forms of adult learning are included too, then $73 \%$ have participated at some time during a 12-month period $-50 \%$ through on-the-job training. The rest comes from study circles, participation in seminars, conferences etc.

There are both public and private providers of LLL services in Sweden. Traditionally Komvux has been provided by the municipalities. Today the municipalities frequently purchase the services from private companies.

A law from 1974 stipulates the right for employees to take a break from their job for studies (without restrictions for time or type of studies) and after studies to return to the same job (Ericson 2006). There are also

\footnotetext{
${ }^{38}$ The description is mainly built on Anxo, Dominique (2007), “Sweden”, in European Employment Observatory Review, Autumn 2007, 157-161.
} 
possibilities to have quite generous public loans to afford the studies. Unemployed people who participate in labour market training get a special activity support equal to their unemployment benefit.

Table 4. Overview of life-long learning systems

\begin{tabular}{|c|c|c|c|c|}
\hline Item & Denmark & Finland & Norway & Sweden \\
\hline $\begin{array}{l}\text { Statistical infor- } \\
\text { mation about } \\
\text { participants } \\
\text { (persons and full- } \\
\text { time participants) }\end{array}$ & $\begin{array}{l}\text { Public LLL } \\
\text { (2005): } 883,000 \\
\text { persons (whereof } \\
751,500 \text { aged } \\
25+\text { ) } \\
\text { Public LLL } \\
\text { (2005): } 45,900 \\
\text { full-time } \\
\text { Private LLL } \\
\text { (2005): } 273,000\end{array}$ & $\begin{array}{l}\text { For } 2006,55 \% \text { of } \\
25-64-y e a r-o l d s \\
\text { had participated } \\
\text { in formal or non- } \\
\text { formal education } \\
\text { or training during } \\
\text { the preceding } 12 \\
\text { months. In edu- } \\
\text { cation aiming at } \\
\text { formal qualifica- } \\
\text { tions the partici- } \\
\text { pation rate was } \\
10 \% \text { and in non- } \\
\text { formal education } \\
51 \%\end{array}$ & $\begin{array}{l}\text { No statistics on full- } \\
\text { time participants } \\
2007 \text {, last } 12 \\
\text { months, } 22 \text { years+ } \\
10 \% \text { participated in } \\
\text { formal education } \\
6 \% \text { formal further } \\
\text { education } \\
53 \% \text { courses and } \\
\text { other training meas- } \\
\text { ures }\end{array}$ & $\begin{array}{l}\text { Formal education: } \\
\text { Ca. } 4 \% \text { of adult } \\
\text { population } \\
\text { Informal educa- } \\
\text { tion: } \\
\text { Ca. } 69 \% \\
\text { On-the-job train- } \\
\text { ing: } \\
50 \%\end{array}$ \\
\hline $\begin{array}{l}\text { Share of partici- } \\
\text { pants in LLL } \\
\text { (LFS-info from } \\
\text { Eurostat). Parti- } \\
\text { pated in educa- } \\
\text { tion and training } \\
\text { four weeks before } \\
\text { the interview. } \\
2006 \text {. }\end{array}$ & $29.2 \%$ & $23.1 \%$ & $18.7 \%$ & $32.1 \%$ \\
\hline Targeting & $\begin{array}{l}\text { The vast majority } \\
\text { of those taking } \\
\text { part in LLL are in } \\
\text { employment }\end{array}$ & $\begin{array}{l}\text { In } 2006, \text { among } \\
\text { the employed the } \\
\text { participation rate } \\
\text { in adult education } \\
\text { was } 60 \% \text {, among } \\
\text { the unemployed } \\
29 \% \text { and among } \\
\text { the inactive } 34 \%\end{array}$ & $\begin{array}{l}\text { The vast majority of } \\
\text { those taking part in } \\
\text { LLL are in employ- } \\
\text { ment }\end{array}$ & $\begin{array}{l}\text { The vast majority } \\
\text { of those taking } \\
\text { part in LLL are in } \\
\text { employment }\end{array}$ \\
\hline $\begin{array}{l}\text { Structure of } \\
\text { public supply of } \\
\text { LLL }\end{array}$ & $\begin{array}{l}\text { The public sys- } \\
\text { tem of LLL for } \\
\text { adults mirrors the } \\
\text { system for youth. } \\
\text { Most important } \\
\text { are the institu- } \\
\text { tions for labour } \\
\text { market training } \\
(\text { AMU). }\end{array}$ & $\begin{array}{l}\text { Formal education } \\
\text { at all levels is in } \\
\text { principle open to } \\
\text { all age groups. } \\
\text { Special incen- } \\
\text { tives and oppor- } \\
\text { tunities for further } \\
\text { education of } \\
\text { adults. }\end{array}$ & $\begin{array}{l}\text { The public system of } \\
\text { LLL for adults } \\
\text { mirrors the system } \\
\text { for youth, but also a } \\
\text { number of pro- } \\
\text { grammes are mainly } \\
\text { aimed at continuous } \\
\text { vocational train- } \\
\text { ing/adult students }\end{array}$ & $\begin{array}{l}\text { The public system } \\
\text { of LLL for adults } \\
\text { mirrors the system } \\
\text { for youth. Most } \\
\text { important activity } \\
\text { is Komvux (adult } \\
\text { education organ- } \\
\text { ised by the mu- } \\
\text { nicipalities) }\end{array}$ \\
\hline $\begin{array}{l}\text { Information about } \\
\text { private supply of } \\
\text { LLL }\end{array}$ & $\begin{array}{l}\text { Characterised by } \\
\text { small private } \\
\text { commercial } \\
\text { providers. Focus } \\
\text { on "soft" compe- } \\
\text { tences. }\end{array}$ & Wide variety & $\begin{array}{l}\text { Variety of private } \\
\text { providers including } \\
\text { private universi- } \\
\text { ties/university } \\
\text { colleges, adult } \\
\text { education organisa- } \\
\text { tions and small } \\
\text { commercial provid- } \\
\text { ers. }\end{array}$ & $\begin{array}{l}\text { Variety of private } \\
\text { providers. }\end{array}$ \\
\hline $\begin{array}{l}\text { Economic support } \\
\text { to participants in } \\
\text { public LLL }\end{array}$ & $\begin{array}{l}\text { The standard } \\
\text { support to partici- } \\
\text { pants is equal to } \\
\text { unemployment } \\
\text { benefits. Em- } \\
\text { ployed will mostly } \\
\text { be paid normal } \\
\text { wage and em- } \\
\text { ployer gets the } \\
\text { subsidy. Unem- }\end{array}$ & $\begin{array}{l}\text { General support } \\
\text { for students or } \\
\text { special (higher) } \\
\text { support for adult } \\
\text { students with } \\
\text { work experience }\end{array}$ & $\begin{array}{l}\text { No public support for } \\
\text { participation as } \\
\text { such. Adults have } \\
\text { been given access } \\
\text { to student loans. } \\
\text { Unemployed and } \\
\text { others in need of } \\
\text { new/further qualifica- } \\
\text { tions will keep their } \\
\text { unemployment }\end{array}$ & $\begin{array}{l}\text { Adults have } \\
\text { access to student } \\
\text { loans. } \\
\text { Unemployed will } \\
\text { get so-called } \\
\text { activity support } \\
\text { when participating } \\
\text { in LMT. }\end{array}$ \\
\hline
\end{tabular}




\begin{tabular}{lllll}
\hline Item & Denmark & Finland & Norway & Sweden \\
\hline ployed gets UI- & & $\begin{array}{l}\text { benefit or get special } \\
\text { support. }\end{array}$ & \\
\hline benefits. & $\begin{array}{l}\text { Small. Mostly } \\
\text { paid by employ- } \\
\text { ers or job centre. }\end{array}$ & $\begin{array}{l}\text { Mainly free or } \\
\text { paid by employer }\end{array}$ & $\begin{array}{l}\text { Mostly paid by } \\
\text { employers or the } \\
\text { NAV }\end{array}$ & $\begin{array}{l}\text { Adult education is } \\
\text { free. } \\
\text { LMTs are paid by } \\
\text { job centre }\end{array}$ \\
\hline $\begin{array}{lllll}\text { Collective agree- } \\
\text { ments }\end{array}$ & $\begin{array}{l}\text { Most collective } \\
\text { agreements give } \\
\text { right to 2-4 } \\
\text { weeks of LLL per } \\
\text { year. }\end{array}$ & $\begin{array}{l}\text { Right to take } \\
\text { breaks from work } \\
\text { for studies if } \\
\text { employer has no } \\
\text { good reasons to } \\
\text { deny this. }\end{array}$ & $\begin{array}{l}\text { Mainly framework } \\
\text { agreements stress- } \\
\text { ing the importance } \\
\text { of LLL. }\end{array}$ & $\begin{array}{l}\text { Right to take } \\
\text { breaks from job } \\
\text { for studies is } \\
\text { stipulated by law. }\end{array}$ \\
& & & & \\
\hline
\end{tabular}




\section{Appendix B}

B1: Variable list and definitions 



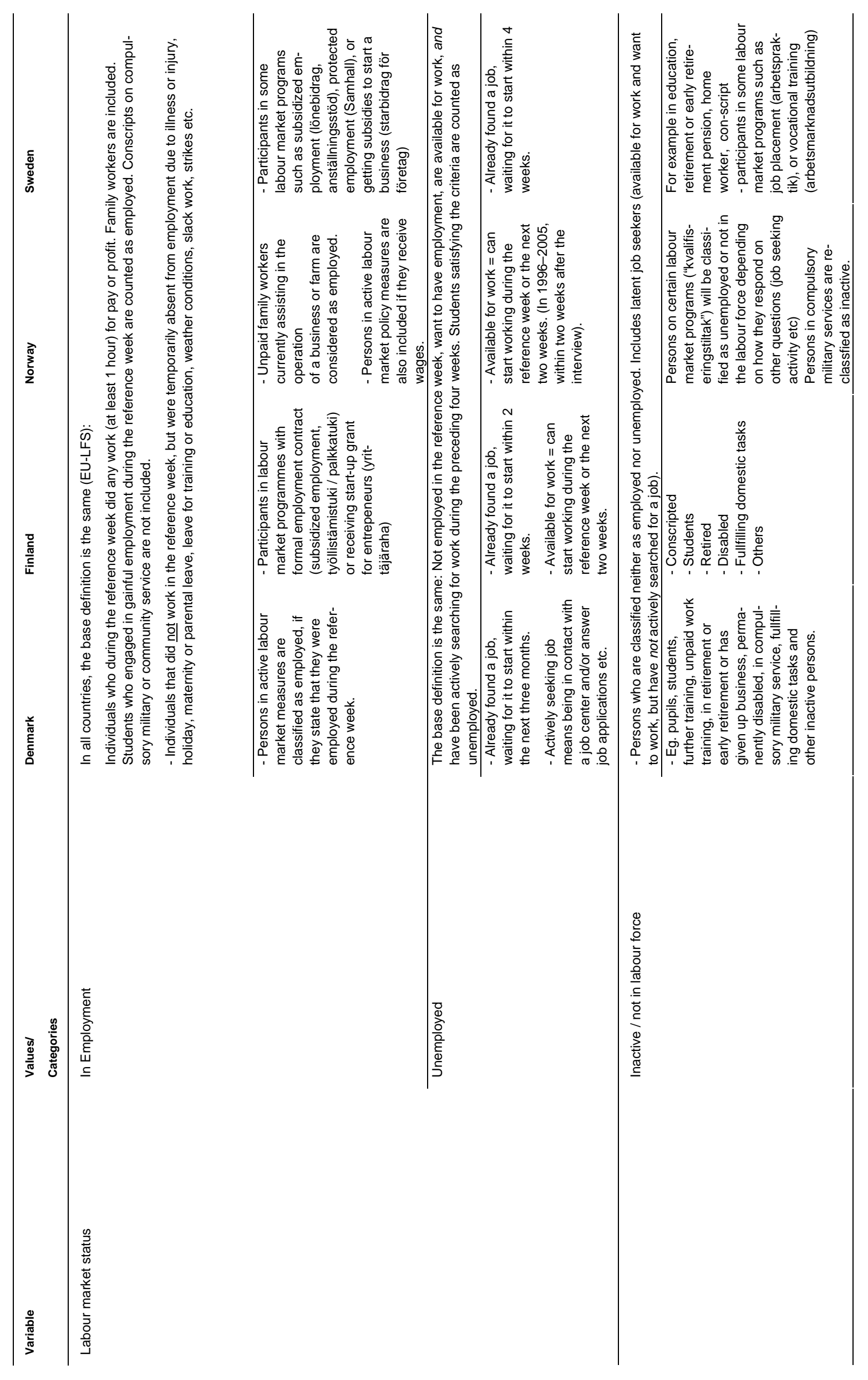




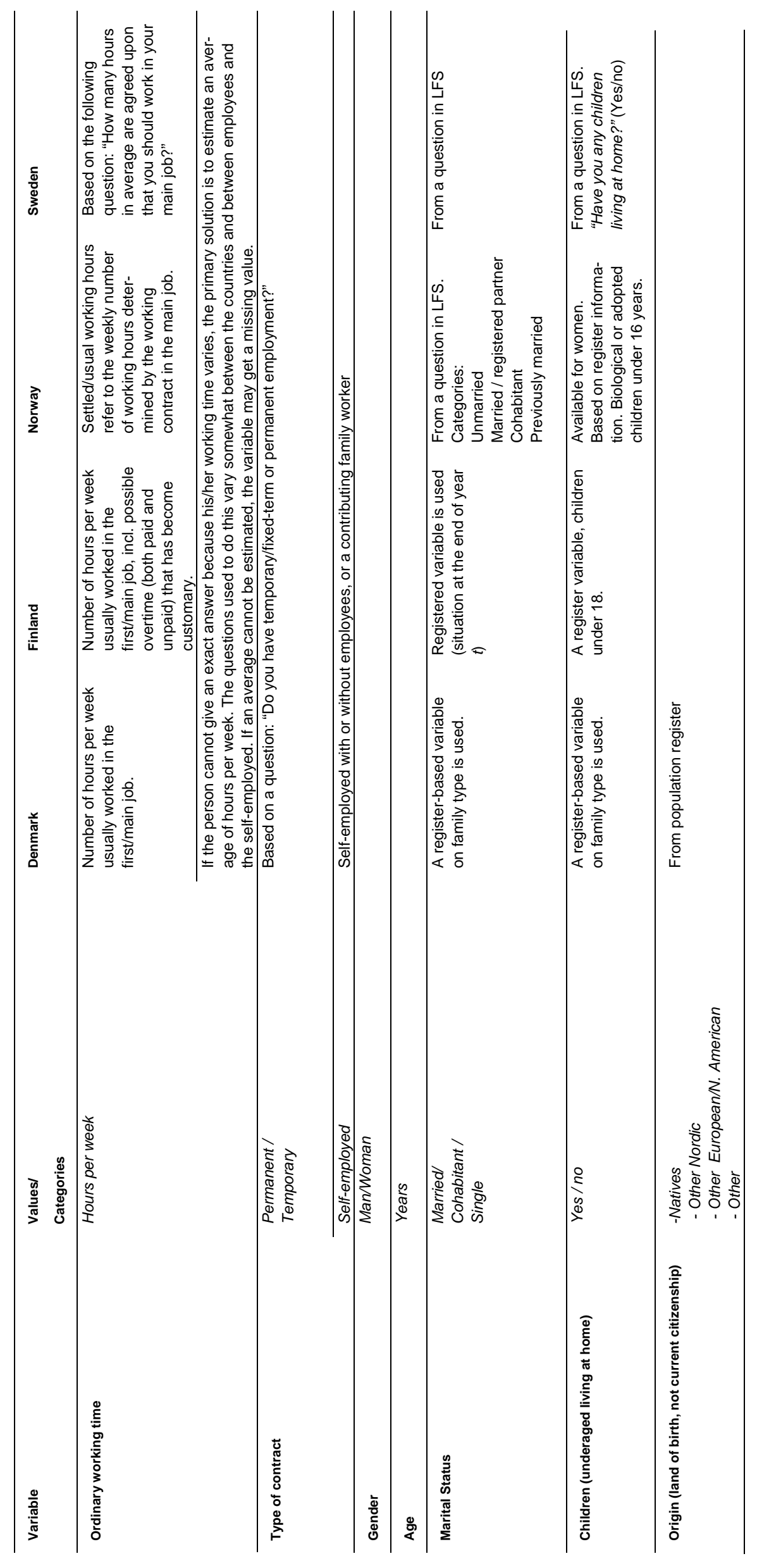




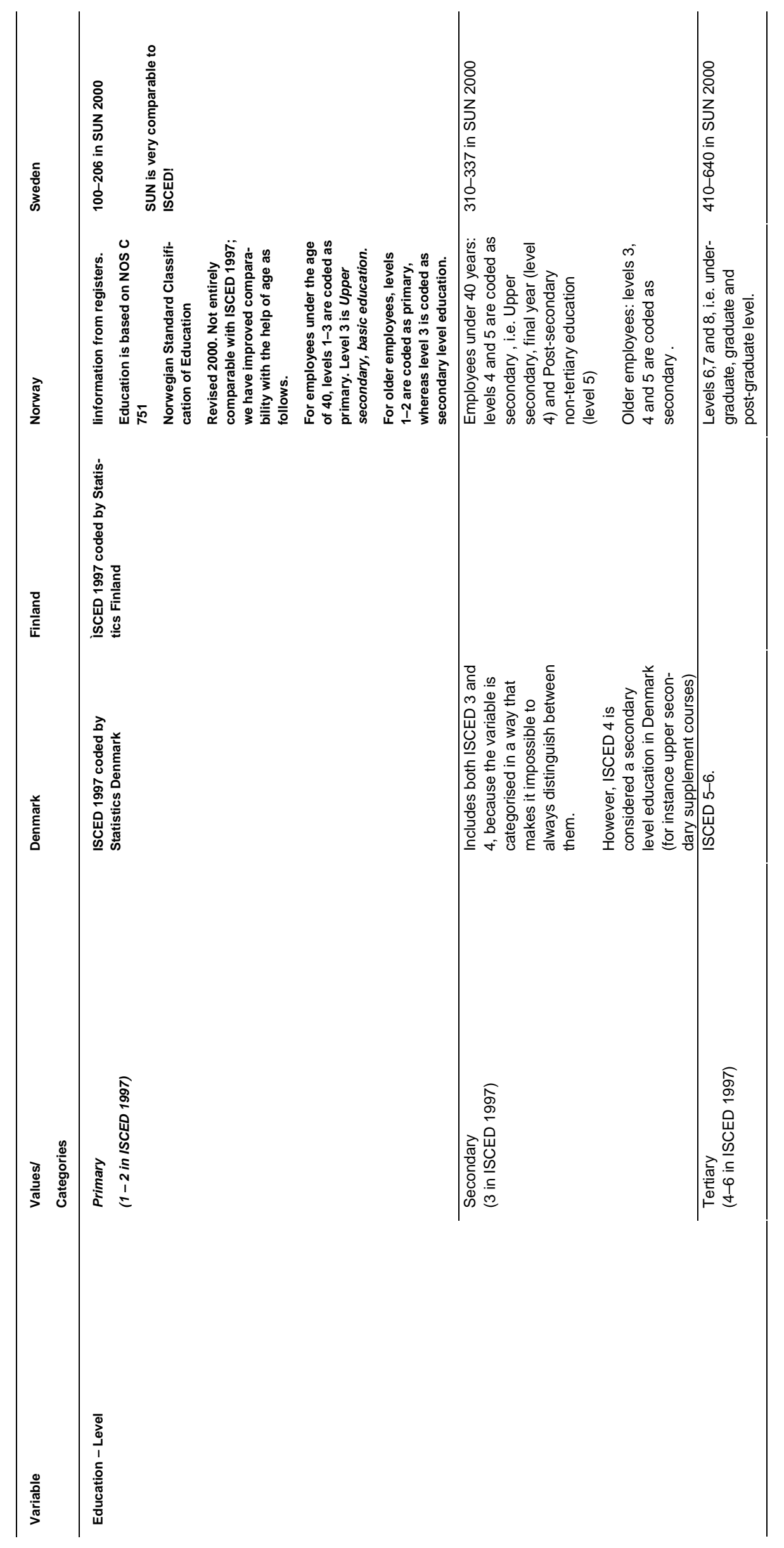




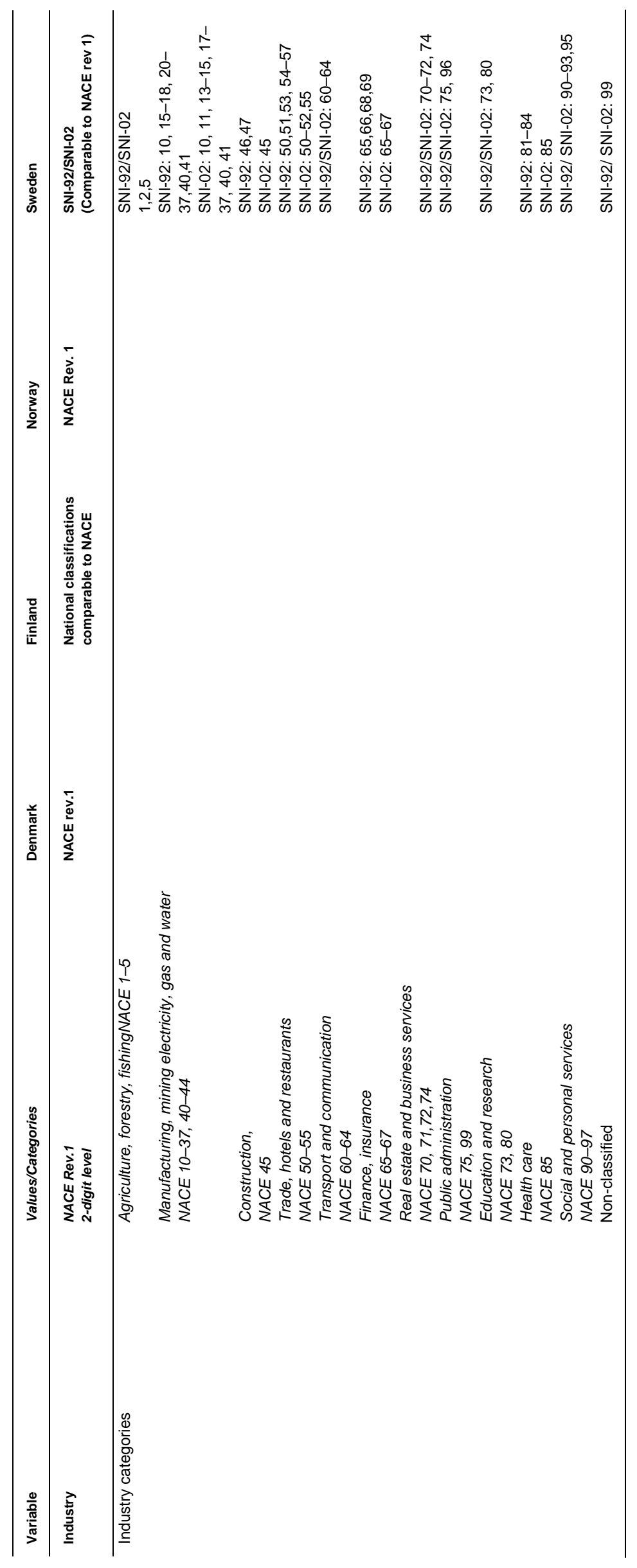




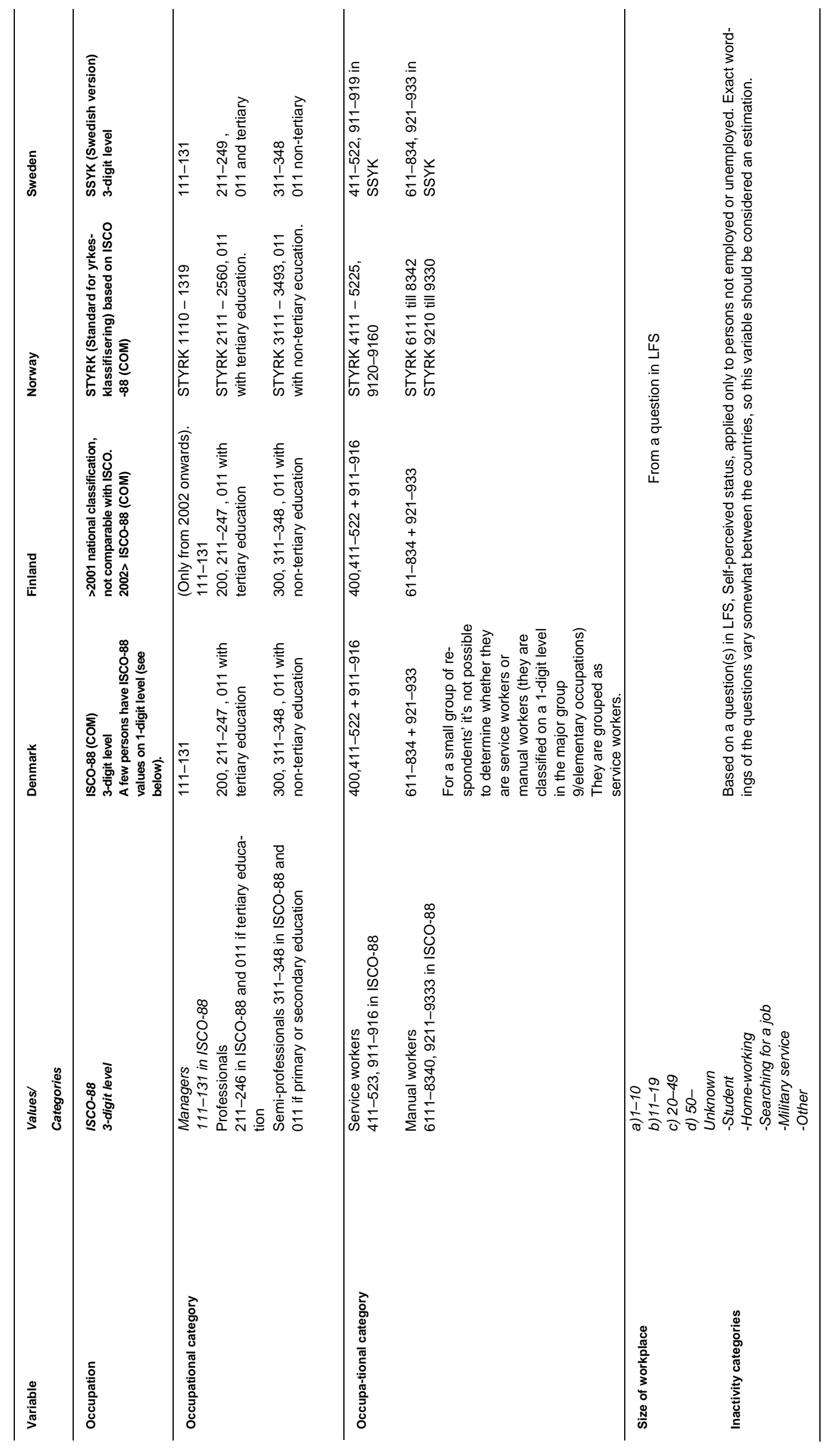




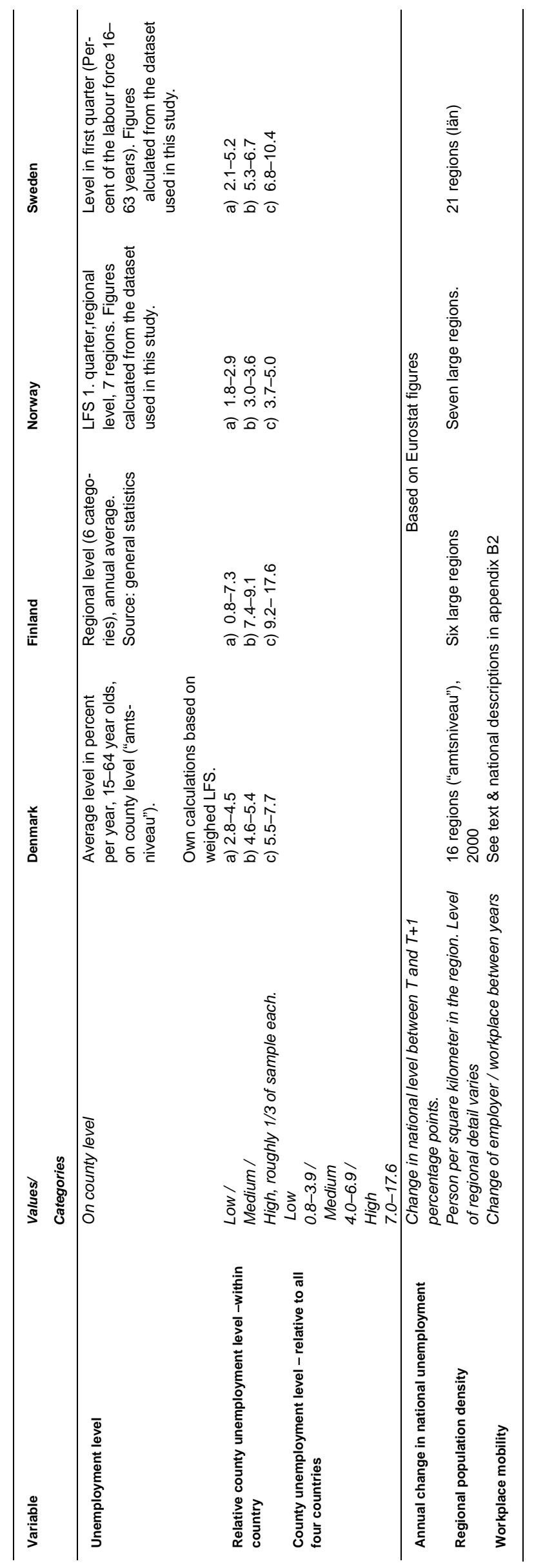




\section{B2: Methods for studying workplace, industrial and occupational mobility}

In the following, we present details about two methodological issues. First, we describe in more detail how independent and dependent coding (see Chapter 4) are used in our countries. Second, we present detailed accounts of how the workplace mobility variable has been constructed in each country.

\section{Dependent and independent coding}

It is a well-known fact that the use of independent coding will, in general, result in higher mobility levels than the use of dependent coding. Thus, we can assume that our results will somewhat overestimate mobility in countries where independent coding is more widely applied. This is somewhat limited by the fact that the cases coded independently are not randomly selected, but are for the most part people who are more likely to be mobile in any case. In addition, the share of people coded independently can vary across time as well as across countries.

The period studied is one year. In Sweden and Norway, this means five interviews (a first one and four follow-ups). In Finland, the number of interviews is four and in Denmark two. If the country applies independent coding in some cases, the share of those who will be coded independently at least once during the year will be higher if there are many interviews.

For Norway, we have information about the extent of independent coding of occupation. Unfortunately, this is affected by the outcome; everyone who has changed occupation has of course been coded independently. When it comes to the non-mobile, we know if this information has been acquired with independent or dependent coding. The share of independent coding in this table means people who have at least one instance of independent coding in the three follow-up interviews.

Table B.2. Dependent and independent coding of occupation in Norway.

\begin{tabular}{ccrr}
\hline & \multicolumn{3}{c}{ Same occupation } \\
\cline { 2 - 3 } & $\begin{array}{r}\text { Dependent } \\
\text { coding }\end{array}$ & $\begin{array}{r}\text { Independent } \\
\text { coding }\end{array}$ & Change of occupation \\
\hline 2000 & $48.9 \%$ & $30.7 \%$ & $20.4 \%$ \\
2001 & $46.9 \%$ & $32.5 \%$ & $20.7 \%$ \\
2002 & $55.3 \%$ & $27.6 \%$ & $17.1 \%$ \\
2003 & $53.4 \%$ & $30.8 \%$ & $15.8 \%$ \\
2004 & $55.0 \%$ & $29.5 \%$ & $15.5 \%$ \\
2005 & $46.5 \%$ & $39.3 \%$ & $14.2 \%$ \\
2006 & $55.2 \%$ & $32.3 \%$ & $12.5 \%$ \\
\hline
\end{tabular}

It appears that the use of independent coding is not at all straightforwardly correlated with the mobility rate in our data. For instance, there 
were considerably more independent codings in 2005 than 2004, yet the mobility rate was lower in 2005. Thus, it seems that even though we can assume that independent coding will increase observed mobility to some extent, this is not a very large problem, because it is not applied to all cases or randomly.

Situations when dependent coding is not used in a follow-up interview:

In all countries:

If a person has not been employed in the previous interview.

Denmark:

Independent coding will only be used in cases where information from the previous interview is incomplete (e.g. occupational code is not exact). In these cases, independent coding can easily lead to artificial mobility if no mobility has in fact taken place. The number of such cases is likely to be very small, though.

\section{Finland:}

No other known exceptions.

Norway:

- Change of workplace triggers independent coding of occupation.

- If a person misses an interview or an interview is given by a substitute (such as a family member), the next interview will be independent.

- Those answering that they only have a very temporary ("tilfeldig") job will be coded independently in the next interview. Very few respondents use this option.

- Family workers are coded independently in the next interview.

- If the interviewee does not answer to the question about the name of his/her employer, the next interview will be independent.

Sweden:

If a person misses an interview, dependent coding will still be used in the following interview if the person holds a permanent job. Thus, independent coding will be applied if a) an interview is missed in between and b) the interviewee was without a permanent position in the last interview.

\section{Construction of workplace mobility indicators}

\section{Finland}

- Indicator is based on a question (asked at $t+1$ ): "When did you start working at your current workplace?” 
- Until 2000, the start time was registered as an exact date. From 2001, only month and year have been registered.

- Interview time is recorded on the level of month and year.

- Both times are converted to an exact date. When only month and year have been recorded, the date will be the $15^{\text {th }}$ of that month.

Obviously, this only has bearing to year 2000, when start time at job was recorded as an exact date - after that, all dates will be registered as the $15^{\text {th }}$.

- After a simple calculation, workplace mobility is indicated if the start date occurred less than 365 days before the interview - provided, of course, that the person has been employed both at $t$ and $t+1$. As the dates are not recorded exactly - and the answer to the retrospective question relies on the interviewee's memory - there are inaccuracy factors.

\section{Denmark}

The variable is constructed from these questions:

When (what year) did you start working at your current workplace?

Has to be continuous work except from sickness, holidays and leave.

Do you also remember the month

The question is only asked if the respondent has started working at the current workplace in the last two years before the interview.

On basis of this information we constructed a variable with month and year for start at current workplace. We also constructed variables with the month and year for the interviews. If a person was employed at time $t$ and time $t+1$ and the start date is in between them, then change of workplace is indicated.

Since we do not have the exact dates for the interviews or the start at the current workplace, there are inaccuracy factors in the variable.

\section{Sweden}

For convenience, we use the term workplace mobility for all countries, even though the variable in practice in Sweden refers to employer change.

In the Swedish LFS, the interviewer registers if a change of employer has been made since the last interview. A change of employer is noticed if the name of the employer has changed since the last interview. With control questions it is then verified that there has been an employer change. If the employer has changed its name, no employer change will be recorded. When an employer change is indicated, special questions on the employer change should be asked (Blankett 2).

In our data, we have two types of variables from which workplace mobility has been constructed. The first variable tells us whether a change has occurred, and in that case what kind of change it is (employer change, transition from non-employment to employment, or a change of 
position within employer). The maximal number of changes that can be registered during a person's participation in LFS is 7. In the dataset, 5 changes is the maximum number empirically present, which is why we have 5 variables of this type.

Each change-variable has a variable of the second type linked to it, telling us when that particular change has happened.

From these variables, workplace change has been constructed with the following criteria:

First, there has to be at least one relevant transition (change of employer or a transition into employment) registered in the data.

Second, only changes that have taken place during the reference year are counted. More precisely, the second criterion states that at least one relevant change must be registered sometime between the second quarter year $t$ and the first quarter year $t+1$. If the first quarter year $t$ would have been included, mobility "into" the year would have been registered as well. The current construction means that workplace mobility is measured for the same time period of the other Swedish mobility variables (between first quarter $t$ and first quarter $t+1$ ).

Third, only people who are employed both at $t$ and $t+1$ are included in the variable. This is why we count in not only employer changes, but also transitions into employment - otherwise, job changes taking place indirectly via unemployment or time out of the labour force would not be registered.

\section{Norway}

Workplace mobility in Norway is constructed in two different ways and both alternatives are used in the report. The first alternative described below has been named as the primary indicator, as it refers to the same period as the other Norwegian mobility indicators (first quarter $t$ - first quarter $t+1$ ). The alternative indicator refers to second quarter $t-$ second quarter $t+1$ and it has more missing values. It has been constructed in order to have an indicator that resembles the Finnish and Danish variables as much as possible.

\section{Primary indicator:}

Information has been used in the following order. If information a) has not been available, we have used b) and if that has been missing as well, then we have used c).

a) Information from the retrospective questions "Have you been working continuously in this company/establishment for more than one year?" and "When did you start working in this company?" Before 2006, this question was asked once a year, in the April-June interviews. The information from the April-June interviews are 
used and adapted to the period we are interested in (first quarter $t$ to first quarter $t+1$ )

b) Information from the question in the repeated interview questionnaire (skjema for flergangsintervju). The information is based on the following question: "Three months ago you were working for $X X X$, do you still work for this employer?" (yes/no). Information is collected from all the interviews, i.e. also the three interviews in the period between $t$ and $t+1$.

c) For the remaining respondents we used information on whether they had the same industry code (NACE three digits) at $t$ and $t+1$.

\section{Alternative indicator:}

Workplace mobility was constructed solely on information from the retrospective question "Have you been working continuously in this company/establishment for more than one year"(YES/NO). ("Har du arbeidet sammenhengende i denne bedriften i over ett år?"). The reference is the interview conducted three months after $t+1$, since this question only was asked in April-June ( $2^{\text {nd }}$ quarter). Information is available for the period 2000-2004.

The alternative indicator has only been used in descriptive statistics, when comparing the countries' mobility rates to one another. In these comparisons, it is preferable to the primary indicator, as it is constructed in a similar way as the Finnish and Danish variables. In the other analyses, we have had to use the primary variable, as the alternative variable refers to a different time period than other relevant variables (independent variables and other mobility indicators) in the Norwegian data set. 